EGG-FSP-11193

ITER/94/US/TE/SA-1

\title{
A Summary and Assessment of Oxidation Driven Volatility Experiments at the INEL and Their Application to Fusion Reactor Safety Assessments
}

\author{
K. A. McCarthy \\ G. R. Smolik \\ S. L. Harms
}

September 1994

\section{Idaho National Engineering Laboratory EG\&G Idaho, Inc. Idaho Falls, Idaho 83415}

Prepared for the

U.S. Department of Energy

Office of Fusion Energy

Under DOE Idaho Operations Office

Contract DE-AC07-76ID01570

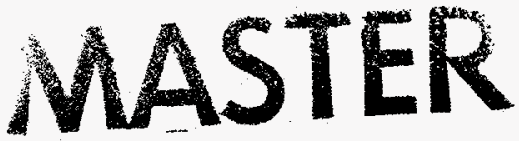




\section{DISCLAIMER}

This report was prepared as an account of work sponsored by an agency of the United States Government. Neither the United States Government nor any agency thereof, nor any of their employees, make any warranty, express or implied, or assumes any legal liability or responsibility for the accuracy, completeness, or usefulness of any information, apparatus, product, or process disclosed, or represents that its use would not infringe privately owned rights. Reference herein to any specific commercial product, process, or service by trade name, trademark, manufacturer, or otherwise does not necessarily constitute or imply its endorsement, recommendation, or favoring by the United States Government or any agency thereof. The views and opinions of authors expressed herein do not necessarily state or reflect those of the United States Government or any agency thereof. 


\section{DISCLAIMER}

Portions of this document may be illegible in electronic image products. Images are produced from the best available original document. 


\section{ABSTRACT}

This report contains a summary and assessment of oxidation-driven volatility tests through March 1994 at the Idaho National Engineering Laboratory. Materials tested include a Cu alloy in air and steam, PCA stainless steel (similar to 316SS) in air and steam, AMCR-033 steel in air, HT-9 steel in air and steam, a Nb alloy in air and steam, a $\mathrm{W}$ alloy in air and steam, and two $\mathrm{V}$ alloys in air with a limited number of tests in steam. We give a brief description of the tests, including alloy compositions and test temperatures. For many materials, our results indicate that both volatility and oxide spalling are responsible for mobilizing mass, thus we refer to our measurements as mass flux or mobility flux. We plot mobility data for each element and present curve fits to the data.

We include a section on how the mobility information is used in safety assessments. We calculate the early dose inventory of a first wall made of each material tested (the early dose to the maximum exposed individual that would result if all the material were mobilized and transported to the site boundary), and the early dose that would result when mobility fractions are considered in the calculation. We use this information to assess the data by determining which elements are the most important and concentrating on providing the mobility data for those elements.

We discuss where more data are needed, and our plans for obtaining that data.

Additionally, we discuss what must be done to produce a database that will withstand regulatory scrutiny. 



\section{EXECUTIVE SUMMARY}

\section{Background}

The purpose of the activation products task at the Idaho National Engineering Laboratory (INEL) is to provide information on the mobilization and transport of activated materials (and beryllium because of its toxicity) under accident conditions in fusion reactors. This information is useful to designers by providing guidance toward safer designs. We are working towards compiling a defensible data base for use in the regulatory process for the International Thermonuclear Experimental Reactor (ITER) in the near-term, and for commercial reactors in the long-term. The compilation of this report was supported with funds from both ITER and the base program (which covers non-ITER commercial-reactor relevant materials).

Solid activation products can be mobilized by four methods, two of which require the ingress of some gas or gases (air, steam, or other): reactions with air or steam leading to volatile oxides or hydroxides, and the escape of tokamak erosion dust from the vacuum chamber (the third is the vaporization of material by the plasma during a disruption, and the fourth is activated corrosion products). The activation products task covers activation products mobilized by reactions with gases, primarily steam and air.

\section{Database}

A significant amount of data has been compiled at the INEL since the activation product task began. We prepare samples that include non-radioactive elements to represent transmutation products induced by irradiation. In using these samples, we assume that the irradiated material would not behave differently than unirradiated material. Samples that we prepare through powder metallurgy are conservative in the respect that the oxygen content and porosity are higher than in dense solid material, thus there is already higher oxidation and migration behavior than in dense solid material. We will carry out a very limited number of confirmatory tests with radioactive samples in the future.

A transpiration test method is used to determine the amount of material mobilized when exposed to steam or air at typical accident temperatures. Materials tested include $\mathrm{Be}, \mathrm{a}$ $\mathrm{Cu}$ alloy, austenitic and ferritic steel, a Nb alloy, a W alloy, and two $\mathrm{V}$ alloys. Much of the data has been exploratory in nature with a limited number of tests, while for steels, a very large number of tests have been done. For many materials, the database provides enough information to allow us to focus on certain elements to ensure that we have adequate data to support ITER in the regulatory arena. Additionally, data validation activities will begin in 1994 to ensure that data will pass regulatory scrutiny.

For many materials, our results indicate that both volatility and oxide spalling are responsible for mobilizing mass, thus we present our measurements as mass flux or 
mobility flux. To evaluate the mobility data, we plot the data, perform a regression analysis to fit a curve to the data, and then determine which elements contribute most to the early dose. Using the first wall as an example, we calculate the early dose inventory (the early dose to the maximum exposed individual assuming the entire inventory is mobilized and transported to the site boundary), and the early dose in air and water ingress accidents when mobility fractions based on our measurements are considered. This enables us to focus our future testing activities on measuring those elements that contribute more than $1 \%$ to the dose.

To produce data for use in a PSAR (Preliminary Safety Analysis Report), based on calculations of possible accident temperatures in ITER, the $600-1200^{\circ} \mathrm{C}$ temperature range should be covered. We do not expect analyses to show temperatures above $1200^{\circ} \mathrm{C}$, the upper bound for lithium-air fires. Decay heat and chemical reactions have not been found even in "beyond design basis events" to lead to temperatures above this value. It may be desirable to measure activation product mobility at temperatures as low as $400^{\circ} \mathrm{C}$, however measurements at these low temperatures are often below detection limits. ${ }^{1}$ The temperature ranges in our tests were $400-1200^{\circ} \mathrm{C}$ for $\mathrm{Be}, 400-1200^{\circ} \mathrm{C}$ for the $\mathrm{Cu}$ alloy, $600-1300^{\circ} \mathrm{C}$ for PCA steel, $600-1500^{\circ} \mathrm{C}$ for HT-9 steel, $800-1200^{\circ} \mathrm{C}$ for the $\mathrm{Nb}$ alloy, $600-1200^{\circ} \mathrm{C}$ for $\mathrm{W}$, and $600-1600^{\circ} \mathrm{C}$ for the $\mathrm{V}$ alloys.

We measure the mobility of Be because of its toxicity. We have completed exploratory tests on Be mobility in steam, however additional tests are necessary to support a PSAR. We have no data on Be mobility in air. Because $B e$ is part of the current ITER Engineering Design Activity (EDA) design, we plan to do additional Be-steam tests in 1994, and Be-air tests in 1995.

\section{Doses Based on Experiments}

The mobility flux can be used to calculate the dose to the maximum exposed individual at the site boundary. The fractional mobilization rate for each element is multiplied by the time at temperature, its corresponding radioactive inventory and dose per unit of radioactivity of element released. This gives the offsite dose per unit of time assuming all material mobilized is released. (In actuality, some of the material mobilized will settle out during transport to the site boundary; the activation product task also includes investigations of the transport behavior of materials, however that is not covered in this report. ${ }^{2}$ )

1 Detection limits are based on the ability of the analytic instruments to measure certain elements. The engineering design file "Mobilization Tests - Data Base Uncertainties," ITER/94/US/TE/SA-17, September 27,1994 , by S.C. Wilkins, explains compiling a statistically defensible data base and goes into detail on detection limits.

2 Documentation of our transport investigations can be found in the engineering design file by G.R. Smolik, A.W. Erickson, and D.L. Hagrman, "Characterization of Aerosols Released by a Tungsten Alloy," ITER/93/US/TE/SA-6, June 25, 1993; D.L. Hagrman, G.R. Smolik, D.A. Petti, and K.A. McCarthy, "Aerosol Behavior of a Tungten Alloy for Fusion Reactors," presented at the 11th Topical Meeting on the Technology of Fusion Energy, New Orleans, Louisiana, June 19-23, 1994; G.R. 
The total early dose inventory of dispersion strengthened $\mathrm{Cu}$ is dominated by $\mathrm{Co}$ (Co isotopes contribute a larger percentage to the dose than do isotopes from any other element) and $\mathrm{Cu}$. When using mobility fractions in air and steam, $\mathrm{Co}, \mathrm{Fe}, \mathrm{Cu}, \mathrm{Zn}$, and $\mathrm{Na}$ dominate. There were very few Co data above detection limits in air, and a large amount of scatter in the steam data. We need additional data for $\mathrm{Cu}$ mobility in steam. Because the composition of a $\mathrm{Cu}$ alloy can change considerably over the reactor lifetime because of irradiation-induced transmutation, tests should focus on the effect of composition on mobility. Because a $\mathrm{Cu}$ alloy is proposed for use in the ITER EDA design, we have recently carried out $\mathrm{Cu}$ alloy tests focusing on the effect of composition change on mobility. This results will be included in a future update to this report.

The early dose inventory of PCA steel (different from 316 SS because of the addition of a small amount of $\mathrm{Ti}$, a slightly lower $\mathrm{Cr}$ content, and a slightly higher $\mathrm{Ni}$ content) is dominated by $\mathrm{Co}, \mathrm{Mn}, \mathrm{Ta}, \mathrm{Cr}, \mathrm{Ni}$, and $\mathrm{Fe}$. When mobility fractions in air are considered, $\mathrm{Ta}, \mathrm{W}$, and Mo dominate. The plotted data show less than an order of magnitude spread at a given temperature, giving us confidence in the data. Ta mobility, which was not measured in earlier tests, should be measured. Because 316SS is the proposed structural material in the ITER EDA design, further 316SS tests are needed. Additional 316SS or PCA tests are planned for 1995.

The early dose inventory of HT-9 steel is dominated by $\mathrm{Mn}, \mathrm{Fe}, \mathrm{Cr}$, and $\mathrm{Co}$. Including mobility fractions based on mobility in air in the calculations, $\mathrm{Co}, \mathrm{P}, \mathrm{Cr}, \mathrm{Mn}$, and $\mathrm{Mo}$ dominate, with $\mathrm{Ta}, \mathrm{Nb}, \mathrm{Zr}$, and $\mathrm{Sc}$ contributing from 1-3\% depending on the accident temperature. At lower temperatures (around $600^{\circ} \mathrm{C}$ ), Co is by far the largest contributor to dose, while at higher temperatures, $\mathrm{Mn}$ is by far dominant. Considering mobility fractions based on mobility in steam in the calculations, $\mathrm{Mn}, \mathrm{Co}, \mathrm{Ta}, \mathrm{Nb}, \mathrm{Zr}$, and $\mathrm{Fe}$ dominate, with $\mathrm{Sc}, \mathrm{Cr}, \mathrm{Y}, \mathrm{Mo}, \mathrm{V}, \mathrm{Ni}$, and $\mathrm{W}$ contributing from 1-3\% depending on the accident temperature. $\mathrm{Mn}$ is the most dominant contributor to dose. The current ITER EDA design does not include HT-9 as a structural material, however should HT-9 become a candidate, additional tests would be necessary. These tests would focus on Co, $\mathrm{P}$, and Mo data.

The early dose inventory of $\mathrm{Nb}$ is dominated by $\mathrm{Nb}$ and $\mathrm{Ta} . \mathrm{Ta}, \mathrm{Nb}$, and $\mathrm{W}$ dominate when mobility fractions in air and steam are included. In our tests, only $\mathrm{Nb}$ and Mo were measured above detection limits, and very few data points were above detection limits at lower temperatures. The data exhibited very little scatter. We did not measure Ta mobility. $\mathrm{Nb}$ is not currently an ITER EDA or commercial reactor candidate, thus we do not have any plans for more $\mathrm{Nb}$ tests. If $\mathrm{Nb}$ were chosen for ITER, additional tests would

Smolik, "Aerosol Characterization for PCA Steels and a Copper Alloy," ITER/US/94/TE/SA-19, October 1994. 
be necessary, particularly in the $600-800^{\circ} \mathrm{C}$ range. If additional tests are done, Ta mobility should be measured.

The early dose inventory of $\mathrm{W}$ is dominated by $\mathrm{W}$, with about $3 \%$ coming from Ta. When including mobility fractions, W, Ta, Re, and Hf dominate in air-ingress accidents, and $\mathrm{W}, \mathrm{Hf}$, and $\mathrm{Ta}$ dominate in water-ingress accidents. There was very little scatter in the data. W is not currently included in the ITER EDA design, therefore we have no plans for additional $\mathrm{W}$ tests. Should $\mathrm{W}$ be identified for ITER, additional tests would be necessary, and Hf mobility would need to be measured.

The early dose inventory of V-5Cr-5Ti is dominated by $\mathrm{Sc}$ and $\mathrm{Cr}$, with all other elements contributing less than $1 \%$ to the total dose. When mobility fractions are included, $\mathrm{Sc}, \mathrm{Ca}$, and $\mathrm{Na}$ dominate, with $\mathrm{Ho}$ and $\mathrm{Nb}$ contributing from 1 to $5 \%$, depending on temperature. Very few Sc data points were above detection limits (none in steam), and much of the measured Ca data appears to be from Ca present in the environment rather than released from the sample. We have not measured $\mathrm{Na}$ release; because of its ubiquitous nature, it is difficult, if not impossible, to measure without using radioactive samples. Because $\mathrm{V}-5 \mathrm{Cr}-5 \mathrm{Ti}$ is the structural material in the ITER EDA backup design, we recently carried out additional $\mathrm{V}$ alloy tests in air, concentrating on Sc and Ca mobility. The results of these tests will be included in a future update to this report. We modeled Na volatility (these calculations will not include contributions from spalled oxide) this year. Should a need for V alloy data in steam arise (for example, if the ITER shield in the backup design were water-cooled), experiments concentrating on the mobility of $\mathrm{Sc}$ and $\mathrm{Ca}$ would be necessary, in addition to modeling Na volatility.

\section{Future Plans}

The majority of our future work will involve supporting ITER. We must assemble mobility information in 1994 for the Early Site Environmental Characterization Study (ESECS), and later provide input for a PSAR. A part of our work will continue to support commercial reactor designs, when those materials are different from those planned for ITER.

Based on the information in this report, we will concentrate on improving our database where adequate data does not exist. Additionally, we must focus on data validation to ensure that we have a database that will be defensible in a regulatory arena. We will continue to be flexible to ITER needs.

We must continue to look for ways of lowering detection limits. We must argue for mobilization fractions at least below $0.1 \%$ for ITER. One method for lowering detection limits is to use larger samples. Our plans for our 1995 work include designing and building a moderate scale facility; this will use a considerably larger sample than our current facility. 
In some cases, we recommend modeling as opposed to experiments. It is difficult, if not impossible (without using radioactive samples) to measure the mobility of elements that are also present in glassware and reagents as contamination. Also, when measurements of mobility are below detection limits, as is often true at lower temperature, modeling will supplement experimental results.

This report will be updated as additional data become available. 



\section{ACKNOWLEDGMENTS}

The authors gratefully acknowledge Steve Piet, who was instrumental in starting the activation products task at the INEL. Also, the authors thank Ron Wallace, Kyle Messick and Ed McNew for their invaluable support.

The authors wish to thank their colleagues for their comments and critiques of this report, most notably Dave Petti, Steve Piet, and Don Hagrman. 



\section{ACRONYMS}
AES/ICP Atomic emission spectroscopy inductive coupled plasma
CF Confinement release fraction
EDA Engineering Design Activity
EED Early Effective Dose
ESECS Early Site Environmental Characterization Study
EST Environmental source term
FSP Fusion Safety Program
IBD Inventory-based dose
IBEED Inventory-based Early Effective Dose
INEL Idaho National Engineering Reactor
ITER International Thermonuclear Experimental Reactor
MBD , Mobility-based dose
MBEED Mobility-based Early Effective Dose
MF Mobilization fraction
PSAR Preliminary Safety Analysis Report
RI Radioactive inventory 



\section{CONTENTS}

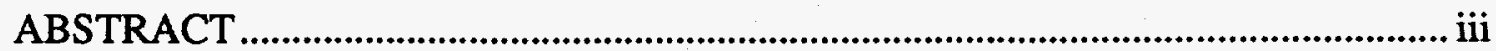

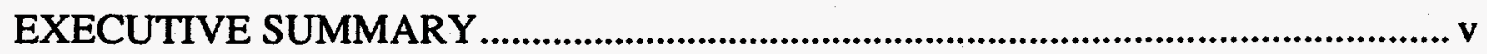

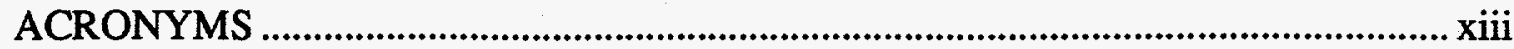

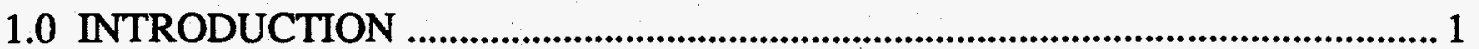

2.0 EXPERIMENTAL PROCEDURE, DATA ARCHIVING AND DATA

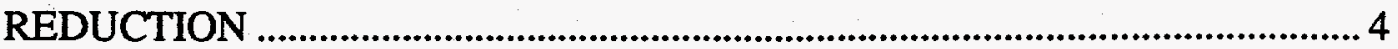

3.0 MATERIALS TESTED AND TEST RESULTS ............................................ 8

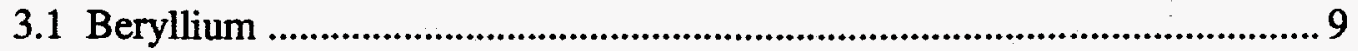

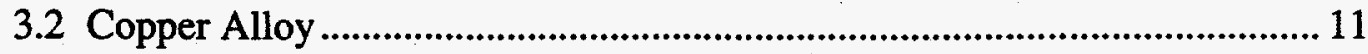

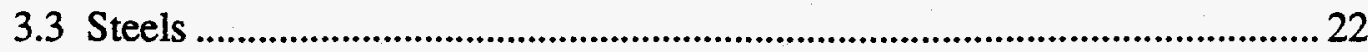

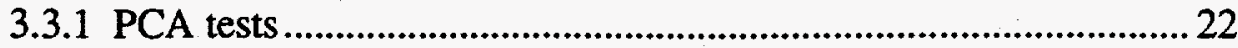

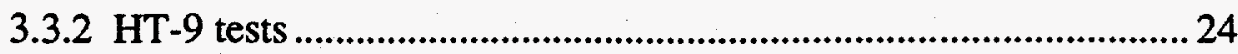

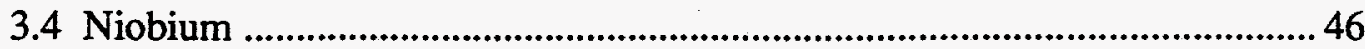

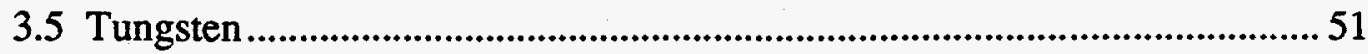

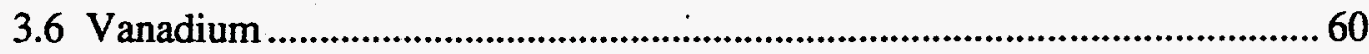

4.0 USING MOBILITY DATA IN SAFETY ASSESSMENTS ............................. 71

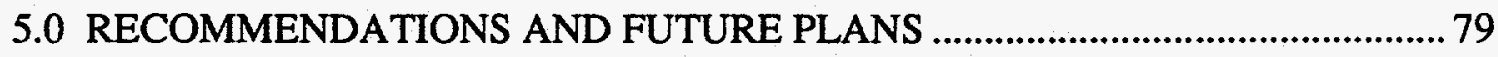

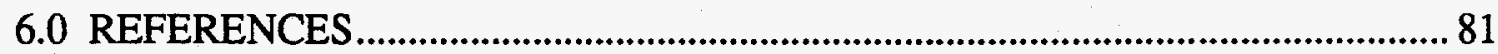

APPENDIX A LISTING OF LAB NOTEBOOKS ............................................ A-1

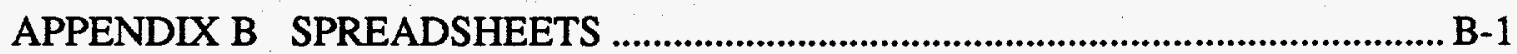

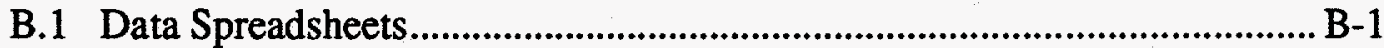

B.2 Mobility Data Analysis Spreadsheet …................................................ B-2

B.3 Master Spreadsheet.......................................................................... B-3

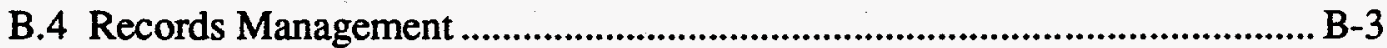

APPENDIX C ELEMENTAL RELEASE CATEGORIES ....................................... C-1 



\section{FIGURES}

1. Process for evaluation of source term .......................................................... 2

2. VAPOR apparatus for measuring mobility of elements from materials ..................5

3. Mobility of Be from Be exposed to steam ...................................................... 10

4. Cumulative maximum mobility of Be from Be exposed to steam......................... 11

5. Co mobility from $\mathrm{Cu}$ exposed to air..................................................................... 14

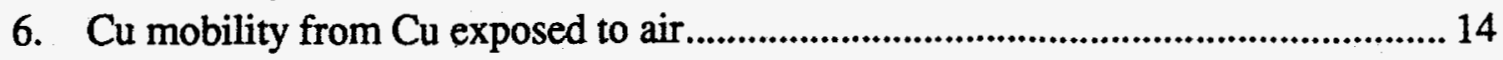

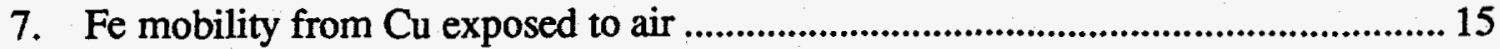

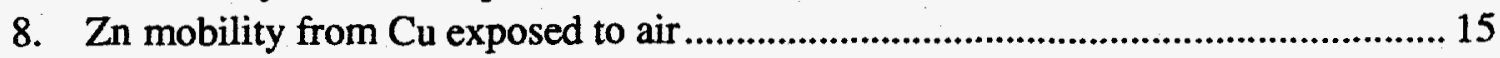

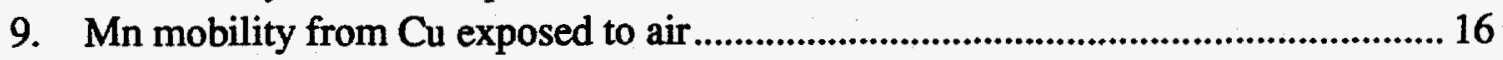

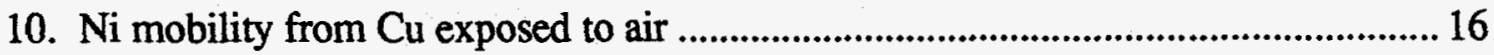

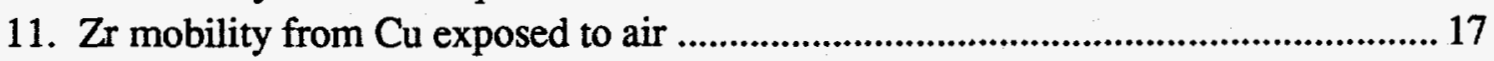

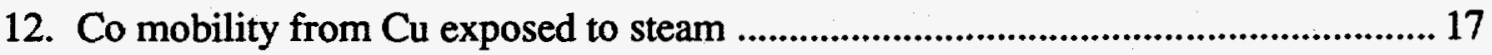

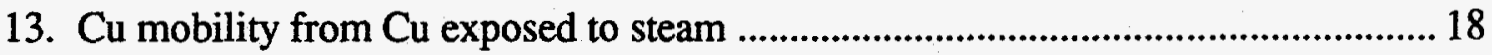

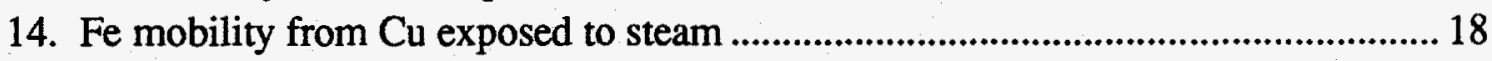

15. $\mathrm{Zn}$ mobility from $\mathrm{Cu}$ exposed to steam.......................................................... 19

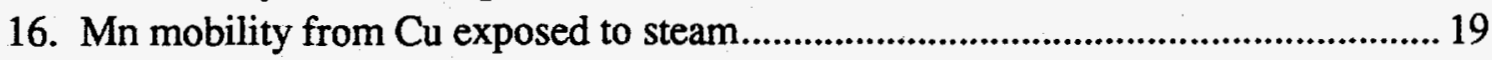

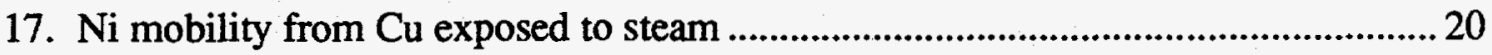

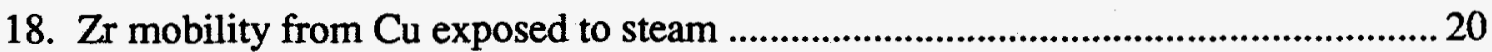

19. Cumulative maximum mobility of elements from copper exposed to air................ 21

20. Cumulative maximum mobility of elements from copper exposed to steam .......... 21

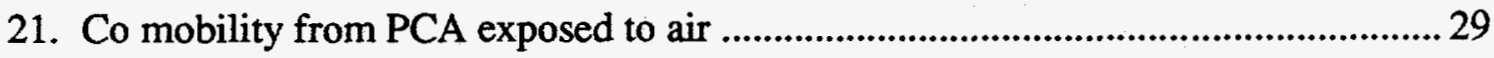

22. Cr mobility from PCA exposed to air ............................................................... 29

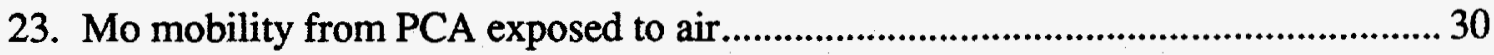

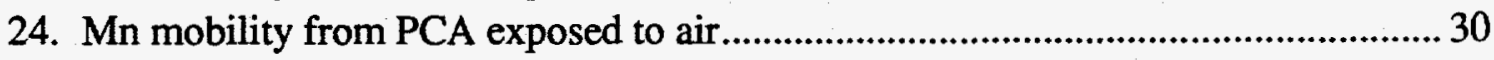

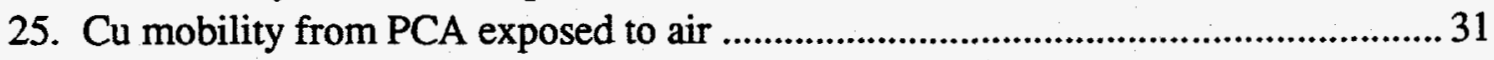

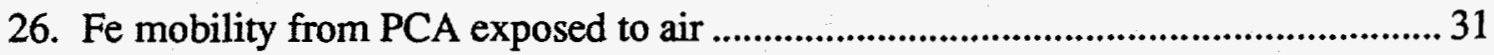

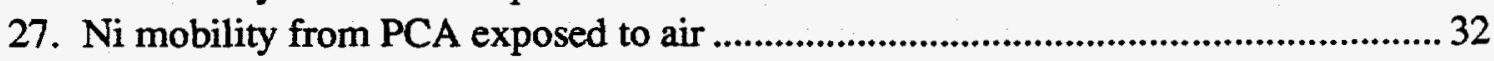

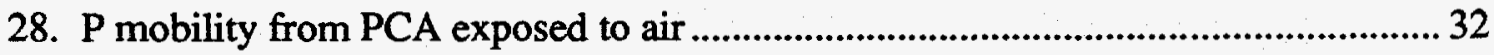

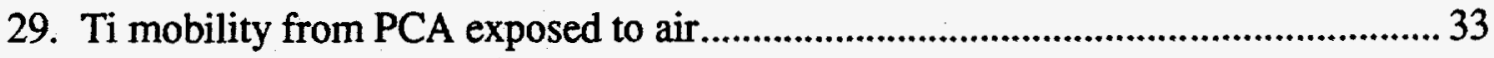

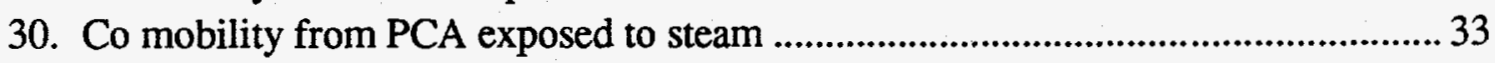

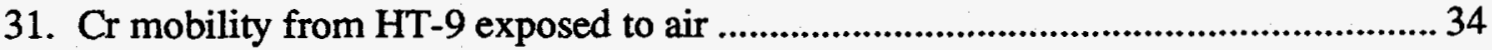

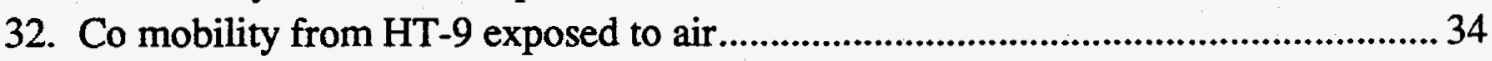

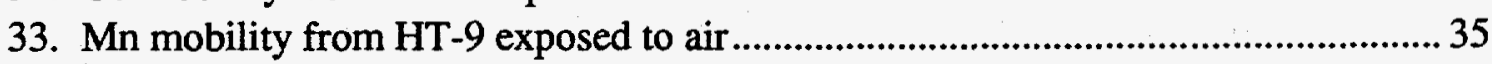

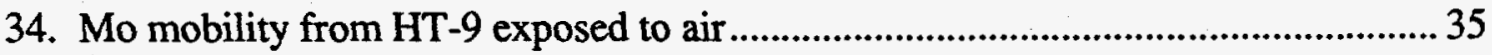

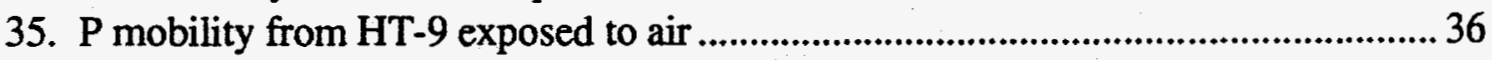

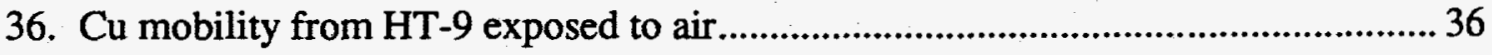

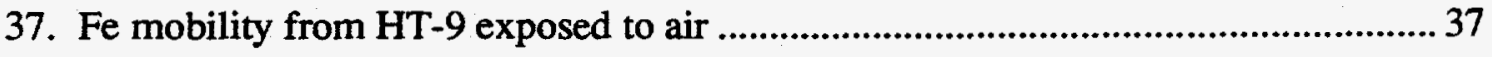

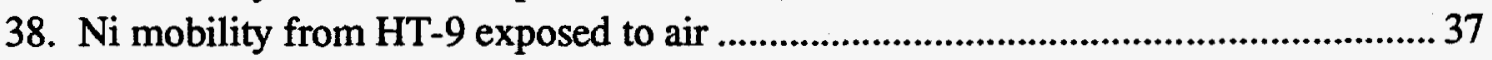

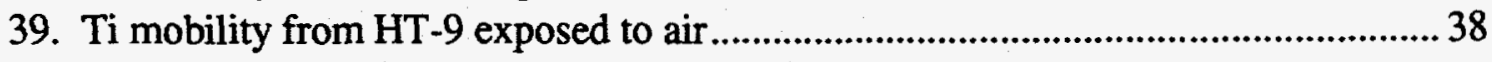

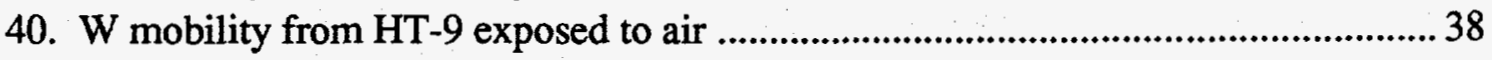




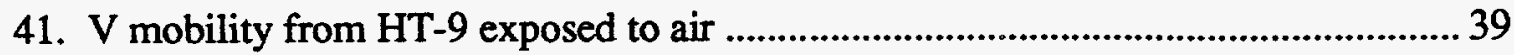

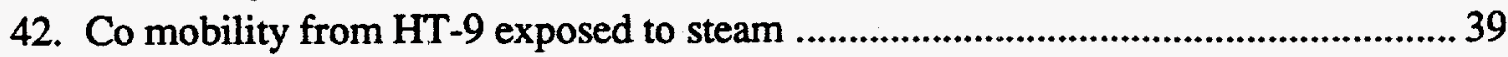

43. Cr mobility from HT-9 exposed to steam ................................................................. 40

44. Mn mobility from HT-9 exposed to steam.................................................................. 40

45. Mo mobility from HT-9 exposed to steam.................................................................. 41

46. V mobility from HT-9 exposed to steam .................................................................... 41

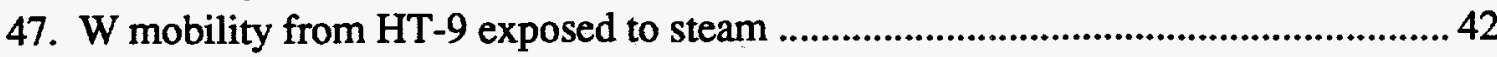

48. Cu mobility from HT -9 exposed to steam .............................................................. 42

49. Fe mobility from HT-9 exposed to steam ................................................................... 43

50. P mobility from HT-9 exposed to steam .................................................................. 43

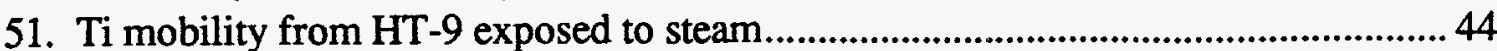

52. Cumulative maximum mobility of elements from PCA exposed to air..................... 44

53. Cumulative maximum mobility of Co from PCA exposed to steam .........................45

54. Cumulative maximum mobility of elements from HT-9 exposed to air .................... 45

55. Cumulative maximum mobility of elements from HT-9 exposed to steam.............. 46

56. Mo mobility from $\mathrm{Nb}$ alloy exposed to air ............................................................... 48

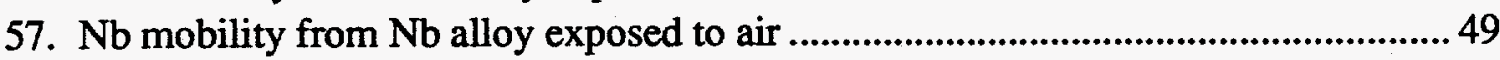

58. Mo mobility from $\mathrm{Nb}$ alloy exposed to steam ......................................................... 49

59. $\mathrm{Nb}$ mobility from $\mathrm{Nb}$ alloy exposed to steam .........................................................5 50

60. Cumulative maximum mobility of elements from niobium alloy exposed to air

61. Cumulative maximum mobility of elements from niobium alloy exposed to steam

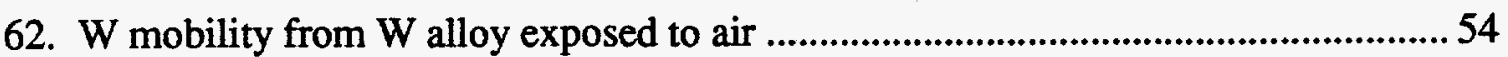

63. Re mobility from $W$ alloy exposed to air.............................................................. 54

64. W mobility from $W$ alloy exposed to steam ………….............................................. 55

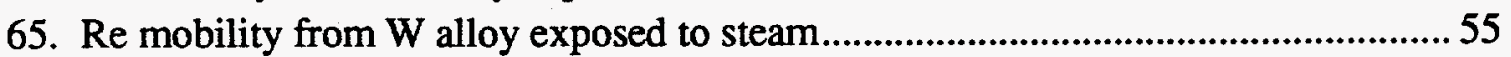

66. Mn mobility from $W$ alloy exposed to steam .......................................................... 56

67. Fe mobility from $W$ alloy exposed to steam ………....................................................5 56

68. Co mobility from $W$ alloy exposed to steam .......................................................... 57

69. Ni mobility from W alloy exposed to steam ............................................................ 57

70. Cu mobility from $W$ alloy exposed to steam .............................................................. 58

71. Ta mobility from $W$ alloy exposed to steam ............................................................ 58

72. Cumulative maximum mobility of elements from tungsten alloy exposed to

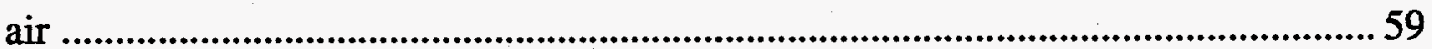

73. Cumulative maximum mobility of elements from tungsten alloy exposed to

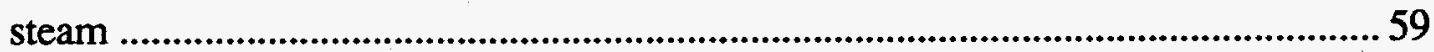

74. Sc mobility from $\mathrm{V}$ alloy exposed to air .................................................................6 63

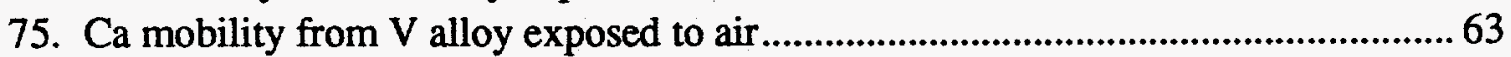

76. Ca mobility from $V$ alloy exposed to air................................................................64

77. Mn mobility from $V$ alloy exposed to air ................................................................64

78. Mn mobility from $V$ alloy exposed to air ................................................................... 65

79. $\mathrm{V}$ mobility from $\mathrm{V}$ alloy exposed to air ...............................................................6 65 
80. $\mathrm{V}$ mobility from $\mathrm{V}$ alloy exposed to air

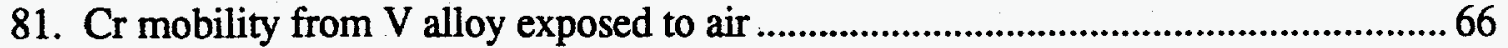

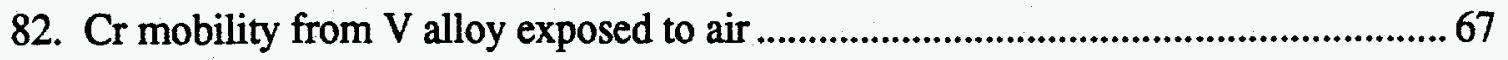

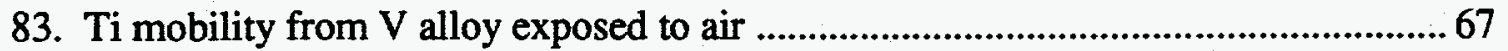

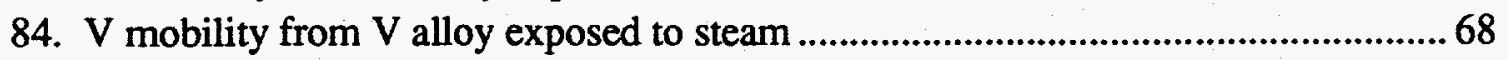

85. Ti mobility from $V$ alloy exposed to steam ............................................................6 68

86. Cr mobility from $\mathrm{V}$ alloy exposed to steam ............................................................69

87. Cumulative maximum mobility of elements from $\mathrm{V}$ alloy exposed to air............... 69

88. Cumulative maximum mobility of elements from $\mathrm{V}$ alloy exposed to steam .......... 70 



\section{TABLES}

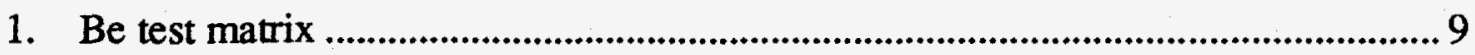

2. Regression coefficients for Be mobility in steam ..................................................10

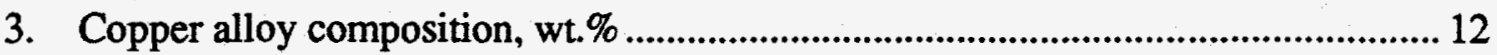

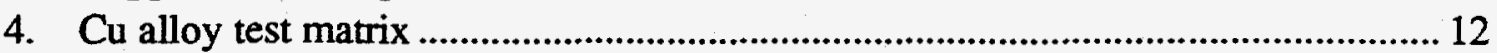

5. Regression coefficients for $\mathrm{Cu}$ alloy mobility in air ................................................ 13

6. Regression coefficients for $\mathrm{Cu}$ alloy mobility in steam ..........................................13

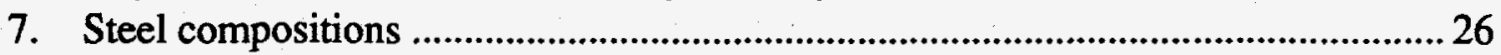

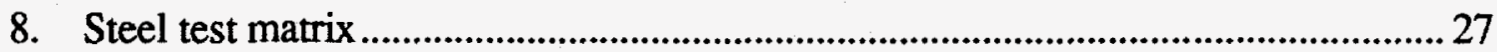

9. Regression coefficients for PCA mobility in air ......................................................... 27

10. Regression coefficients for PCA mobility in steam .................................................27

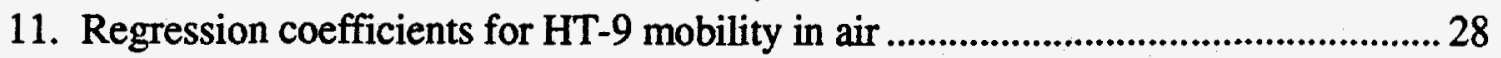

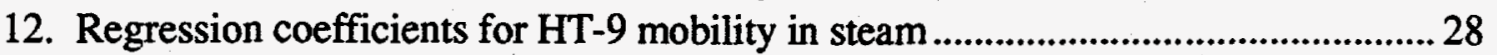

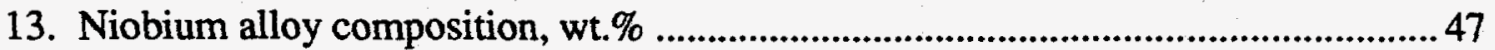

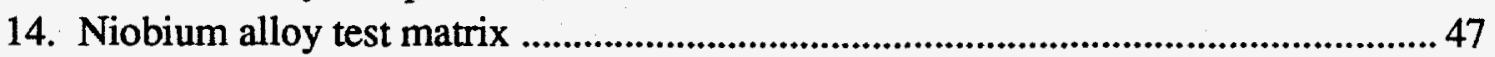

15. Regression coefficients for $\mathrm{Nb}$ alloy mobility in air................................................4

16. Regression coefficients for $\mathrm{Nb}$ alloy mobility in steam............................................ 48

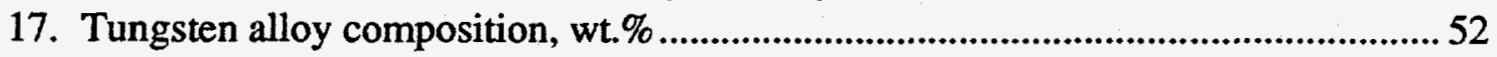

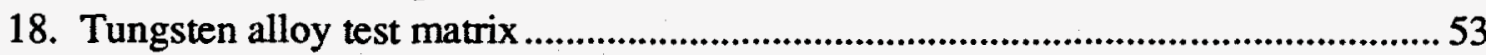

19. Regression coefficients for $W$ alloy mobility in air ...............................................53

20. Regression coefficients for $W$ alloy mobility in steam.........................................53

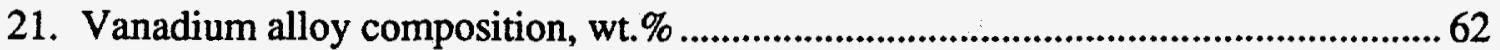

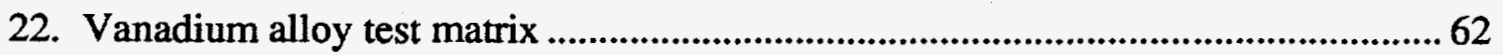

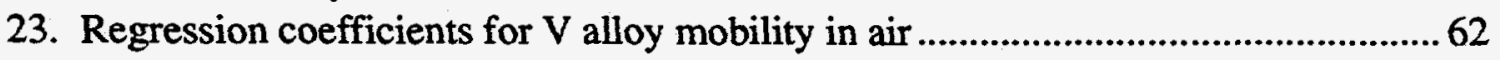

24. Regression coefficients for $\mathrm{V}$ alloy mobility in steam...............................................62 62

25 . Isotopes contributing more than $1 \%$ of the early dose during 1-hour air ingress accident with dispersion-strengthened copper ............................................ 73

26. Isotopes contributing more than $1 \%$ of the early dose during 1 -hour water ingress accident with dispersion-strengthened copper ............................................ 74

27. Isotopes contributing more than $1 \%$ of the early dose during 1 -hour air

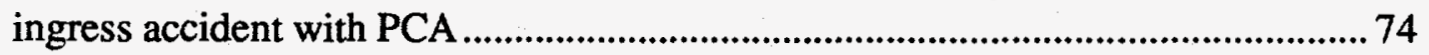

28. Isotopes contributing more than $1 \%$ of the early dose during 1-hour air

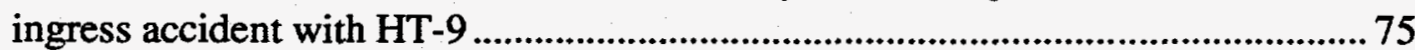

29. Isotopes contributing more than $1 \%$ of the early dose during 1 -hour water

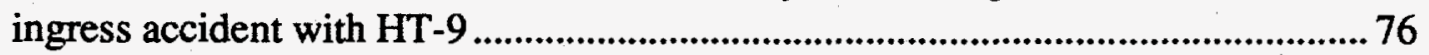

30. Isotopes contributing more than $1 \%$ of the early dose during 1 -hour air ingress accident with $\mathrm{Nb}$

31. Isotopes contributing more than $1 \%$ of the early dose during 1 -hour water-

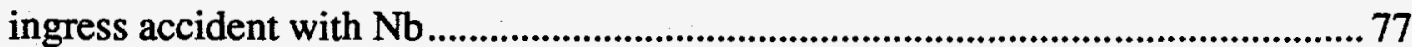

32. Isotopes contributing more than $1 \%$ of the early dose during 1 -hour air ingress accident with $\mathrm{W}$ alloy 
33. Isotopes contributing more than $1 \%$ of the early dose during 1 -hour water ingress accident with $\mathrm{W}$ alloy

34. Isotopes contributing more than $1 \%$ of the early dose during 1-hour air ingress accident with $\mathrm{V}-5 \mathrm{Cr}-5 \mathrm{Ti}$

35. Isotopes contributing more than $1 \%$ of the early dose during 1 -hour water ingress accident with $\mathrm{V}-5 \mathrm{Cr}-5 \mathrm{Ti}$ 


\subsection{INTRODUCTION}

The purpose of the activation products task under the Fusion Safety Program (FSP) at the Idaho National Engineering Laboratory (INEL) is to provide information on the mobilization and transport of activated materials (and beryllium because of its toxicity) under accident conditions in fusion reactors. This information is useful to designers by providing guidance toward safer designs. We are working towards compiling a defensible data base for use in the regulatory process for ITER in the near-term, and for commercial reactors in the long-term. The compilation of this report was supported with funds from both ITER and the base program (which covers non-ITER commercial-reactor relevant materials).

To avoid confusion over terminology, we define the following terms:

mobilization a general term describing the means by which activation products become available for release

release

a term used to refer to the mobilization and transport of material to some specified location

source term ${ }^{3}$ the mass, chemical form and physical form of radioactive and toxic material released to the environment during a postulated accident

spallation flaking of oxide material from structure due to thermal stresses

transport the process by which the mobilized material is moved away from the point of mobilization to the environment through the confinement barriers that may or may not be degraded

volatilization the conversion of a chemical substance from a liquid or solid state to a gaseous or vapor state; vaporization

Over $99 \%$ of the activation products in a fusion reactor are normally within solid materials, particularly in plasma-facing material and structural material; activated corrosion products make up the balance. Solid activation products can be mobilized by four methods, two of which require the ingress of some gas or gases (air, steam, or other): reactions with air or steam leading to volatile oxides, or hydroxides, and the escape of

3 Information on estimating the source term can be found in the engineering design file by D.A. Petti, "Methodology for Estimating the Activation Product Source Term for ESECS," ITER/US/94/EN/SA-6, May 6, 1994. 
tokamak erosion dust from the vacuum chamber (the third is the vaporization of material by the plasma during a disruption, and the fourth is activated corrosion products). The activation products task covers activation products mobilized by reactions with gases, primarily steam and air.

This task began in the early 1980s and continues today. The purpose of the first tests was to identify the most volatile elements in potential fusion structural materials and provide exploratory data on the magnitude of the volatility. Our initial focus was on volatility, but examination of our data indicates that in many cases the mass mobilized is due to both volatilization and oxide spalling. Thus when we talk about mass mobilized, we refer to mass volatilized, plus contributions due to spalled oxide. In some of our more recent tests, we have attempted to separate contributions from volatility and contributions from spalled oxide. ${ }^{4}$ In this case we are concerned with the pieces of spalled oxide that are small enough that they do not fall from the quartz tube when the tube is tapped. These pieces may be small enough to be transported out of the reactor. We have also investigated the breakup of larger pieces of spalled oxide in convective currents in postulated accidents. ${ }^{5}$ Details on spalled oxide contribution to dose are beyond the scope of this report and can be found in the references indicated in footnotes 4 and 5 .

Our test and analytical procedures have changed and improved over the years, and we are now able to measure mobility of many elements that are present in small quantities. The task now covers both mobilization and transport (the process of aerosol formation, agglomeration, and deposition); this report will cover only the mobilization work. Figure 1 shows how the mobilization work fits into the calculation of a source term.

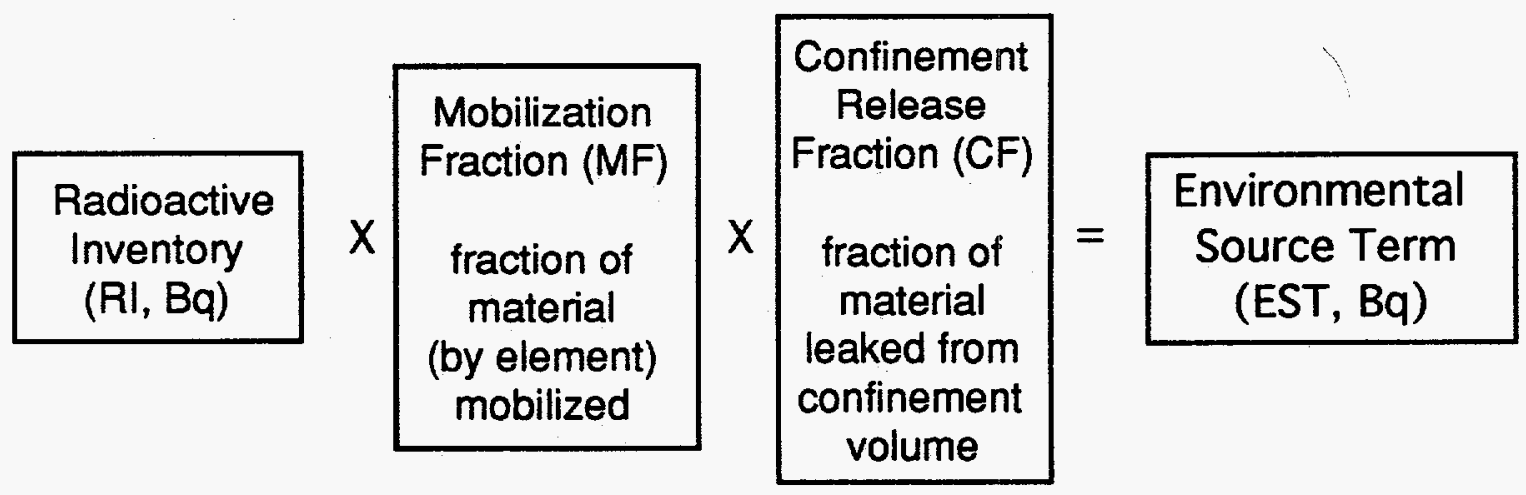

Figure 1. Process for evaluation of source term

4 K.A. McCarthy and G.R. Smolik, "Cobalt Release from PCA Steel," [TER/94/US/TE/SA-5, June 3, 1994.

5 G.R. Smolik, K.A. McCarthy, V.L. Smith-Wackerle, "Oxide Breakup by Convective Currents: Its Role in Activity Release," ITER/US/93/TE/SA-12, September 28, 1993; and D. L. Hagrman, "Breakup of Mechanically Spalled Oxides," ITER/94/US/TE/SA-14, August 18, 1994. 
One of the primary thrusts of the activation products task is to produce data for use in a PSAR (Preliminary Safety Analysis Report) for ITER. Based on calculations of probable accident temperatures in ITER, the $600-1200^{\circ} \mathrm{C}$ temperature range should be covered. We do not expect analyses to show temperatures above $1200^{\circ} \mathrm{C}$, the upper bound for lithium-air fires. Decay heat and chemical reactions have not been found even in "beyond design basis events" to lead to temperatures above this value. It may be desirable to measure activation product mobility at temperatures as low as $400^{\circ} \mathrm{C}$, however measurements at these low temperatures are often below detection limits. 6

The main purpose of this report is to compile and critically assess all of the mobility data to date, and describe where the data can be found and how they are used. We will not give details of the test procedures here, but references are given for the interested reader. Rather, a general overview of the results will be given with emphasis on how this information can be used to determine where further tests are needed. Additionally, we will include a section on how the mobility data are used in safety assessments.

Section 2 gives a brief description of experimental procedures and data reduction, and how the data is archived. The materials tested, test temperatures, and test results are described in Section 3. Section 4 explains how the mobilization data are used in accident assessments. Recommendations and plans for further tests can be found in Section 5.

6 Detection limits are based on the ability of the analytic instruments to measure certain elements. The engineering design file "Mobilization Tests - Data Base Uncertainties," ITER/94/US/TE/SA-17, September 27,1994 , by S.C. Wilkins, explains compiling a statistically defensible data base and goes into detail on detection limits. 


\subsection{EXPERIMENTAL PROCEDURE, DATA ARCHIVING AND DATA REDUCTION}

In a loss of coolant accident, material that is normally contained within the vacuum chamber can be exposed to air (all designs) or steam (water-cooled designs). Temperatures at which the material will be exposed depend primarily on decay heat and chemical reaction between the ingressed gas and the coolant or structural material. Our aim in these experiments is to simulate accident conditions, and determine the amount of material mobilized from the material surface per unit time.

We prepare samples that include non-radioactive elements to represent transmutation products induced by irradiation. In using these samples, we assume that the irradiated material would not behave differently than unirradiated material. Samples that we prepare through powder metallurgy are conservative in the respect that the oxygen content and porosity are higher than in dense solid material, thus there is already higher oxidation and migration behavior than in dense solid material. We will carry out a very limited number of confirmatory tests with radioactive samples in the future.

We have carried out the mobilization experiments in our VAPOR apparatus (Volatilization of Activation Products Oxides Reactor). A schematic of the apparatus as it is currently configured is shown in Figure 2. Most of the samples have been tested using induction heating to simulate decay heating following an accident (we use resistive heating in some tests). For ITER purposes, we are primarily concerned with the temperature range $400-1200^{\circ} \mathrm{C}$, however we have performed some tests at higher temperatures. Argon is used to purge the system while the sample is brought to temperature. Air or steam is then flowed over the specimen. We generally run tests of varying duration, usually around 1 hour, 5 hours, and 20 hours. Depending on the material tested, the mass flux of some elements is either approximately constant with time (rated limited by surface or gas phase processes), or decreases with time (rate limited by solid phase diffusion processes) (Piet, et. al (1989a)). The species mobilized are deposited on the test components or carried downstream and collected in a filter. The system components and the filter, both of which are made of quartz, are chemically cleaned with hydrofluoric acid and processed into solutions that are analyzed by atomic emission spectroscopy inductive coupled plasma (AES/ICP). A more detailed description of the experimental method and analytical method can be found in Piet et. al (1989a).

In many cases, the detection limits of the analytical instrument limit our ability to analyze all of the elements of interest. In these cases, we do not know whether any material has been mobilized. We can decrease detection limits by increasing test duration and sample size. However because volatility is often a function time, increasing test duration is not always desirable. In some cases we must assume mobility fractions established by detection limits when carrying out safety assessments. For some elements, the offsite 
dose based on these detection limits is undesirably high. Thus, our current work concentrates on lowering detection limits for certain elements.

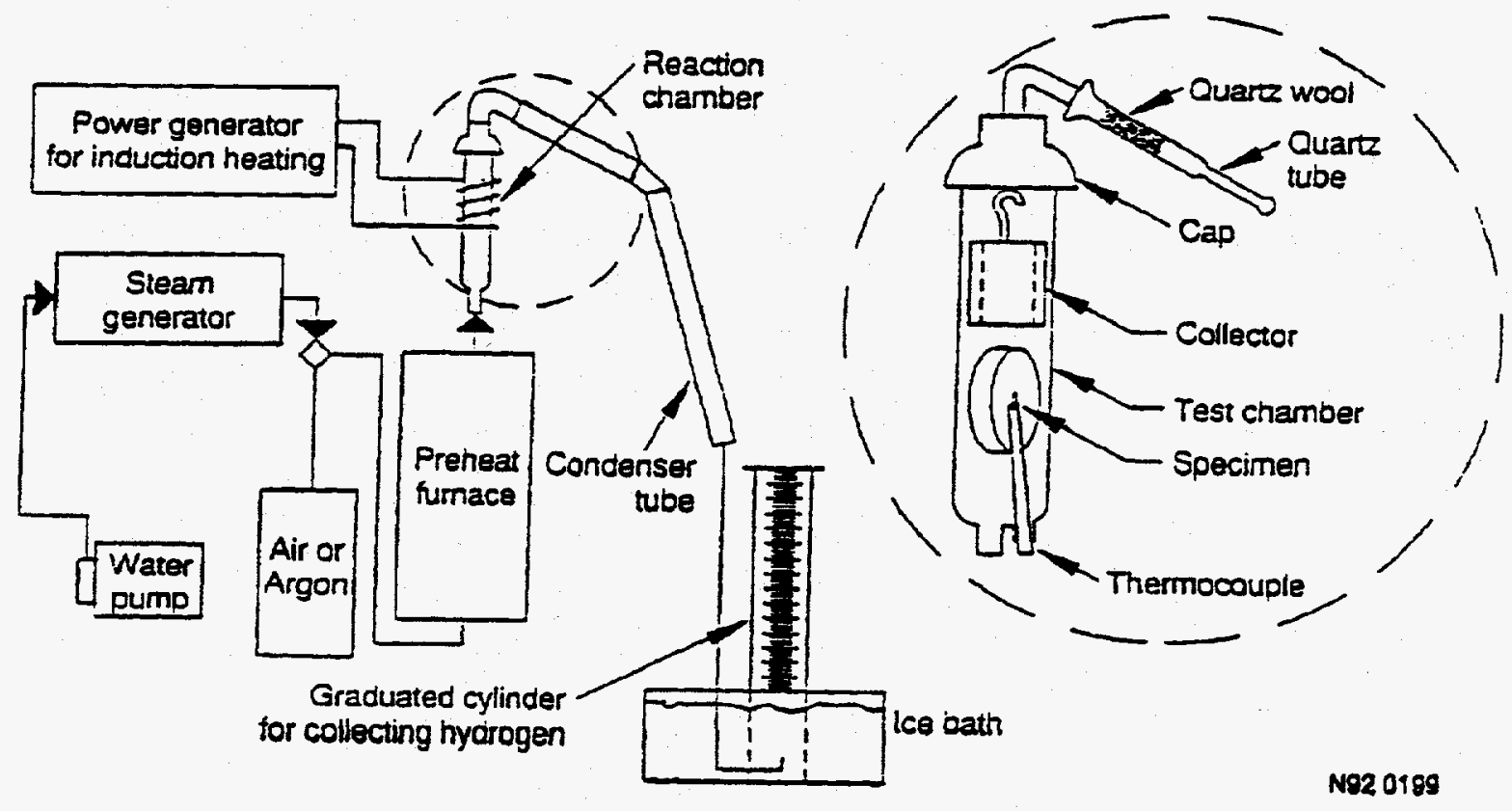

Figure 2. VAPOR apparatus for measuring mobility of elements from materials

An additional difficulty in testing is that as the sample cools down, bits of oxide often spall off the sample. Some of the very fine oxide pieces adhere to the wall of the test components. In these cases, it is impossible to differentiate between material that is volatilized and spalled oxide. We attempt to remove material that is obviously spalled, however it is often not possible to avoid including some of the spalled material in the volatility measurements. This could be the reason for some of the observed scatter in the data.

Details about the experimental procedure, test results, and results of sample analytical analyses are recorded in a series of lab notebooks. We have included a listing of these notebooks and a brief description of their contents in Appendix A. We are currently developing certification procedures for this data.

The raw data from the tests are recorded in a series of spreadsheets. There is a separate spreadsheet for each material tested. For each material, another spreadsheet is used to analyze the data to reduce the data points into a form directly usable in accident safety assessments. This data reduction involves calculating a mass flux $\left(\mathrm{g} / \mathrm{m}^{2}-\mathrm{h}\right)$ based on the mass of material mobilized, the surface area of the sample, and the test duration. A third spreadsheet is then used to record the mass flux for each material as a function of 
temperature. This information is in tabular form, and for some materials, includes a curve fit to the data. We have included a list of current spreadsheets in Appendix B.

The mass flux tables use the concept of "cumulative maximum" mobility in safety assessments; that is, if the maximum mobility measured at $600^{\circ} \mathrm{C}$ for example, is higher than the maximum measured at $700^{\circ} \mathrm{C}$, the value from the $600^{\circ} \mathrm{C}$ test is used in place of the $700^{\circ} \mathrm{C}$ test value. In general, the maximum value comes from the 1 hour tests. In some materials, the oxide layer cracks, exposing fresh material, thus the mobilization rate does not decrease as significantly with time. Using the cumulative maximum introduces conservatism, however at present, we have not validated our data, so we cannot discard any individual data points. Our plans for this year call for beginning statistical data validation, but until that has been done, we feel that all data points should be used.

For materials where there are a sufficient number of data points, a curve fit to the data can be performed. Based on work presented in earlier reports (Piet, et. al (1986) and Piet, et. al (1989a)) we use the following functional form:

$$
\Gamma=A t^{B} \exp (-C / R T)
$$

where $\Gamma$ is the mass flux ( $\mathrm{g} / \mathrm{m}^{2}-\mathrm{h}$ ) averaged over the test duration, $A$ is a constant, $t$ is time (h), $B$ is the time exponent, $C$ is an apparent activation energy ( $/ / \mathrm{mole}), R$ is the gas constant $(8.314 \mathrm{~J} /$ mole- $\mathrm{K})$, and $T$ is temperature $(\mathrm{K})$. A time exponent $(B)$ near 0 would indicate that the mass flux did not change with time. This would suggest some constant rate process such as an unprotective oxide layer or gas phase diffusion. A time exponent near -1 would indicate that the mass flux decreased rapidly with increased time and the mass mobilization could be dominated by initial short-term exposure of relatively unoxidized surfaces. As pointed out by Piet, et. al (1989a), this functional form may not be applicable to all cases over the entire temperature range. Our purpose is more in evaluating existing data rather than attempting curve fits to the data, so in some cases the plots of the data are useful for visualizing data scatter, while the curve fits are not particularly useful. In cases where oxide spalling contributes significantly to mobility, we would expect to see scatter in the data.

It is also possible to do curve fits for alloy classes. In this case composition must be considered, since the amount of a particular element present may vary from material to material. Also, the composition of a particular alloy may change considerably during irradiation, so it is useful to know how volatility varies with composition. We use the following function form when composition is considered:

$$
\Gamma=A t^{B} \exp (-C / R T) w^{D}
$$

where $w$ is the moler fraction of the element in the alloy, $D$ is a composition exponent, and the other variables are the same as equation (1). A composition exponent (D) of 0 
would indicate that the mass flux was independent of composition. A value of 1 would indicate that the mass flux varied linearly with the moler fraction of the element in the alloy.

We present curve fits in the following sections for materials where there are an adequate number of data points. Generally we plot the curves for 1,5 , and 20 hour test duration. We do not include points below detection limits in the plots or in the regression analyses. 


\subsection{MATERIALS TESTED AND TEST RESULTS}

In this section we give compositions of the materials tested, the test matrix, and provide a brief description of the test results. References are provided at the end of each section for more detailed information. We also present curve fits to the data for materials with an adequate amount of data. The following is a descriptive list of the plotted data:

- Data and the associated curve fits are generally plotted for test durations of 1,5 , and 20 hours.

- In some cases additional tests at times other than those plotted were performed, but to improve plot readability, these points are not included in the graphs.

- We plot only points that are above detection limits.

- All points, excluding those below detection limits, but including those from tests other than 1,5 , or 20 hours, are used in the curve fits.

- In some cases, the usefulness of the plotted data is more in evaluating the scatter than in the curve fits themselves.

- We present the correlation coefficient, $\mathrm{r}^{2}$, a measure of data correlation to curve fit $\left(r^{2}=1\right.$ means perfect correlation and $r^{2}=0$ indicates no correlation).

- We evaluate the data based on the contribution of each element to early offsite dose.

In the discussions of the doses for each material, we refer to elements that "dominate" dose calculations. What we mean by this is these elements contribute a significantly larger percentage to dose than do other elements in the material. We present an "inventory-based dose" and a "mobility-based dose." The inventory-based dose is

$$
I B D=R I \times(\text { dose } / \text { unit radioactivity released })
$$

where $I B D$ is the inventory based dose and $R I$ is the radioactive inventory $(\mathrm{Bq})$. We will use the Early Effective Dose (EED), thus we will refer to the inventory-based Early Effective Dose (IBEED). The mobility-based dose is

$$
M B D=I B D \times M F
$$

where $M B D$ is the mobility-based dose and $M F$ is the mobilization fraction. We will use the Early Effective Dose (EED), thus we will refer to the mobility-based Early Effective Dose (MBEED). The details of the dose calculations are in Section 4.

The following sections will cover Be tests in steam, $\mathrm{Cu}$ alloy tests in air and steam, PCA steel (different from $316 \mathrm{SS}$ because of the addition of a small amount of $\mathrm{Ti}$, a slightly lower $\mathrm{Cr}$ content, and a slightly higher Ni content) tests in air and steam, HT-9 steel tests in air and steam, Nb alloy tests in air and steam, $\mathrm{W}$ alloy tests in air and steam, and $\mathrm{V}$ 
alloy tests in air and steam. We have also tested graphites and carbon composites in steam to measure recession rates and hydrogen production. These tests will not be covered in this report, however, because the issue is not strictly mobility (the irradiated carbon-based materials are not an activation hazard, rather, tritium release is a concern). For details concerning these tests, see Smolik, et. al (1990), and Smolik, et. al (1991a).

\subsection{Beryllium}

We are concerned with $\mathrm{Be}$ mobility because of its toxicity, not its activation products. We have measured mobility from two different forms of pure Be: fully-dense (Smolik, et. al, 1992a) and porous (Smolik, et. al, 1992a and Smolik, et. al, 1992d), all in a steam environment. ${ }^{7}$ The test matrix appears in Table 1. It was difficult to control temperatures in the porous Be tests because the samples became thermally unstable around $650^{\circ} \mathrm{C}$, thus it was difficult to measure mobility above this temperature. In tests where the Be ignited, the relevant temperature (and the temperature that is plotted) is the ignition temperature (about $1300^{\circ} \mathrm{C}$ ), not the initial test temperature. Thus in Figure 3, there are no data from porous Be tests between 650 and $1300^{\circ} \mathrm{C}$. Our mobility tests did not show a large dependence on the form of the Be. (Reaction rates were highly dependent on the $\mathrm{Be}$ form, however, reaction rates are not part of the scope of this report. Information on reaction rates can be found in Smolik, et. al, 1992a and Smolik, et. al, 1992d). The maximum cumulative mobility (including both dense and porous material) is plotted in Figure 4.

The curve fit for the Be mobility is plotted in Figure 3. The values for the regression coefficients are in Table 2 . The fit, as indicated by an $\mathrm{r}^{2}$ value of .69 , is relatively good. The tests to date have been exploratory tests, adequate for the ITER Early Safety and Environmental Characterization Study (ESECS). However, additional tests are needed, along with data validation, before the data can be used in a regulatory assessment.

\begin{tabular}{|c|c|c|c|c|c|c|c|c|}
\hline Be & \multicolumn{7}{|c|}{ Test Temperature $\left({ }^{\circ} \mathrm{C}\right.$} \\
\cline { 2 - 9 } Form & 400 & 500 & 600 & 700 & 800 & 900 & 1000 & 1200 \\
\hline Dense & & & $\mathrm{x}$ & $\mathrm{x}$ & $\mathrm{x}$ & $\mathrm{x}$ & $\mathrm{x}$ & $\mathrm{x}$ \\
\hline Porous & $\mathrm{x}$ & $\mathrm{x}$ & $\mathrm{x}$ & $\mathrm{x}$ & $\mathrm{x}$ & & & \\
\hline
\end{tabular}

Table 1. Be test matrix

7 Results of tests with plasma-sprayed Be can be found in a document by G.R. Smolik, "Test Results from Plasma-Sprayed Beryllium," ITER/92/TE/SA-4, February 18, 1992. 


\begin{tabular}{|c|c|c|c|c|}
\hline Element & $\mathbf{A}\left(\mathrm{g} / \mathbf{m}^{2}-\mathbf{h}\right)$ & $\mathbf{B}$ & $\mathbf{C}(\mathbf{J} / \mathbf{m o l e})$ & $\mathbf{r}^{\mathbf{2}}$ \\
\hline $\mathrm{Be}$ & $1.11 \mathrm{E}+05$ & $4.26 \mathrm{E}-01$ & $1.21 \mathrm{E}+05$ & .69 \\
\hline
\end{tabular}

Table 2. Regression coefficients for Be mobility in steam

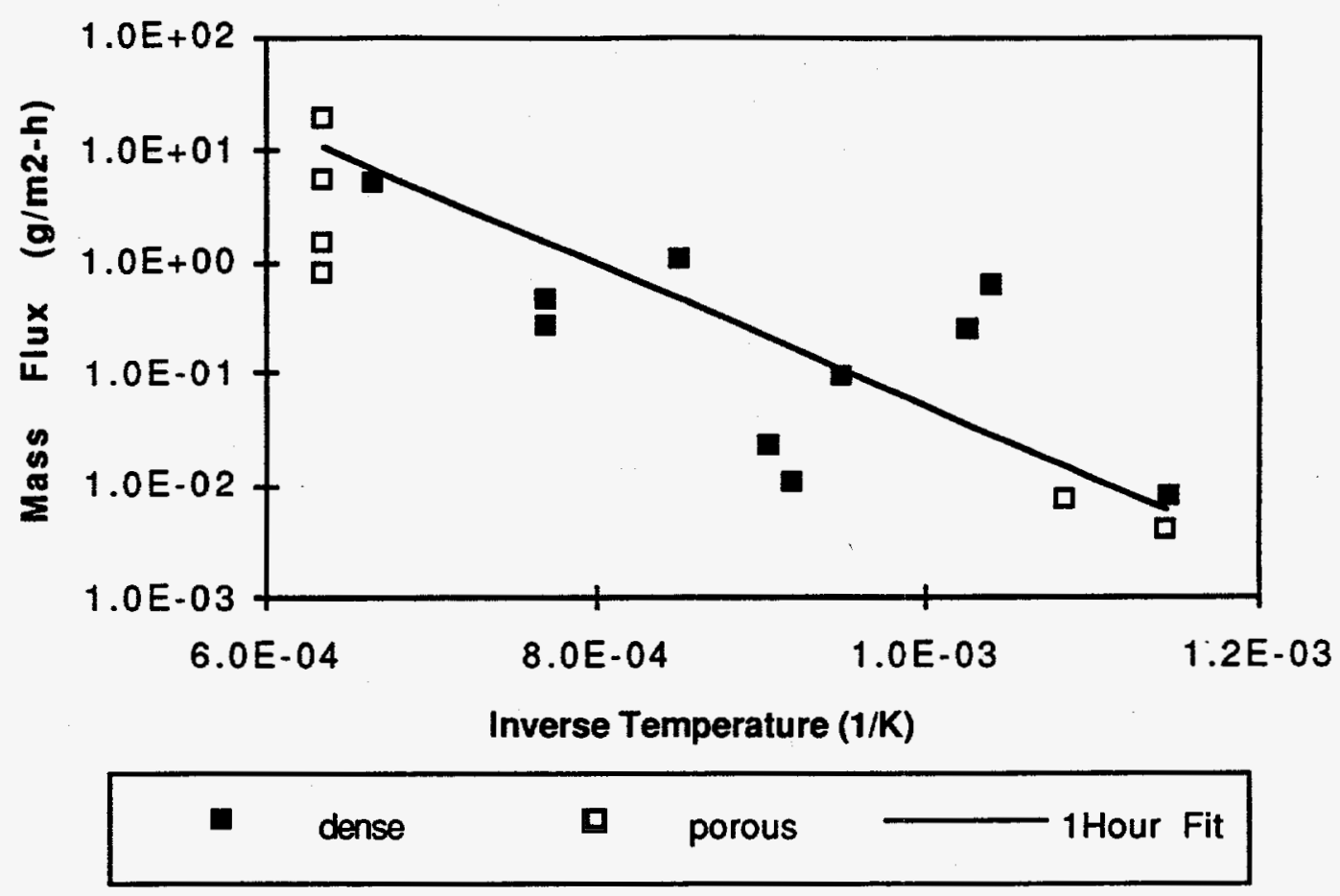

Figure 3. Mobility of Be from Be exposed to steam 


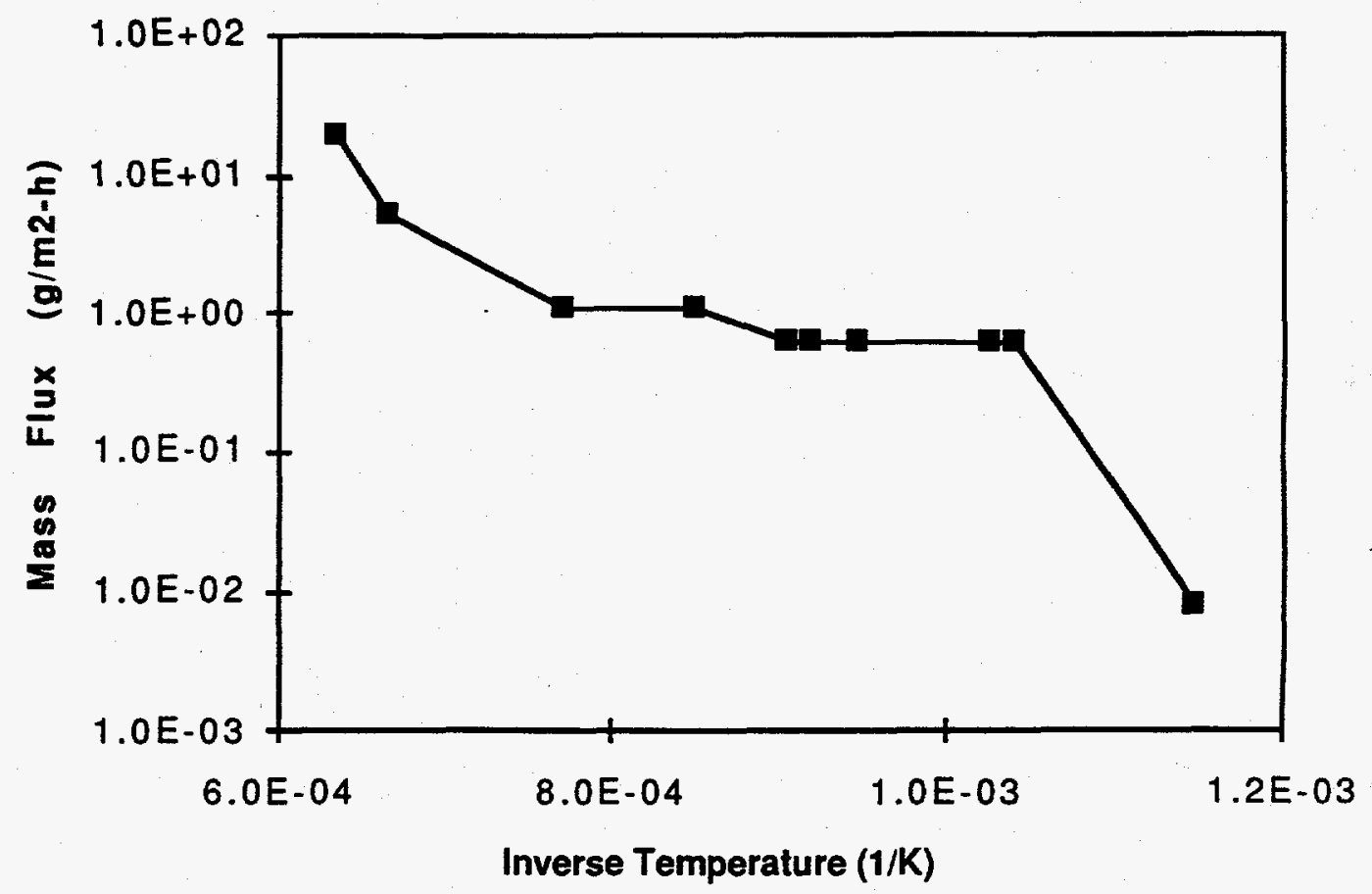

Figure 4. Cumulative maximum mobility of Be from Be exposed to steam

\subsection{Copper Alloy}

The copper alloy we tested had the composition shown in Table 3. We tested the $\mathrm{Cu}$ alloy in both air and steam. Table 4 presents the test matrix for the $\mathrm{Cu}$ alloy tests. The temperature span in the test, $400-1200^{\circ} \mathrm{C}$, is adequate to provide the necessary information for safety assessments. See Smolik, et. al (1989) for details about these tests.

We attempted curve fits for $\mathrm{Co}, \mathrm{Cu}, \mathrm{Fe}, \mathrm{Mn}, \mathrm{Ni}, \mathrm{Zn}$, and $\mathrm{Zr}$ mobility from the $\mathrm{Cu}$ alloy. The values of the regression coefficients for air as the oxidizing environment are given in Table 5 , and for steam in Table 6 . The mobililty plots are presented in Figures 5 through 18. As can be seen in the plots, there is considerable scatter in much of the data, indicating oxide spalling may be significant. Figures 19 and 20 show the cumulative maximum mobility, in air and steam respectively, for the various elements in the copper alloy as a function of temperature. This information is used together with activation calculations and dose code results to calculate offsite dose (see Section 4). The IBEED of dispersion-strengthened copper (an ITER EDA material candidate) irradiated for 1 year at $1 \mathrm{MW} / \mathrm{m} 2$ is dominated by $\mathrm{Co}$ and $\mathrm{Cu}$. The MBEED for dispersion-strengthened copper (an ITER EDA material candidate) is dominated by $\mathrm{Co}, \mathrm{Fe}, \mathrm{Cu}, \mathrm{Zn}$, and $\mathrm{Na}$. We will concentrate on these elements. 
There were very few points above detection limits for Co mobility in air (Figure 5), and a large amount of scatter in the steam data (Figure 12). The Fe curve fits are relatively good indicating less scatter in the data (Figures 7 and 14). The $\mathrm{Cu}$ data in air show fairly good correlation (Figure 6), however the $\mathrm{Cu}$ data in steam show poor correlation (Figure 13). Additionally, these data are questionable because the mobility appears to decrease with increasing temperature. This is not the trend we would expect. Oxide spalling may have contributed significantly to the measured $\mathrm{Cu}$ mobility. The curve fit to the $\mathrm{Zn}$ data shows relatively good correlation, however the data plotted in Figures 8 and 15 indicate that the data would be fit better by two equations with different slopes. The limited number of data points makes drawing conclusions difficult. We did not measure the mobility of Na. Na mobility is extremely difficult to measure due to its ubiquitous nature. Modeling should be done to estimate the volatility of $\mathrm{Na}$ from a $\mathrm{Cu}$ alloy.

Because $\mathrm{Cu}$ is a likely candidate for the first wall material in ITER, more tests are needed to support the regulatory approval process. We recently tested a $\mathrm{Cu}$ alloy in air and steam, concentrating on the effect of composition on mobility. These results will be included in a future update to this report. Because our testing and analysis are more sophisticated than in earlier years, this data should show improvement over earlier data.

\begin{tabular}{|c|c|c|c|c|c|c|c|c|}
\hline $\mathrm{Cu}$ & $\mathrm{Ni}$ & $\mathrm{Zn}$ & $\mathrm{Co}$ & $\mathrm{Zr}$ & $\mathrm{Fe}$ & $\mathrm{Mg}$ & $\mathrm{Al}$ & $\mathrm{Mn}$ \\
\hline 91 & 4.5 & 2.1 & 1.0 & 0.9 & 0.14 & 0.16 & 0.11 & 0.11 \\
\hline
\end{tabular}

Table 3. Copper alloy composition, wt.\%

\begin{tabular}{|c|c|c|c|c|c|}
\hline \multirow{2}{*}{$\begin{array}{c}\text { Oxidizing } \\
\text { Environment }\end{array}$} & \multicolumn{5}{|c|}{ Test Temperature $\left.{ }^{\circ} \mathrm{C}\right)$} \\
\cline { 2 - 6 } & 400 & 600 & 800 & 1000 & 1200 \\
\hline Air & $\mathrm{x}$ & $\mathrm{x}$ & $\mathrm{x}$ & $\mathrm{x}$ & $\mathrm{x}$ \\
\hline Steam & $\mathrm{x}$ & $\mathrm{x}$ & $\mathrm{x}$ & $\mathrm{x}$ & $\mathrm{x}$ \\
\hline
\end{tabular}

Table 4. Cu alloy test matrix 


\begin{tabular}{|c|c|c|c|c|}
\hline Element & $\mathbf{A}\left(\mathbf{g} / \mathbf{m}^{2}-\mathbf{h}\right)$ & $\mathbf{B}$ & $\mathbf{C}(\mathbf{J} / \mathbf{m o l e})$ & $\mathbf{r}^{\mathbf{2}}$ \\
\hline $\mathrm{Co}$ & $1.32 \mathrm{E}-03$ & $-9.5 \mathrm{E}-01$ & $-8.46 \mathrm{E}+03$ & 0.66 \\
\hline $\mathrm{Cu}$ & $7.72 \mathrm{E}-01$ & $-1.2 \mathrm{E}+00$ & $1.78 \mathrm{E}+04$ & 0.82 \\
\hline $\mathrm{Fe}$ & $1.51 \mathrm{E}-01$ & $-7.4 \mathrm{E}-01$ & $1.88 \mathrm{E}+04$ & 0.70 \\
\hline $\mathrm{Mn}$ & $8.83 \mathrm{E}-03$ & $-5.8 \mathrm{E}-01$ & $2.68 \mathrm{E}+04$ & 0.79 \\
\hline $\mathrm{Ni}$ & $5.31 \mathrm{E}-02$ & $-9.4 \mathrm{E}-01$ & $1.84 \mathrm{E}+04$ & 0.79 \\
\hline $\mathrm{Zr}$ & $2.81 \mathrm{E}-02$ & $-8.5 \mathrm{E}-01$ & $1.67 \mathrm{E}+04$ & 0.79 \\
\hline $\mathrm{Zn}$ & $8.52 \mathrm{E}+00$ & $-1.13 \mathrm{E}+00$ & $4.66 \mathrm{E}+04$ & 0.70 \\
\hline
\end{tabular}

Table 5. Regression coefficients for Cu alloy mobility in air

\begin{tabular}{|c|c|c|c|c|}
\hline Element & $\mathbf{A}\left(\mathbf{g} / \mathbf{m}^{\mathbf{2}}-\mathbf{h}\right)$ & $\mathbf{B}$ & $\mathbf{C}(\mathrm{J} /$ mole $)$ & $\mathbf{r}^{\mathbf{2}}$ \\
\hline $\mathrm{Co}$ & $1.63 \mathrm{E}-03$ & $-4.0 \mathrm{E}-01$ & $9.24 \mathrm{E}+03$ & 0.31 \\
\hline $\mathrm{Cu}$ & $1.19 \mathrm{E}-02$ & $-5.8 \mathrm{E}-01$ & $-3.29 \mathrm{E}+03$ & 0.28 \\
\hline $\mathrm{Fe}$ & $6.83 \mathrm{E}-02$ & $-7.6 \mathrm{E}-01$ & $4.08 \mathrm{E}+03$ & 0.76 \\
\hline $\mathrm{Mn}$ & $1.68 \mathrm{E}-03$ & $-8.2 \mathrm{E}-01$ & $-2.48 \mathrm{E}+03$ & 0.62 \\
\hline $\mathrm{Ni}$ & $7.26 \mathrm{E}-03$ & 0.09 & $1.17 \mathrm{E}+04$ & 0.08 \\
\hline $\mathrm{Zr}$ & $1.16 \mathrm{E}-02$ & $-2.8 \mathrm{E}-01$ & $1.79 \mathrm{E}+04$ & 0.62 \\
\hline $\mathrm{Zn}$ & $4.96 \mathrm{E}+02$ & $-9.2 \mathrm{E}-01$ & $6.76 \mathrm{E}+04$ & 0.78 \\
\hline
\end{tabular}

Table 6. Regression coefficients for $\mathrm{Cu}$ alloy mobility in steam 


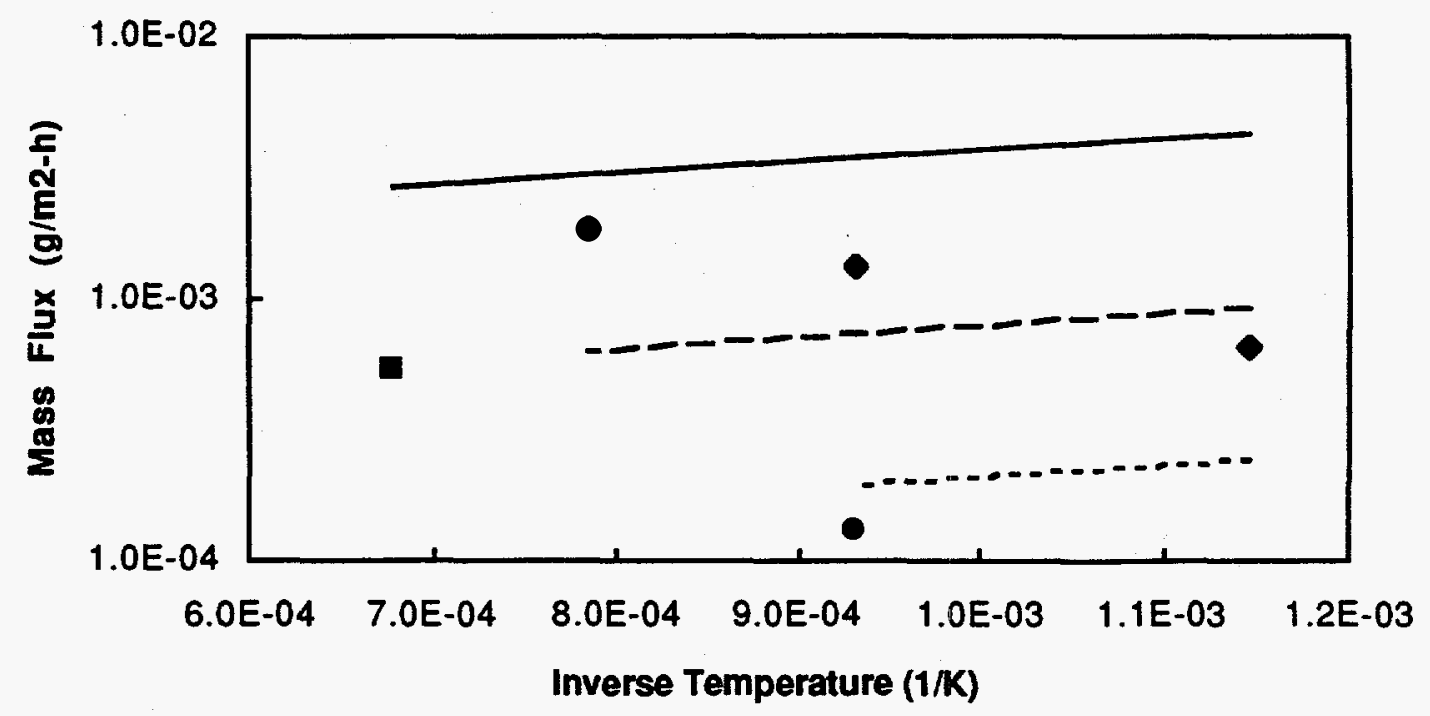

Figure 5. Co mobility from $\mathrm{Cu}$ exposed to air
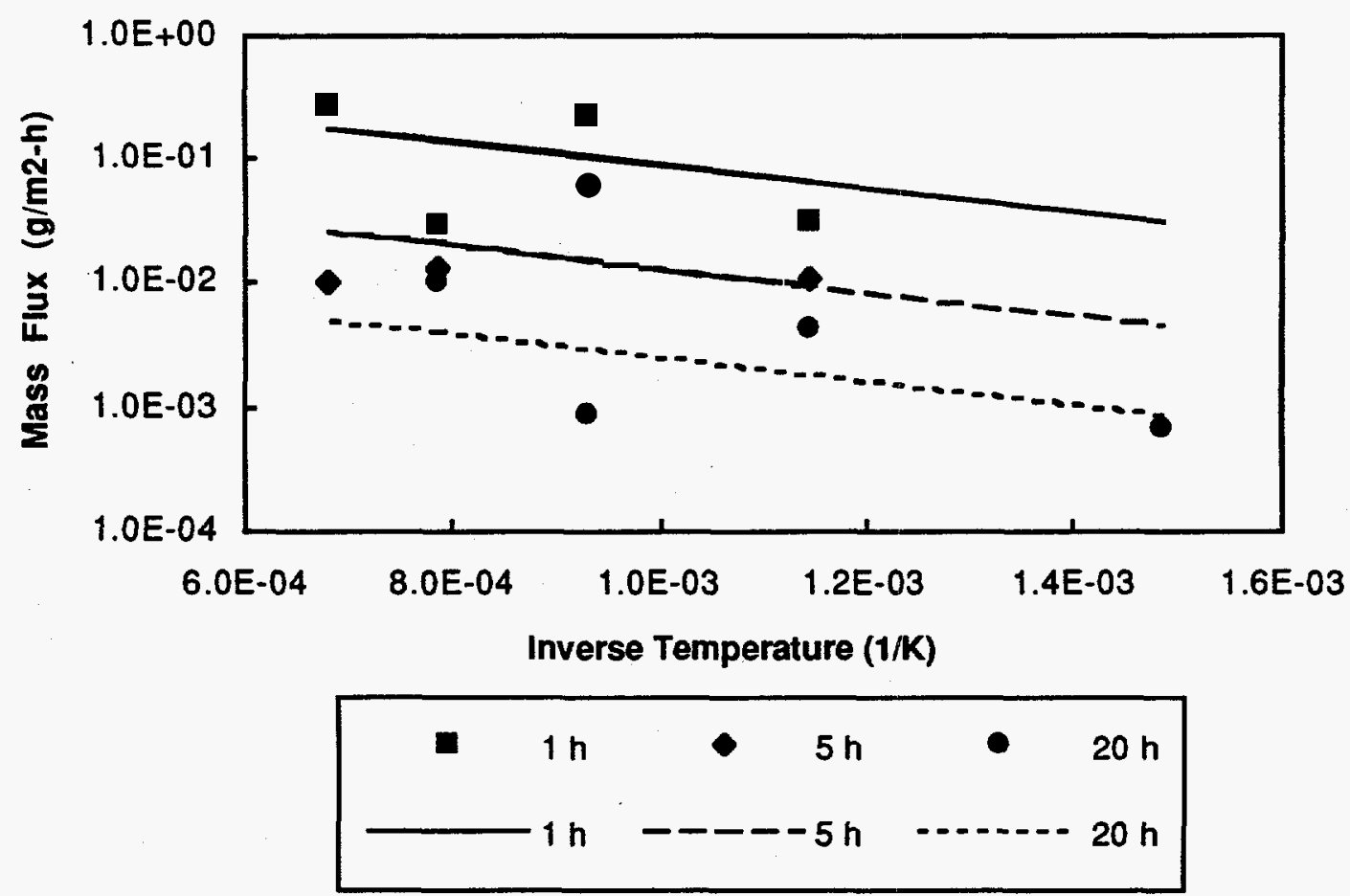

Figure 6. $\mathrm{Cu}$ mobility from $\mathrm{Cu}$ exposed to air 

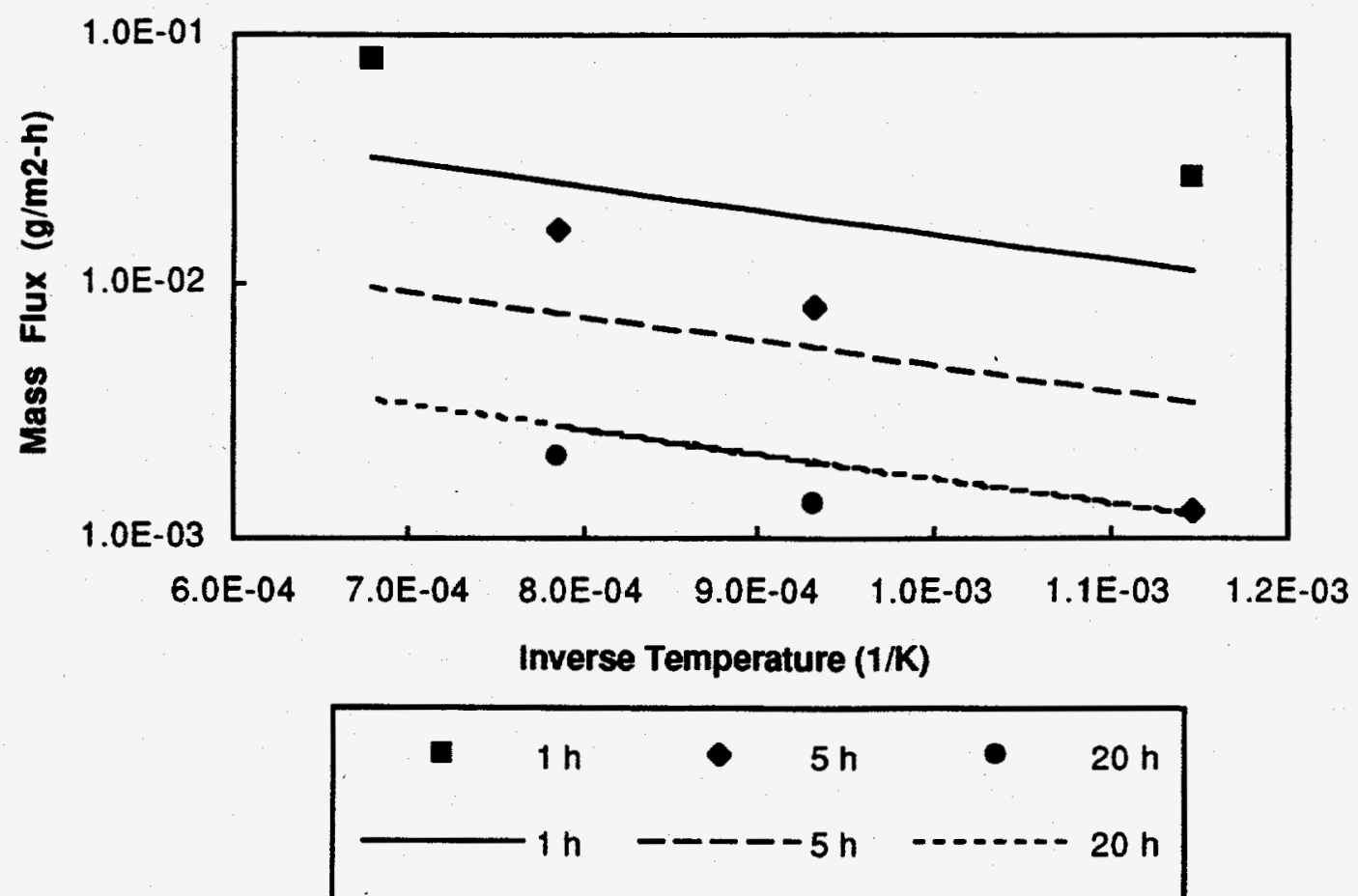

Figure 7. Fe mobility from $\mathrm{Cu}$ exposed to air
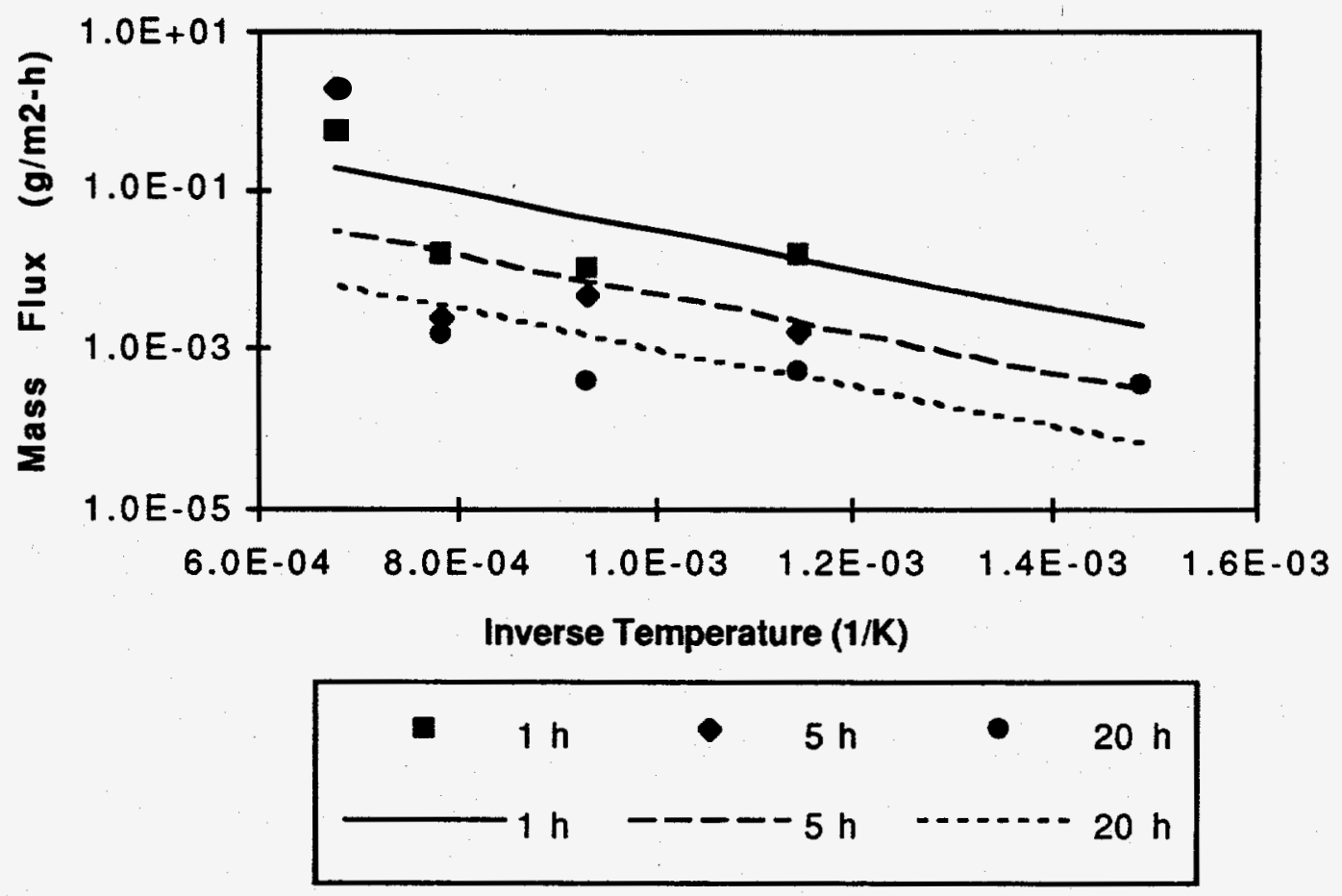

Figure 8. $\mathrm{Zn}$ mobility from $\mathrm{Cu}$ exposed to air 


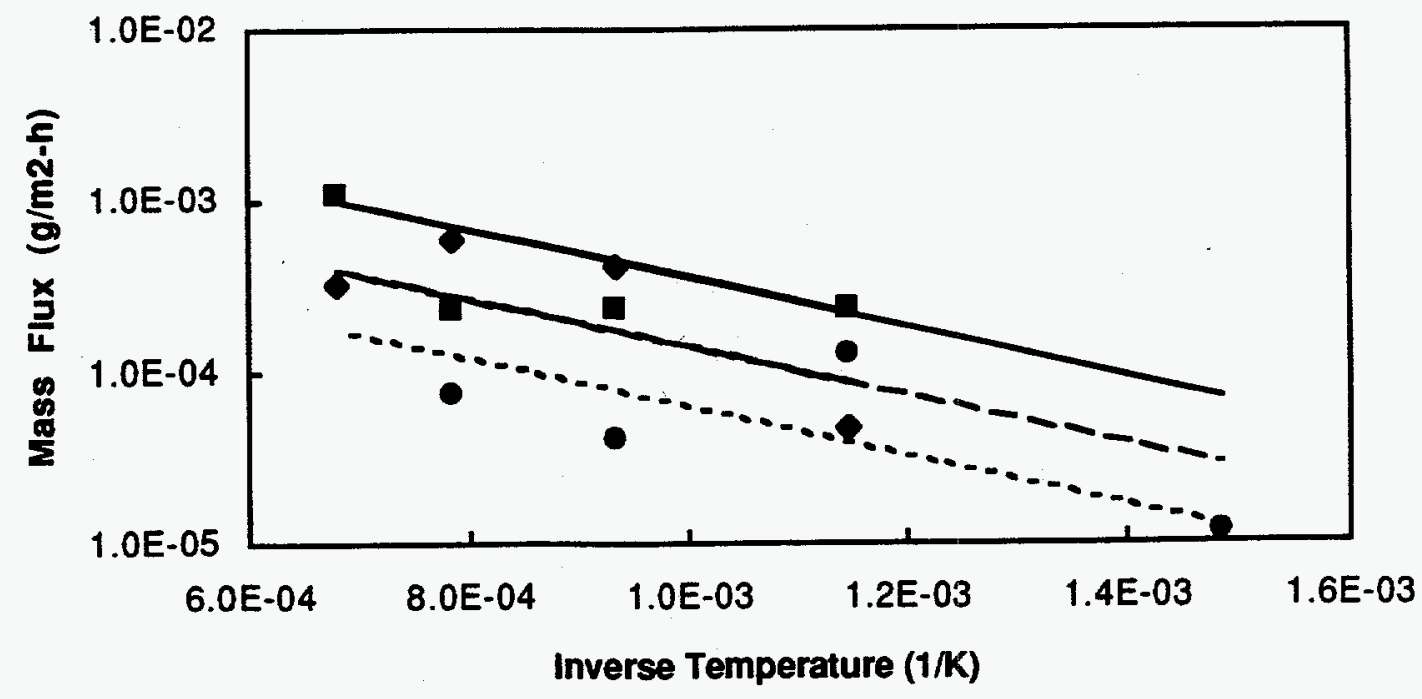

- $1 \mathrm{~h} \quad 5 \mathrm{~h} \quad-20 \mathrm{~h}$

$1 \mathrm{~h} \quad-----5 \mathrm{~h} \quad \cdots \cdots \cdot 20 \mathrm{~h}$

Figure 9. Mn mobility from $\mathrm{Cu}$ exposed to air

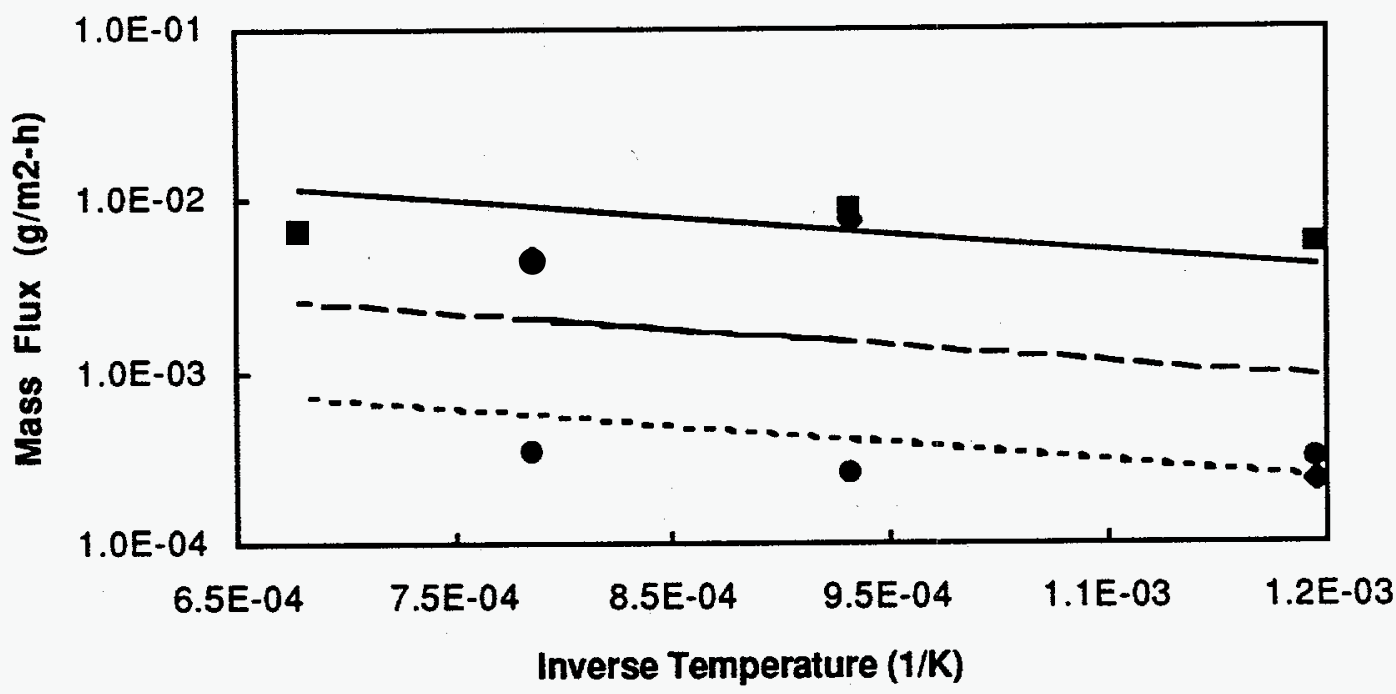

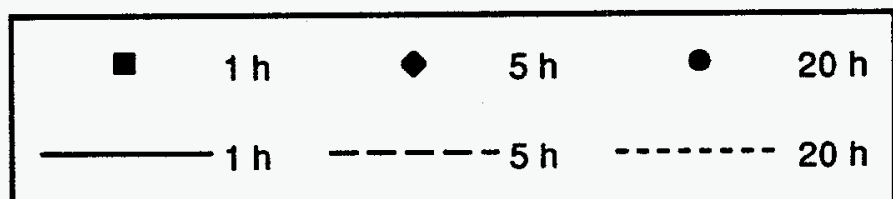

Figure 10. Ni mobility from $\mathrm{Cu}$ exposed to air 


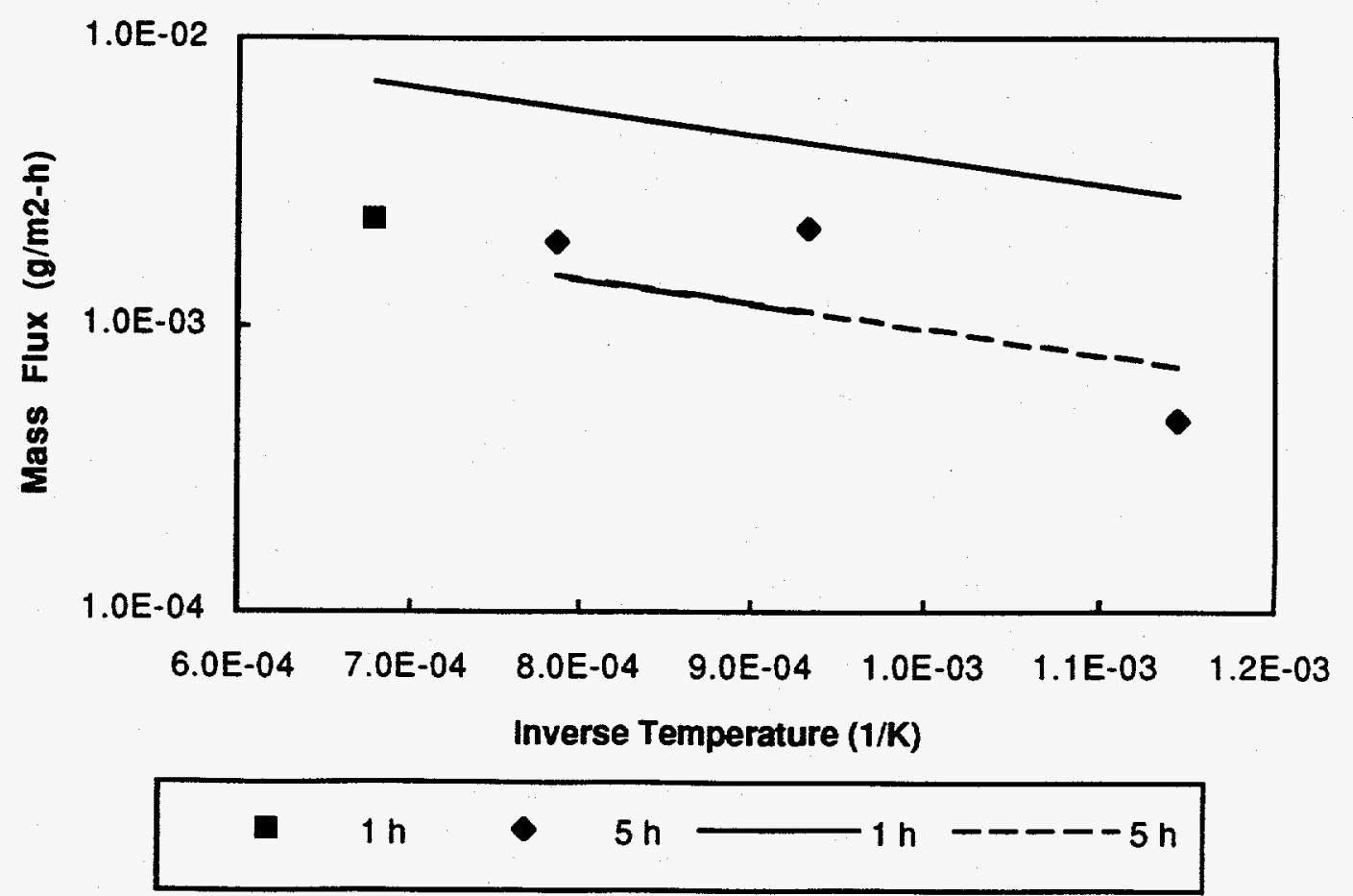

Figure 11. $\mathrm{Zr}$ mobility from $\mathrm{Cu}$ exposed to air

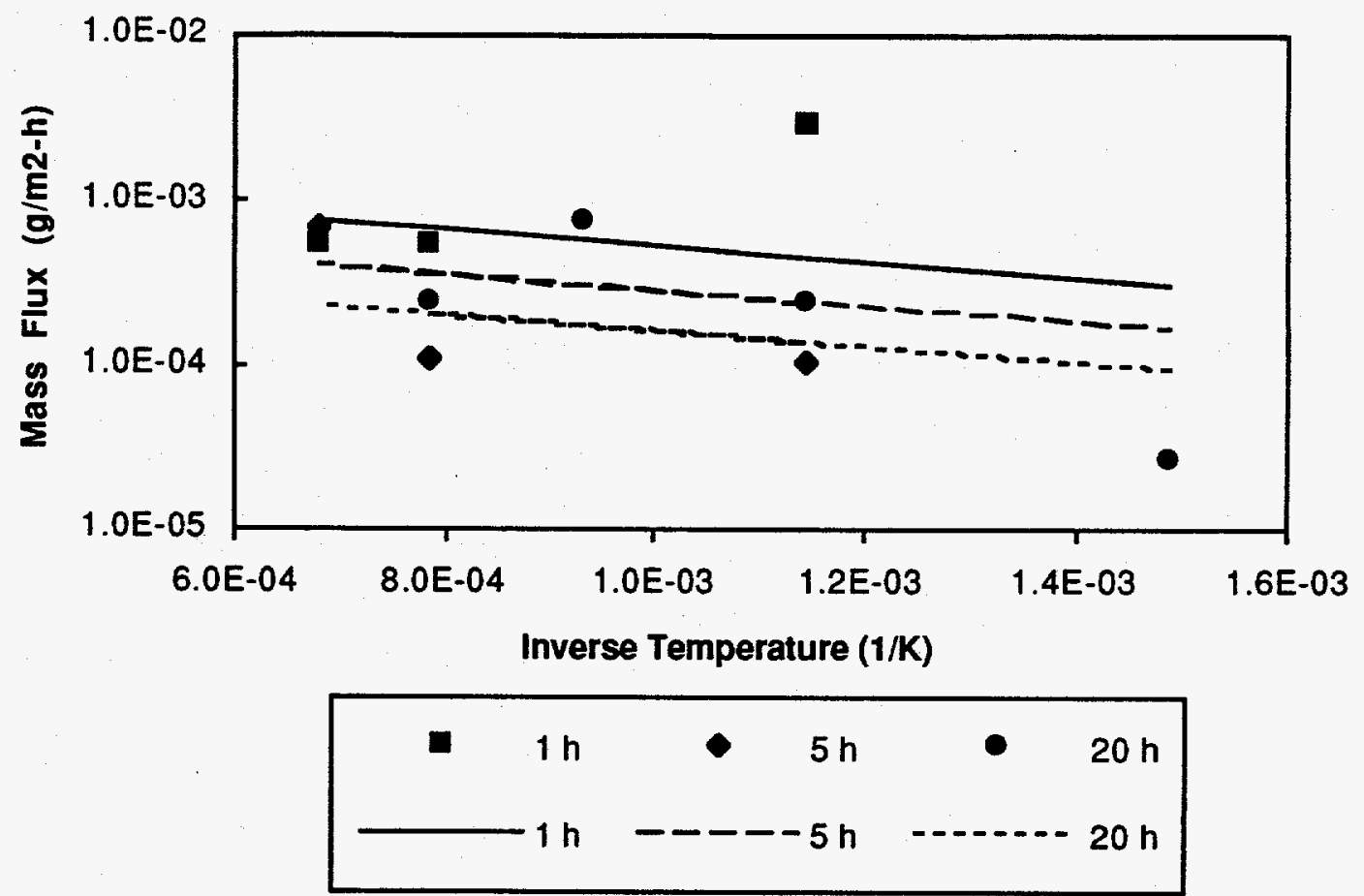

Figure 12. Co mobility from $\mathrm{Cu}$ exposed to steam 

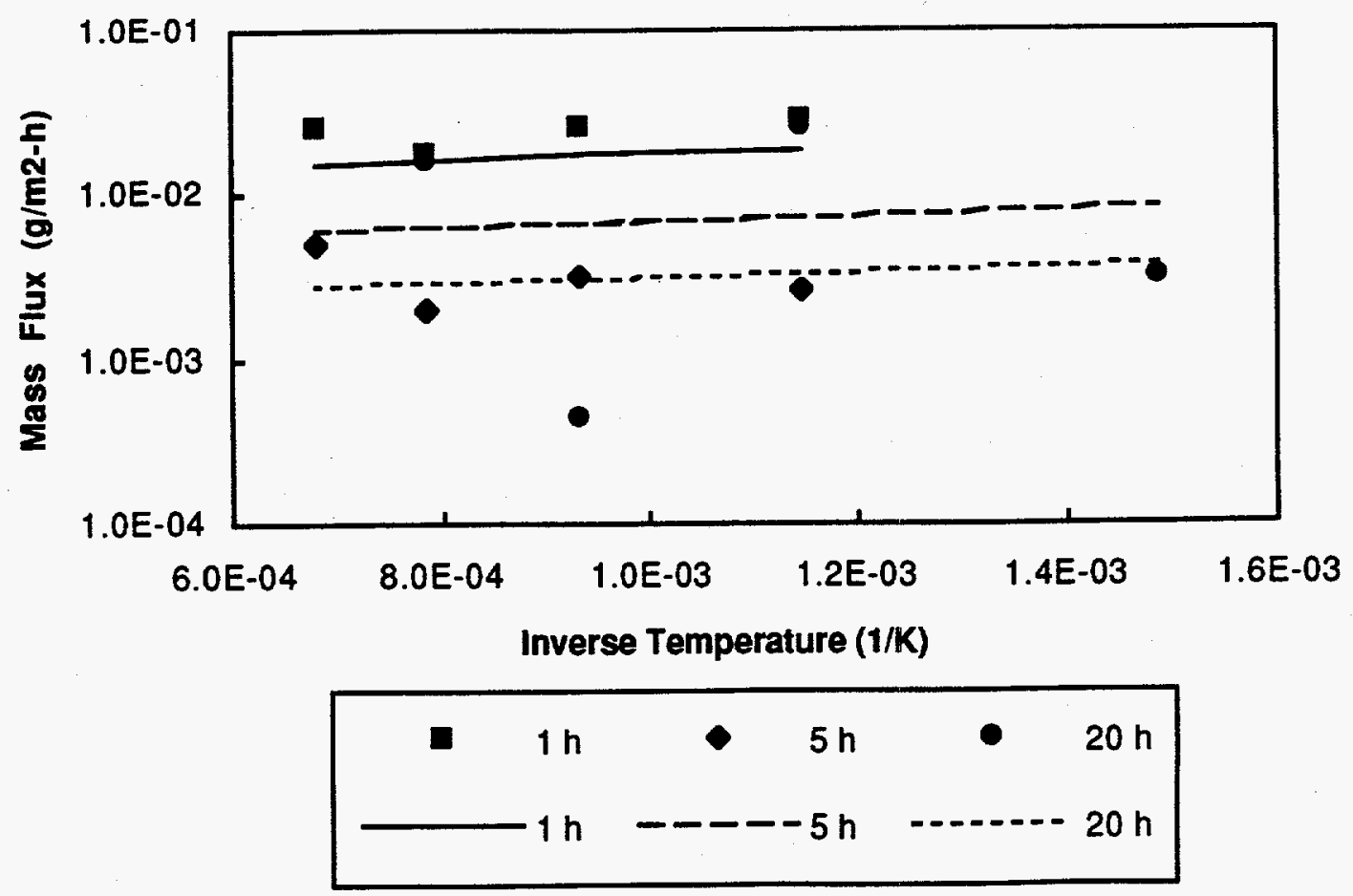

Figure 13. $\mathrm{Cu}$ mobility from $\mathrm{Cu}$ exposed to steam

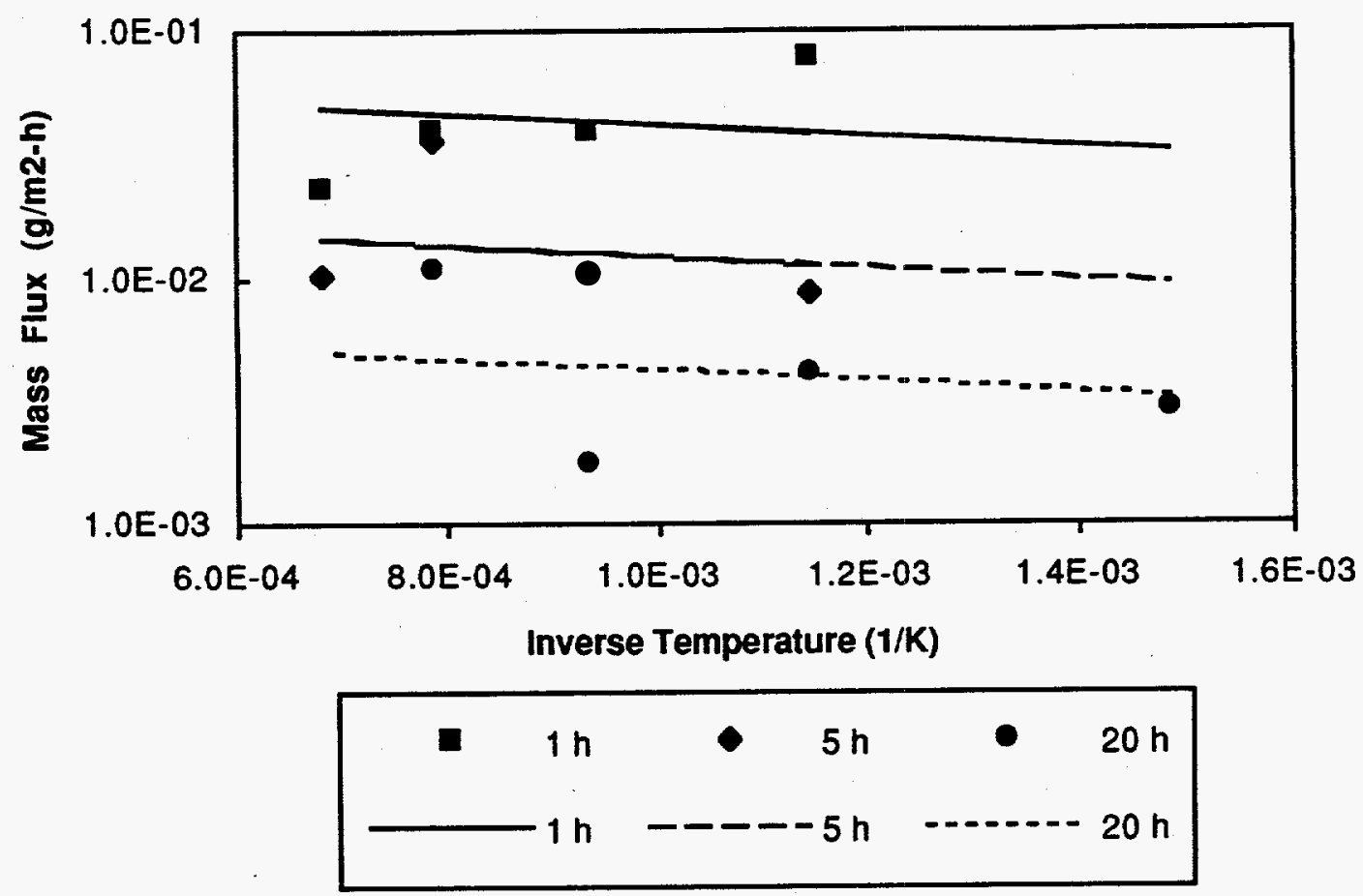

Figure 14. Fe mobility from $\mathrm{Cu}$ exposed to steam 


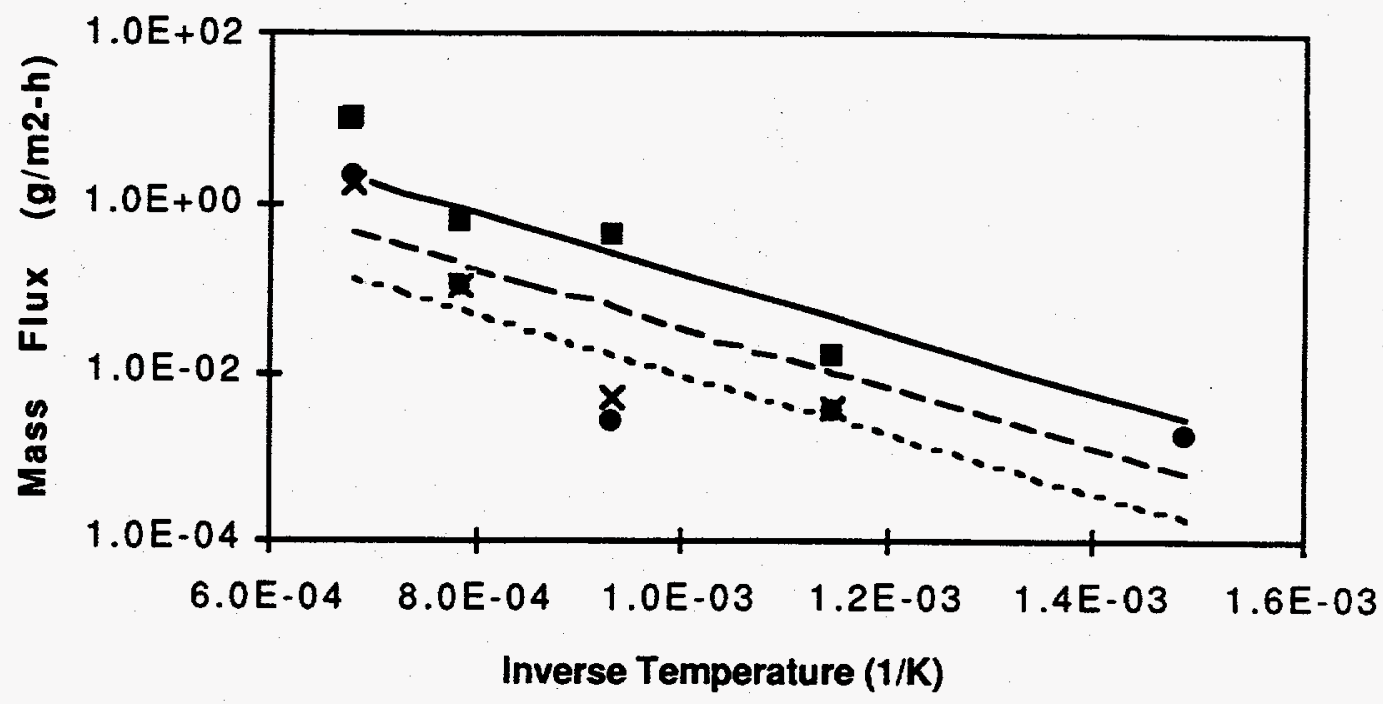

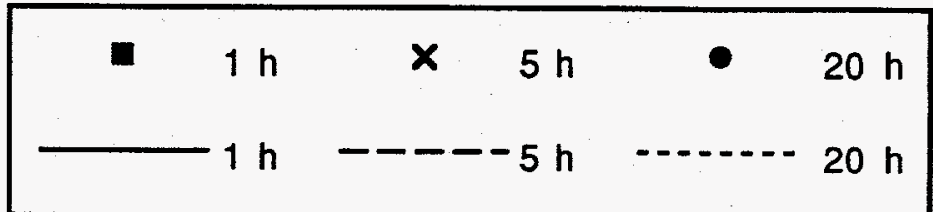

Figure 15. $\mathrm{Zn}$ mobility from $\mathrm{Cu}$ exposed to steam

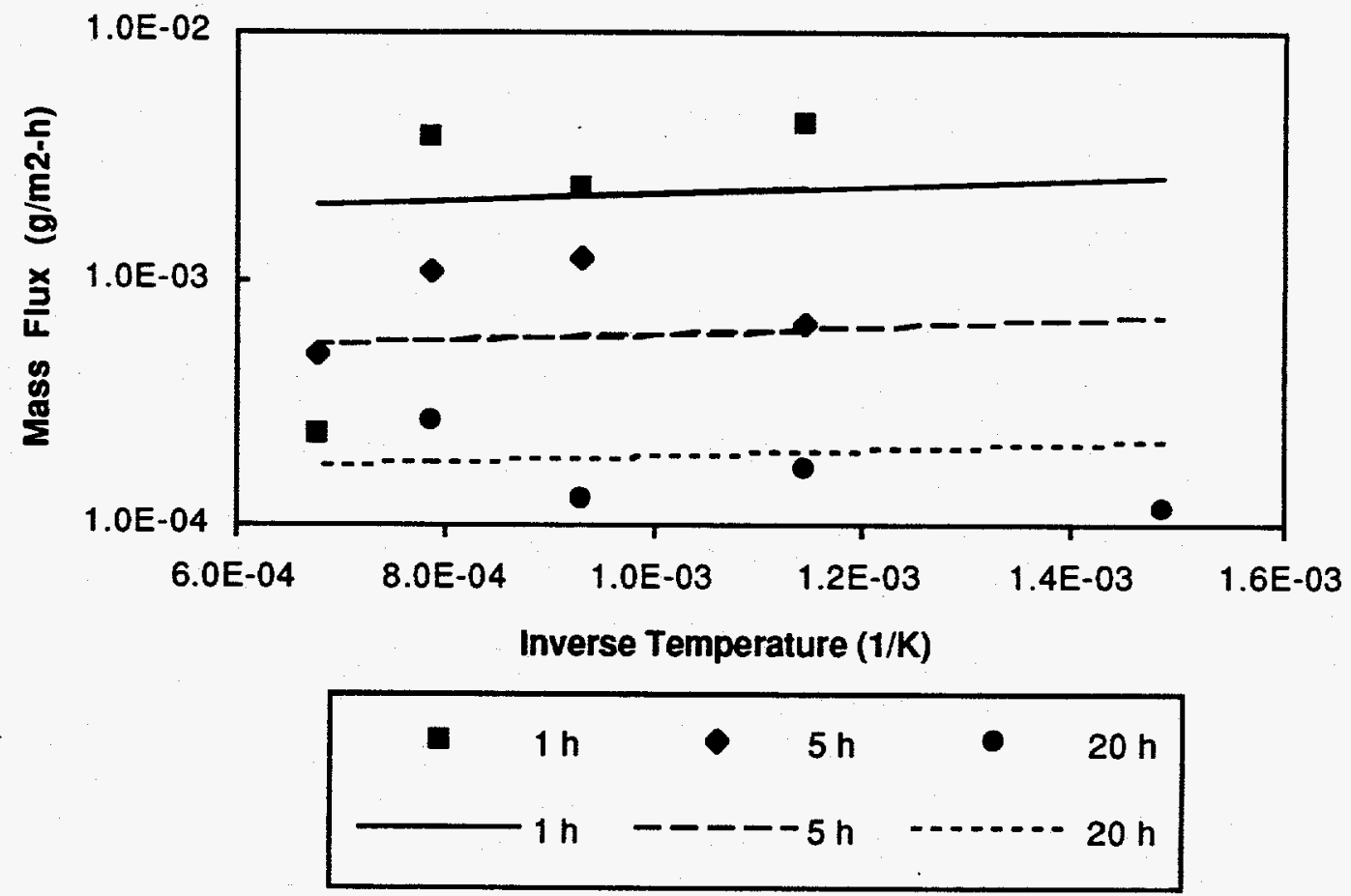

Figure 16. Mn mobility from $\mathrm{Cu}$ exposed to steam 


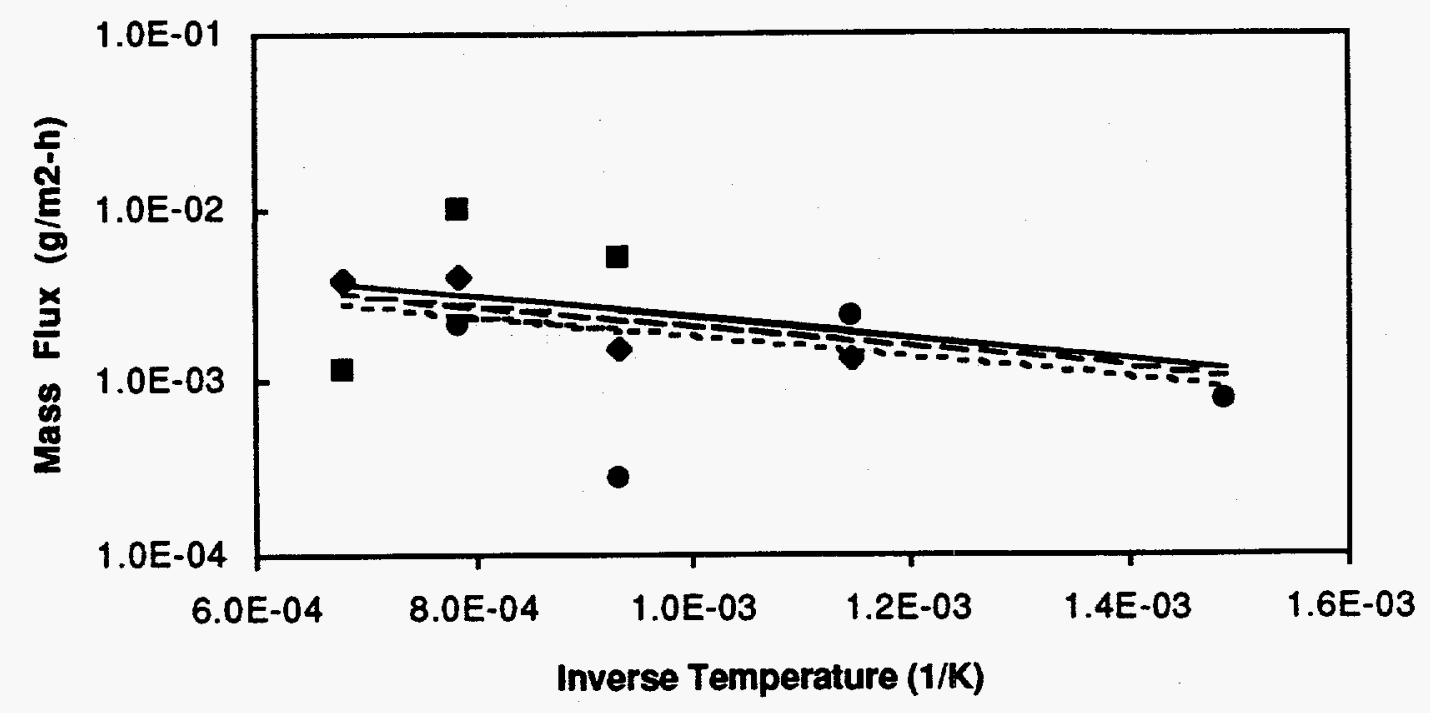

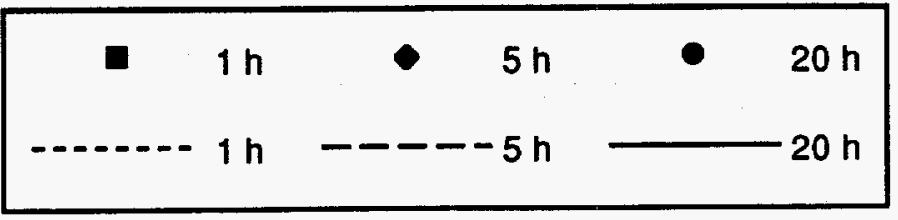

Figure 17. Ni mobility from $\mathrm{Cu}$ exposed to steam

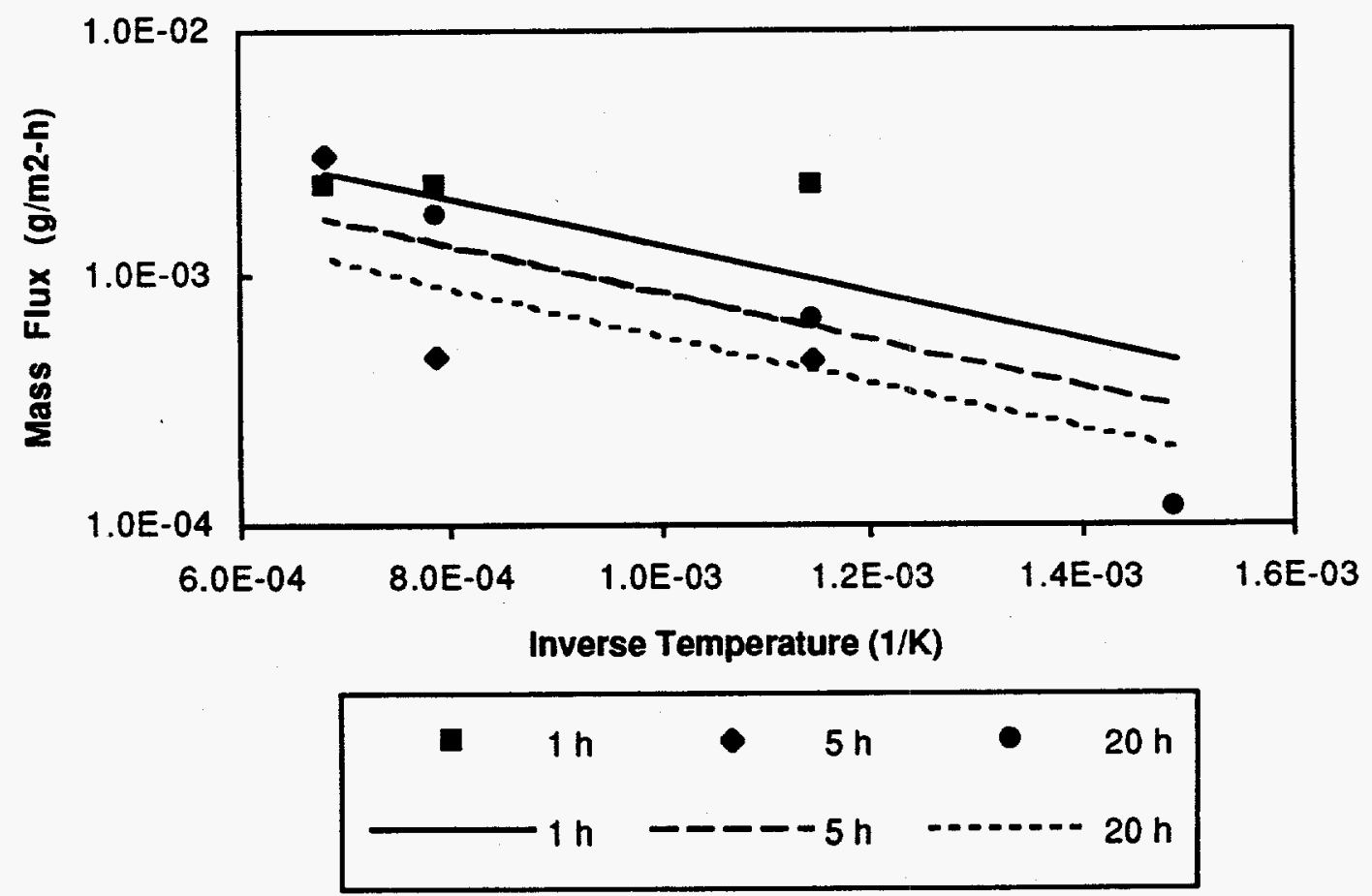

Figure 18. $\mathrm{Zr}$ mobility from $\mathrm{Cu}$ exposed to steam 


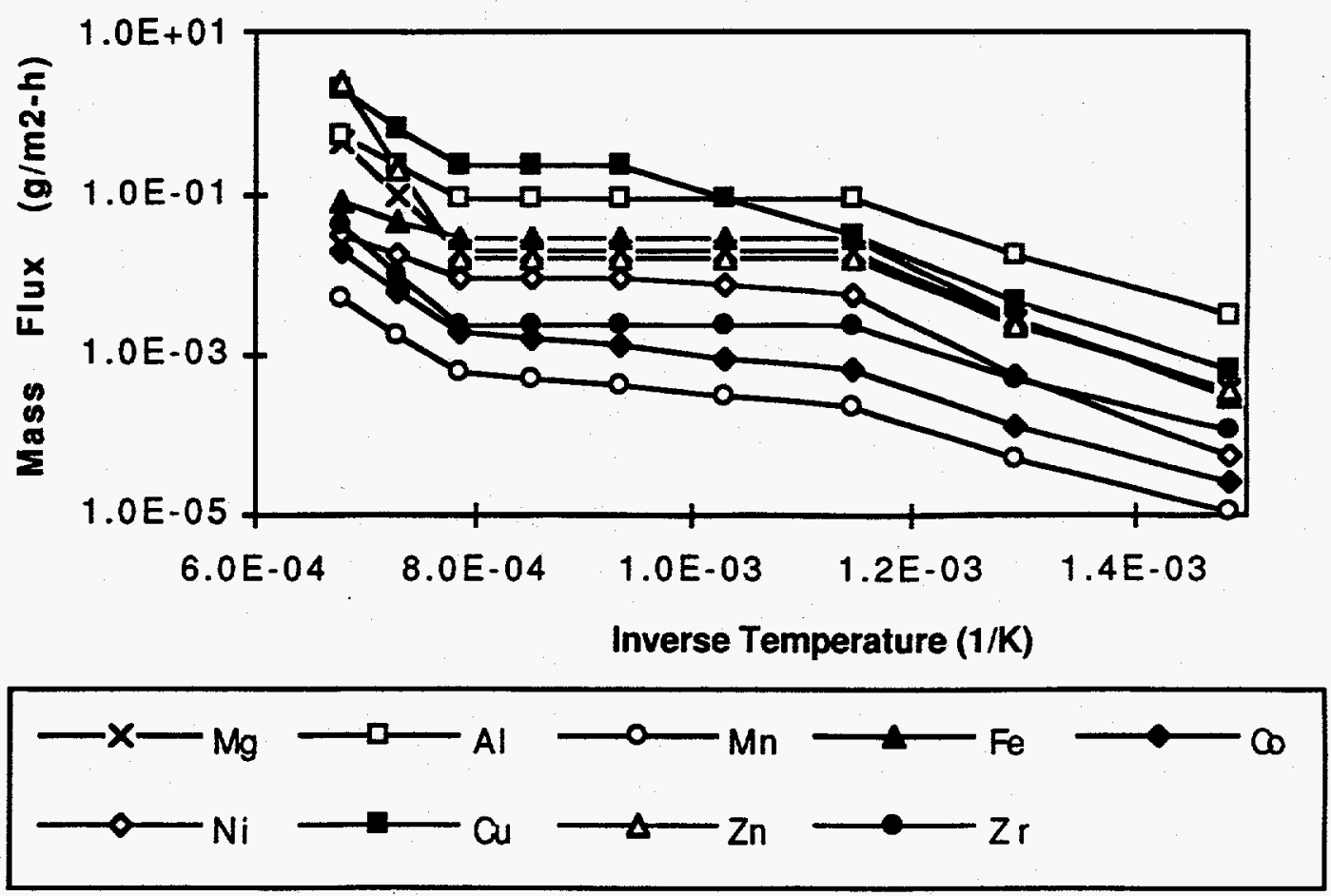

Figure 19. Cumulative maximum mobility of elements from copper exposed to air
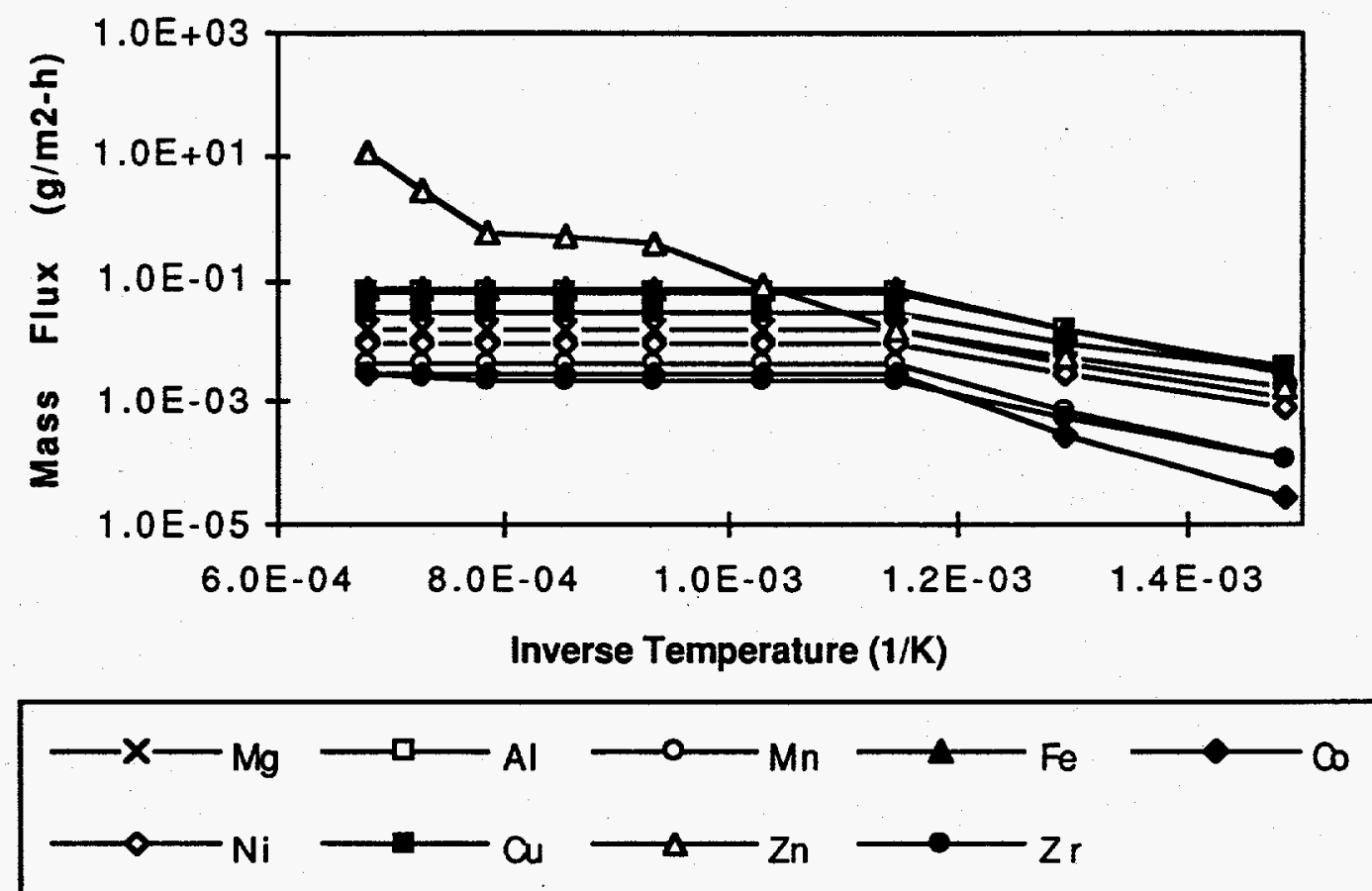

Figure 20. Cumulative maximum mobility of elements from copper exposed to steam 


\subsection{Steels}

We have tested three types of steels: austenitic steel PCA (Primary Candidate Alloy modified 316SS), ferritic steel HT-9 (12Cr-1Mo), and the high-manganese austenitic steel AMCR-033. The composition of the steels tested is given in Table 7. We tested AMCR033 in air only. PCA steel has been tested in both air and steam; the steam tests concentrated on Co and Mn mobilization. We tested HT-9 in both air and steam. Table 8 contains the test matrix for the steel tests. The temperature span is adequate for input to the ESECS for ITER, however, information down to $400^{\circ} \mathrm{C}$ may be desirable for the PSAR for ITER. Data on mobility at this low temperature may not be experimentally achievable however, due to detection limits imposed by limitations of analytic instruments. We will address this further in Sections 3.3.1 and 3.3.2. The results of the AMCR-033 and earlier PCA and HT-9 tests were published in Henslee, 1985, Piet, et. al, 1989a and Piet, et. al, 1986. We carried out a test series that concentrated on Co and Mn mobilization from PCA steel in air and steam. The Co results have been analyzed, ${ }^{8}$ and are included in this section. The Mn results will be published in late 1994.

The regression coefficients for curve fits of mobility are shown in Table 9 for PCA in air (Co, $\mathrm{Cr}, \mathrm{Cu}, \mathrm{Fe}, \mathrm{Mn}, \mathrm{Mo}, \mathrm{Ni}, \mathrm{P}, \mathrm{Ti}$ ), Table 10 for $\mathrm{Co}$ mobilization from PCA in steam, Table 11 for HT-9 in air (Co, Cr, Cu, Fe, Mn, Mo, Ni, P, Ti, V, W), and Table 12 for HT9 in steam (Co, Cr, Cu, Fe, Mn, Mo, Ni, P, Ti, V, W). In a few of the HT-9 tests in air, the temperature was cycled to determine the effect of cycling on mobility. In general, these cycled tests tend to result in higher mobility, probably because as the temperature decreases, thermal stress can cause pieces of the oxide to spall off, exposing fresh surface for oxidation. The results of these tests are included on the graphs (indicated in the legend by $-c$ ), however they were not included when calculating the curve fits. There were very few AMCR-033 tests, so we have not attempted curve fits for this alloy. Curve fits for PCA and HT-9 in air and steam appear in Figures 21 through 51. The cumulative maximum mobility for elements from PCA in air is plotted in Figure 52, for Co from PCA in Figure 53, for elements from HT-9 in air in Figure 54, and for elements from HT9 in steam in Figure 55. The mobility of V and As from HT-9 was also measured, however it is not included in Figures 54 and 55 to improve readability of the plots.

\subsubsection{PCA tests}

IBEED of PCA is dominated by $\mathrm{Co}, \mathrm{Mn}, \mathrm{Ta}, \mathrm{Cr}, \mathrm{Ni}$, and $\mathrm{Fe}$ (see Section 4.0). The MBEED in an air-ingress accident is dominated by $\mathrm{Ta}, \mathrm{W}$, and Mo dominate the dose. We will concentrate on these elements.

8 Details on these tests can be found in the engineering design file by K.A. McCarthy and G.R. Smolik, "Cobalt Release from PCA Steel," ITER/94/US/TE/SA-5,, June 3, 1994. 
We did not measure Ta mobilization in these tests, so we use a temperature-independent release fraction (the release fraction includes both mobilization and transport) developed by Piet, et. al (July 1989b) (see Appendix C for a listing of these release fractions). This release fraction is based on material properties, and tends to be conservative. In the absence of experimental data, we will use it as a mobility fraction. The release fraction is different from the mobility fraction because it includes both mobilization and transport, however we are assuming here that it is conservative enough that we are not underestimating mobility. We will investigate this issue further in future work. Because Ta contributes significantly to the dose when using this release fraction, Ta mobility will be measured in future experiments, or at least modeled. W mobility was not measured in these experiments, however even when using the default release fraction developed by Piet, et. al (July 1989b), it contributes less than $2 \%$ to the dose. We will use mobility results from other alloys and scale them and compare the scaled mobility fraction with these release fractions in the future.

Co mobilization was above detection limits only in our 1994 test series. In this test series, we concentrated on lowering detection limits, and were able to lower them by a factor of about 100 relative to earlier tests. As indicated in Figures 21 and 30 and by the correlation coefficient in Tables 9 and 10, scatter in the Co data is relatively low.

$\mathrm{Fe}, \mathrm{Ni}, \mathrm{Cr}, \mathrm{Mn}$, and Mo are the only elements measured above detection limits that contribute more than $1 \%$ to the offsite dose. There were very few Mo data points above detection limits (Figure 23), so it is difficult to evaluate the validity of the curve fit, even though it resulted in a relatively high regression coefficient of 0.86 . It appears from the limited number of data points that two lines with different slopes would better fit the data. Mo contributes less than $3 \%$ to the dose in the calculations done for this report. Mn tends to be quite volatile, and this is evident in the large number of data points above detection limits (Figure 24). There is not more than an order of magnitude spread in the data at any given temperature, however, the relatively low regression coefficient of 0.61 may indicate two lines with different slopes would be more appropriate for curve fitting. Data from recent tests should show less scatter. There were many $\mathrm{Cr}$ data points above detection limits, and the regression coefficient for the data is 0.71 . Again, two lines might better fit the data. There were very few $\mathrm{Ni}$ data points above detection limits (Figure 27), and the low correlation coefficient of 0.39 indicates the poor fit to the data. The data spread at $1200^{\circ} \mathrm{C}$ is just over an order of magnitude. The data for Fe (Figure 26) indicate that two separate curves might better fit the data.

Our recent Mn data from steam and air tests will be added to the database and included in an update to this report. For many of the elements, a different curve fit will be attempted as part of our data validation effort that will begin in 1994. We will either measure, model, or scale other data for Ta mobility. 
316SS (PCA differs from 316SS only in the addition of a small amount of titanium) is the structural material in the current ITER EDA design. Because only Co and Mn mobilization in PCA steel-steam tests was analyzed analytically, we will analyze additional elements in 1994 and 1995. Scaling HT-9 tests in steam is adequate for input to the ESECS, however for a PSAR, data are considered preferable to scaling.

\subsubsection{HT-9 tests}

The IBEED is dominated by $\mathrm{Mn}, \mathrm{Fe}, \mathrm{Cr}$, and $\mathrm{Co}$ (see Section 4). Co, P, Cr, Mn, and Mo dominate the MBEED, with $\mathrm{Ta}, \mathrm{Nb}, \mathrm{Zr}$, and $\mathrm{Sc}$ contributing from 1-3\% depending on the accident temperature. At lower temperatures (around $600^{\circ} \mathrm{C}$ ), Co is by far the largest contributor to dose, while at higher temperatures, $\mathrm{Mn}$ is by far the most dominant. This calculation assumes default release fractions developed by Piet et. al (July, 1989b), for $\mathrm{Ta}, \mathrm{Nb}, \mathrm{Zr}$, and $\mathrm{Sc}$ due to the absence of experimental data (see 3.3.1 for an explanation of the default release fraction). We will concentrate on $\mathrm{Co}, \mathrm{P}, \mathrm{Cr}, \mathrm{Mn}, \mathrm{Fe}$, and $\mathrm{Mo}$, since these are by far the most significant contributors to dose.

There is about an order of magnitude spread in the Mn data (Figure 33). Mn tends to be highly volatile, so there are many data points above the detection limits. The plot of the data indicates that a better fit to the data might be two lines with different slopes. The correlation coefficient for this fit is 0.61 , indicating moderate correlation. There are very few Co data points above detection limits at temperatures below $1200^{\circ} \mathrm{C}$ (Figure 32). There is less than an order of magnitude spread in the data, giving us confidence in the limited data we have. The correlation coefficient for the Co mobility data is 0.90 . However, because of the limited number of points, it is not clear whether the functional form used is the best choice. Since Co is most important in the $600-1000^{\circ} \mathrm{C}$ range, there is a need for more Co mobility data, particularly at the lower temperatures. There is considerable scatter in the $\mathrm{P}$ data (Figure 35 ), and the data indicate decreasing mobility with increasing temperature, contrary to what we would expect. It is possible that some of the scatter is due to spalling as opposed to volatility (see Section 2). The $\mathrm{Cr}$ data (Figure 31 ) and a correlation coefficient of 0.62 indicate that a different functional form would fit the data better, however the data have a spread of less than an order of magnitude. The slightly positive slope indicates we may be seeing the effect of spalling. There is just over an order of magnitude spread at some temperatures in the Fe data (Figure 37), and the correlation coefficient is fair (0.57). There is a large amount of scatter in the Mo data (Figure 34), indicated by the poor correlation coefficient $(0.30)$.

HT-9 is not likely to be used in ITER, however if it were, enough data exists for input to the ESECS, however more data would be necessary for a PSAR, particularly Co data in the $600-1000^{\circ} \mathrm{C}$ range, $P$ and Mo data. Additionally, curve fits with two slopes should be attempted. We currently have no plans for further HT-9 tests. 
Water-ingress accidents are dominated by $\mathrm{Mn}, \mathrm{Co}, \mathrm{Ta}, \mathrm{Nb}, \mathrm{Zr}, \mathrm{Fe}$, and $\mathrm{Cr}$ with $\mathrm{Sc}, \mathrm{Y}$, $\mathrm{Mo}, \mathrm{V}, \mathrm{Ni}$, and $\mathrm{W}$ contributing from $1-3 \%$ depending on temperature. We will concentrate on the first group of elements.

There are many Mn data points above detection limits (Figure 44), and the correlation of 0.74 is fairly good. It appears from the plot that two lines would better fit the data. There is less than an order of magnitude spread in the data at a particular temperature. There is considerable scatter in the Co data (Figure 42) indicated by the poor correlation coefficient $(0.38)$. There were not a large number of points above detection limits. The iron data (Figure 49) indicates two lines would better fit the data, however even the fit used results in a fairly good correlation factor (0.76). There is less than an order of magnitude spread in the data at a given temperature. There were not many $\mathrm{Cr}$ data points above detection limits (Figure 43) and the correlation was poor (0.44).

We did not measure $\mathrm{Ta}, \mathrm{Nb}$, and $\mathrm{Zr}$ mobility. If further testing were desired by ITER, first tests should concentrate on $\mathrm{Co}$. If testing proved that lower $\mathrm{Ta}, \mathrm{Nb}$, and $\mathrm{Zr}$ mobility would make a significant difference in the calculated dose, these tests should be done. 


\begin{tabular}{|l|c|c|c|}
\hline \multirow{2}{*}{ Element } & \multicolumn{3}{|c|}{ composition, weight percent } \\
\cline { 2 - 4 } & HT-9/12Cr-1Mo & PCA/Mod. 316SS & High Mn Steel \\
\hline $\mathrm{B}$ & $<0.001$ & 0.001 & $\approx 0.0025$ \\
\hline $\mathrm{C}$ & 0.20 & 0.046 & $\approx 0.11$ \\
\hline $\mathrm{N}$ & 0.027 & 0.008 & $\approx 0.2$ \\
\hline $\mathrm{Al}$ & 0.006 & 0.05 & $<0.005$ \\
\hline $\mathrm{Si}$ & 0.17 & 0.53 & 0.53 \\
\hline $\mathrm{P}$ & 0.016 & 0.014 & 0.016 \\
\hline $\mathrm{S}$ & 0.003 & 0.002 & $<0.005$ \\
\hline $\mathrm{Ti}$ & 0.001 & 0.32 & $<0.005$ \\
\hline $\mathrm{V}$ & 0.28 & 0.04 & 0.16 \\
\hline $\mathrm{Cr}$ & 12.1 & 14.27 & 10.41 \\
\hline $\mathrm{Mn}$ & 0.57 & 1.62 & 17.51 \\
\hline $\mathrm{Fe}$ & 84.5 & 64.4 & 70.9 \\
\hline $\mathrm{Co}$ & $<0.05$ & 0.04 & $<0.005$ \\
\hline $\mathrm{Ni}$ & 0.51 & 16.59 & 0.09 \\
\hline $\mathrm{Cu}$ & 0.07 & 0.02 & 0.024 \\
\hline $\mathrm{As}$ & 0.003 & $<0.01$ & $<0.005$ \\
\hline $\mathrm{Zr}$ & -- & $<0.03$ & $<0.005$ \\
\hline $\mathrm{Nb}$ & $<0.001$ & 0.02 & $<0.005$ \\
\hline $\mathrm{Mo}$ & 1.04 & 1.96 & 0.01 \\
\hline $\mathrm{Ta}$ & -- & 0.01 & $<0.005$ \\
\hline $\mathrm{W}$ & 0.45 & -- & $<0.005$ \\
\hline & & & \\
\hline
\end{tabular}

Table 7. Steel compositions 


\begin{tabular}{|c|c|c|c|c|c|c|c|c|c|c|}
\hline \multirow{2}{*}{$\begin{array}{c}\text { Steel/ } \\
\text { Environment }\end{array}$} & \multicolumn{10}{|c|}{ Test Temperature ${ }^{\circ} \mathrm{C}$} \\
\hline & 600 & 700 & 800 & 900 & 1000 & 1100 & 1200 & 1300 & 1400 & 1500 \\
\hline AMCR-033/air & & & $\mathrm{x}$ & & $\mathbf{x}$ & & $\mathrm{x}$ & & & \\
\hline HT-9/air & $x$ & & $x$ & $x$ & $x$ & & $x$ & $\mathrm{x}$ & $\mathrm{x}$ & $x$ \\
\hline HT-9/steam & $\bar{x}$ & & $\mathrm{x}$ & $x$ & $\bar{x}$ & & $x$ & & & \\
\hline PCA/air & $\mathrm{x}$ & & $\mathrm{x}$ & & $\mathrm{x}$ & & $\mathbf{x}$ & $\mathrm{x}$ & & \\
\hline $\begin{array}{l}\text { Co from } \\
\text { PCA/air }\end{array}$ & & $\mathrm{x}$ & $\mathrm{x}$ & $\mathrm{x}$ & $\mathrm{x}$ & $\mathbf{x}$ & $\mathrm{x}$ & & & \\
\hline $\begin{array}{l}\text { Co from } \\
\text { PCA/steam }\end{array}$ & & $\mathrm{x}$ & $\mathrm{x}$ & $\mathbf{x}$ & $\mathbf{x}$ & $\mathbf{x}$ & $\mathbf{x}$ & & & \\
\hline
\end{tabular}

Table 8. Steel test matrix

\begin{tabular}{|c|c|c|c|c|}
\hline Element & $\mathbf{A}\left(\mathbf{g} / \mathbf{m}^{\mathbf{2}}-\mathbf{h}\right)$ & $\mathbf{B}$ & $\mathbf{C}(\mathrm{J} / \mathbf{m o l e})$ & $\mathbf{r}^{\mathbf{2}}$ \\
\hline $\mathrm{Co}$ & $2.04 \mathrm{E}-02$ & $-5.67 \mathrm{E}-01$ & $6.64 \mathrm{E}+04$ & 0.76 \\
\hline $\mathrm{Cr}$ & $1.50 \mathrm{E}+02$ & $-8.34 \mathrm{E}-01$ & $8.92 \mathrm{E}+04$ & 0.71 \\
\hline $\mathrm{Cu}$ & $1.86 \mathrm{E}+01$ & $-9.02 \mathrm{E}-01$ & $1.09 \mathrm{E}+05$ & 0.78 \\
\hline $\mathrm{Fe}$ & $7.40 \mathrm{E}+01$ & $-9.46 \mathrm{E}-01$ & $7.09 \mathrm{E}+04$ & 0.60 \\
\hline $\mathrm{Mn}$ & $5.49 \mathrm{E}+01$ & $-5.10 \mathrm{E}-01$ & $1.00 \mathrm{E}+05$ & 0.61 \\
\hline $\mathrm{Mo}$ & $7.81 \mathrm{E}+04$ & $-3.98 \mathrm{E}-01$ & $1.57 \mathrm{E}+05$ & 0.86 \\
\hline $\mathrm{Ni}$ & $3.18 \mathrm{E}+00$ & $-1.09 \mathrm{E}+00$ & $4.86 \mathrm{E}+04$ & 0.39 \\
\hline $\mathrm{P}$ & $4.33 \mathrm{E}-02$ & $-8.64 \mathrm{E}-01$ & $-2.76 \mathrm{E}+03$ & 0.77 \\
\hline $\mathrm{Ti}$ & $1.22 \mathrm{E}-02$ & $4.49 \mathrm{E}-02$ & $2.84 \mathrm{E}+04$ & 0.22 \\
\hline
\end{tabular}

Table 9. Regression coefficients for PCA mobility in air

\begin{tabular}{|c|c|c|c|c|}
\hline Element & $\mathbf{A}\left(\mathbf{g} / \mathbf{m}^{\mathbf{2}}-\mathbf{h}\right)$ & $\mathbf{B}$ & $\mathbf{C}(\mathbf{J} / \mathbf{m o l e})$ & $\mathbf{r}^{\mathbf{2}}$ \\
\hline Co & $4.95 \mathrm{E}+03$ & $-3.96 \mathrm{E}-01$ & $1.75 \mathrm{E}+05$ & 0.65 \\
\hline
\end{tabular}

Table 10. Regression coefficients for PCA mobility in steam 


\begin{tabular}{|c|c|c|c|c|}
\hline Element & $\mathbf{A}\left(\mathbf{g} / \mathbf{m}^{2}-\mathbf{h}\right)$ & $\mathbf{B}$ & $\mathbf{C}(\mathbf{J} / \mathbf{m o l e})$ & $\mathbf{r}^{\mathbf{2}}$ \\
\hline $\mathrm{Co}$ & $2.13 \mathrm{E}-03$ & $-1.14 \mathrm{E}+00$ & $1.30 \mathrm{E}+04$ & 0.90 \\
\hline $\mathrm{Cr}$ & $1.03 \mathrm{E}-02$ & $-1.72 \mathrm{E}+00$ & $-9.09 \mathrm{E}+03$ & 0.62 \\
\hline $\mathrm{Cu}$ & $2.55 \mathrm{E}-01$ & $-8.12 \mathrm{E}-01$ & $3.38 \mathrm{E}+04$ & 0.38 \\
\hline $\mathrm{Fe}$ & $1.47 \mathrm{E}-01$ & $-1.35 \mathrm{E}+00$ & $1.30 \mathrm{E}+04$ & 0.57 \\
\hline $\mathrm{Mn}$ & $1.08 \mathrm{E}-01$ & $-1.23 \mathrm{E}+00$ & $4.11 \mathrm{E}+04$ & 0.61 \\
\hline $\mathrm{Mo}$ & $1.87 \mathrm{E}+03$ & $-1.44 \mathrm{E}-01$ & $1.42 \mathrm{E}+05$ & 0.30 \\
\hline $\mathrm{Ni}$ & $6.80 \mathrm{E}-03$ & $-1.23 \mathrm{E}+00$ & $3.30 \mathrm{E}+03$ & 0.63 \\
\hline $\mathrm{P}$ & $5.39 \mathrm{E}-04$ & $-1.71 \mathrm{E}+00$ & $-4.98 \mathrm{E}+04$ & 0.66 \\
\hline $\mathrm{Ti}$ & $1.16 \mathrm{E}-01$ & $-7.35 \mathrm{E}-01$ & $3.18 \mathrm{E}+04$ & 0.33 \\
\hline $\mathrm{V}$ & $3.60 \mathrm{E}-03$ & $-1.28 \mathrm{E}+00$ & $4.97 \mathrm{E}+03$ & 0.62 \\
\hline $\mathrm{W}$ & $1.79 \mathrm{E}-01$ & $-5.21 \mathrm{E}-01$ & $4.53 \mathrm{E}+04$ & 0.47 \\
\hline
\end{tabular}

Table 11. Regression coefficients for HT-9 mobility in air

\begin{tabular}{|c|c|c|c|c|}
\hline Element & $\mathbf{A}\left(\mathbf{g} / \mathbf{m}^{2}-\mathbf{h}\right)$ & $\mathbf{B}$ & $\mathbf{C}(\mathbf{J} / \mathbf{m o l e})$ & $\mathbf{r}^{\mathbf{2}}$ \\
\hline $\mathrm{Co}$ & $1.74 \mathrm{E}-03$ & $-7.38 \mathrm{E}-01$ & $1.30 \mathrm{E}+04$ & 0.38 \\
\hline $\mathrm{Cr}$ & $2.71 \mathrm{E}-03$ & $-9.4 \mathrm{E}-01$ & $1.08 \mathrm{E}+04$ & 0.44 \\
\hline $\mathrm{Cu}$ & $1.36 \mathrm{E}-02$ & $-9.17 \mathrm{E}-01$ & $1.04 \mathrm{E}+04$ & 0.62 \\
\hline $\mathrm{Fe}$ & $6.66 \mathrm{E}+02$ & $-7.10 \mathrm{E}-01$ & $8.17 \mathrm{E}+04$ & 0.76 \\
\hline $\mathrm{Mn}$ & $2.77 \mathrm{E}+00$ & $-8.98 \mathrm{E}-01$ & $6.81 \mathrm{E}+04$ & 0.74 \\
\hline $\mathrm{Mo}$ & $2.73 \mathrm{E}+00$ & $3.88 \mathrm{E}-01$ & $7.57 \mathrm{E}+04$ & 0.23 \\
\hline $\mathrm{Ni}$ & $6.59 \mathrm{E}+03$ & $-3.01 \mathrm{E}-01$ & $1.90 \mathrm{E}+05$ & 0.18 \\
\hline $\mathrm{P}$ & $9.19 \mathrm{E}-01$ & $-4.68 \mathrm{E}-01$ & $6.00 \mathrm{E}+04$ & 0.80 \\
\hline $\mathrm{Ti}$ & $8.21 \mathrm{E}-04$ & $-9.88 \mathrm{E}-01$ & $-1.25 \mathrm{E}+04$ & 0.77 \\
\hline $\mathrm{V}$ & $2.12 \mathrm{E}-03$ & $-8.27 \mathrm{E}-01$ & $9.22 \mathrm{E}+03$ & 0.37 \\
\hline $\mathrm{W}$ & $5.50 \mathrm{E}+03$ & $-5.48 \mathrm{E}-01$ & $1.23 \mathrm{E}+05$ & 0.90 \\
\hline
\end{tabular}

Table 12. Regression coefficients for HT-9 mobility in steam 

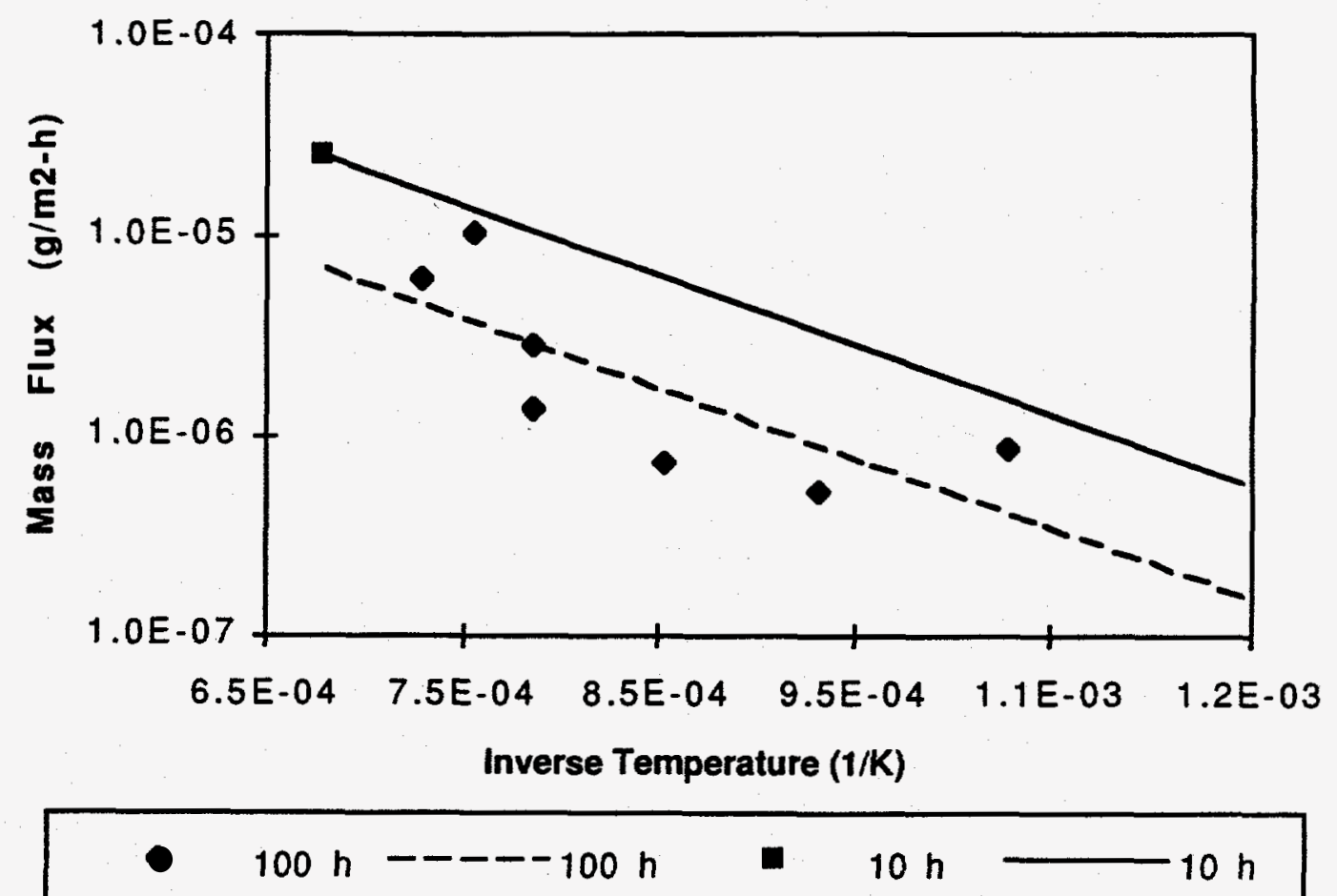

Figure 21. Co mobility from PCA exposed to air

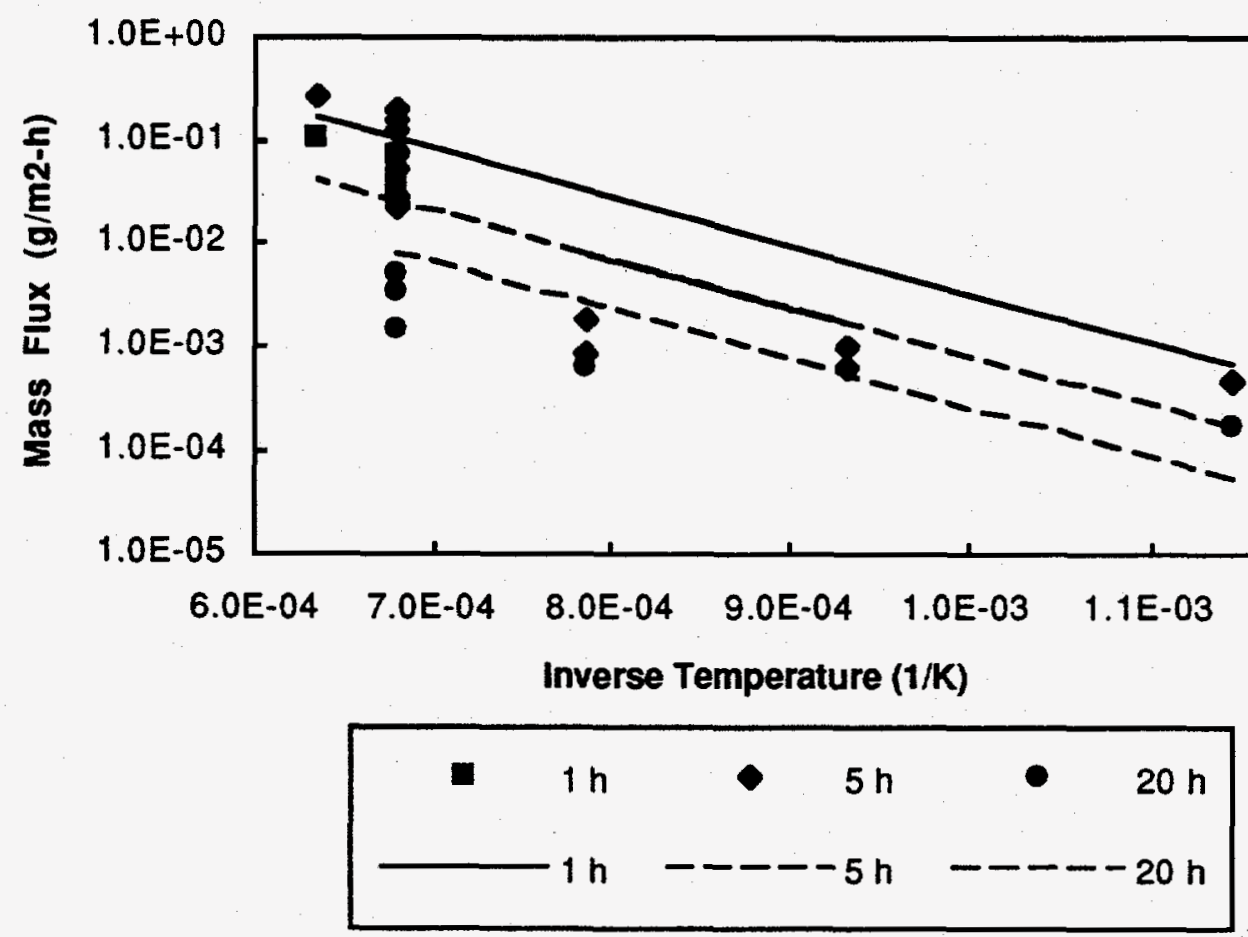

Figure 22. Cr mobility from PCA exposed to air 


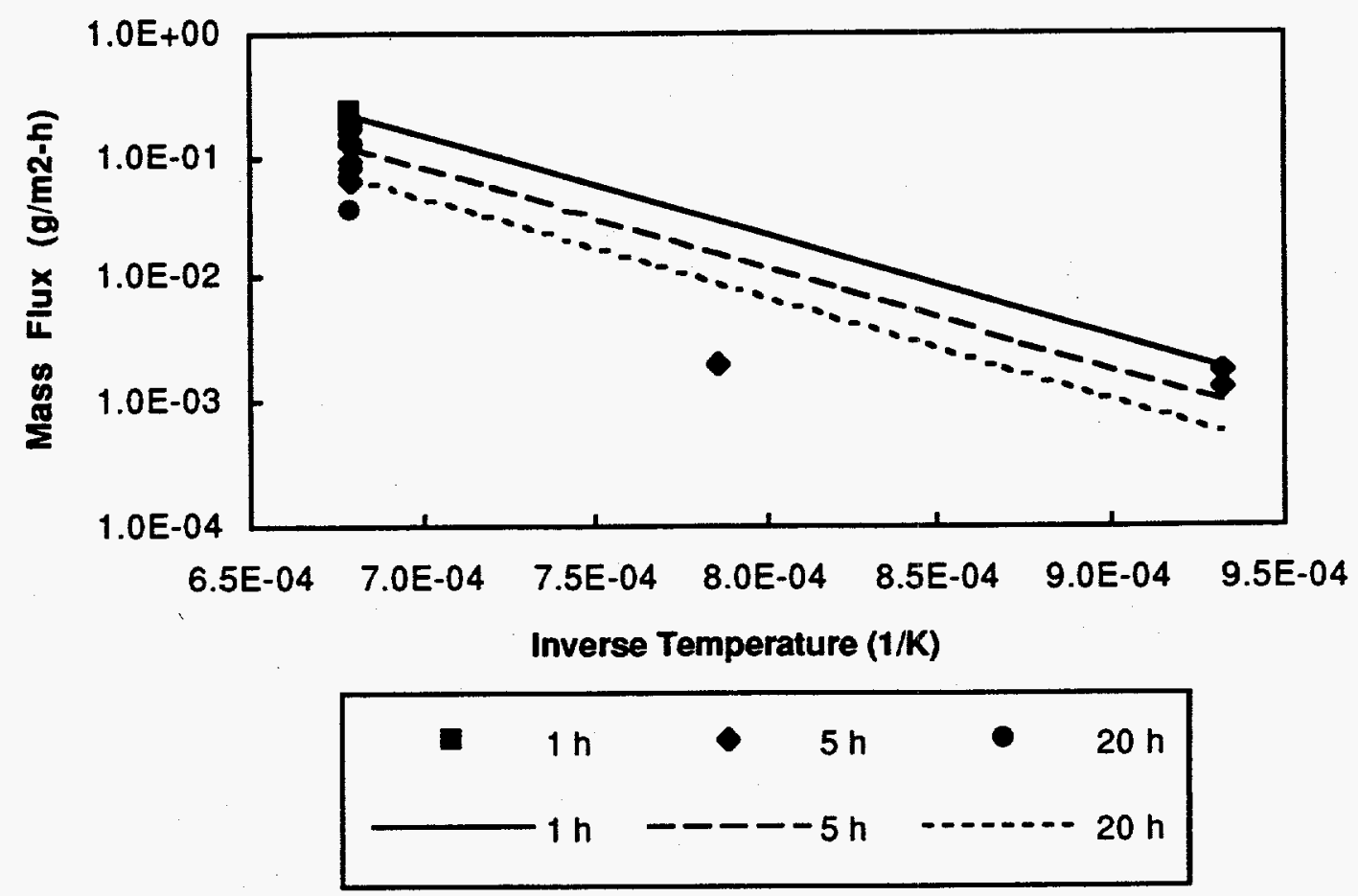

Figure 23. Mo mobility from PCA exposed to air

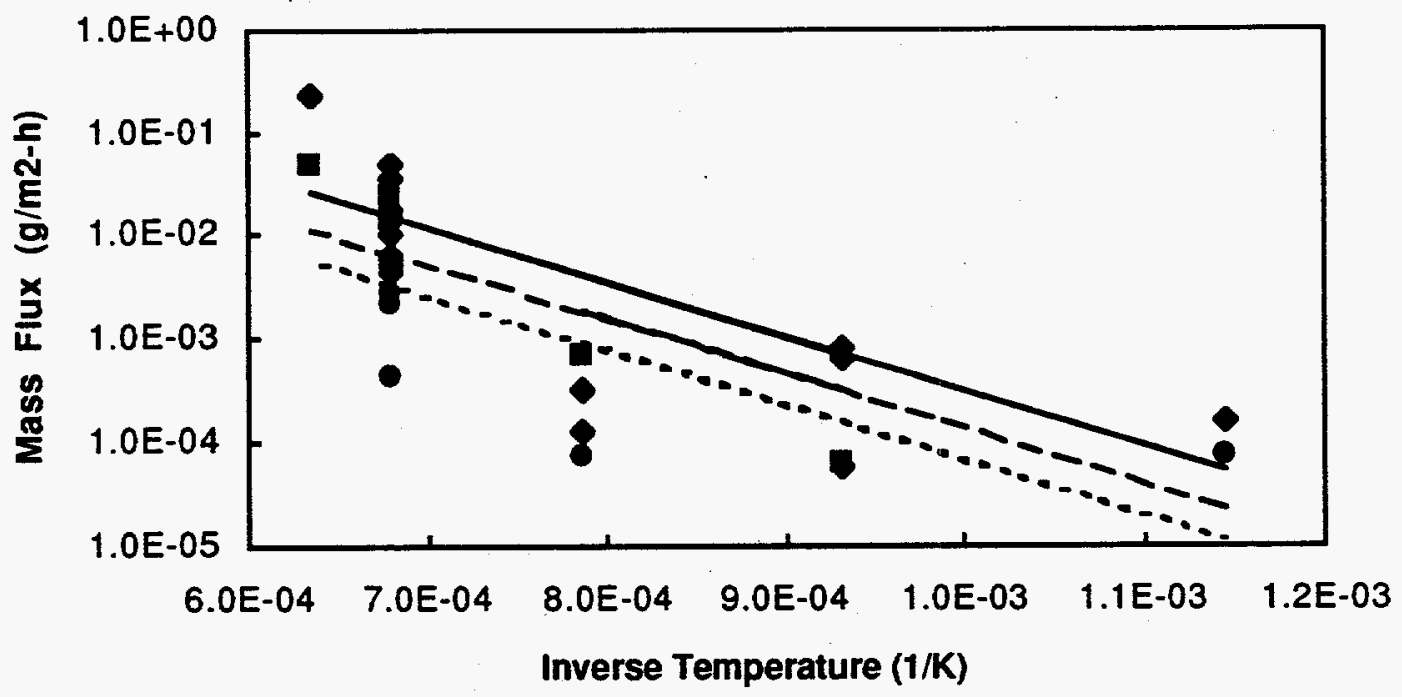

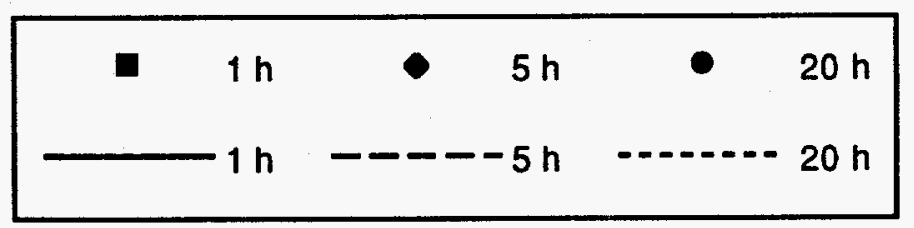

Figure 24. Mn mobility from PCA exposed to air 

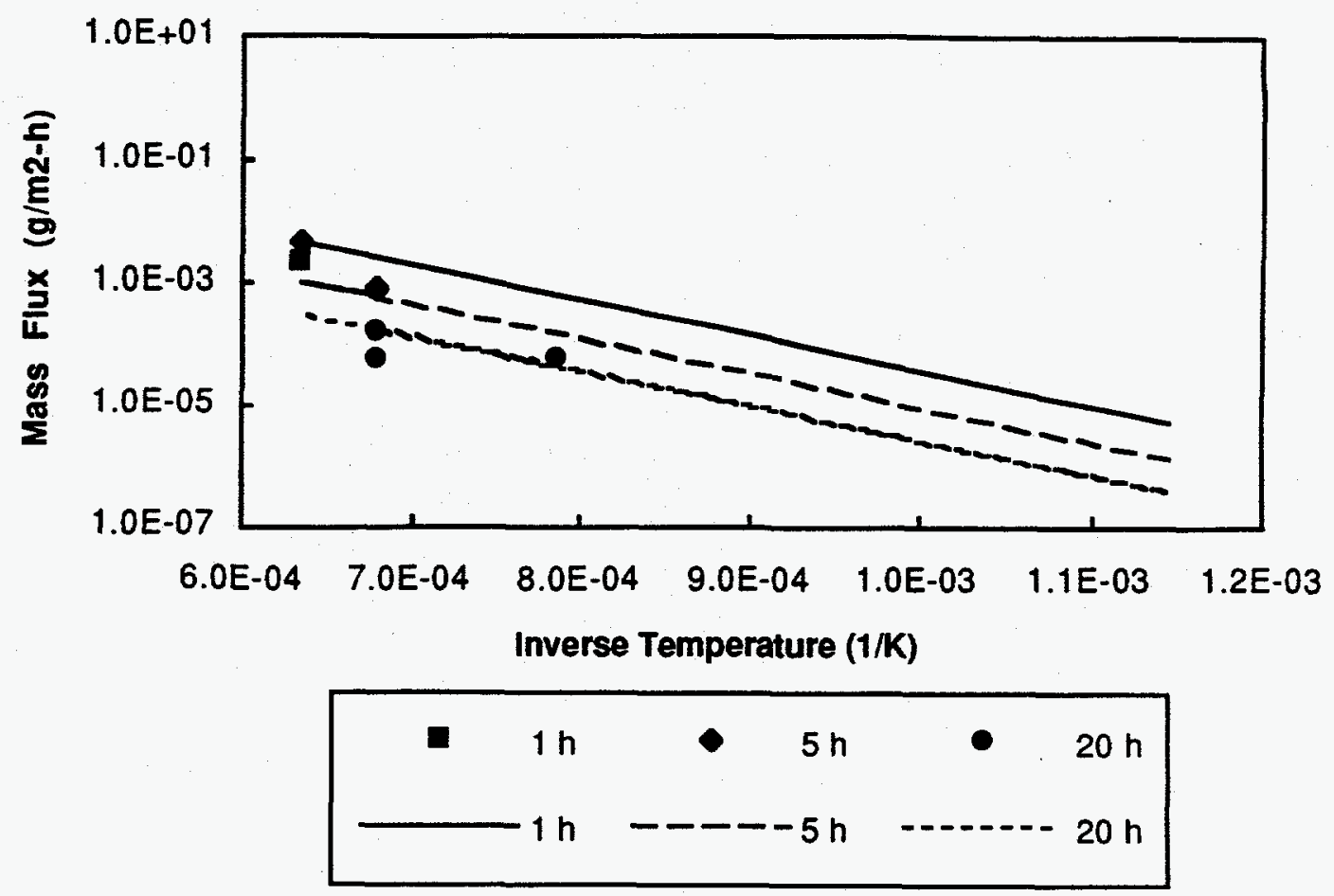

Figure 25. Cu mobility from PCA exposed to air

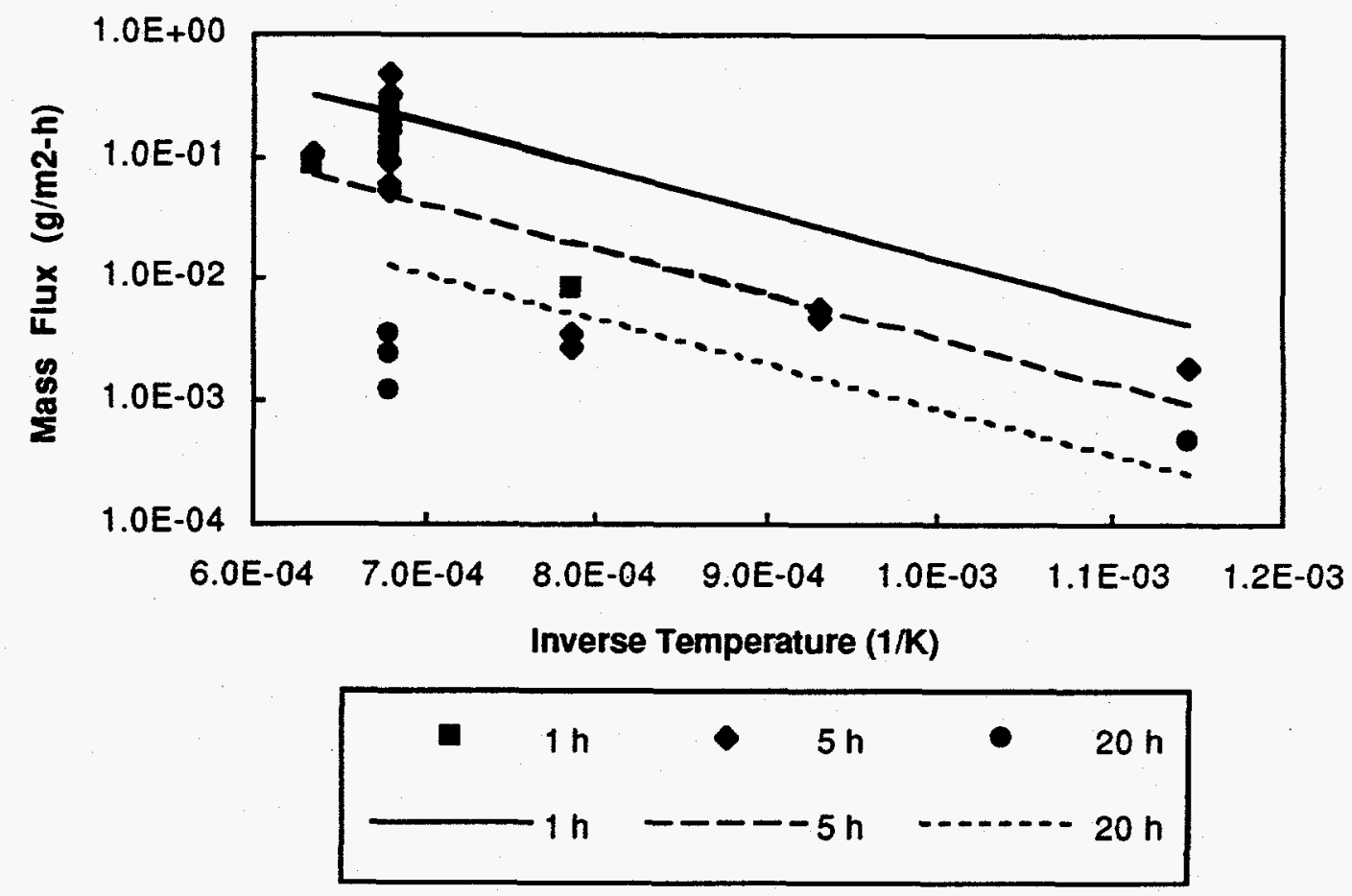

Figure 26. Fe mobility from PCA exposed to air 


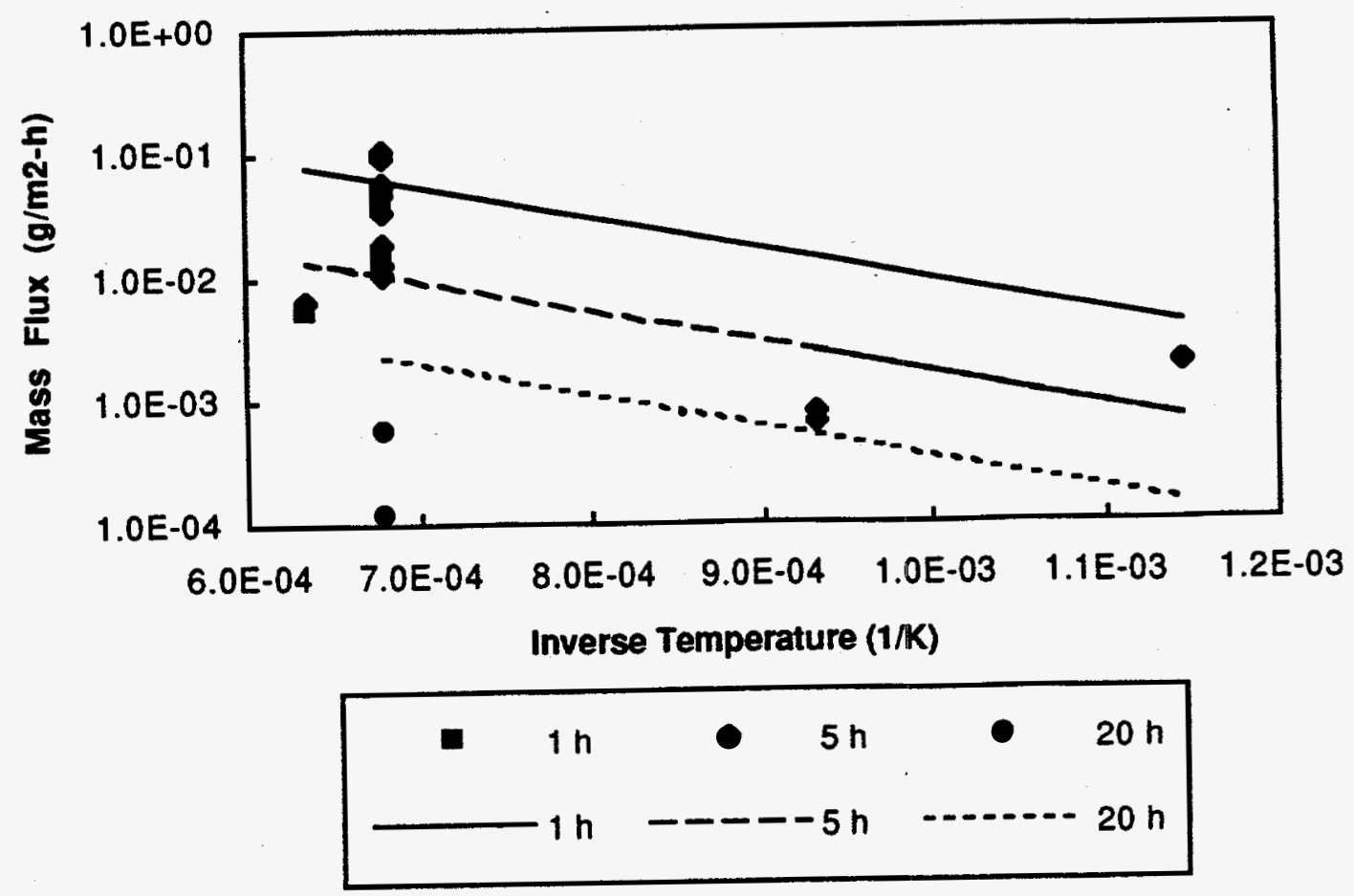

Figure 27. Ni mobility from PCA exposed to air

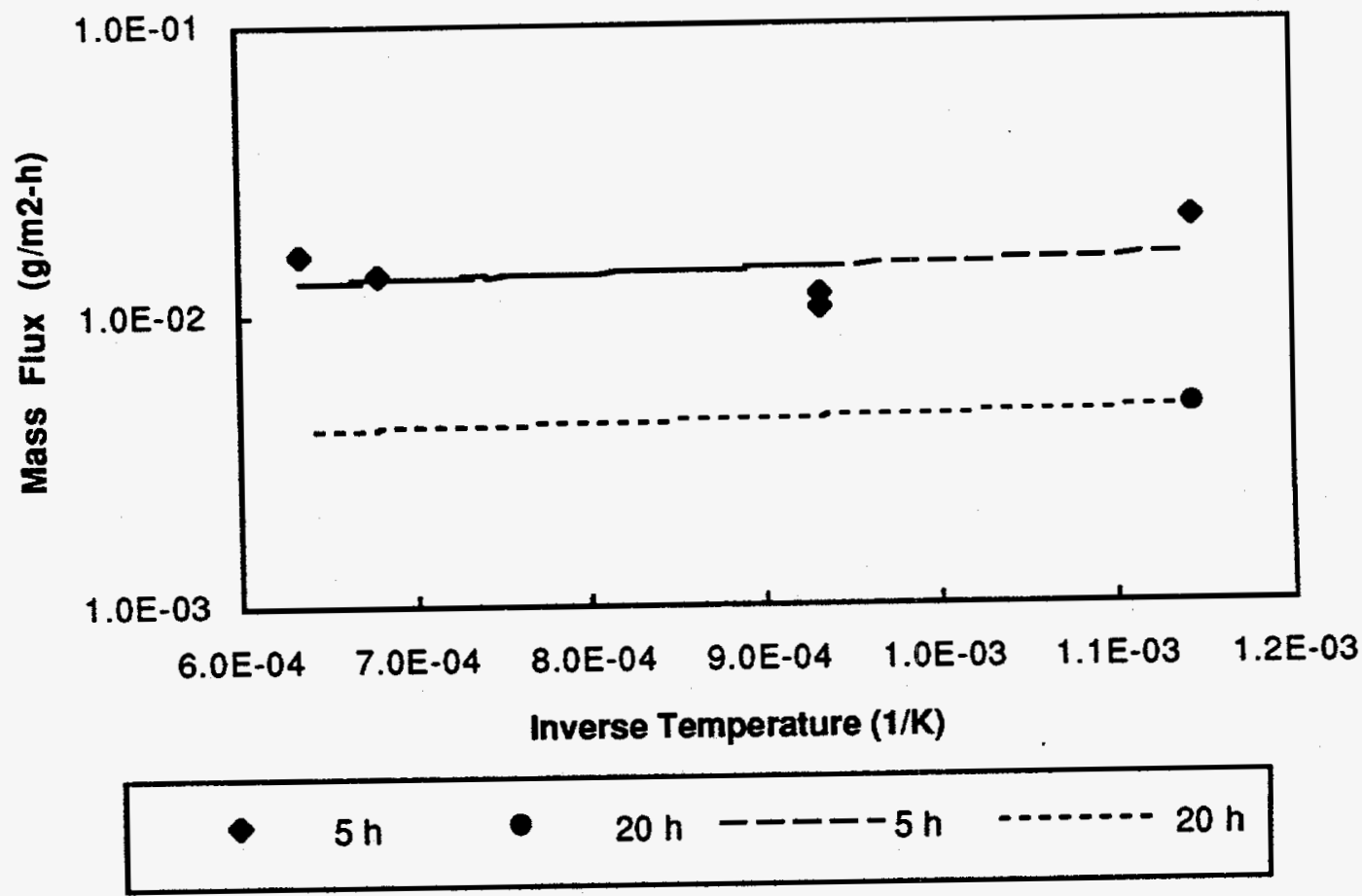

Figure 28. P mobility from PCA exposed to air 


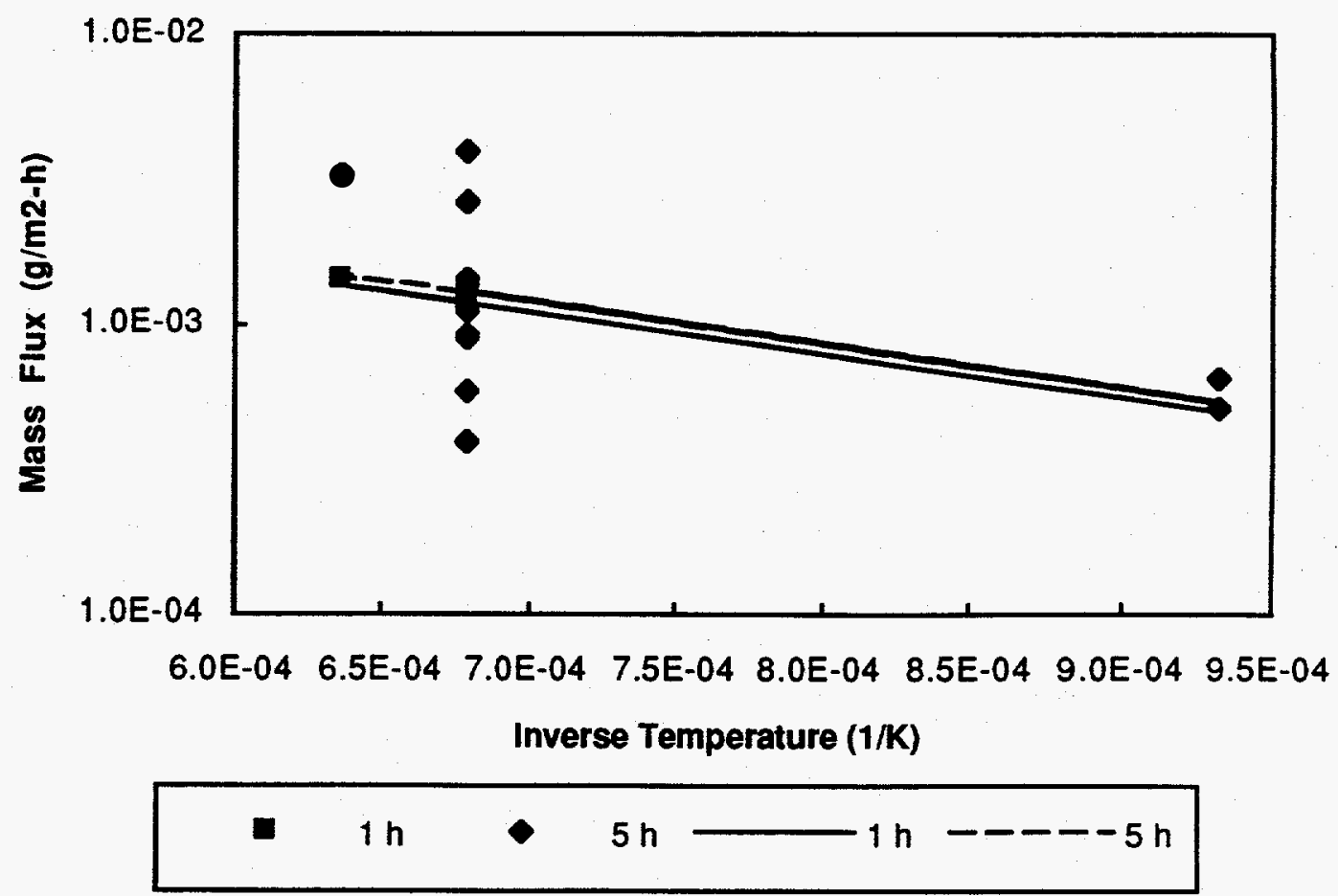

Figure 29. Ti mobility from PCA exposed to air

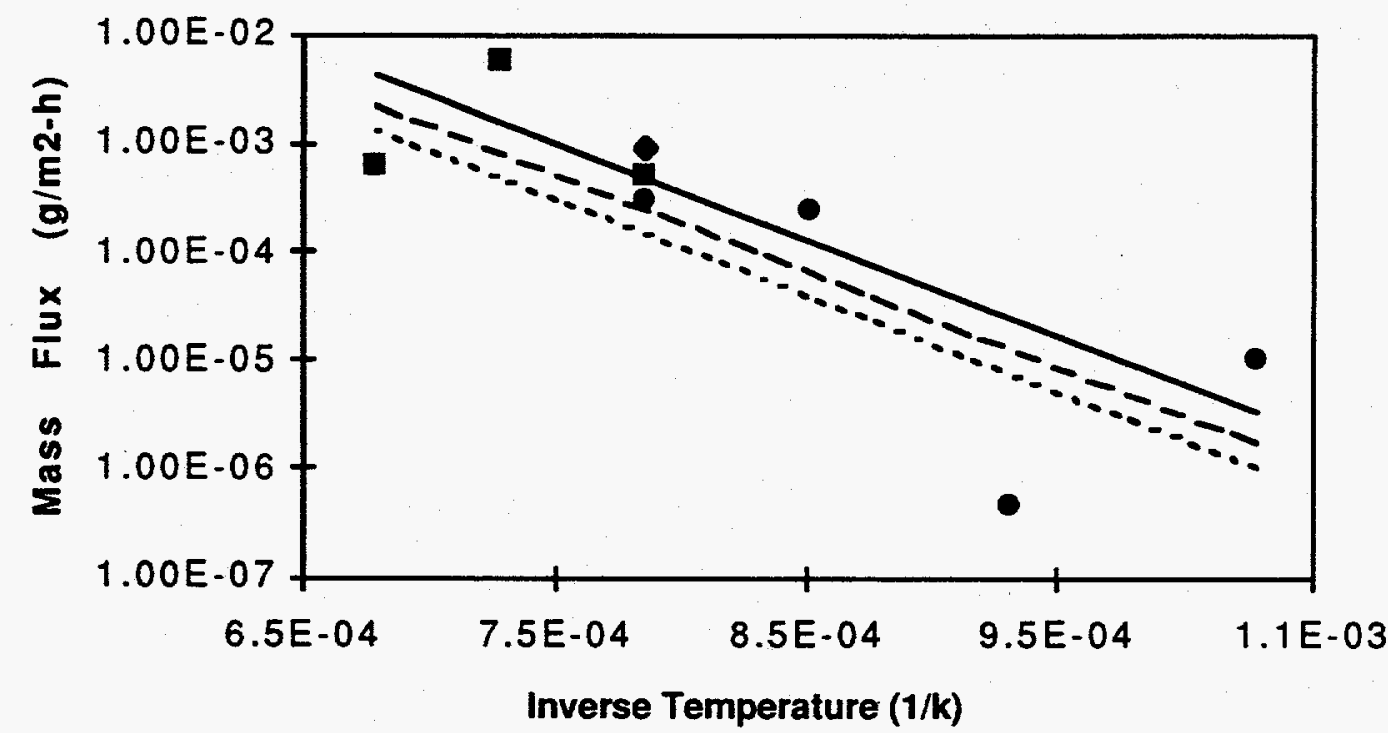

Figure 30. Co mobility from PCA exposed to steam 


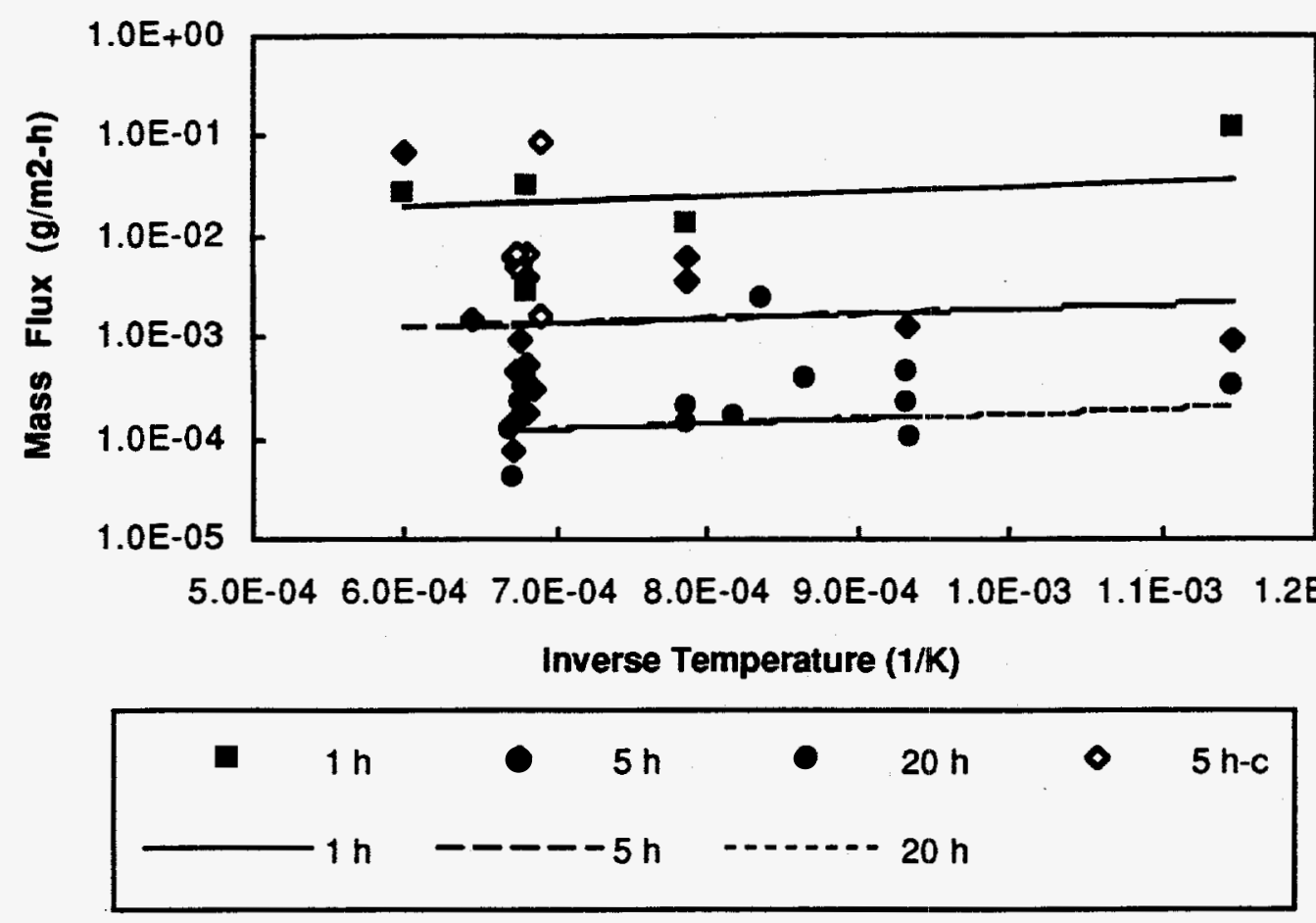

Figure 31. Cr mobility from HT-9 exposed to air

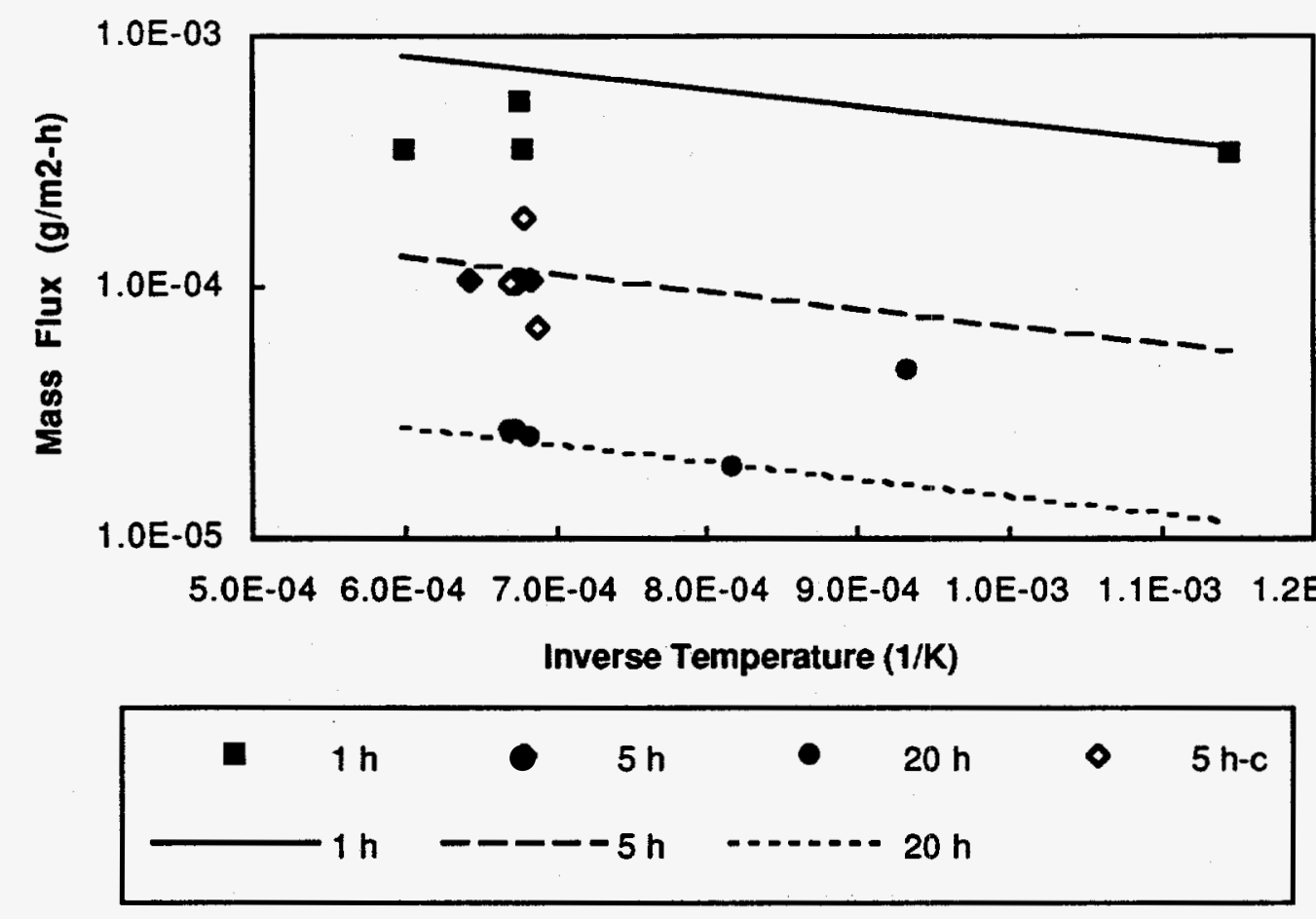

Figure 32. Co mobility from HT-9 exposed to air 


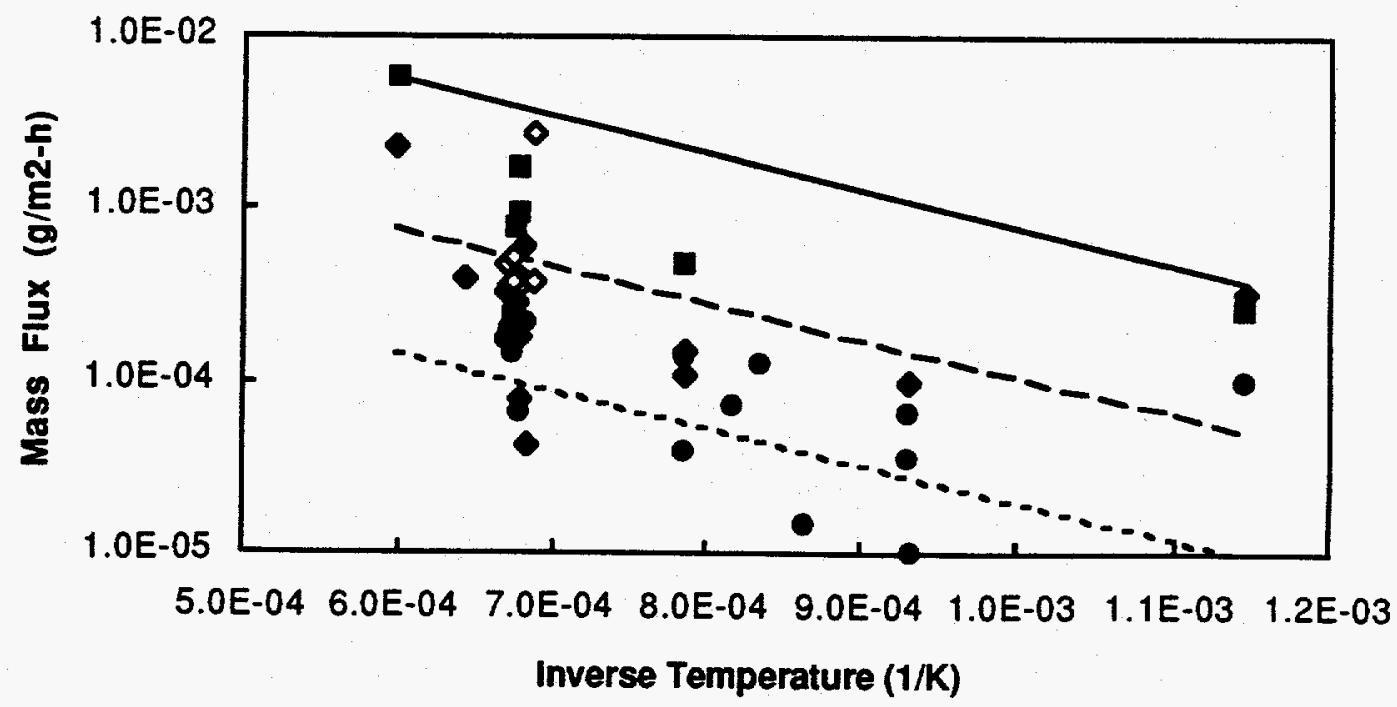

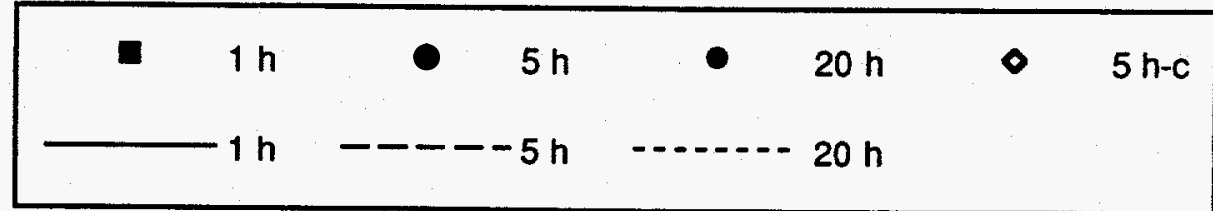

Figure 33. Mn mobility from HT-9 exposed to air

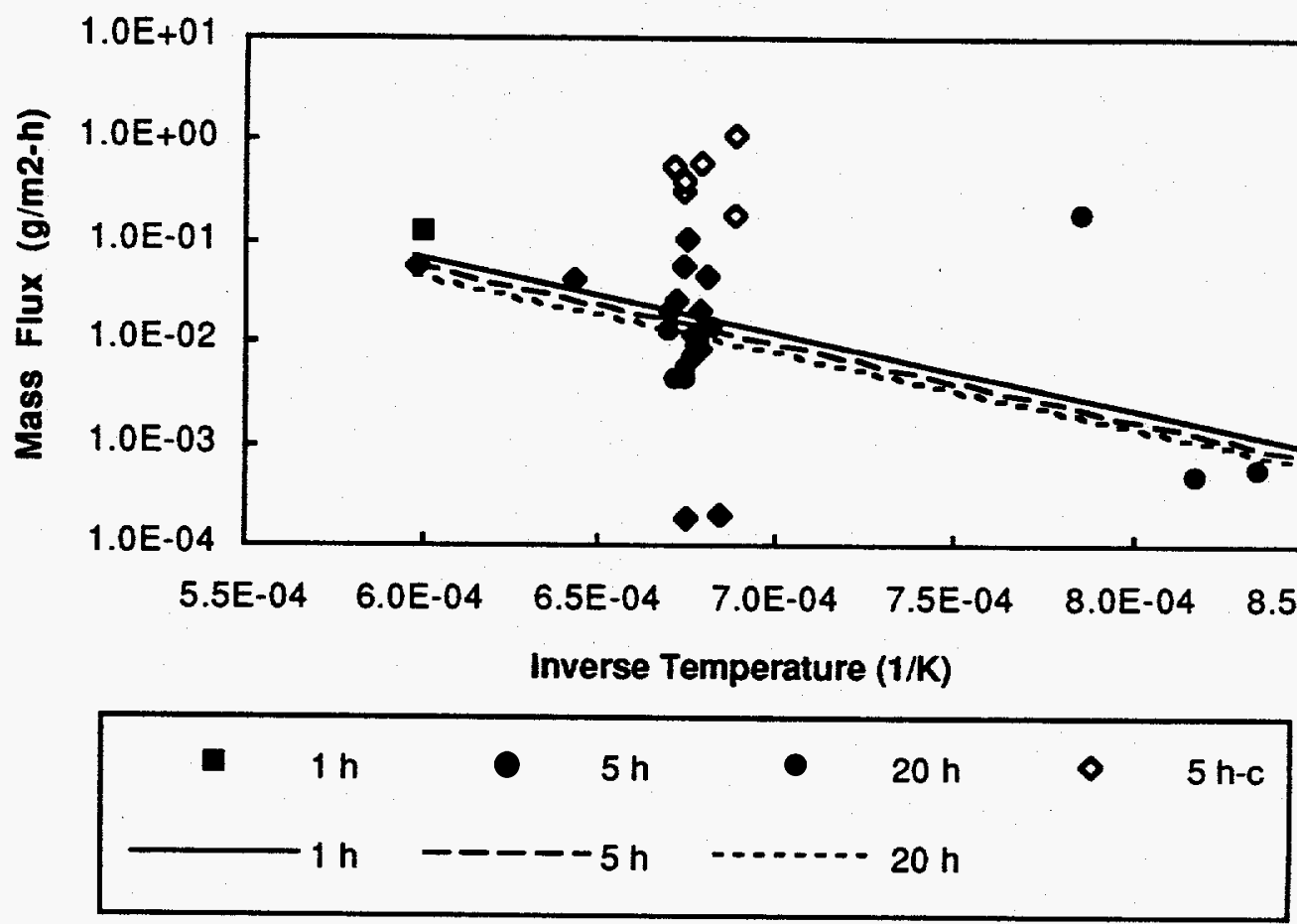

Figure 34. Mo mobility from HT-9 exposed to air 

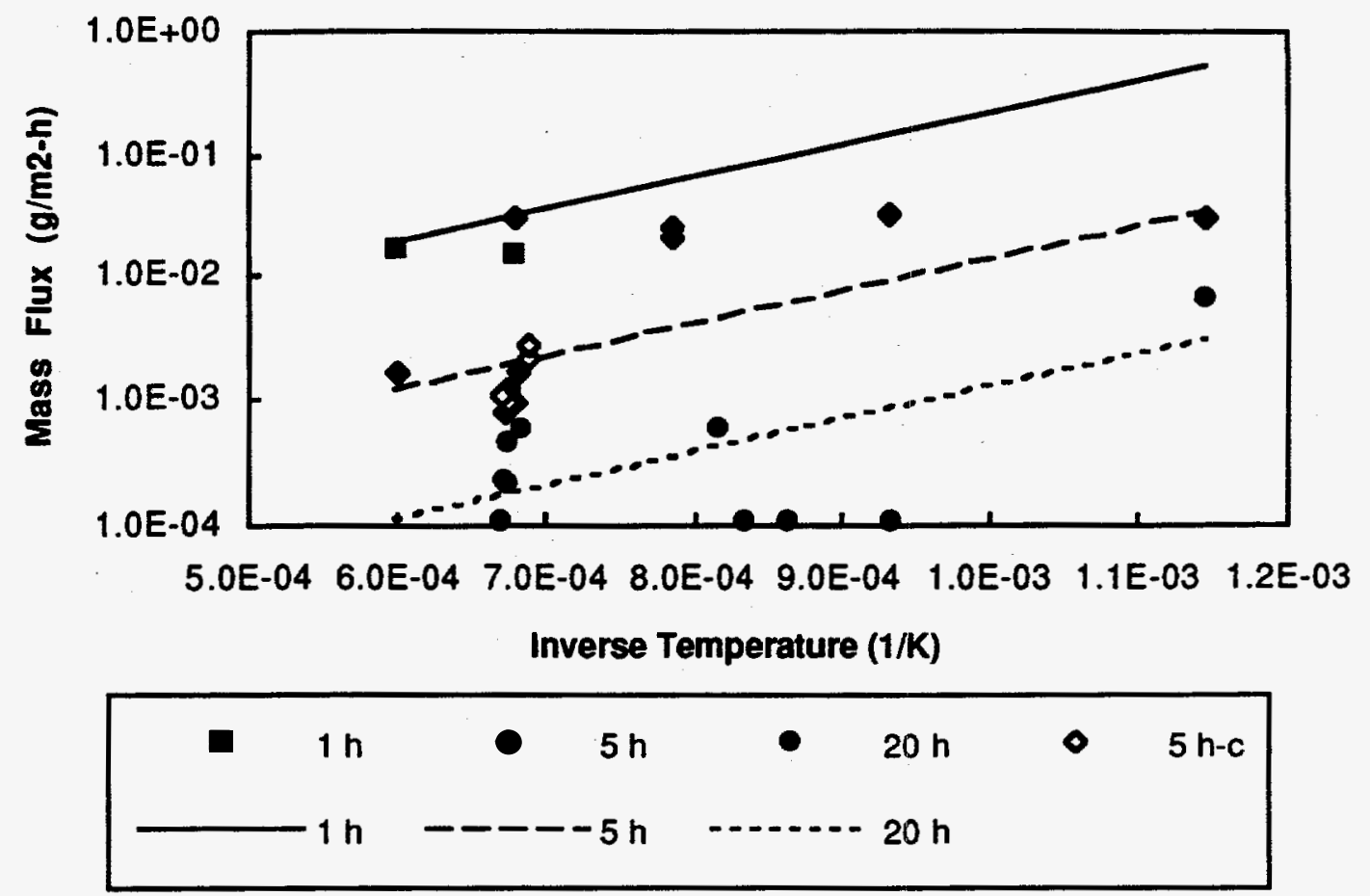

Figure 35. P mobility from HT-9 exposed to air

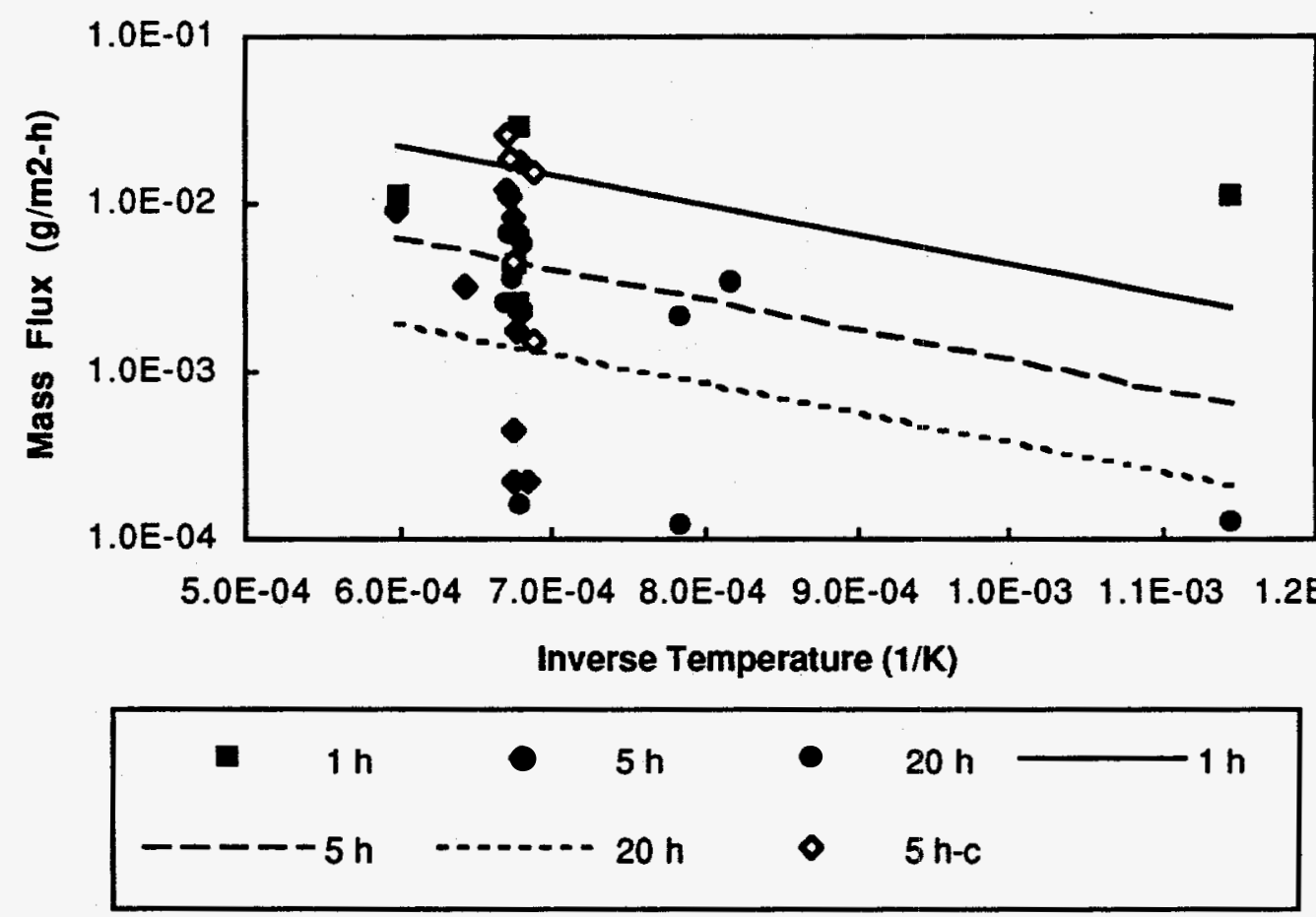

Figure 36. $\mathrm{Cu}$ mobility from HT-9 exposed to air 


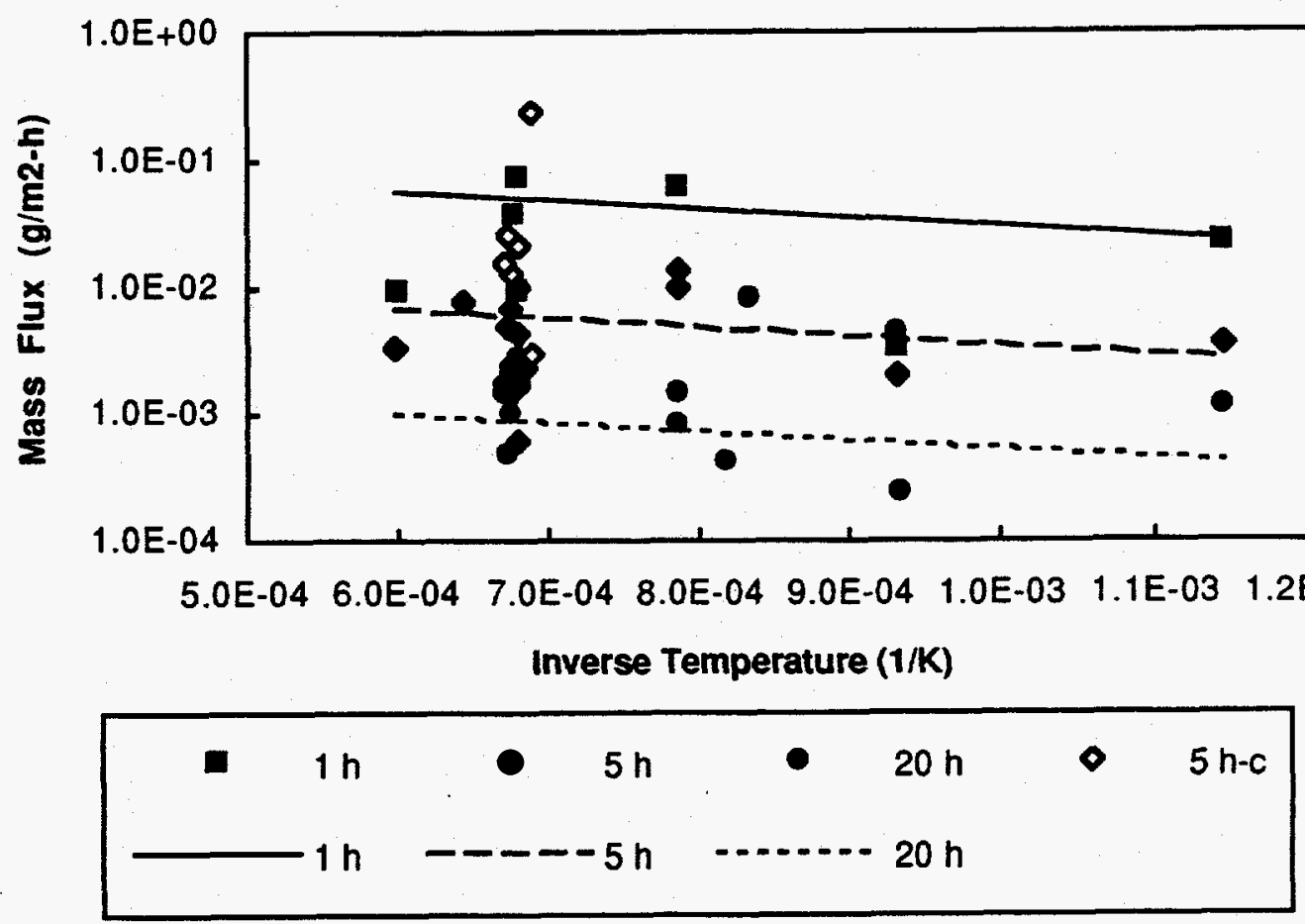

Figure 37. Fe mobility from HT-9 exposed to air

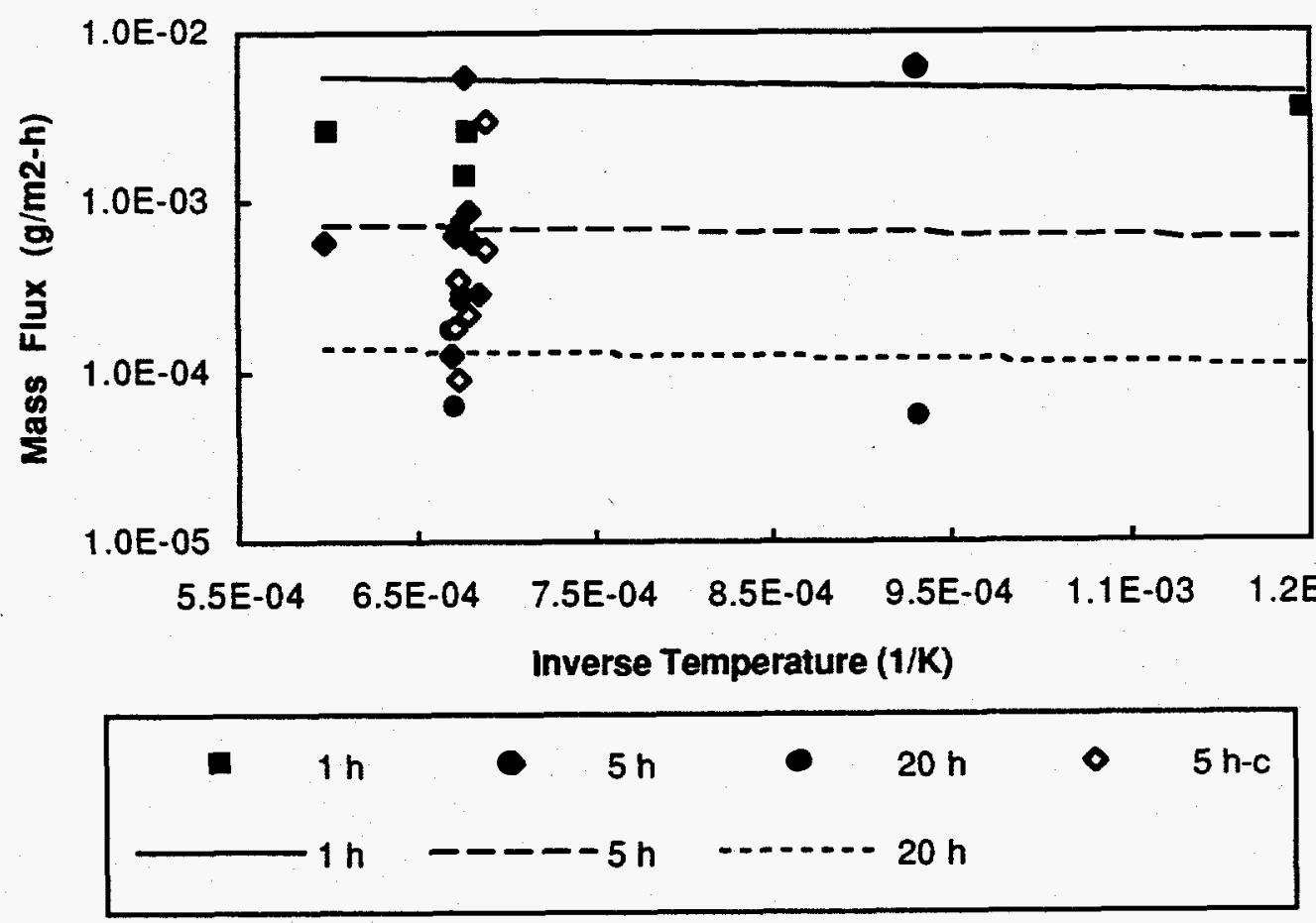

Figure 38. Ni mobility from HT-9 exposed to air 


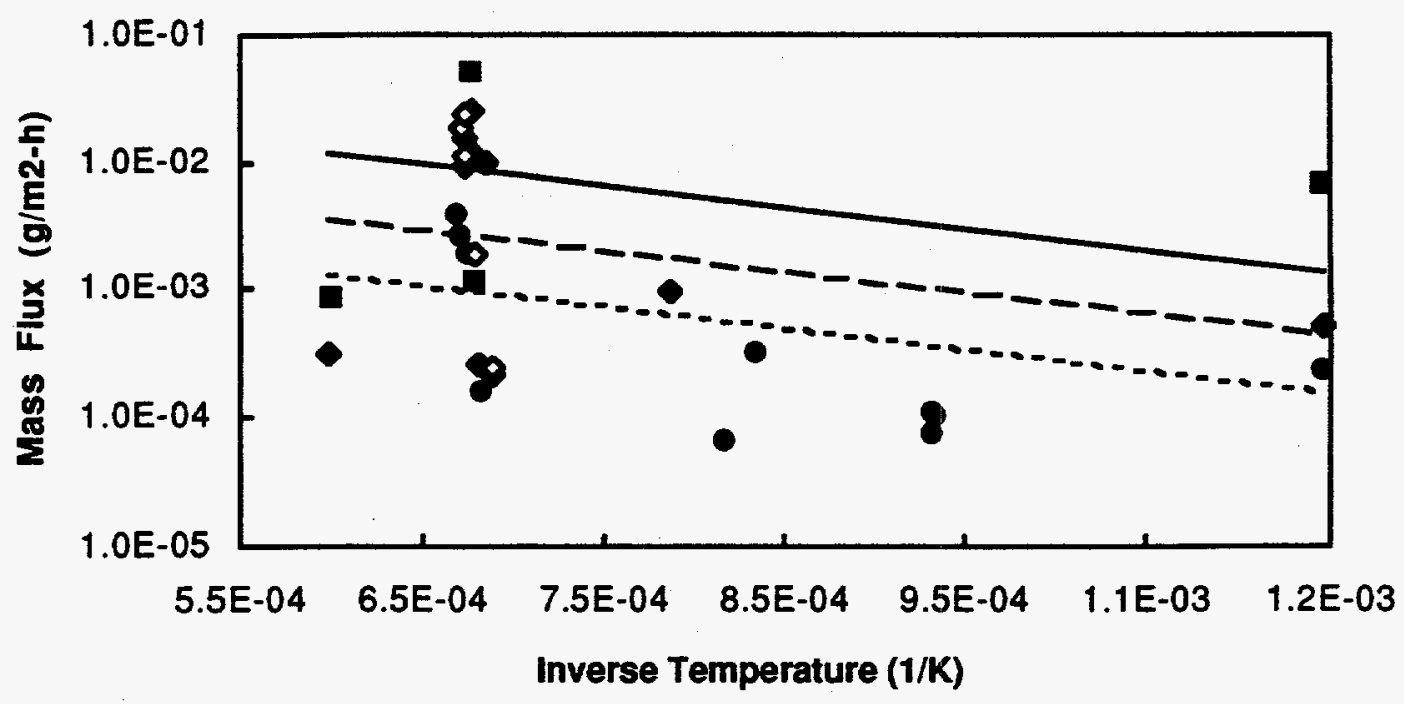

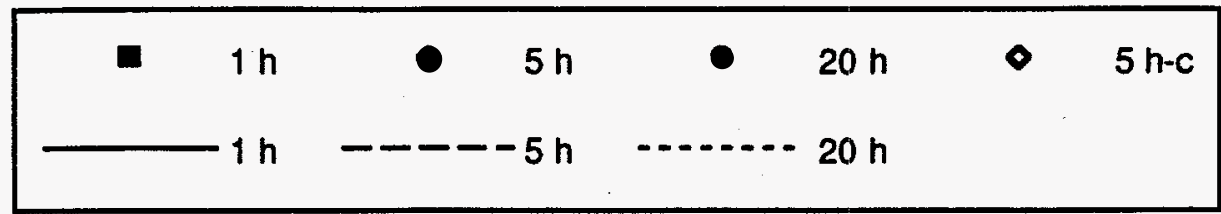

Figure 39. Ti mobility from HT-9 exposed to air

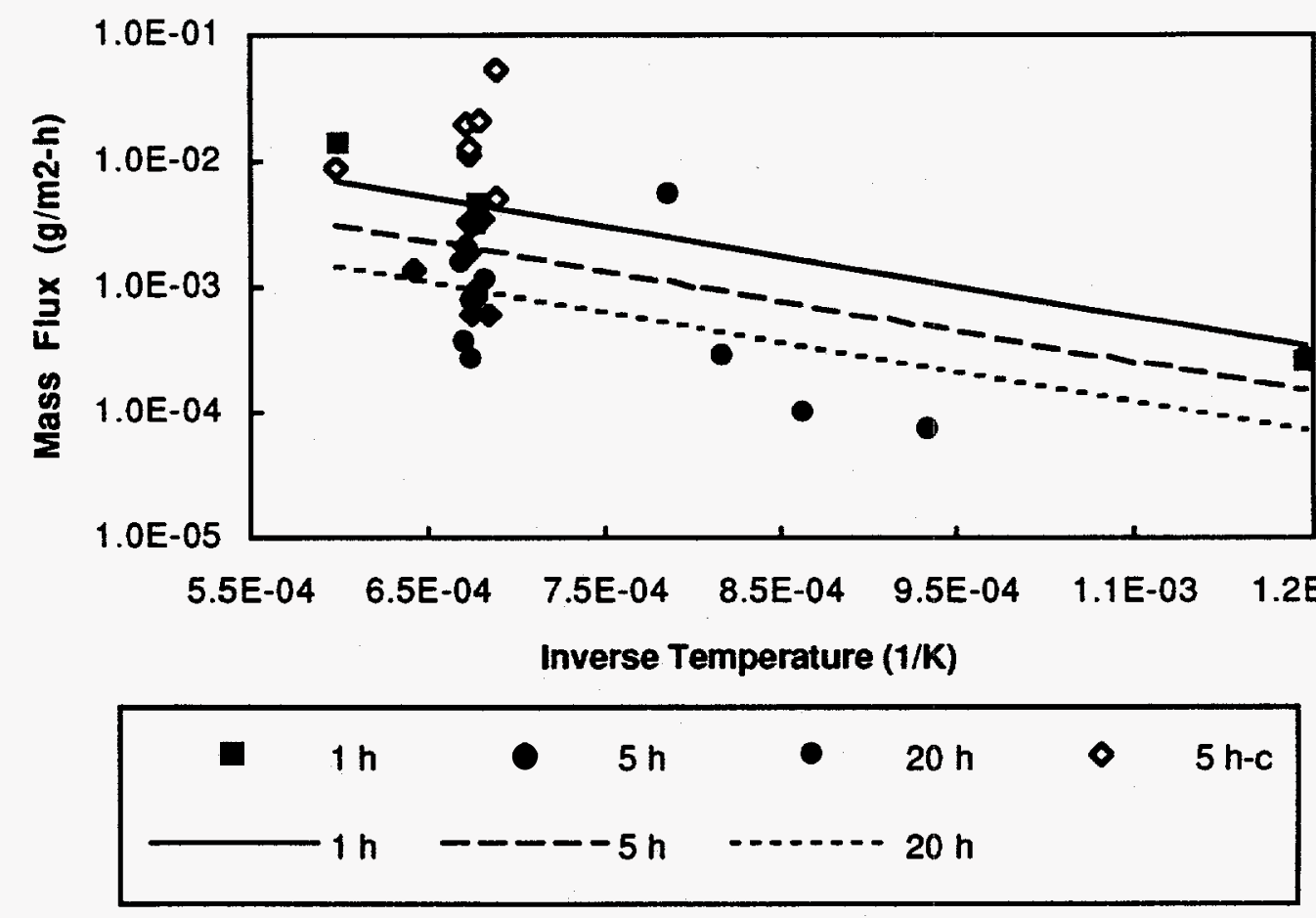

Figure 40. W mobility from HT-9 exposed to air 


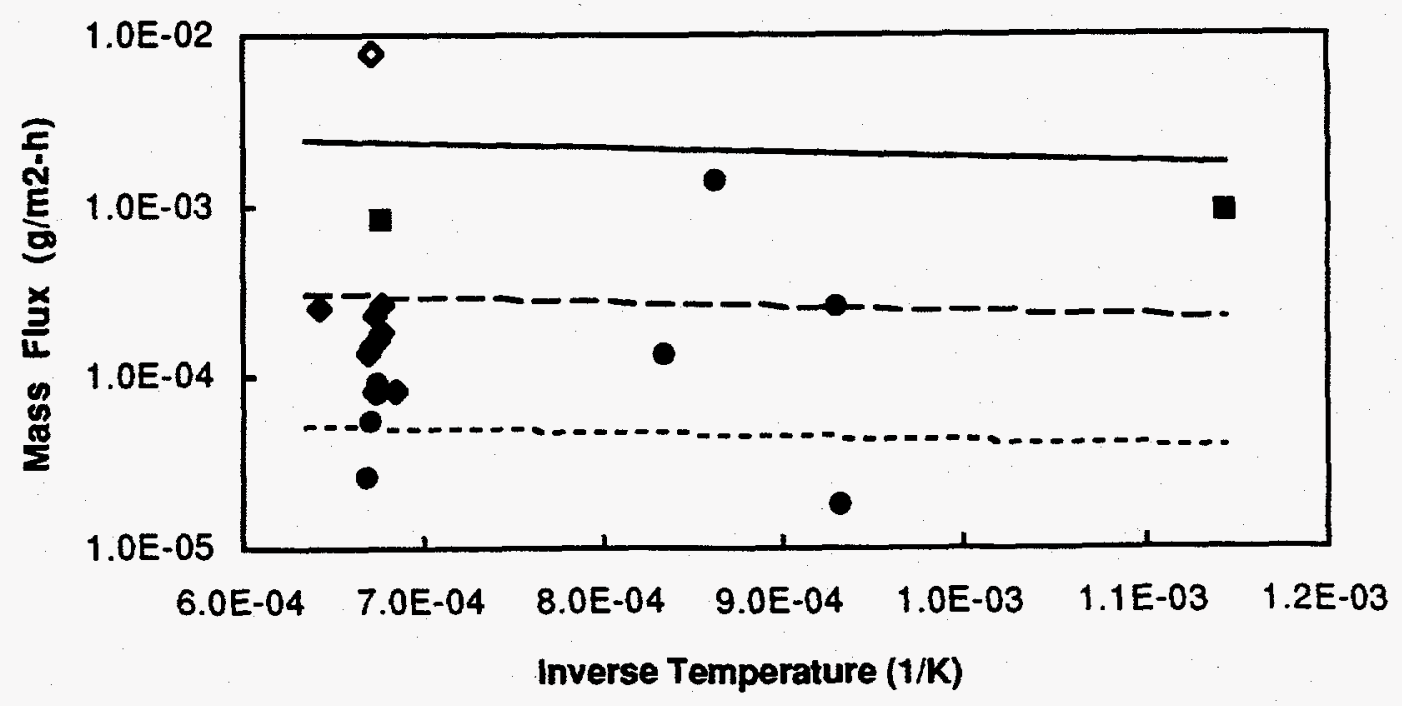

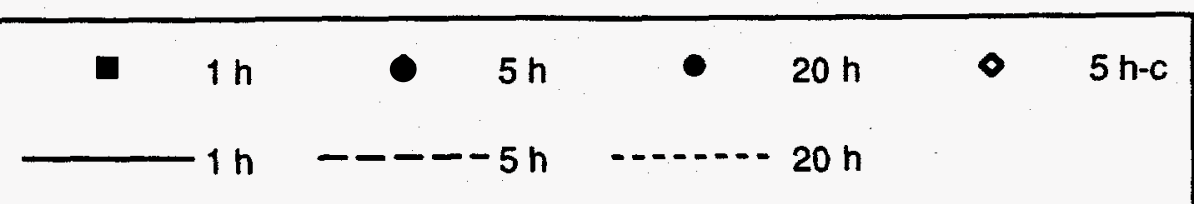

Figure 41. V mobility from HT-9 exposed to air

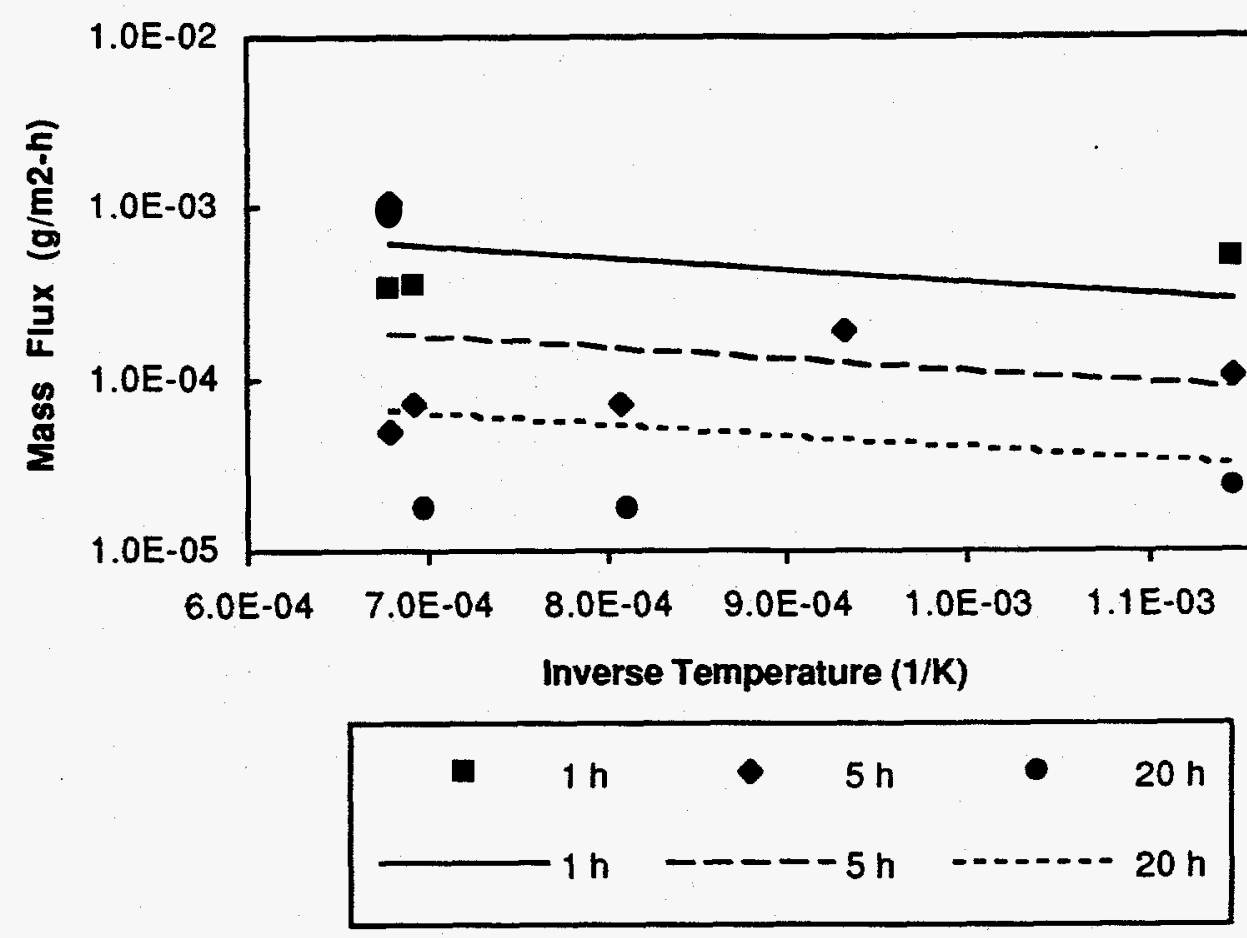

Figure 42. Co mobility from HT-9 exposed to steam 


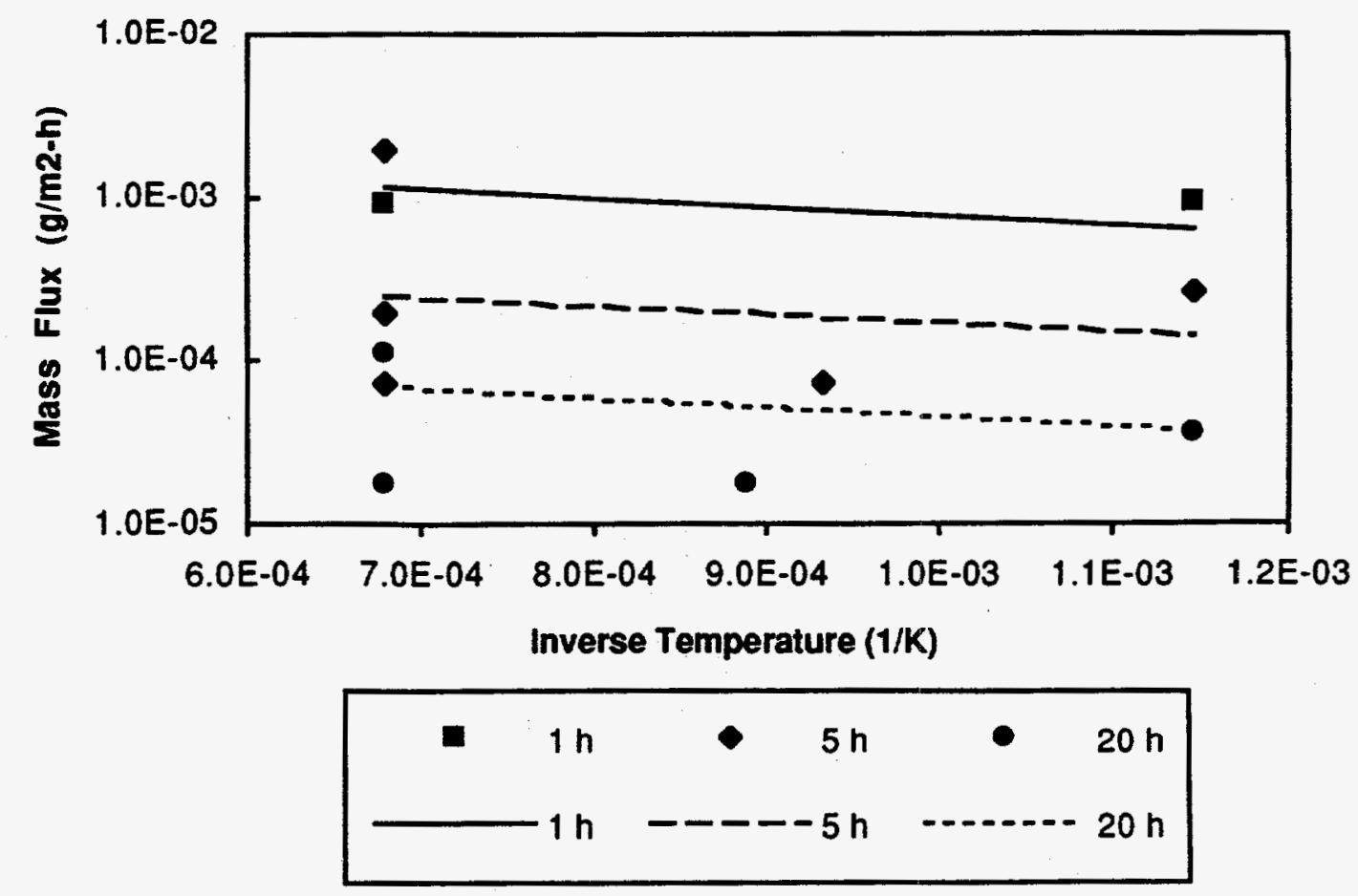

Figure 43. Cr mobility from HT-9 exposed to steam

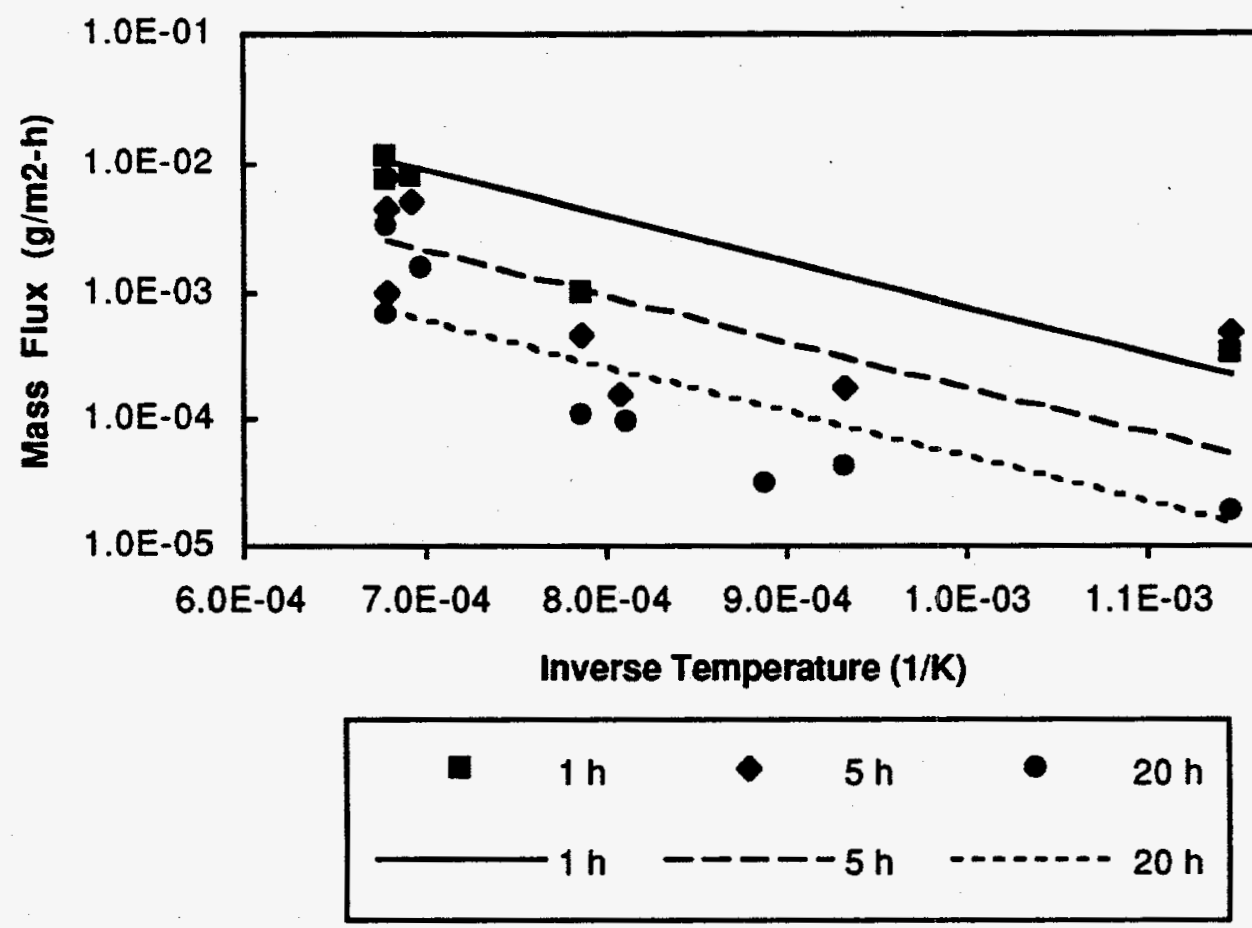

Figure 44. Mn mobility from HT-9 exposed to steam 

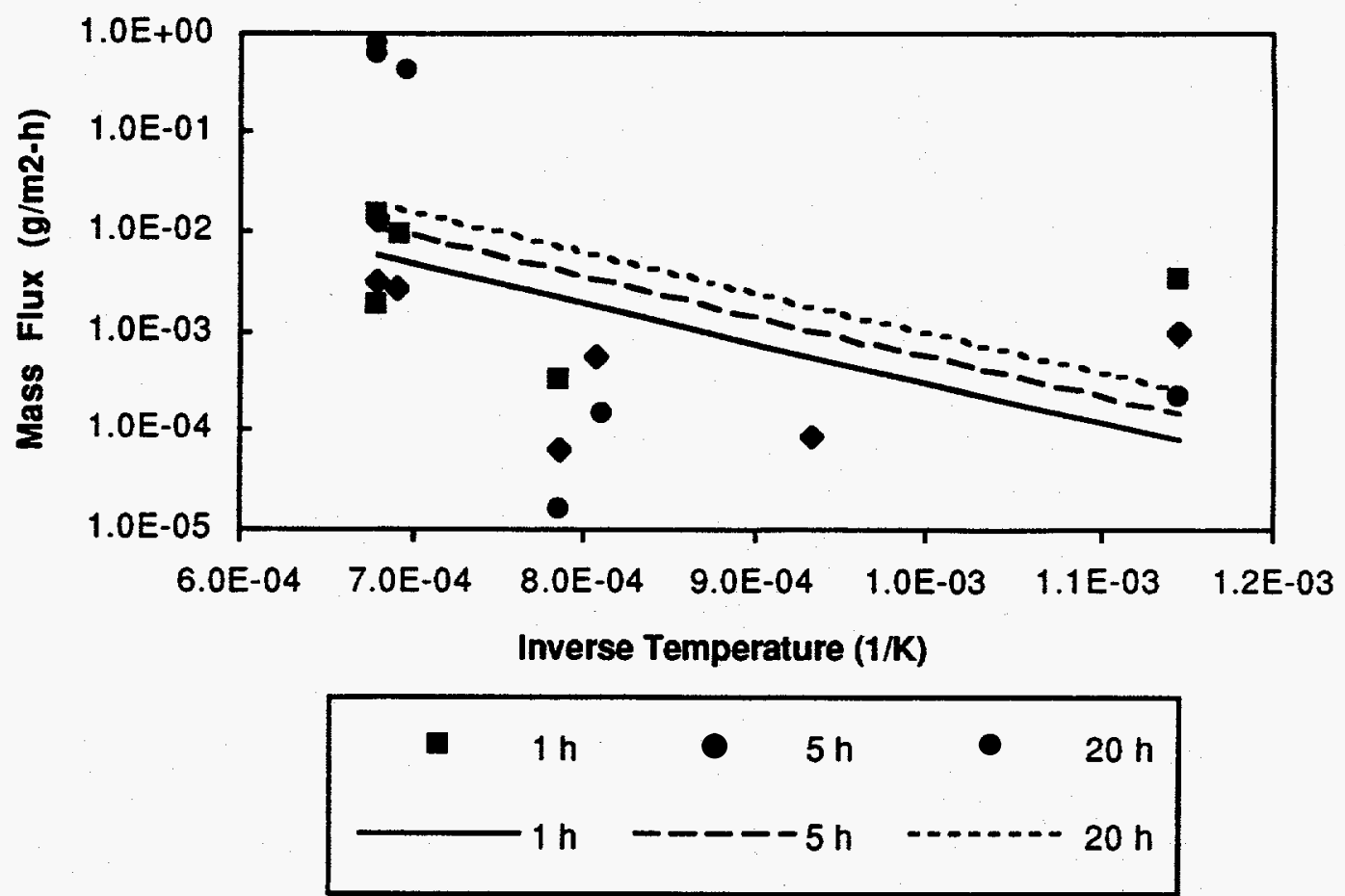

Figure 45. Mo mobility from HT-9 exposed to steam
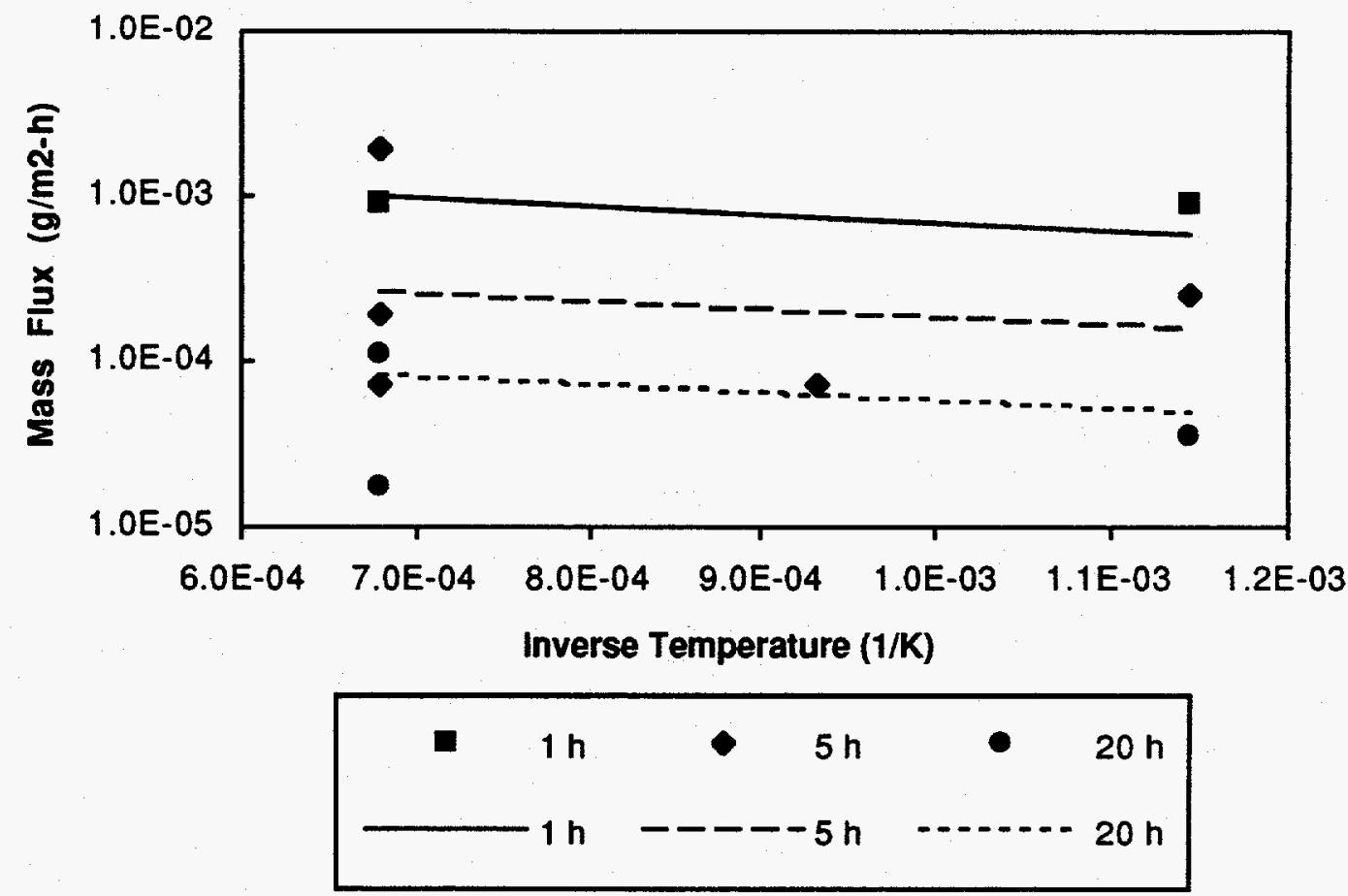

Figure 46. V mobility from HT-9 exposed to steam 

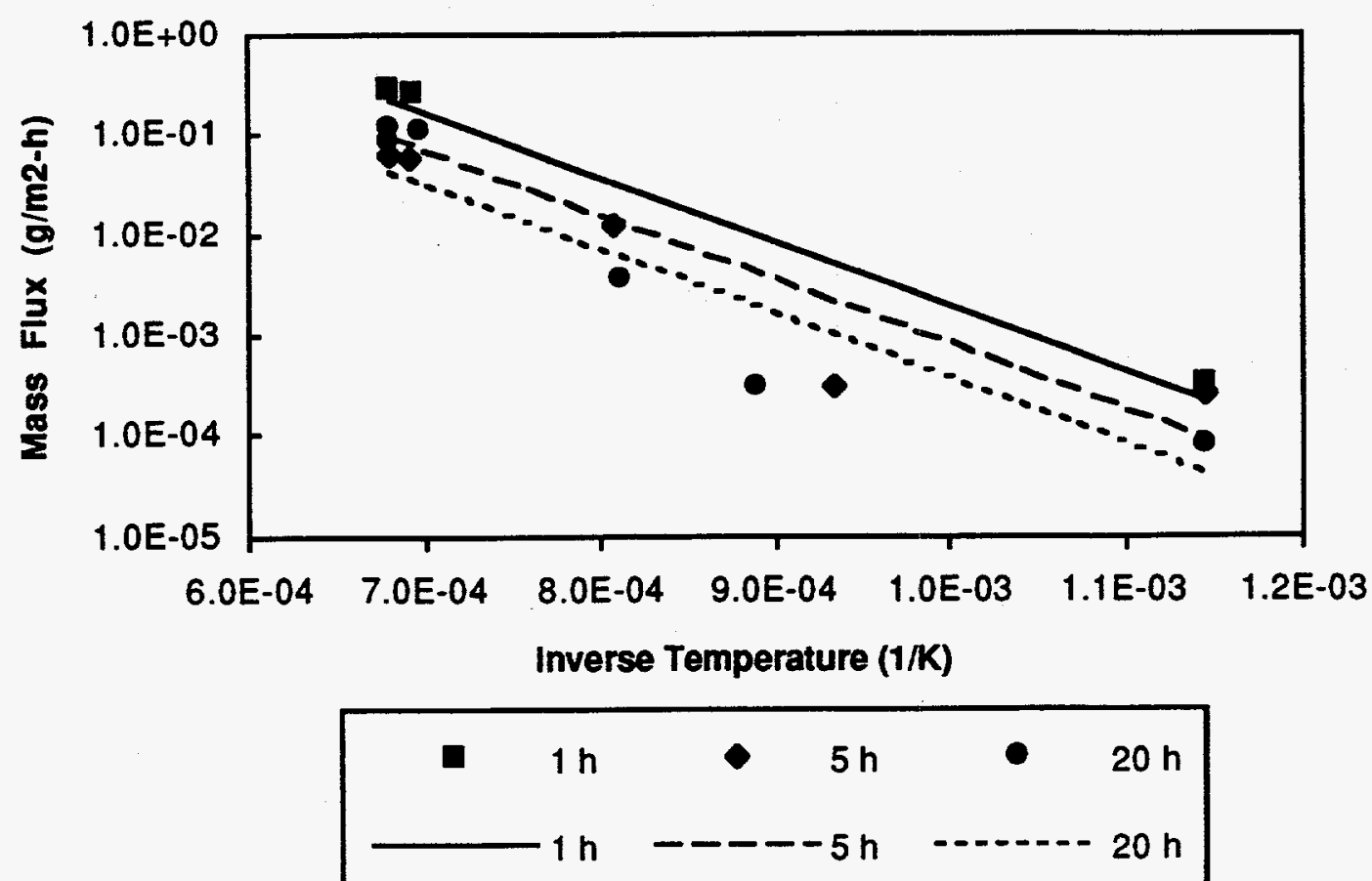

Figure 47. W mobility from HT-9 exposed to steam

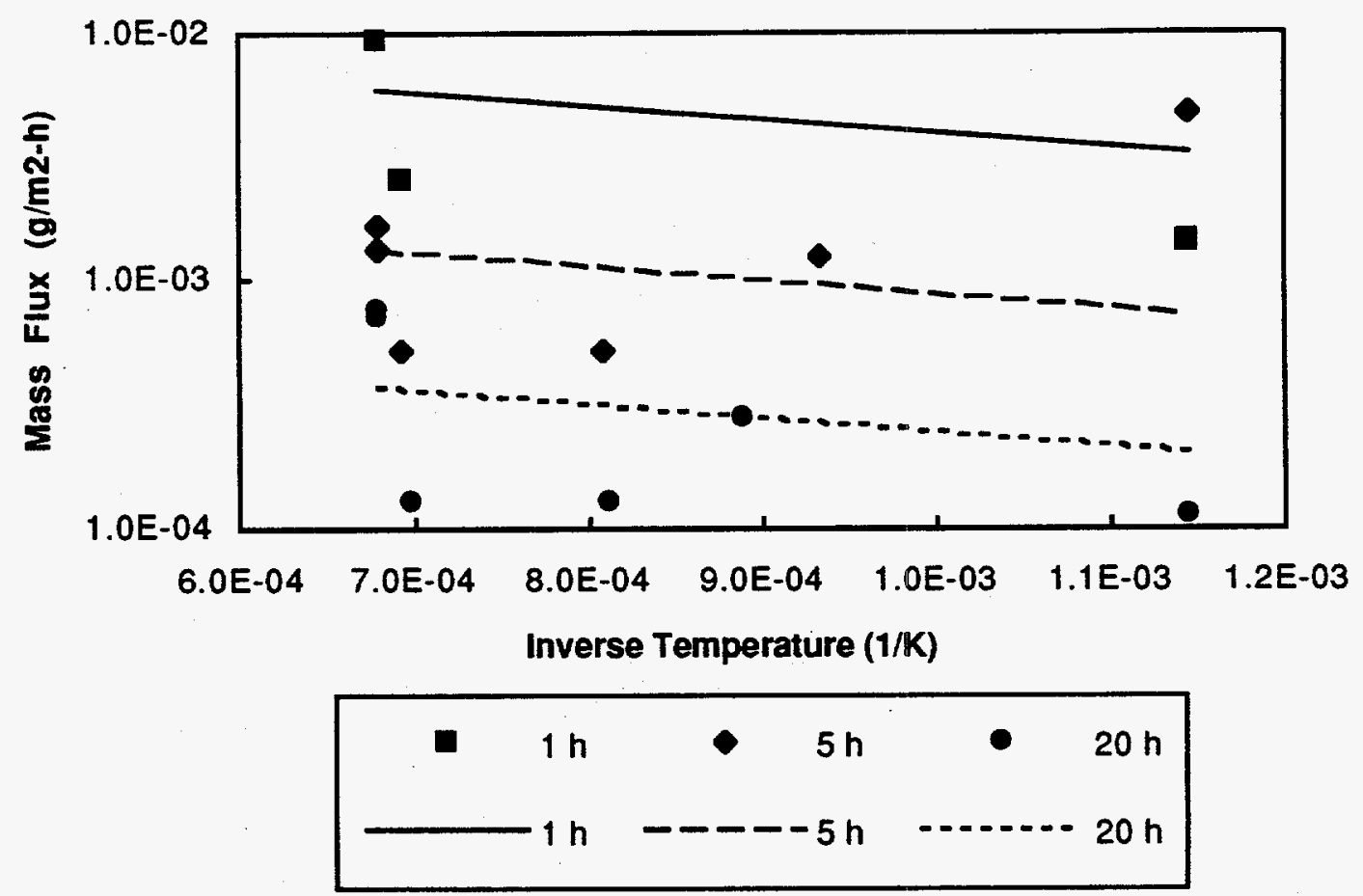

Figure 48. Cu mobility from HT-9 exposed to steam 

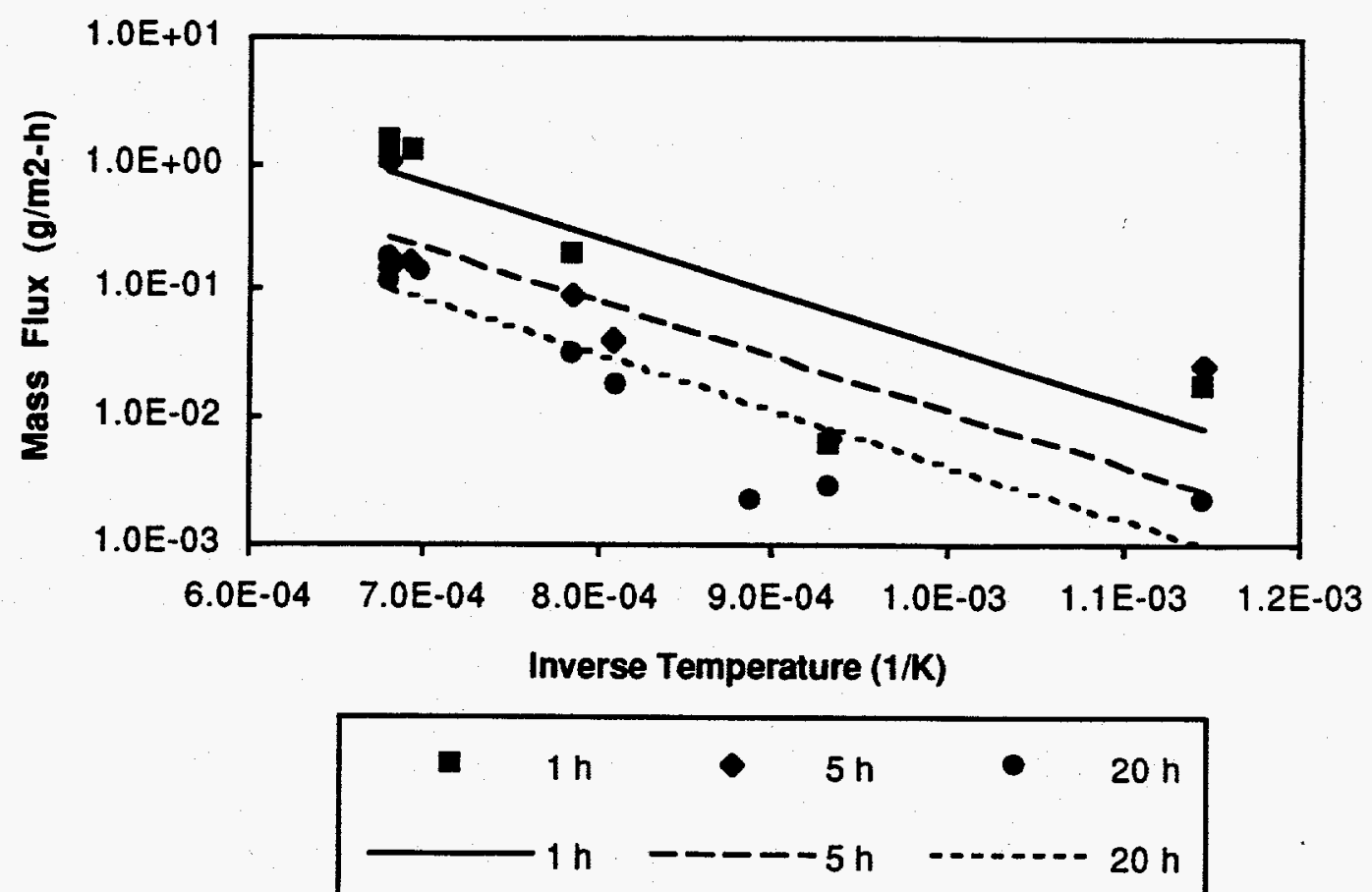

Figure 49. Fe mobility from HT-9 exposed to steam

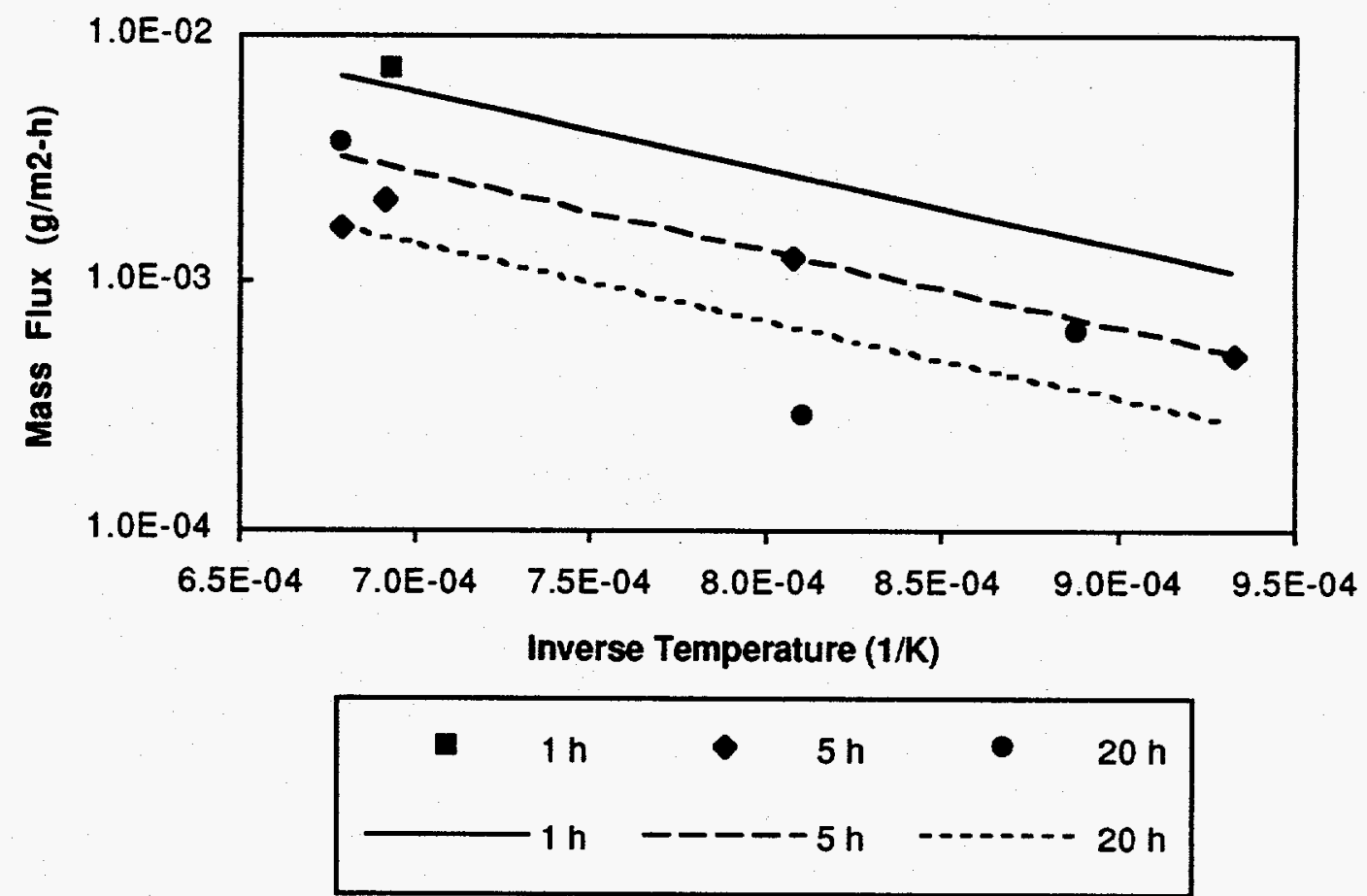

Figure 50. P mobility from HT-9 exposed to steam 

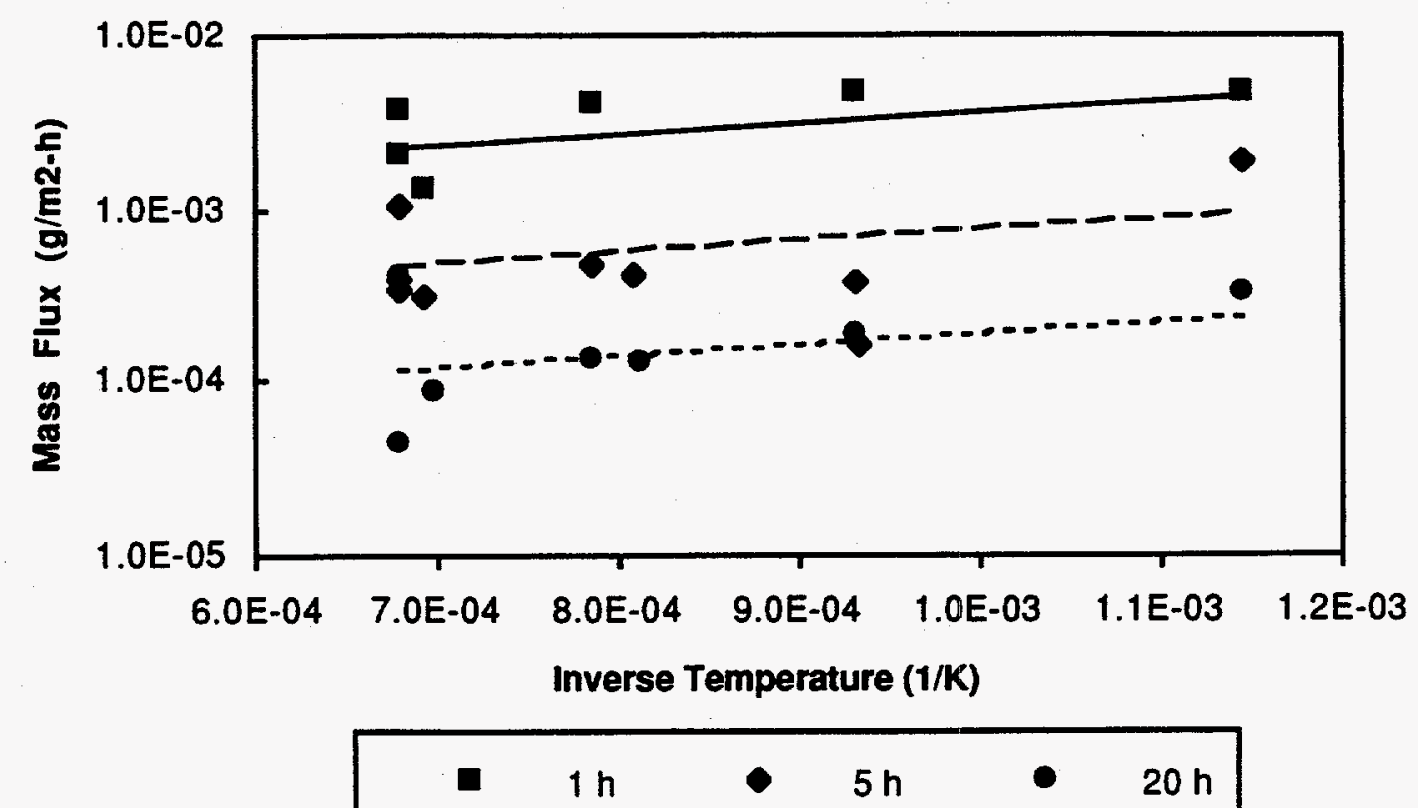

$1 \mathrm{~h} \quad-----5 \mathrm{~h} \quad \cdots \cdots-20 \mathrm{~h}$

Figure 51. Ti mobility from HT-9 exposed to steam
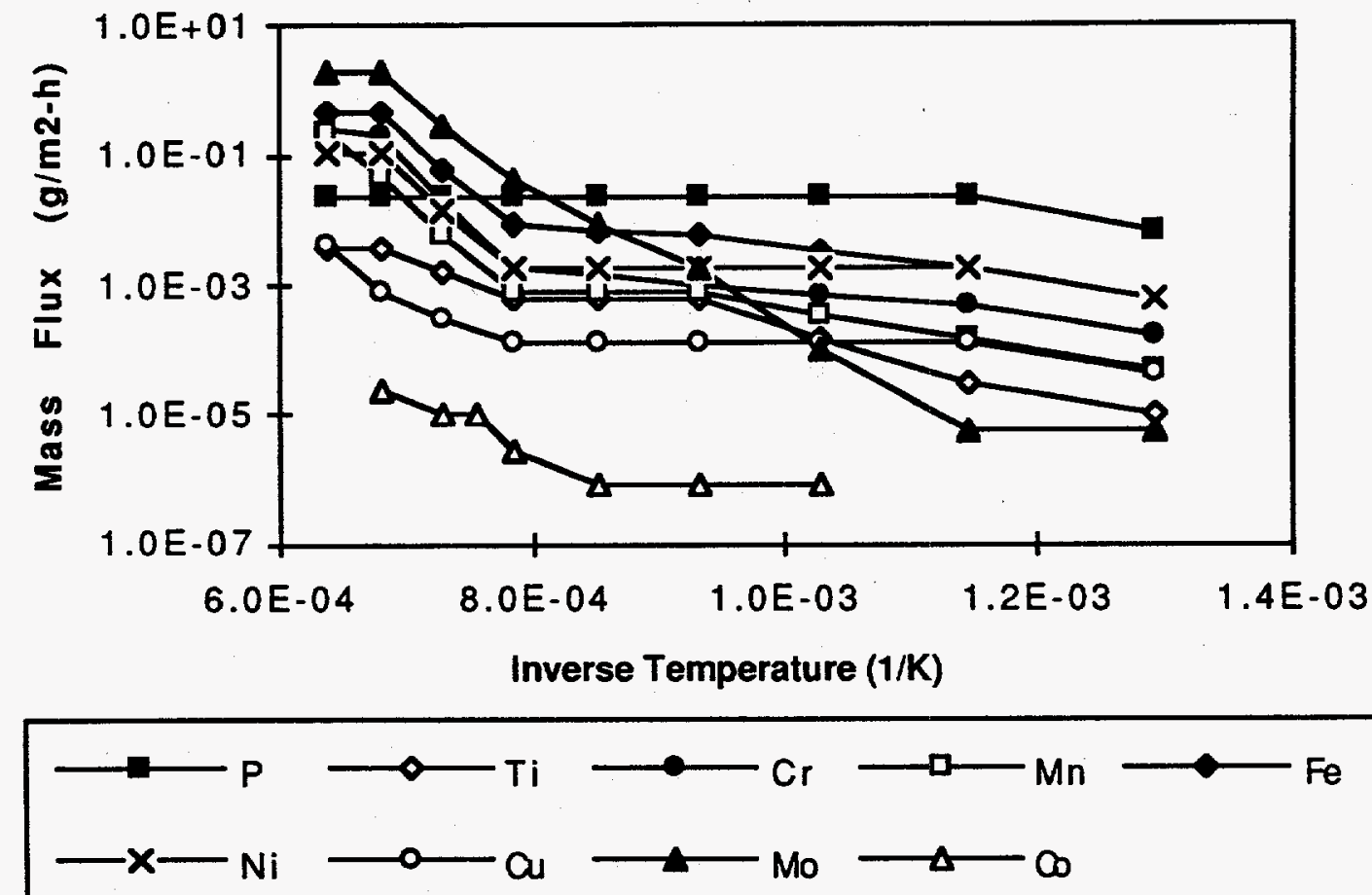

Figure 52. Cumulative maximum mobility of elements from PCA exposed to air 


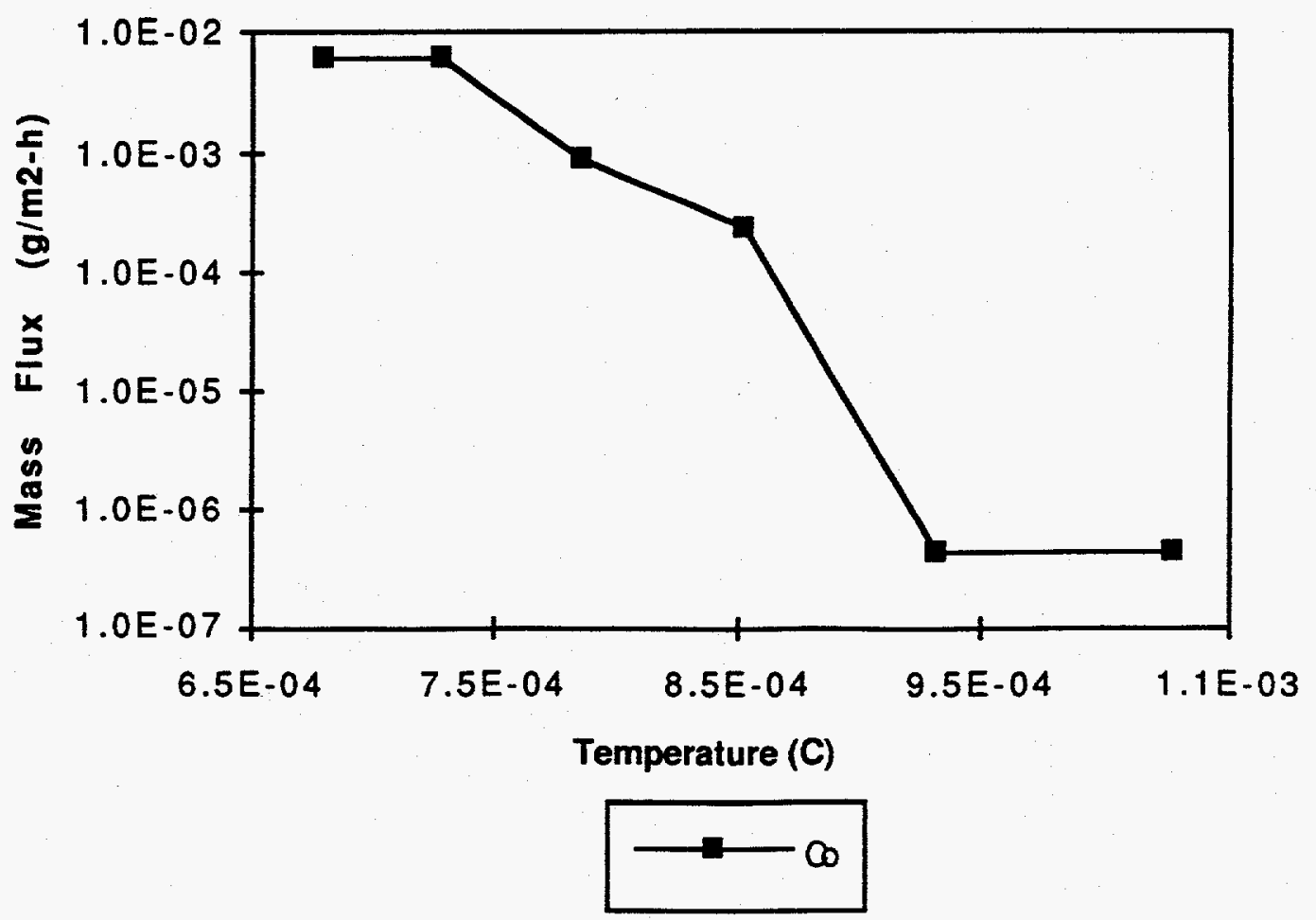

Figure 53. Cumulative maximum mobility of Co from PCA exposed to steam
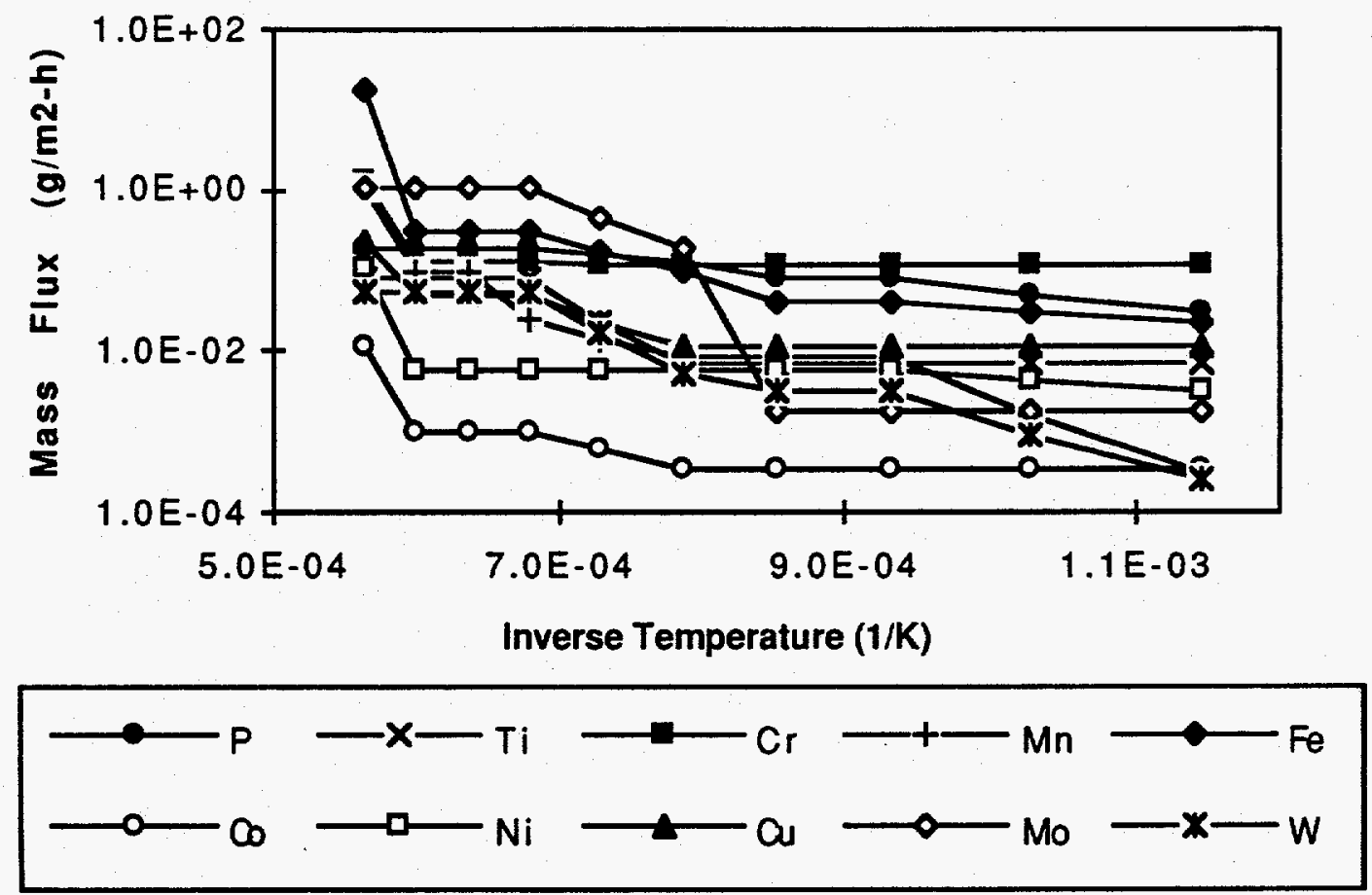

Figure 54. Cumulative maximum mobility of elements from HT-9 exposed to air 

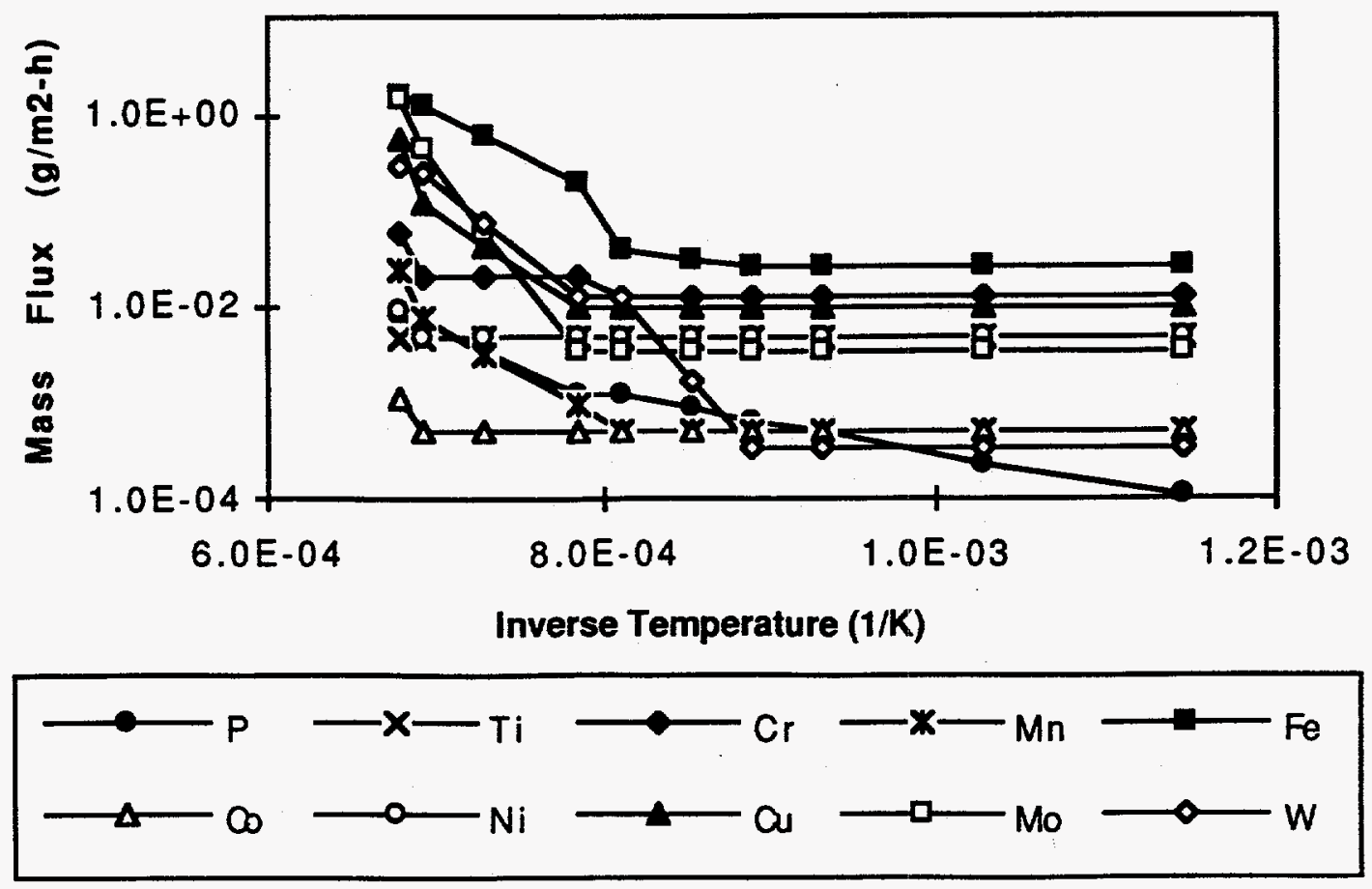

Figure 55. Cumulative maximum mobility of elements from HT-9 exposed to steam

\subsection{Niobium}

The $\mathrm{Nb}$ alloy we tested had the composition shown in Table 13 . We tested the $\mathrm{Nb}$ alloy in both air and steam. Table 14 gives the test matrix for the $\mathrm{Nb}$ alloy tests. Data at lower temperatures $\left(400-600^{\circ} \mathrm{C}\right)$ would be desirable for input to a PSAR were $\mathrm{Nb}$ to be used in ITER (current design to not include Nb). See Smolik et. al (July 1992c) for details about these tests.

In both air and steam, only $\mathrm{Nb}$ and Mo were measured above detection limits. Thus, we attempt curve fits for these two elements. The values of the regression coefficients are given in Table 15 and 16 for air and steam respectively. The data are plotted in Figures 56 through 59. Because these were exploratory tests, there are limited data at each temperature. Figures 60 and 61 give the maximum cumulative volatility of the various elements in air and steam, respectively. For all but $\mathrm{Nb}$ and $\mathrm{Mo}$, the volatility plotted is the detection limit of the particular element.

The IBEED is dominated by $\mathrm{Nb}$ and $\mathrm{Ta}$. (The activation information that we had access to was not as detailed as was used for other alloys, thus there may be some elements that contribute above $1 \%$ that are not listed here.) $\mathrm{Ta}, \mathrm{Nb}$, and $\mathrm{W}$ dominate the MBEED. We 
will consider these elements when evaluating the data. We will also discuss Mo data because it proved to be extremely volatile, and more detailed activation calculations would possibly include it.

There were very few measurements of $\mathrm{Mo}$ and $\mathrm{Nb}$ mobility above detection limits at lower temperatures. At temperatures below which data are available, it is impossible to evaluate whether the curve fit is adequate. For temperatures at which there are data points, the straight line appears to fit the data well, particularly for the data in steam with correlation coefficients of 0.92 for $\mathrm{Nb}$ and 0.94 for $\mathrm{Mo}$. This indicates that the mechanism we are observing is probably volatility as opposed to spalling.

We did not measure $\mathrm{Ta}$ or $\mathrm{W}$ mobility from the $\mathrm{Nb}$ alloy. Ta contributes significantly to the early dose. W is not as important, contributing less than $3 \%$ when mobility fractions are considered. $\mathrm{Nb}$ is not currently an ITER EDA material candidate, but should it become one, more testing would be required, particularly at lower temperatures. More detailed activation calculations should be used to determine what elements are most important (current activation calculations did not indicate that Mo, which is quite volatile, would be present); current calculations indicate testing should concentrate on $\mathrm{Nb}$, and $\mathrm{Ta}$.

\begin{tabular}{|c|c|c|c|c|c|}
\hline $\mathrm{Cu}$ & $\mathrm{Mn}$ & $\mathrm{Mo}$ & $\mathrm{Nb}$ & $\mathrm{Y}$ & $\mathrm{Zr}$ \\
\hline 0.19 & 0.003 & 0.12 & 98.5 & 0.12 & 1.04 \\
\hline
\end{tabular}

Table 13. Niobium alloy composition, wt.\%

\begin{tabular}{|c|c|c|c|c|c|}
\hline \multirow{2}{*}{$\begin{array}{c}\text { Test } \\
\text { Environment }\end{array}$} & \multicolumn{5}{|c|}{ Temperature $\left({ }^{\circ} \mathrm{C}\right)$} \\
\cline { 2 - 6 } & $\mathbf{8 0 0}$ & 900 & 1000 & 1100 & 1200 \\
\hline air & $\mathrm{x}$ & $\mathrm{x}$ & $\mathrm{x}$ & $\mathrm{x}$ & $\mathrm{x}$ \\
\hline steam & $\mathrm{x}$ & $\mathrm{x}$ & $\mathrm{x}$ & $\mathrm{x}$ & $\mathrm{x}$ \\
\hline
\end{tabular}

Table 14. Niobium alloy test matrix

\begin{tabular}{|c|c|c|c|c|}
\hline Element & $\mathbf{A}\left(\mathbf{g} / \mathbf{m}^{2}-\mathbf{h}\right)$ & $\mathbf{B}$ & $\mathbf{C}(\mathbf{J} / \mathbf{m o l e})$ & $\mathbf{r}^{\mathbf{2}}$ \\
\hline $\mathrm{Nb}$ & $2.50 \mathrm{E}-04$ & $-1.34 \mathrm{E}+00$ & $2.42 \mathrm{E}+04$ & 0.84 \\
\hline $\mathrm{Mo}$ & $1.50 \mathrm{E}+00$ & $-9.12 \mathrm{E}-01$ & $4.45 \mathrm{E}+04$ & 0.69 \\
\hline
\end{tabular}

Table 15. Regression coefficients for $\mathrm{Nb}$ alloy mobility in air 


\begin{tabular}{|c|c|c|c|c|}
\hline Element & $\mathbf{A}\left(\mathbf{g} / \mathbf{m}^{2}-\mathbf{h}\right)$ & $\mathbf{B}$ & $\mathbf{C}(\mathrm{J} /$ mole $)$ & $\mathbf{r}^{\mathbf{2}}$ \\
\hline $\mathrm{Nb}$ & $2.76 \mathrm{E}+06$ & $4.08 \mathrm{E}-02$ & $1.81 \mathrm{E}+05$ & 0.92 \\
\hline $\mathrm{Mo}$ & $2.51 \mathrm{E}+04$ & $-7.28 \mathrm{E}-01$ & $2.36 \mathrm{E}+05$ & 0.94 \\
\hline
\end{tabular}

Table 16. Regression coefficients for $\mathrm{Nb}$ alloy mobility in steam

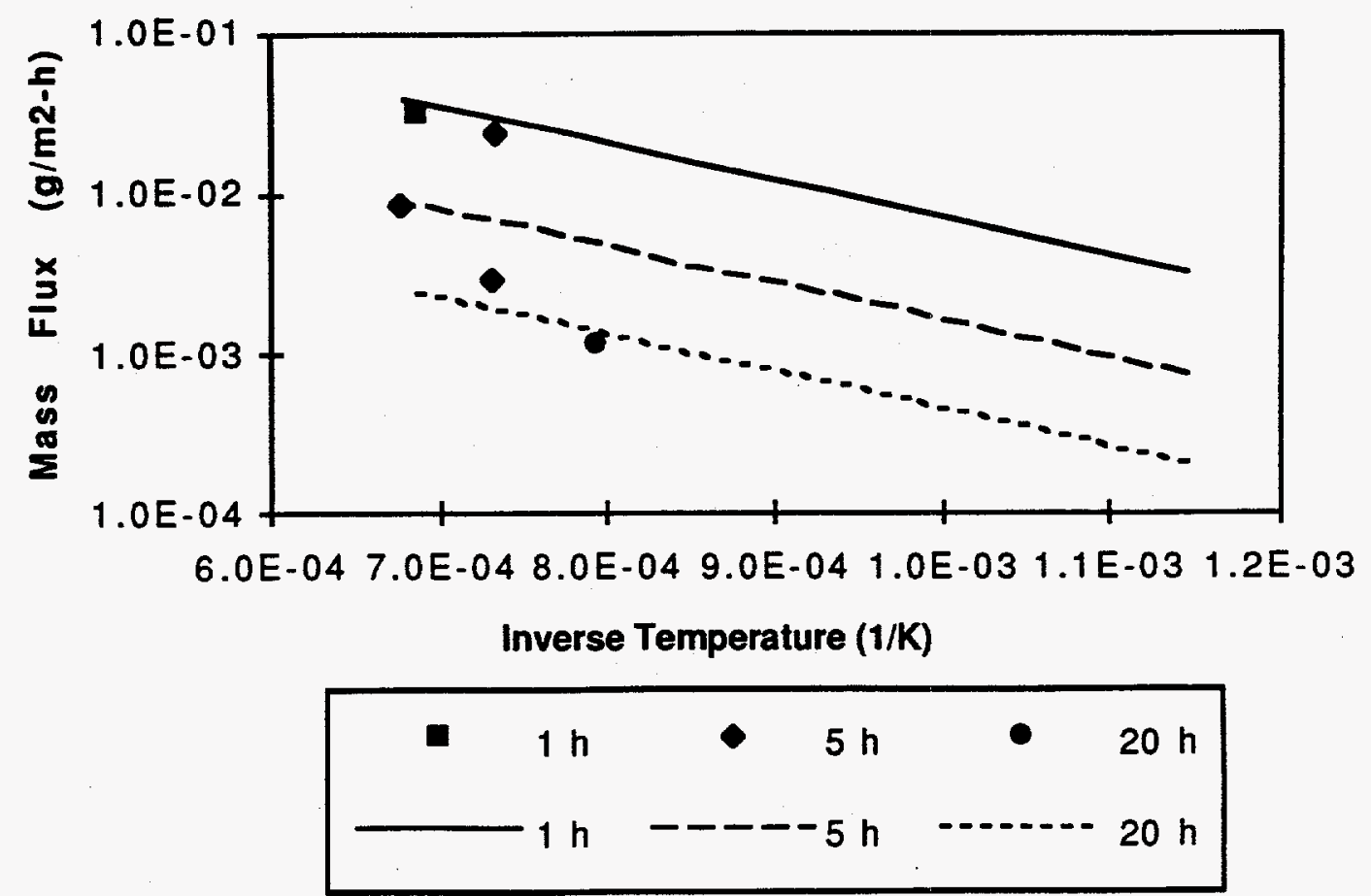

Figure 56. Mo mobility from $\mathrm{Nb}$ alloy exposed to air 


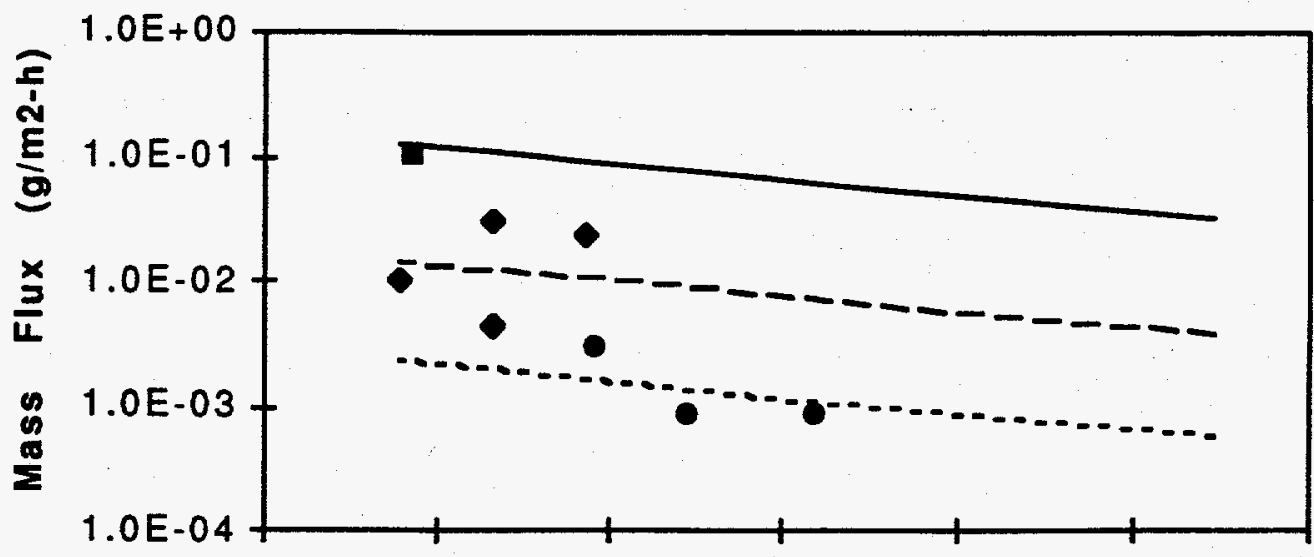

6.0E-04 7.0E-04 8.0E-04 9.0E-04 1.0E-03 1.1E-03 1.2E-03

Inverse Temperature (1/K)

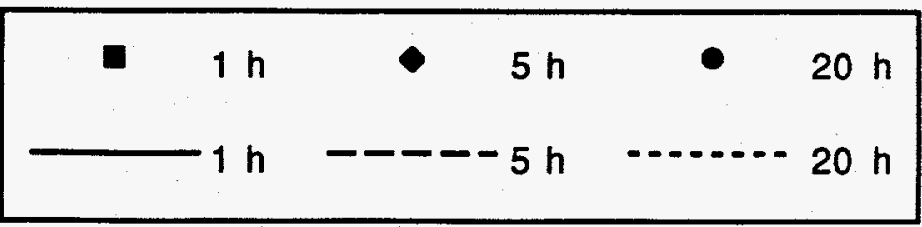

Figure 57. $\mathrm{Nb}$ mobility from $\mathrm{Nb}$ alloy exposed to air
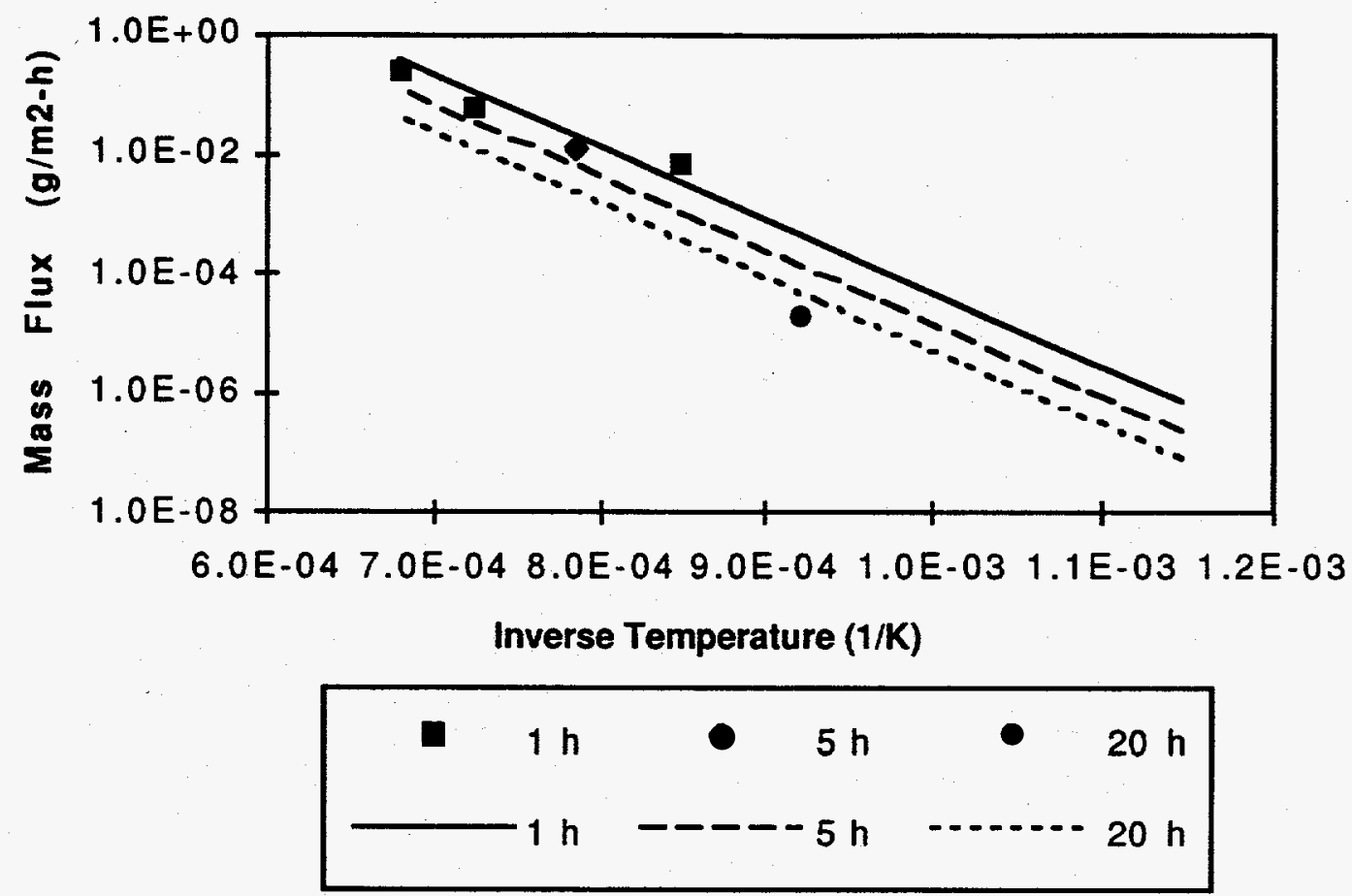

Figure 58. Mo mobility from $\mathrm{Nb}$ alloy exposed to steam 

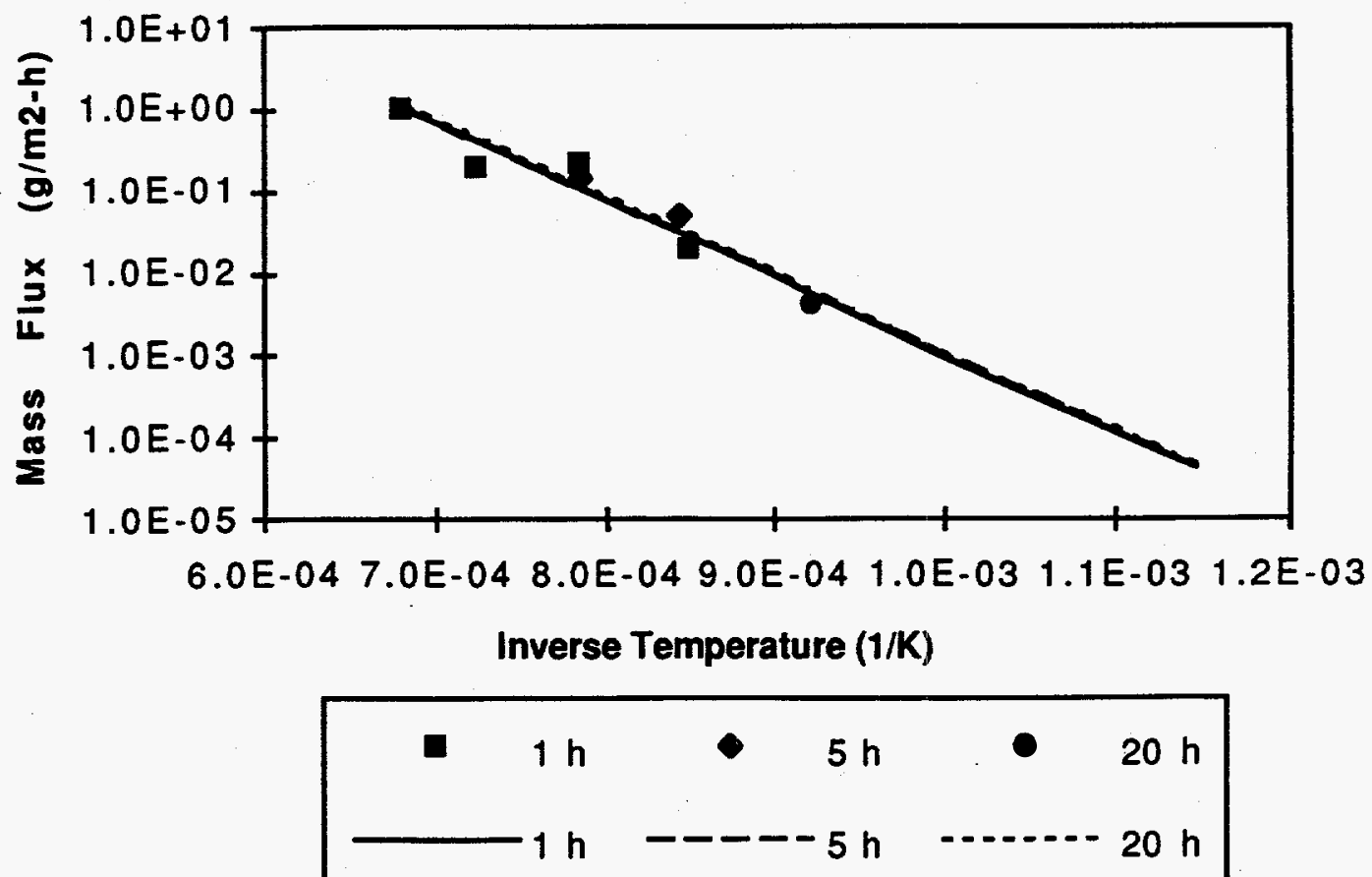

Figure 59. $\mathrm{Nb}$ mobility from $\mathrm{Nb}$ alloy exposed to steam

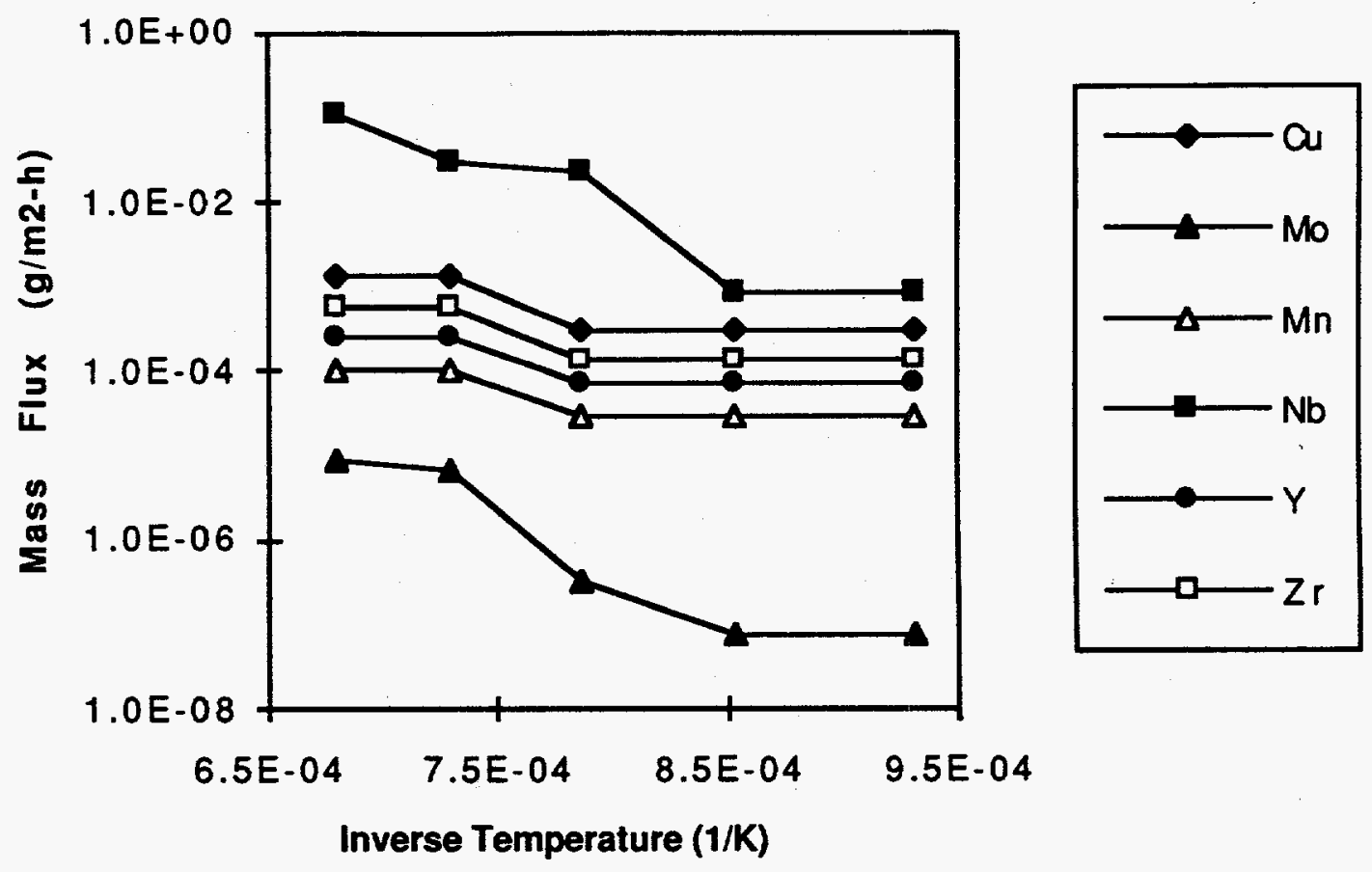

Figure 60. Cumulative maximum mobility of elements from niobium alloy exposed to air 


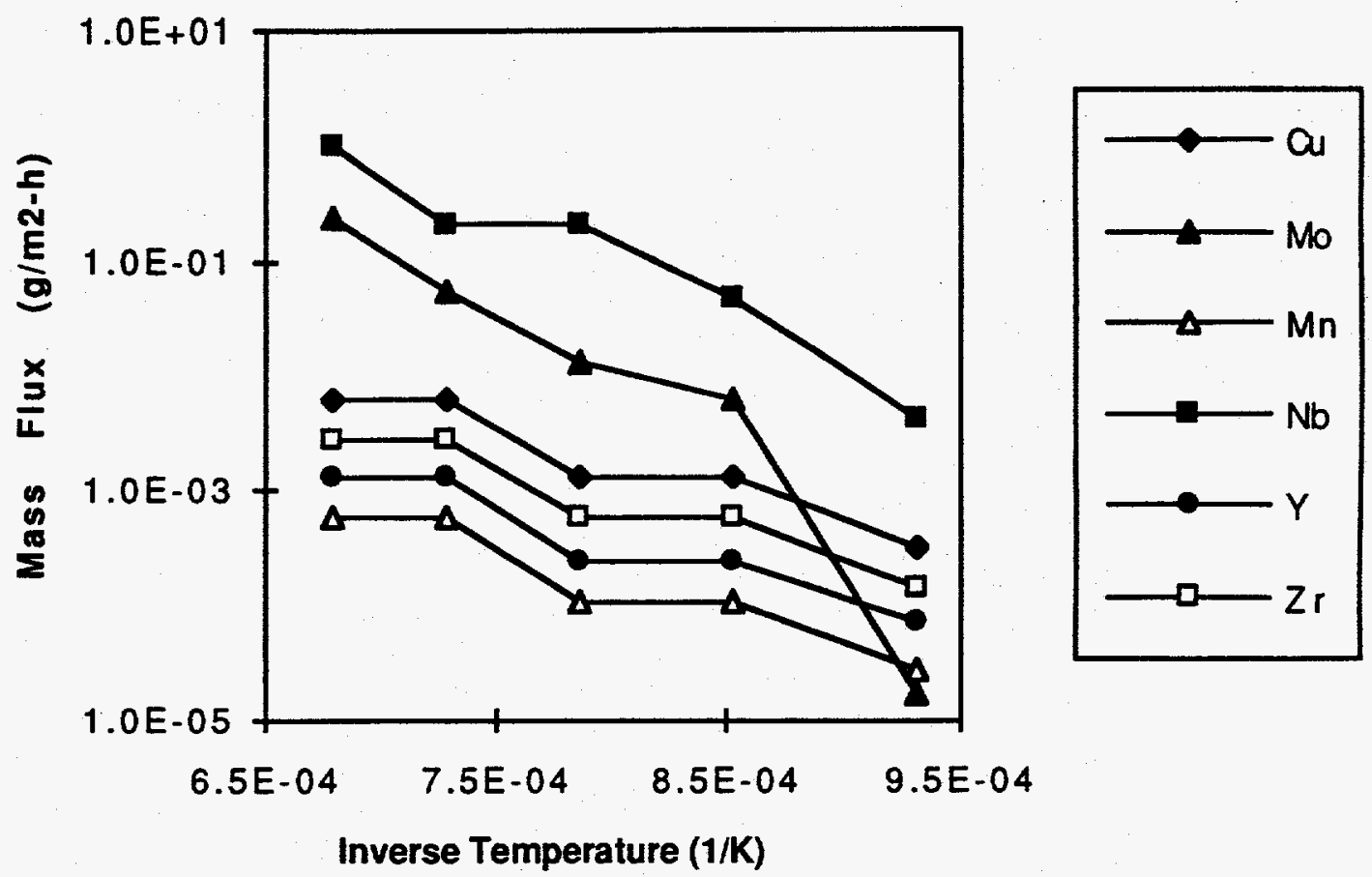

Figure 61. Cumulative maximum mobility of elements from niobium alloy exposed to steam

\subsection{Tungsten}

We have tested two different forms of tungsten: a fully dense tungsten alloy, and plasmasprayed pure tungsten. Table 17 gives the composition of the tungsten alloy. Table 18 gives the test matrix for both the alloy and pure tungsten tests. The temperature span in the tests, $600-1200^{\circ} \mathrm{C}$ is adequate for input to an ESECS (however, $\mathrm{W}$ is not currently planned for use in the ITER EDA design). Information around $400^{\circ} \mathrm{C}$, either through experiments or modeling, may be desirable for a PSAR. Details about these tests can be found in Smolik, et. al (1989), Smolik et. al (1991b), and Smolik (1992b). ${ }^{9}$

For the $\mathrm{W}$ alloy in air, only $\mathrm{W}$ and Re were measured above detection limits in more than a few experiments. The regression coefficients for the curve fits to data in air are given in Table 19. The regression coefficients for the curve fits for $\mathrm{W}, \mathrm{Re}, \mathrm{Mn}, \mathrm{Fe}, \mathrm{Co}, \mathrm{Ni}, \mathrm{Cu}$, and Ta mobility in steam are given in Table 20. The data in air are plotted in Figures 62 and 63 , and the data in steam are plotted in Figures 64 through 71 . These were exploratory tests, therefore a relatively small number of tests were done. The mobility of

9 G.R. Smolik, "Oxidation Behavior of Vacuum Plasma Sprayed Tungsten in Steam," ITER/US/92/TE/SA-24, November 23, 1992. 
the elements from the tungsten alloy in air is plotted in Figure 72, and the mobility in steam is plotted in Figure 73.

The IBEED (see Section 4) is dominated by W, with about 3\% coming from Ta and about $1 \%$ from $\mathrm{Re}$. In air-ingress accidents, $\mathrm{W}, \mathrm{Ta}, \mathrm{Re}$, and $\mathrm{Hf}$ contribute more than $1 \%$ to the MBEED. In water-ingress accidents, W, Hf, and Ta contribute more than $1 \%$ to the MBEED. We will concentrate on these elements in our assessment of the data. (The activation information that we had access to was not as detailed as was used for other alloys, thus there may be some elements that contribute slightly above $1 \%$ that are not listed here.)

More data are needed to adequately evaluate the curve fits for $\mathrm{W}$ and $\operatorname{Re}$ in air, particularly at lower temperatures. Initial indications for W (Figure 62) are that two lines would fit the data better. The maximum Ta mobility fraction occurred during a one hour test at $800^{\circ} \mathrm{C}$. Using the cumulative maximum of the data means this fraction is used for all temperatures. More tests are necessary to determine whether this data point is valid, or whether it should be discarded. We did not measure Hf, but based on release fractions from Piet, et. al (1989b), it is significant at low temperatures. W is not likely to be used in U.S. commercial reactors if a lower-activation alternative is available. W is not currently identified for the ITER EDA design, however should that change, further tests in air would be required to satisfy a PSAR; adequate data exists for the ESECS. Measurement of $\mathrm{W}, \mathrm{Re}, \mathrm{Ta}$, and $\mathrm{Hf}$ mobility would be necessary. Additional activation calculations are necessary to determine whether other elements must be considered in addition to $\mathrm{W}, \mathrm{Re}, \mathrm{Ta}$, and $\mathrm{Hf}$.

The curve fits to the volatility data in steam show very good correlation with correlation coefficients ranging from 0.83 to 0.99 . W is quite volatile in steam, significantly dominating the MBEED. The curve fits indicate that volatility, rather than spalling is the source of the mobile material. There is very little spread in any of the data. We did not measure Hf mobility, and should $\mathrm{W}$ be identified as an ITER material, this would be necessary. Additional activation calculations should be done to further evaluate the need for this data. Existing data is adequate for the ESECS, however further tests would be necessary for a PSAR.

\begin{tabular}{|c|c|c|c|c|c|c|c|c|}
\hline $\mathrm{Co}$ & $\mathrm{Cu}$ & $\mathrm{Fe}$ & $\mathrm{Mn}$ & $\mathrm{Ni}$ & $\mathrm{Os}$ & $\mathrm{Re}$ & $\mathrm{Ta}$ & $\mathrm{W}$ \\
\hline 0.55 & 0.05 & 1.0 & 0.05 & 2.3 & 0.06 & 1.1 & 0.15 & 95 \\
\hline
\end{tabular}

Table 17. Tungsten alloy composition, wt.\% 


\begin{tabular}{|c|c|c|c|c|c|c|}
\hline Form/Test & \multicolumn{7}{|c|}{ Temperature $\left({ }^{\circ} \mathrm{C}\right)$} \\
\cline { 2 - 7 } Environment & $\mathbf{6 0 0}$ & $\mathbf{8 0 0}$ & $\mathbf{9 0 0}$ & $\mathbf{1 0 0 0}$ & $\mathbf{1 1 0 0}$ & $\mathbf{1 2 0 0}$ \\
\hline alloy/air & $\mathrm{x}$ & $\mathrm{x}$ & & $\mathrm{x}$ & & $\mathrm{x}$ \\
\hline alloy/steam & $\mathrm{x}$ & $\mathrm{x}$ & & $\mathrm{x}$ & & $\mathrm{x}$ \\
\hline sprayed/steam & & $\mathrm{x}$ & $\mathrm{x}$ & $\mathrm{x}$ & $\mathrm{x}$ & $\mathrm{x}$ \\
\hline
\end{tabular}

Table 18. Tungsten alloy test matrix

\begin{tabular}{|c|c|c|c|c|}
\hline Element & $\mathbf{A}\left(\mathbf{g} / \mathbf{m}^{2}-\mathbf{h}\right)$ & $\mathbf{B}$ & $\mathbf{C}(\mathbf{J} / \mathbf{m o l e})$ & $\mathbf{r}^{2}$ \\
\hline$W$ & $6.21 \mathrm{E}+02$ & $-1.13 \mathrm{E}+00$ & $6.70 \mathrm{E}+04$ & 0.66 \\
\hline $\operatorname{Re}$ & $1.61 \mathrm{E}+04$ & $-5.73 \mathrm{E}-01$ & $7.69 \mathrm{E}+04$ & 0.85 \\
\hline
\end{tabular}

Table 19. Regression coefficients for $W$ alloy mobility in air

\begin{tabular}{|c|c|c|c|c|}
\hline Element & $\mathbf{A}\left(\mathbf{g} / \mathbf{m}^{2}-\mathbf{h}\right)$ & $\mathbf{B}$ & $\mathbf{C}(\mathrm{J} / \mathbf{m o l e})$ & $\mathbf{r}^{\mathbf{2}}$ \\
\hline $\mathrm{W}$ & $3.97 \mathrm{E}+07$ & $-5.52 \mathrm{E}-01$ & $1.28 \mathrm{E}+05$ & 0.99 \\
\hline $\mathrm{Re}$ & $1.76 \mathrm{E}+05$ & $2.00 \mathrm{E}-01$ & $1.39 \mathrm{E}+05$ & 0.89 \\
\hline $\mathrm{Mn}$ & $4.57 \mathrm{E}+00$ & $-8.39 \mathrm{E}-01$ & $6.59 \mathrm{E}+04$ & 0.96 \\
\hline $\mathrm{Fe}$ & $5.91 \mathrm{E}+00$ & $-7.47 \mathrm{E}-01$ & $4.95 \mathrm{E}+04$ & 0.83 \\
\hline $\mathrm{Co}$ & $1.23 \mathrm{E}+05$ & $-5.69 \mathrm{E}-01$ & $1.24 \mathrm{E}+05$ & 0.99 \\
\hline $\mathrm{Ni}$ & $3.38 \mathrm{E}+03$ & $-7.09 \mathrm{E}-01$ & $8.83 \mathrm{E}+04$ & 0.97 \\
\hline $\mathrm{Cu}$ & $3.56 \mathrm{E}+01$ & $-9.48 \mathrm{E}-01$ & $7.80 \mathrm{E}+04$ & 0.86 \\
\hline $\mathrm{Ta}$ & $3.92 \mathrm{E}+01$ & $-7.79 \mathrm{E}-01$ & $7.12 \mathrm{E}+04$ & 0.96 \\
\hline
\end{tabular}

Table 20. Regression coefficients for $\mathrm{W}$ alloy mobility in steam 

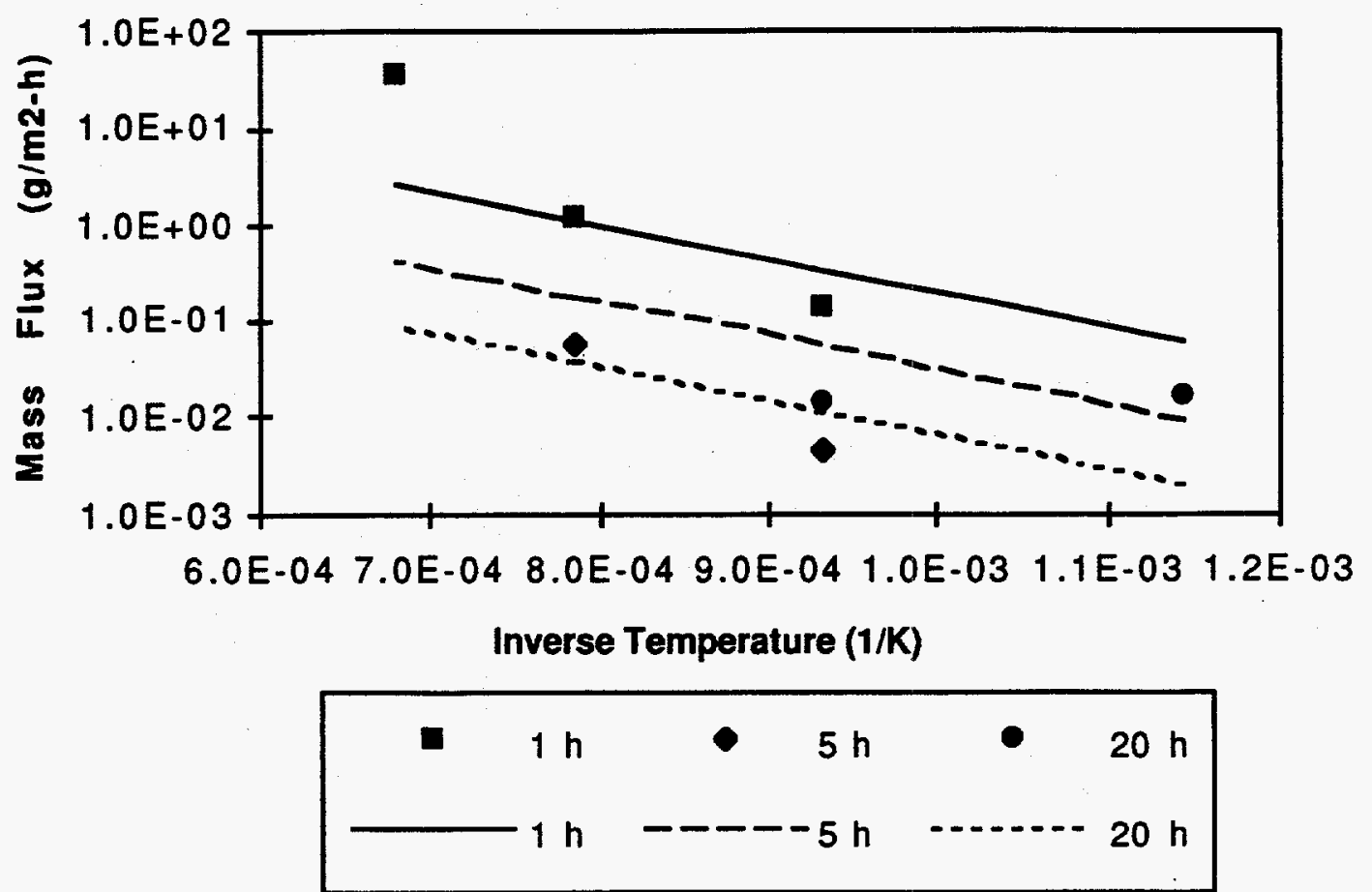

Figure 62. W mobility from $\mathrm{W}$ alloy exposed to air

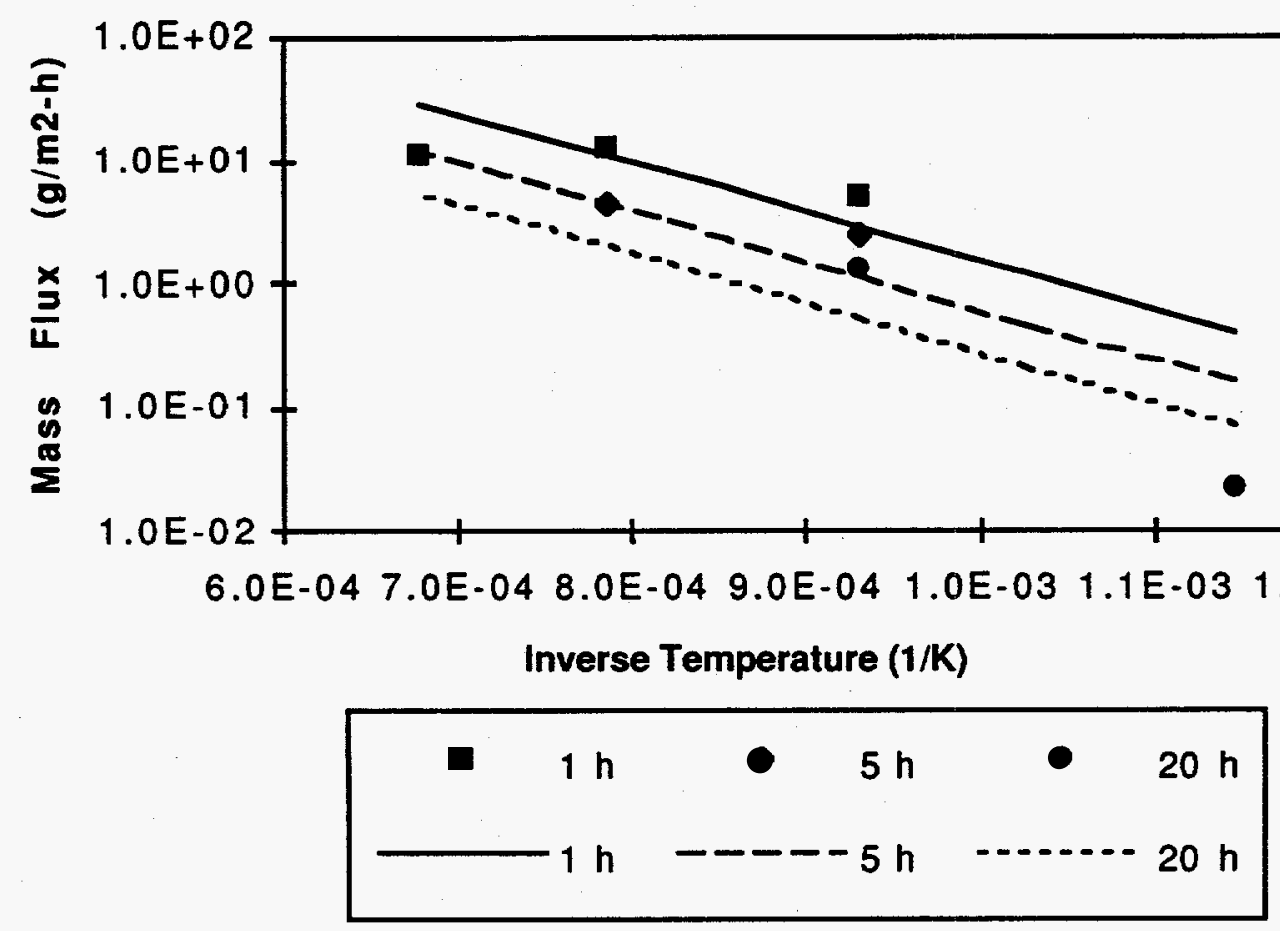

Figure 63. Re mobility from $\mathrm{W}$ alloy exposed to air 


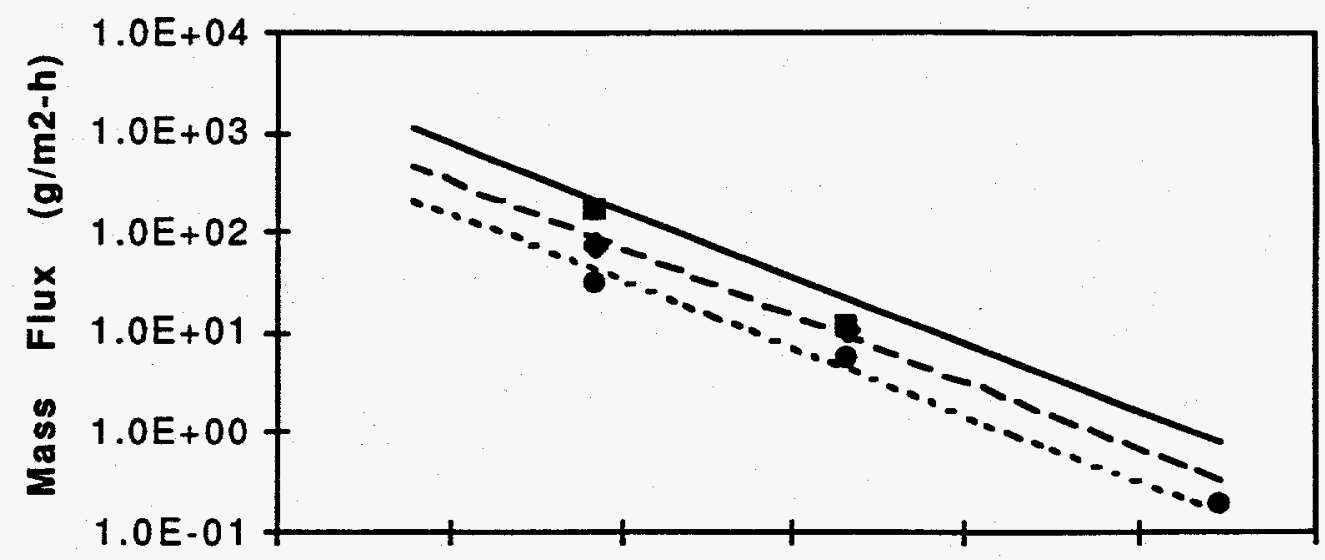

6.0E-04 7.0E-04 8.0E-04 9.0E-04 1.0E-03 1.1E-03 1.2E-03 Inverse Temperature (1/K)

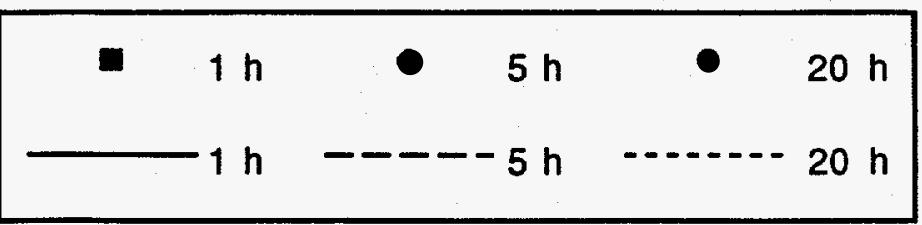

Figure 64. W mobility from $\mathrm{W}$ alloy exposed to steam
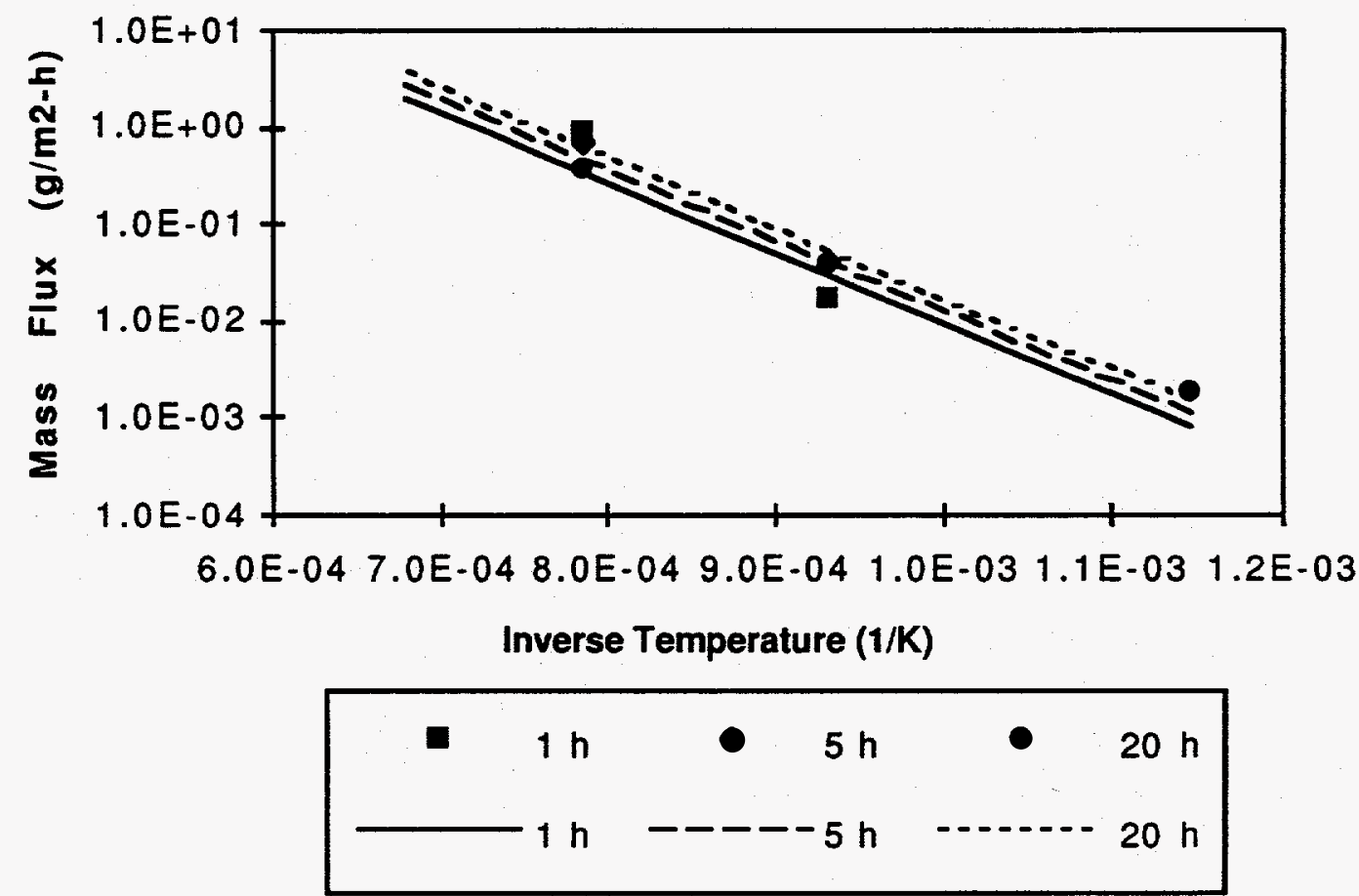

Figure 65. Re mobility from W alloy exposed to steam 

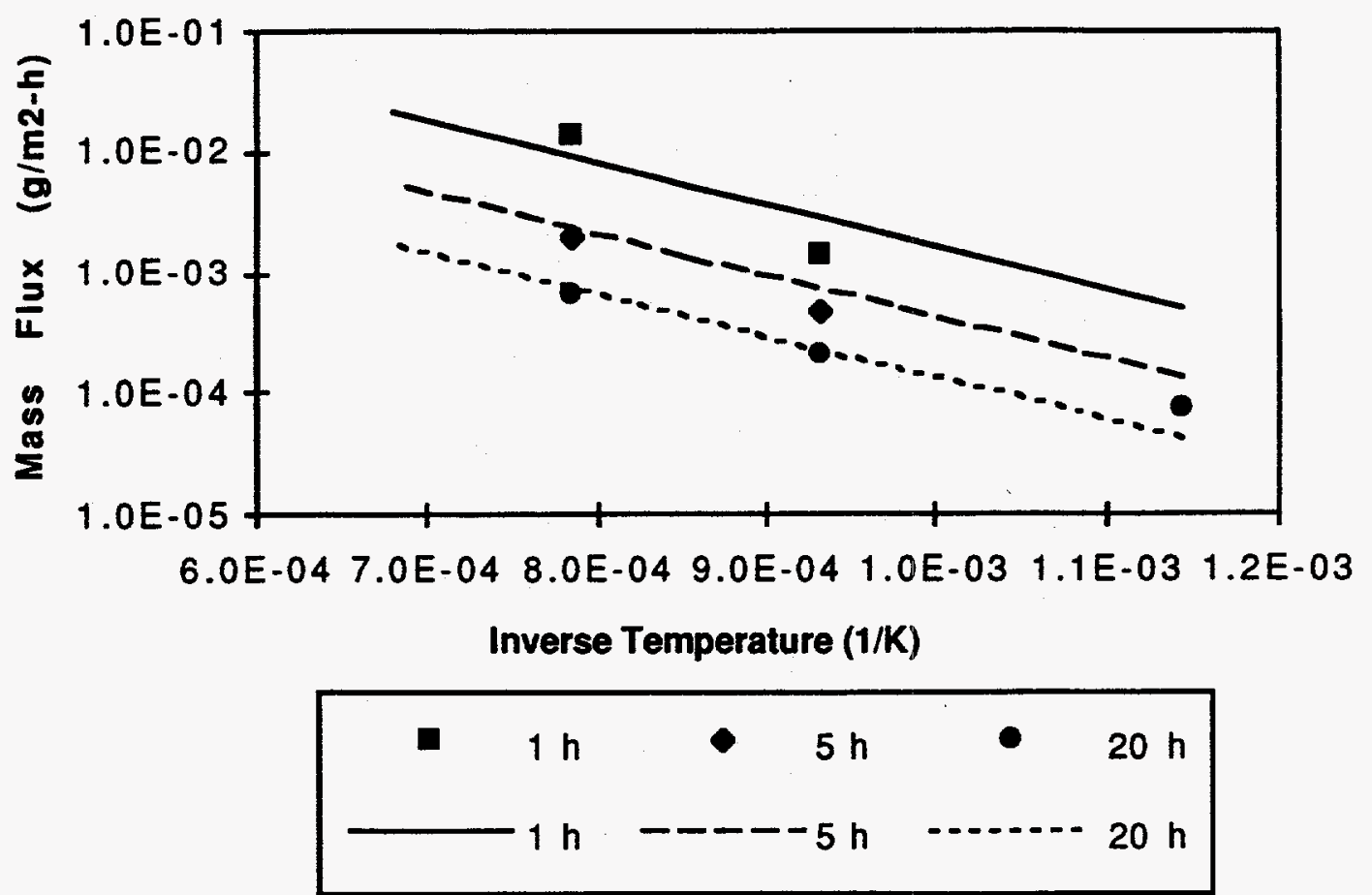

Figure 66. Mn mobility from W alloy exposed to steam

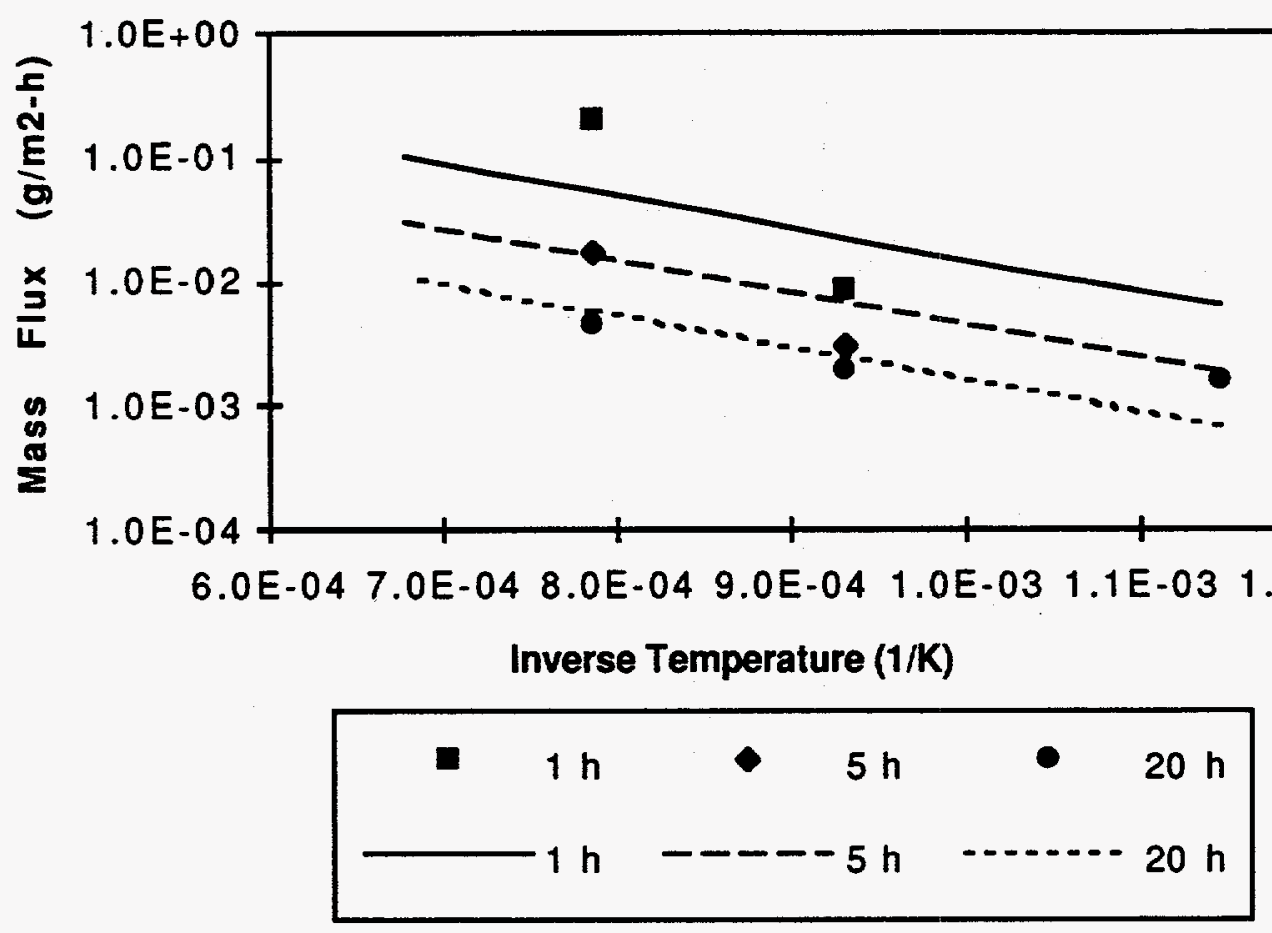

Figure 67. Fe mobility from $\mathrm{W}$ alloy exposed to steam 

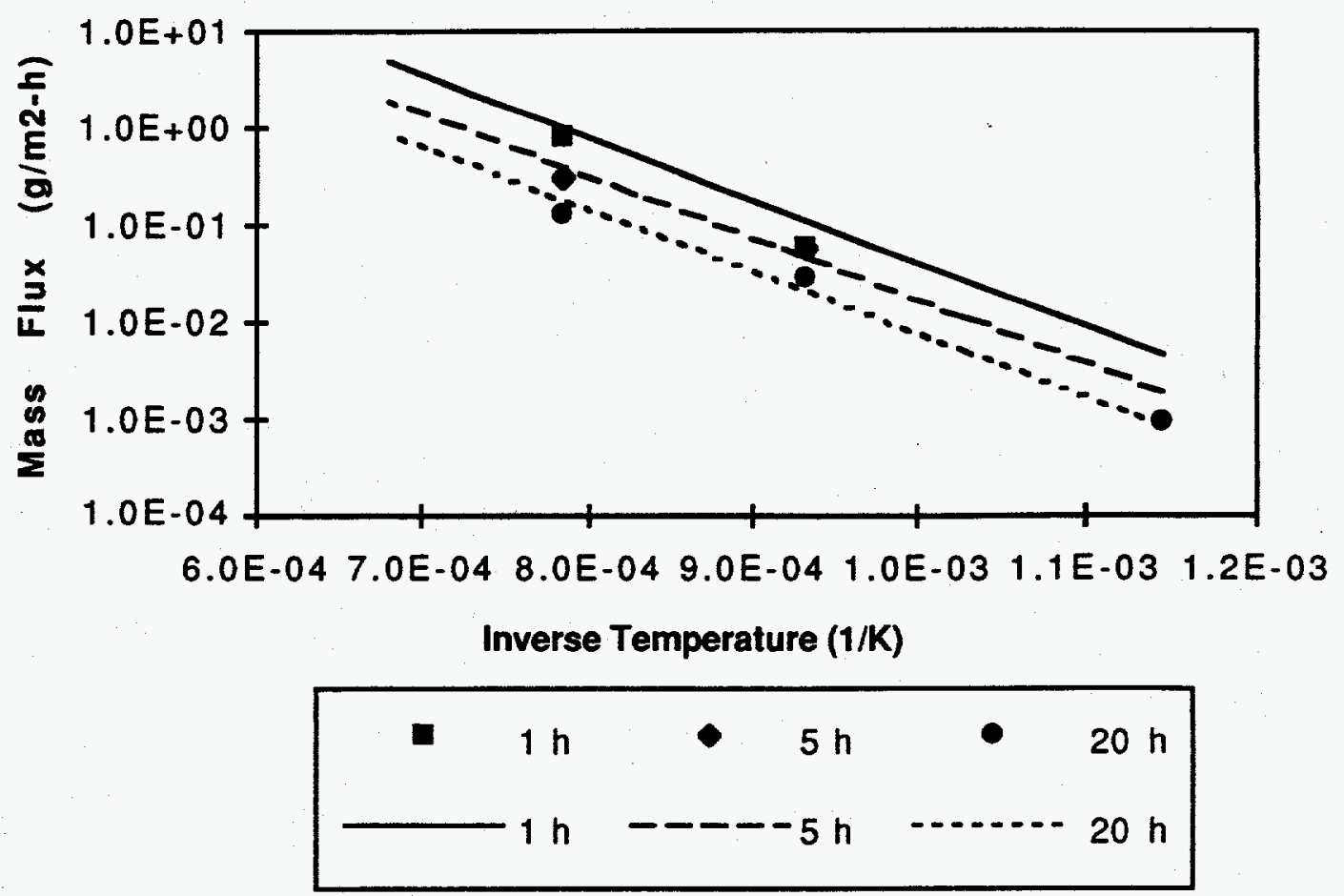

Figure 68. Co mobility from $\mathrm{W}$ alloy exposed to steam

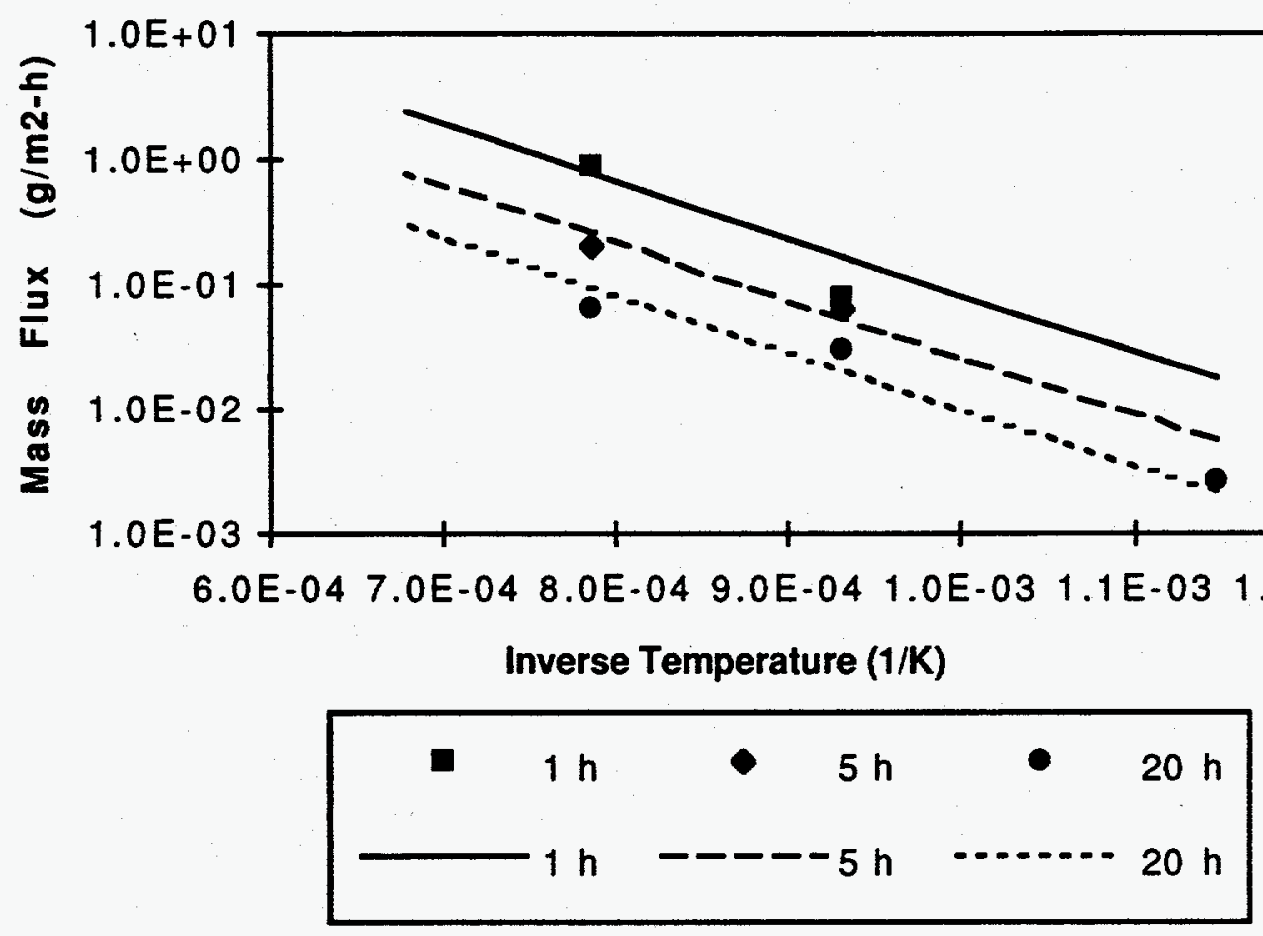

Figure 69. Ni mobility from $\mathrm{W}$ alloy exposed to steam 


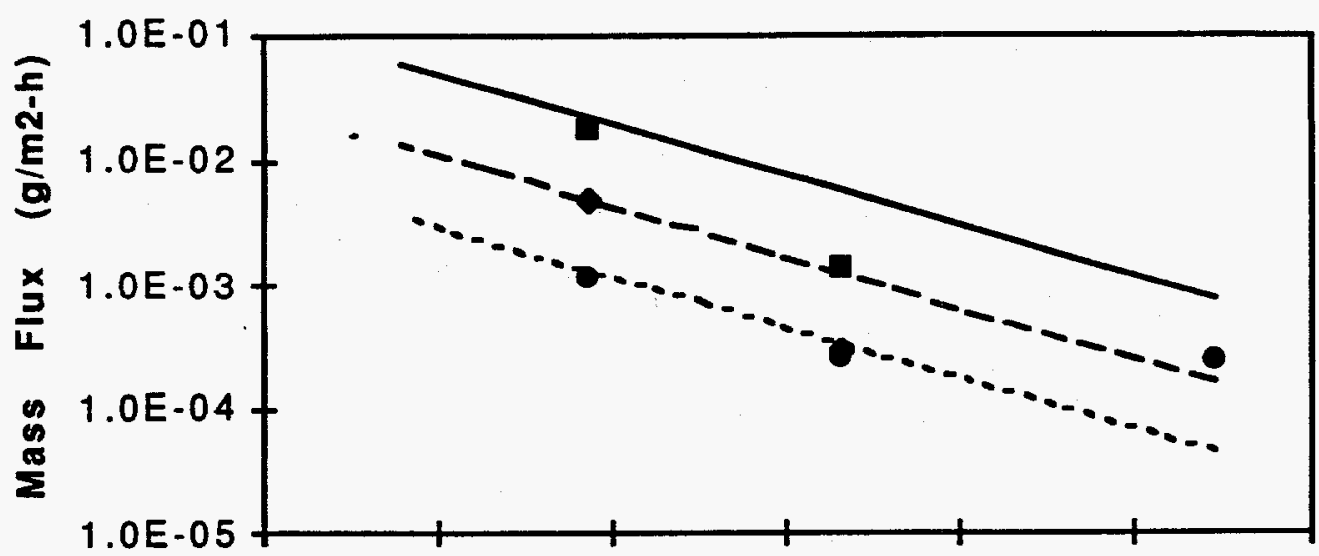

6.0E-04 7.0E-04 8.0E-04 9.0E-04 1.0E-03 1.1E-03 1.2E-03 Inverse Temperature (1/K)

\begin{tabular}{rrrrr}
\hline $1 h$ & 0 & $5 h$ & 0 & $20 h$ \\
\hline $1 h$ & $----5 h$ & $\ldots$ & -5 & $20 h$ \\
\hline
\end{tabular}

Figure 70. Cu mobility from $\mathrm{W}$ alloy exposed to steam

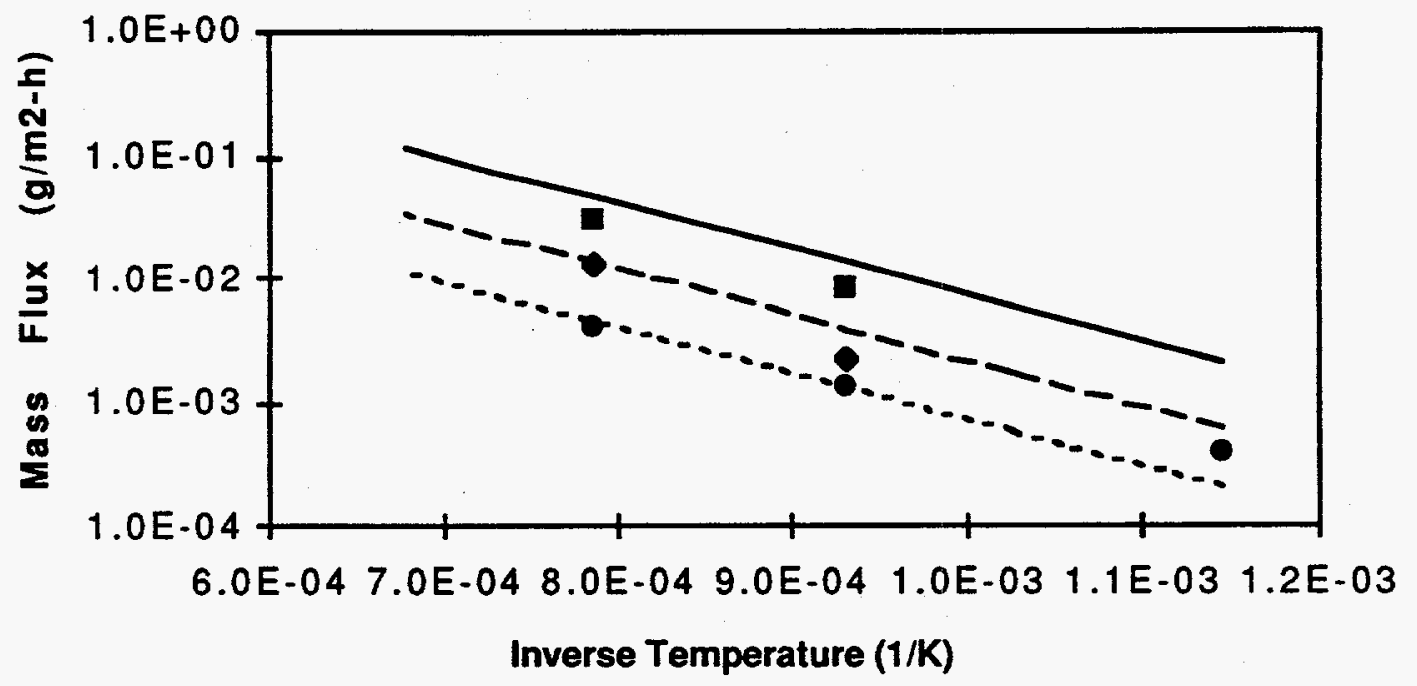

\begin{tabular}{rrrrr}
\hline $1 h$ & 0 & $5 h$ & 0 & $20 h$ \\
$1 h$ & $----5 h$ & - & - & $-20 h$ \\
\hline
\end{tabular}

Figure 71. Ta mobility from $\mathrm{W}$ alloy exposed to steam 

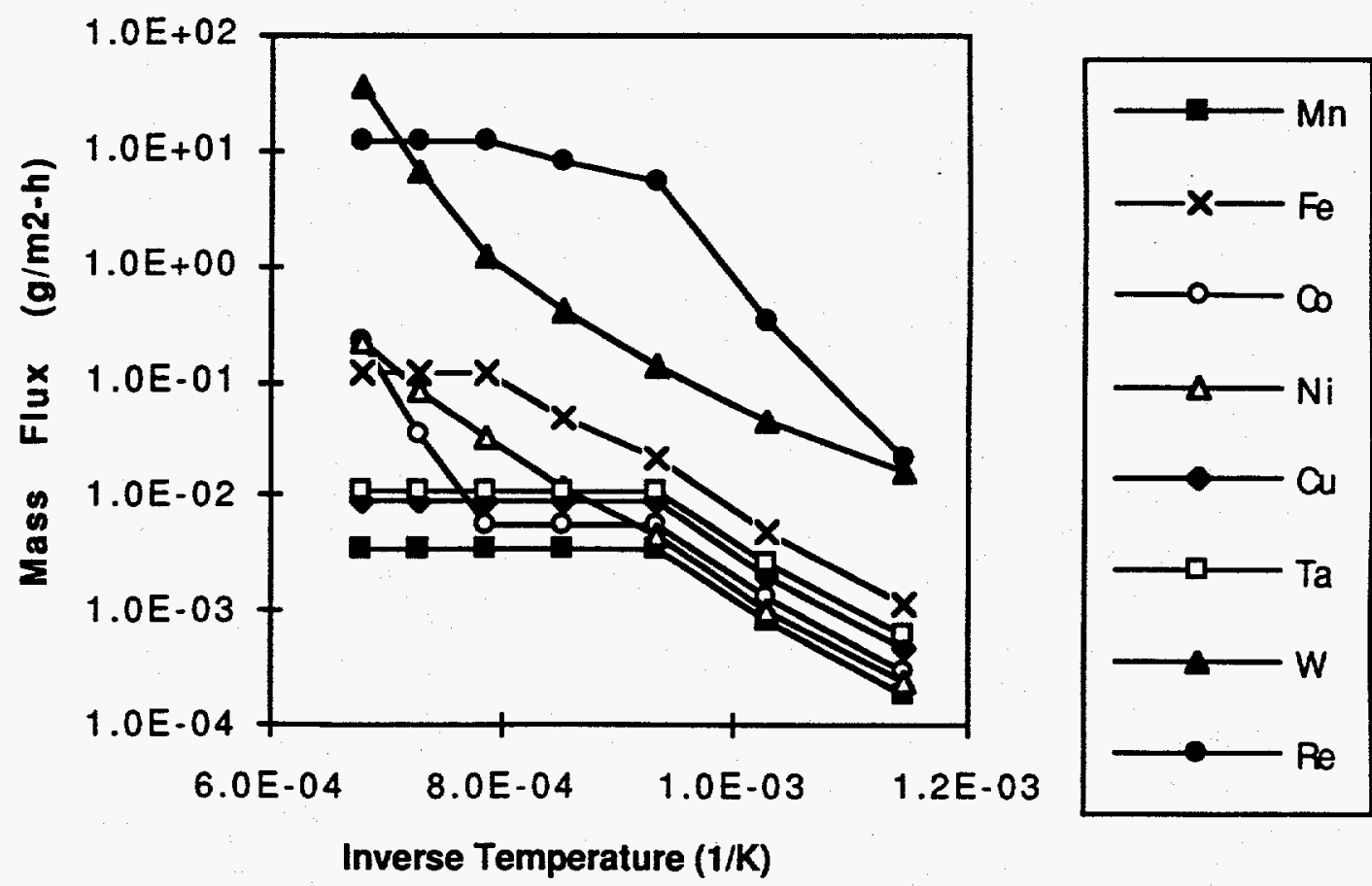

Figure 72. Cumulative maximum mobility of elements from tungsten alloy exposed to air
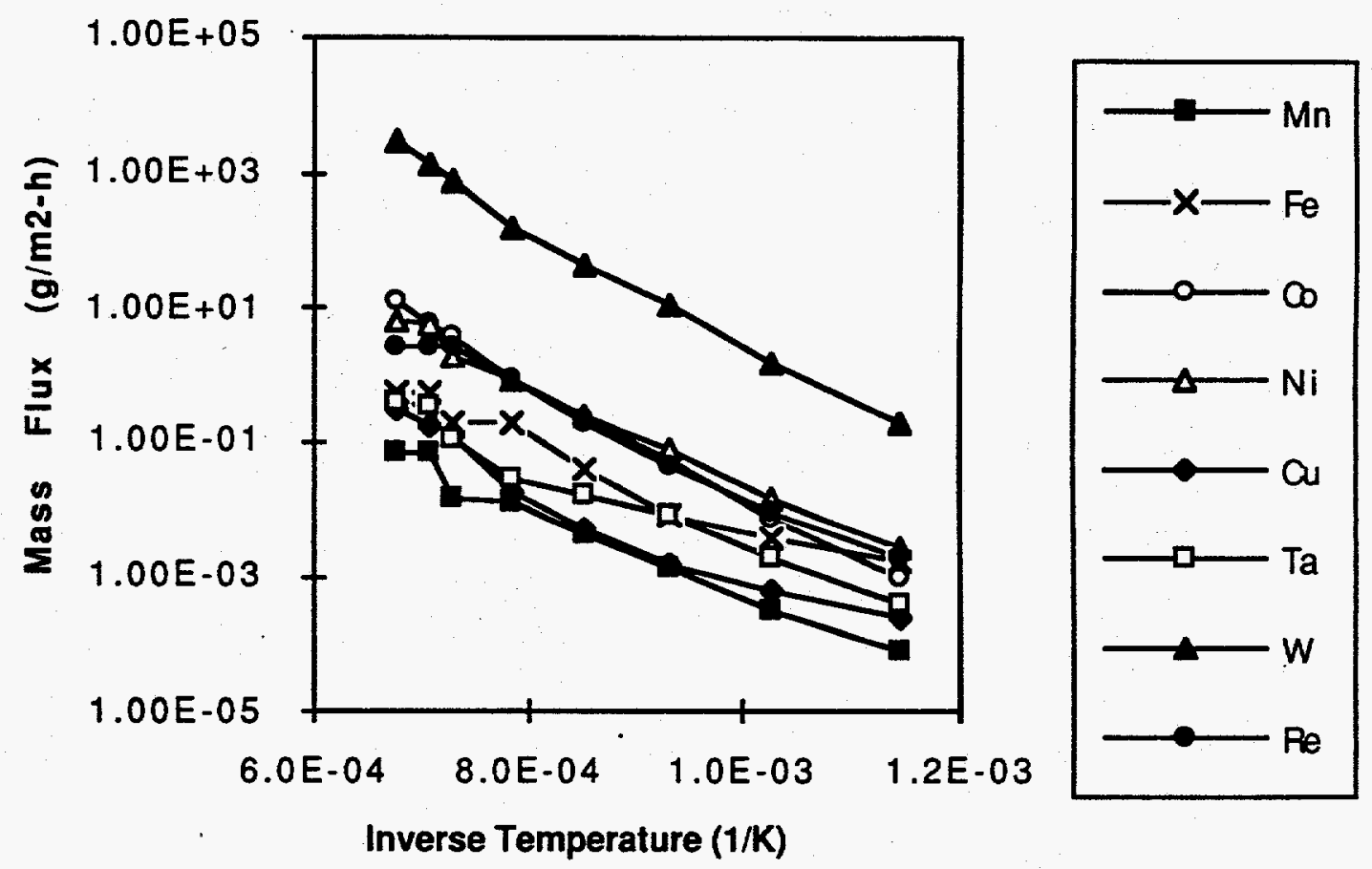

Figure 73. Cumulative maximum mobility of elements from tungsten alloy exposed to steam 


\subsection{Vanadium}

We have tested two basic $\mathrm{V}$ alloys, $\mathrm{V}-15 \mathrm{Cr}-5 \mathrm{Ti}$, and $\mathrm{V}-5 \mathrm{Cr}-5 \mathrm{Ti}$. Table 21 shows the various compositions we have tested. Table 22 gives the test matrix for the tests. The temperature span in the tests, $600-1600^{\circ} \mathrm{C}$ is adequate for input to the ITER ESECS, however information around $400^{\circ} \mathrm{C}$, either through experiments or modeling, may be desirable for a PSAR. Details about these tests can be found in Henslee (1984) and Neilson (1986). 10

We attempted curve fits for the mobility of $\mathrm{Ca}, \mathrm{Sc}, \mathrm{Mn}, \mathrm{V}, \mathrm{Cr}$, and $\mathrm{Ti}$ in air. The regression coefficients for these curve fits are given in Table 23. Notice that these curve fits included the effect of composition (Equation 2 in Section 2 and Equation 6 in Section 4) since the weight percent of $\mathrm{Ca}, \mathrm{Sc}$, and $\mathrm{Mn}$ in the $\mathrm{V}$ alloy varied by an order of magnitude. The plots of the data appear in Figures 74 through 78 . We attempted curve fits in steam for V, Cr, and Ti; there were not enough data for the other elements. The regression coefficients for curve fits in steam are given in Table 24. These curve fits did not include a composition factor because only one alloy composition was tested in steam. The plots of the data in steam appear in Figures 84 through 86 . The cumulative maximum mobility in air and steam is shown in Figures 87 and 88, respectively.

The IBEED (see Section 4) is dominated by $\mathrm{Sc}$ and $\mathrm{Cr}$, all other elements contributing less than $1 \%$ to the total dose. Sc, $\mathrm{Ca}, \mathrm{Na}$, dominate the MBEED, with $\mathrm{Ho}$, and $\mathrm{Nb}$ contributing between 1 and 5\% in air and water-ingress accidents, depending on the temperature (we have not measured mobilization of $\mathrm{Ho}$ and $\mathrm{Nb}$, and have used default release fractions developed by Piet et. al (July, 1989b), as explained in Section 3.3.1). We will concentrate on $\mathrm{Sc}, \mathrm{Cr}, \mathrm{Ca}$, and $\mathrm{Na}$ because they contribute the most to the early dose.

There were only five data points of Sc mobility in air above detection limits (Figure 74 one .5-hour and one 2 hour test are not plotted). The data plotted correspond to Alloy b, the alloy containing the largest amount of Sc. The regression resulted in a correlation coefficient of 0.99 , however because the regression was done with so few points, this is rather misleading. Further tests are necessary to determine whether the curve fit is valid. The Ca data are plotted in Figures 75 and 76 . Figure 75 gives the data and curve fits for 5 -hour tests, and Figure 76 for 20 -hour tests. We have plotted each composition separately, along with a separate curve fit (the composition effect can change the mobility by almost an order of magnitude). There is a considerable amount of scatter in the data as indicated by the regression coefficient of 0.55 . Ca mobility is particularly difficult to

10 G.R. Smolik and K.A. McCarthy, "Volatility Measurements from Vanadium Alloys in Air," ITER/US/93/TE/SA-13, September 30, 1993. 
measure because $\mathrm{Ca}$ contamination can be present in glassware and reagents. We believe that many of our high measurements may be due to contamination. We believe one data point from a 5 hour test and one from a 20 hour test are obviously due to contamination. These are plotted in Figures 75 and 76, however they were not used in the regression analysis. Further data validation may indicate that more points can be attributed to contamination, lowering the $\mathrm{Ca}$ mobility fraction. Data from recent tests are under evaluation. $\mathrm{Cr}$ mobility in air is plotted in Figures 81 and 82. There is quite a bit of scatter in the data. We believe some of the larger measurements may be due to contamination, however we have used all points in the regression analysis. The mobility fractions using the cumulative maximum data points are low enough that $\mathrm{Cr}$ does not contribute more than $1 \%$ to the early dose.

We have not measured $\mathrm{Na}$ mobility from $\mathrm{V}$. As with $\mathrm{Ca}, \mathrm{Na}$ is present in the glassware and reagents used in the experiments. We have recently modeled $\mathrm{Na}$ volatility from $\mathrm{V}$ alloy, 11 and the results show that Na mobilization is orders of magnitude lower than the release fraction developed by Piet et. al (July, 1989b). We have used data from our tests in the dose calculations rather than the modeling results. Further evaluation of the modeling results will determine whether they should be used in place of the data.

Because V-5Cr-5Ti is the material specified in the back-up ITER EDA design, more testing is necessary. For the ESECS, more data are needed for Sc and $\mathrm{Ca}$. Data from modeling will be adequate for $\mathrm{Na}$. In particular, we will concentrate on determining what $\mathrm{Ca}$ data are the result of contamination, and what are due to mobilized mass.

We do not have any measurements of $\mathrm{Sc}$ or $\mathrm{Ca}$ mobility in steam above detection limits, thus detection limits were used in calculating the early dose. We did not measure $\mathrm{Na}$ mobility for the reasons given above. There were very few $\mathrm{Cr}$ data points above detection limits, but when mobility fractions are included, $\mathrm{Cr}$ does not contribute more than $1 \%$ to the early dose. If the ITER design were to use a water coolant (early designs indicated a water-cooled shield, however, the current ITER EDA backup design contains a $\mathrm{NaK}$-cooled shield), more data would be required on $\mathrm{V}$ alloy steam reactions. In particular, experiments should concentrate on Sc and $\mathrm{Ca}$ mobility.

11 D.L. Hagrman, "Volatility Models for Several ITER-Relevant Materials," ITER/94/US/TE/SA-15, September 13, 1994. 


\begin{tabular}{|c|c|c|c|c|c|c|}
\hline Alloy & $\mathrm{Ca}$ & $\mathrm{Cr}$ & $\mathrm{Sc}$ & $\mathrm{Ti}$ & $\mathrm{Mn}$ & $\mathrm{V}$ \\
\hline $\mathrm{a}$ & 0.10 & 15.80 & 0.03 & 5.00 & 0 & 79.10 \\
\hline $\mathrm{b}$ & 0.239 & 4.73 & 0.214 & 4.05 & 0.355 & 90.40 \\
\hline $\mathrm{c}$ & 0.054 & 4.76 & 0.042 & 4.12 & 0.077 & 90.95 \\
\hline $\mathrm{d}$ & 0.032 & 5.04 & 0.024 & 4.69 & 0.042 & 90.17 \\
\hline $\mathrm{e}$ & 0.016 & 15.80 & 0 & 5.00 & 0 & 79.10 \\
\hline $\mathrm{f}$ & 0 & 15.80 & 0.0265 & 5.00 & 0 & 79.10 \\
\hline $\mathrm{g}$ & 0 & 15.80 & 0.0344 & 5.00 & 0 & 79.10 \\
\hline
\end{tabular}

Table 21. Vanadium alloy composition, wt.\%

\begin{tabular}{|c|c|c|c|c|c|c|c|c|}
\hline Alloy/Test & \multicolumn{8}{|c|}{ Temperature $\left({ }^{\circ} \mathrm{C}\right)$} \\
\cline { 2 - 10 } Environment & $\mathbf{6 0 0}$ & $\mathbf{7 0 0}$ & $\mathbf{8 0 0}$ & $\mathbf{9 0 0}$ & $\mathbf{1 0 0 0}$ & $\mathbf{1 2 0 0}$ & $\mathbf{1 4 0 0}$ & $\mathbf{1 6 0 0}$ \\
\hline V-15Cr-5Ti/air & $\mathrm{x}$ & $\mathrm{x}$ & $\mathrm{x}$ & $\mathrm{x}$ & $\mathrm{x}$ & $\mathrm{x}$ & $\mathrm{x}$ & $\mathrm{x}$ \\
\hline V-15Cr-5Ti/steam & & & $\mathrm{x}$ & & $\mathrm{x}$ & $\mathrm{x}$ & & \\
\hline V-5Cr-5Ti/air & $\mathrm{x}$ & $\mathrm{x}$ & $\mathrm{x}$ & & $\mathrm{x}$ & $\mathrm{x}$ & & \\
\hline
\end{tabular}

Table 22. Vanadium alloy test matrix

\begin{tabular}{|c|c|c|c|c|c|}
\hline Element & $\mathbf{A}\left(\mathbf{g} / \mathbf{m}^{2}-\mathbf{h}\right)$ & $\mathbf{B}$ & $\mathbf{C}(\mathrm{J} / \mathbf{m o l e})$ & $\mathbf{D}$ & $\mathbf{r}^{2}$ \\
\hline $\mathrm{V}$ & $3.69 \mathrm{E}-08$ & $-1.14 \mathrm{E}+00$ & $8.92 \mathrm{E}+04$ & $5.66 \mathrm{E}+00$ & 0.78 \\
\hline $\mathrm{Cr}$ & $3.14 \mathrm{E}-01$ & $-9.27 \mathrm{E}-01$ & $3.91 \mathrm{E}+04$ & $3.65 \mathrm{E}-01$ & 0.67 \\
\hline $\mathrm{Ti}$ & $1.50 \mathrm{E}-04$ & $-9.11 \mathrm{E}-01$ & $8.83 \mathrm{E}+03$ & $2.56 \mathrm{E}+00$ & 0.71 \\
\hline $\mathrm{Ca}$ & $3.72 \mathrm{E}-03$ & $-9.33 \mathrm{E}-01$ & $3.73 \mathrm{E}+03$ & $-7.42 \mathrm{E}-01$ & 0.55 \\
\hline $\mathrm{Mn}$ & $7.73 \mathrm{E}-04$ & $-1.06 \mathrm{E}+00$ & $-5.66 \mathrm{E}+03$ & $3.68 \mathrm{E}-01$ & 0.79 \\
\hline $\mathrm{Sc}$ & $1.31 \mathrm{E}-03$ & $-9.37 \mathrm{E}-01$ & $1.26 \mathrm{E}+04$ & $2.99 \mathrm{E}-01$ & 0.99 \\
\hline
\end{tabular}

Table 23. Regression coefficients for $\mathrm{V}$ alloy mobility in air

\begin{tabular}{|c|c|c|c|c|}
\hline Element & $\mathbf{A}\left(\mathbf{g} / \mathbf{m}^{\mathbf{2}}-\mathbf{h}\right)$ & $\mathbf{B}$ & $\mathbf{C}(\mathbf{J} / \mathbf{m o l e})$ & $\mathbf{r}^{\mathbf{2}}$ \\
\hline $\mathrm{V}$ & $2.70 \mathrm{E}+02$ & $-1.36 \mathrm{E}-02$ & $1.12 \mathrm{E}+05$ & 0.74 \\
\hline $\mathrm{Cr}$ & $2.64 \mathrm{E}+00$ & $1.71 \mathrm{E}-01$ & $7.01 \mathrm{E}+04$ & 1.00 \\
\hline $\mathrm{Ti}$ & $7.07 \mathrm{E}-02$ & $-9.08 \mathrm{E}-01$ & $2.81 \mathrm{E}+04$ & 0.96 \\
\hline
\end{tabular}

Table 24. Regression coefficients for $\mathrm{V}$ alloy mobility in steam 


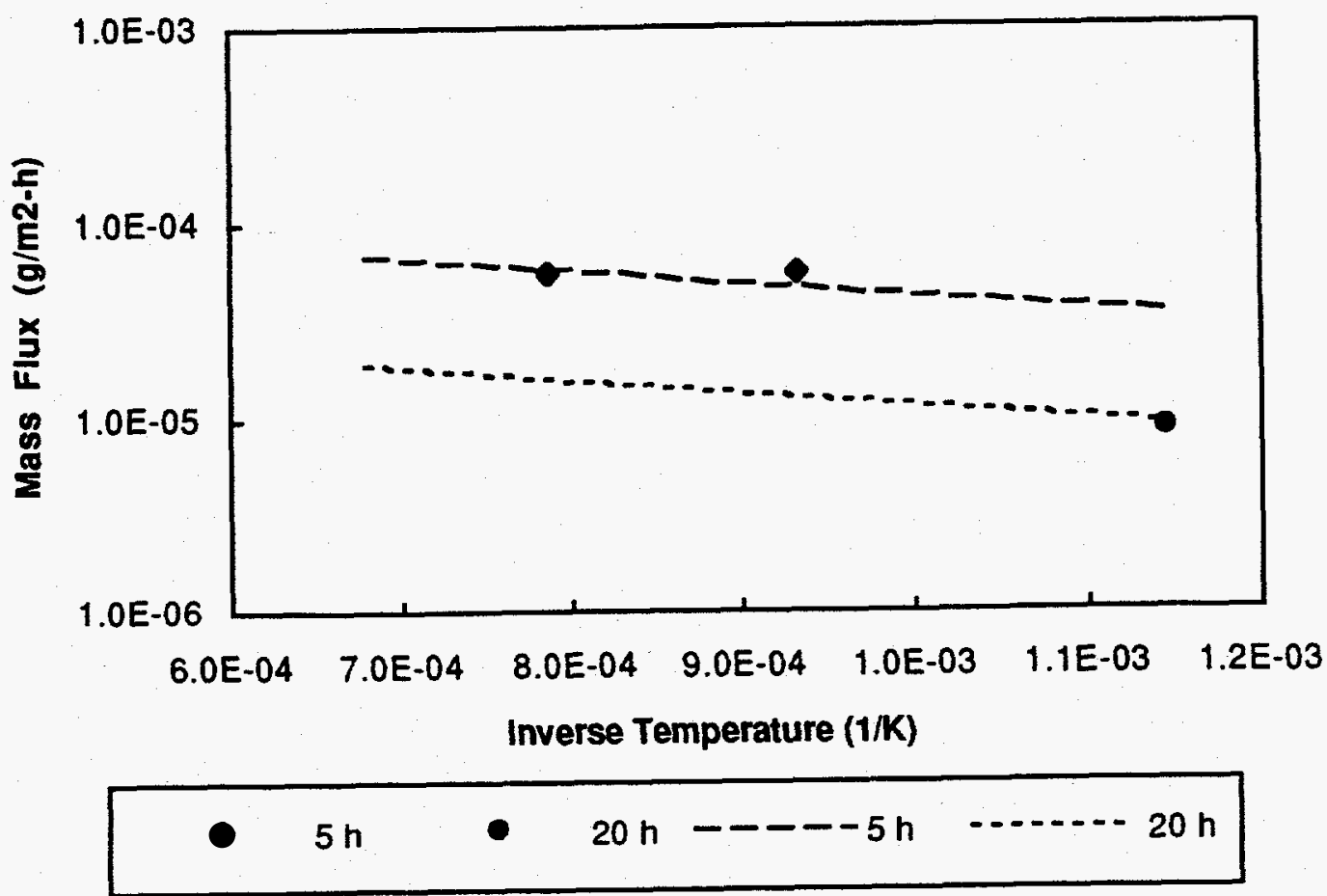

Figure 74. Sc mobility from $V$ alloy exposed to air
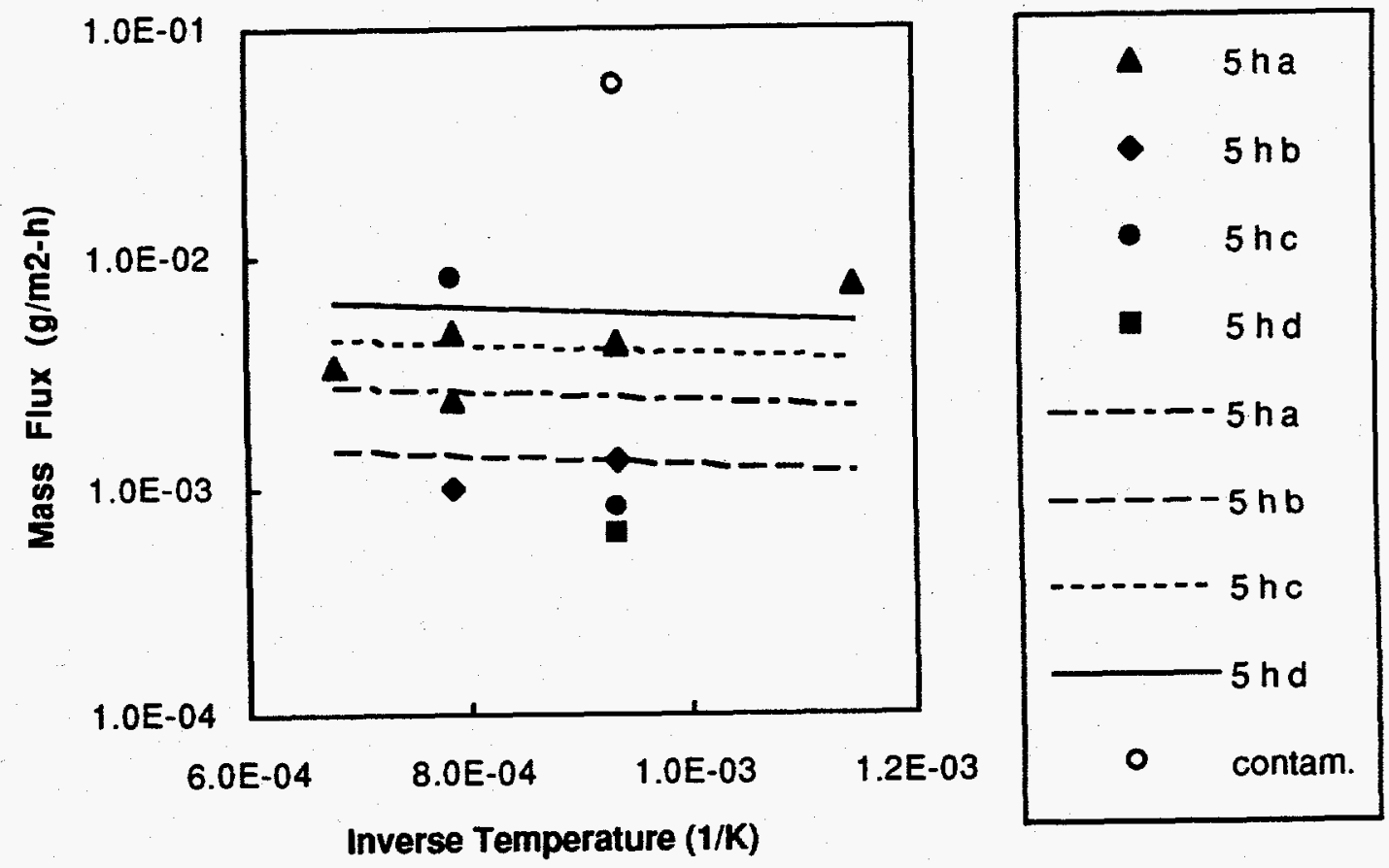

Figure 75. Ca mobility from $V$ alloy exposed to air; 5 hour tests 

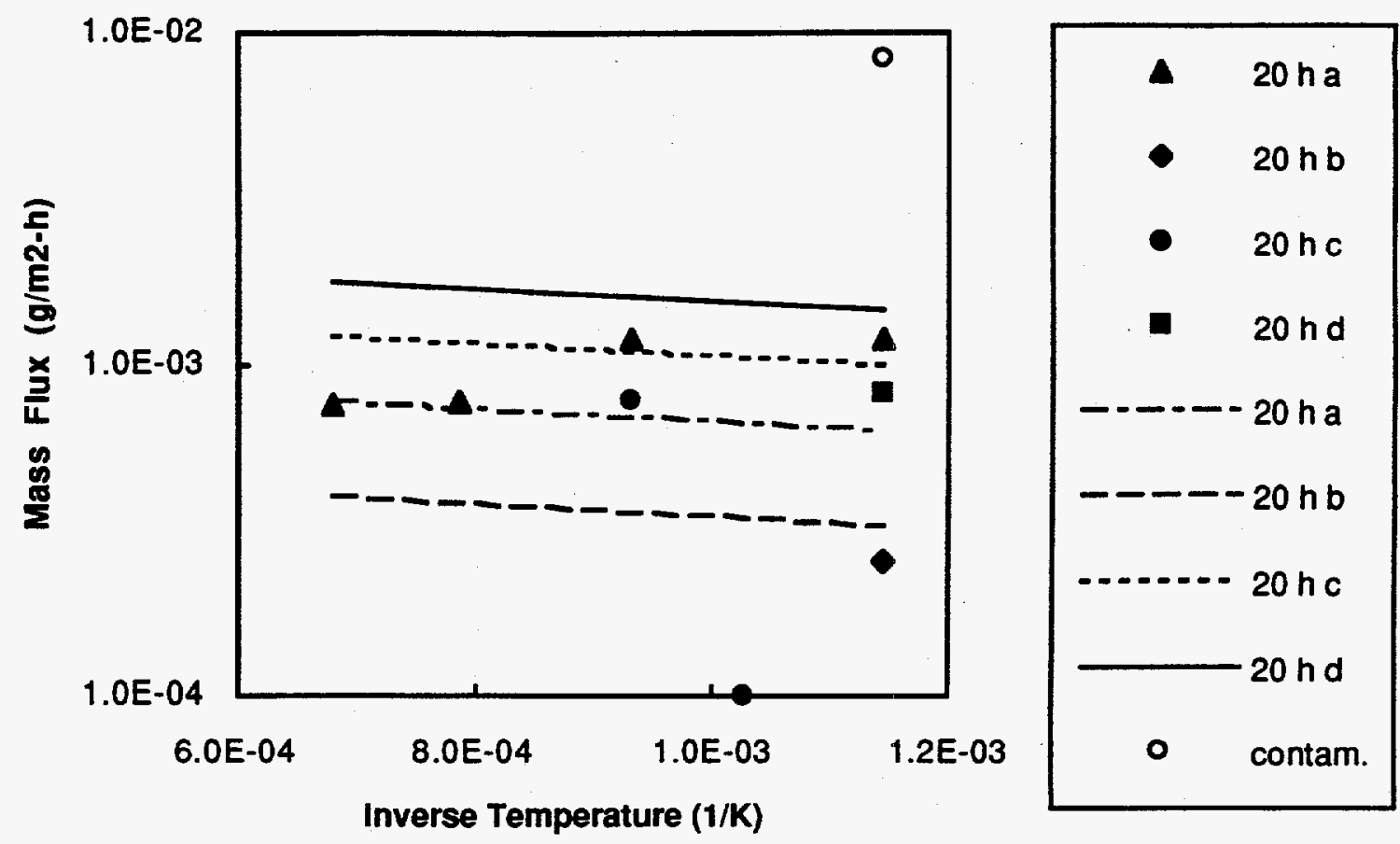

Figure 76. Ca mobility from $V$ alloy exposed to air; 20 hour tests

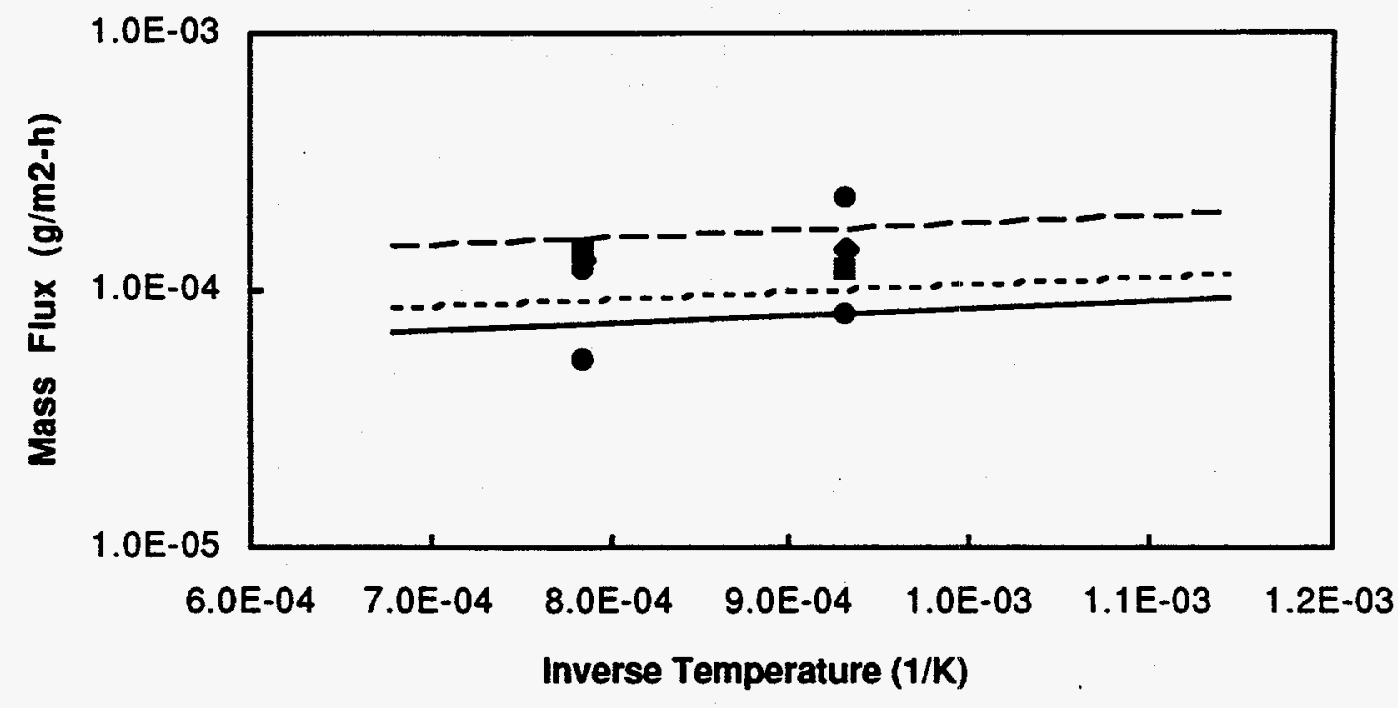

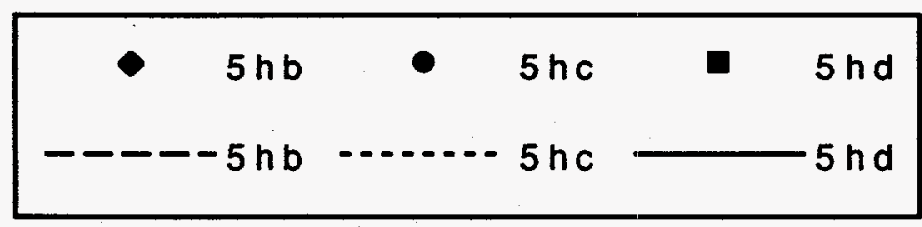

Figure 77. Mn mobility from $V$ alloy exposed to air; 5 hour tests 


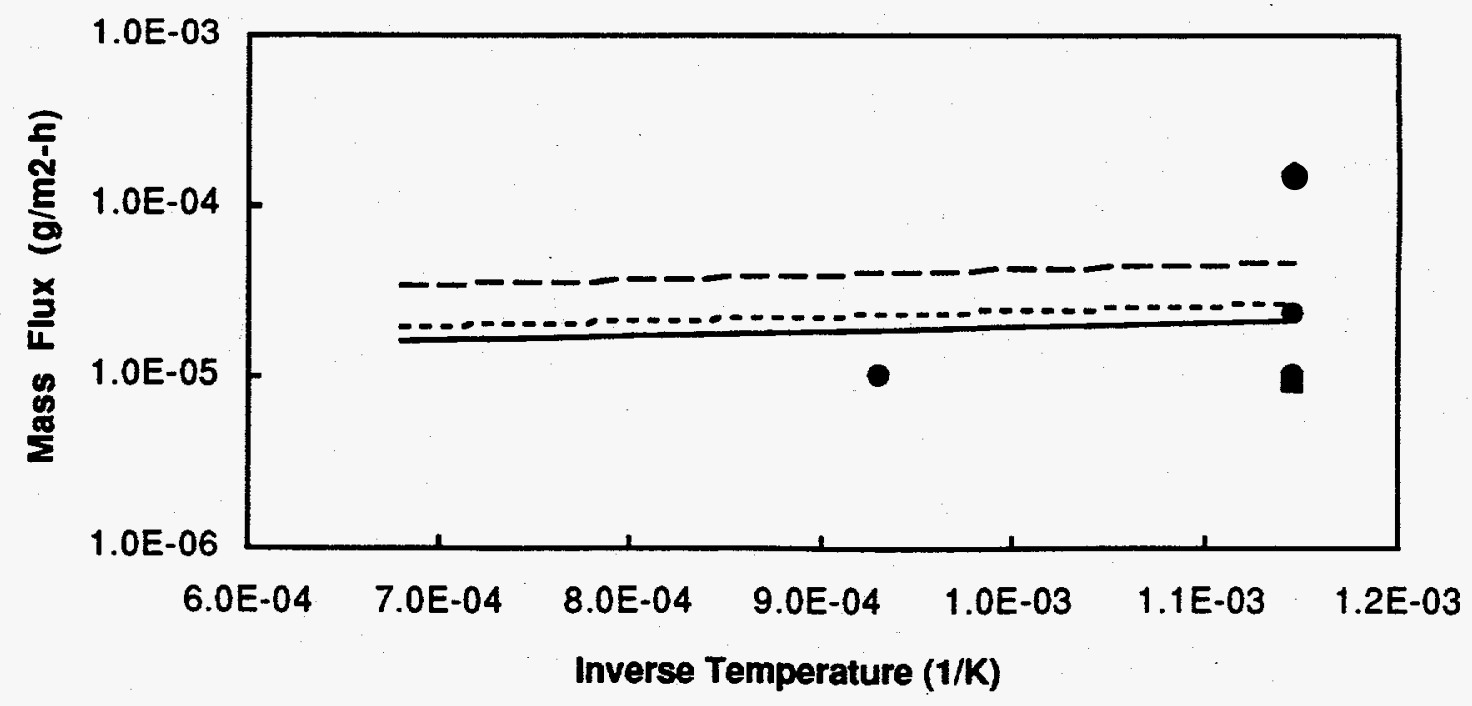

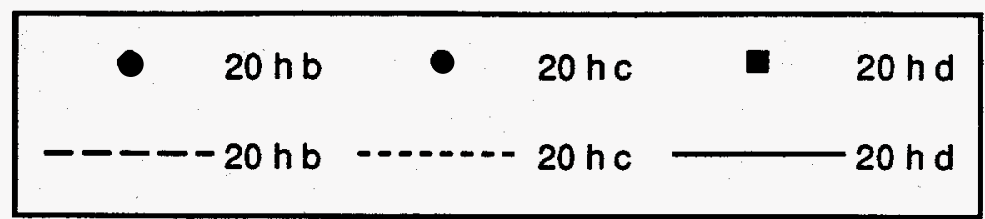

Figure 78. Mn mobility from V alloy exposed to air; 20 hour tests

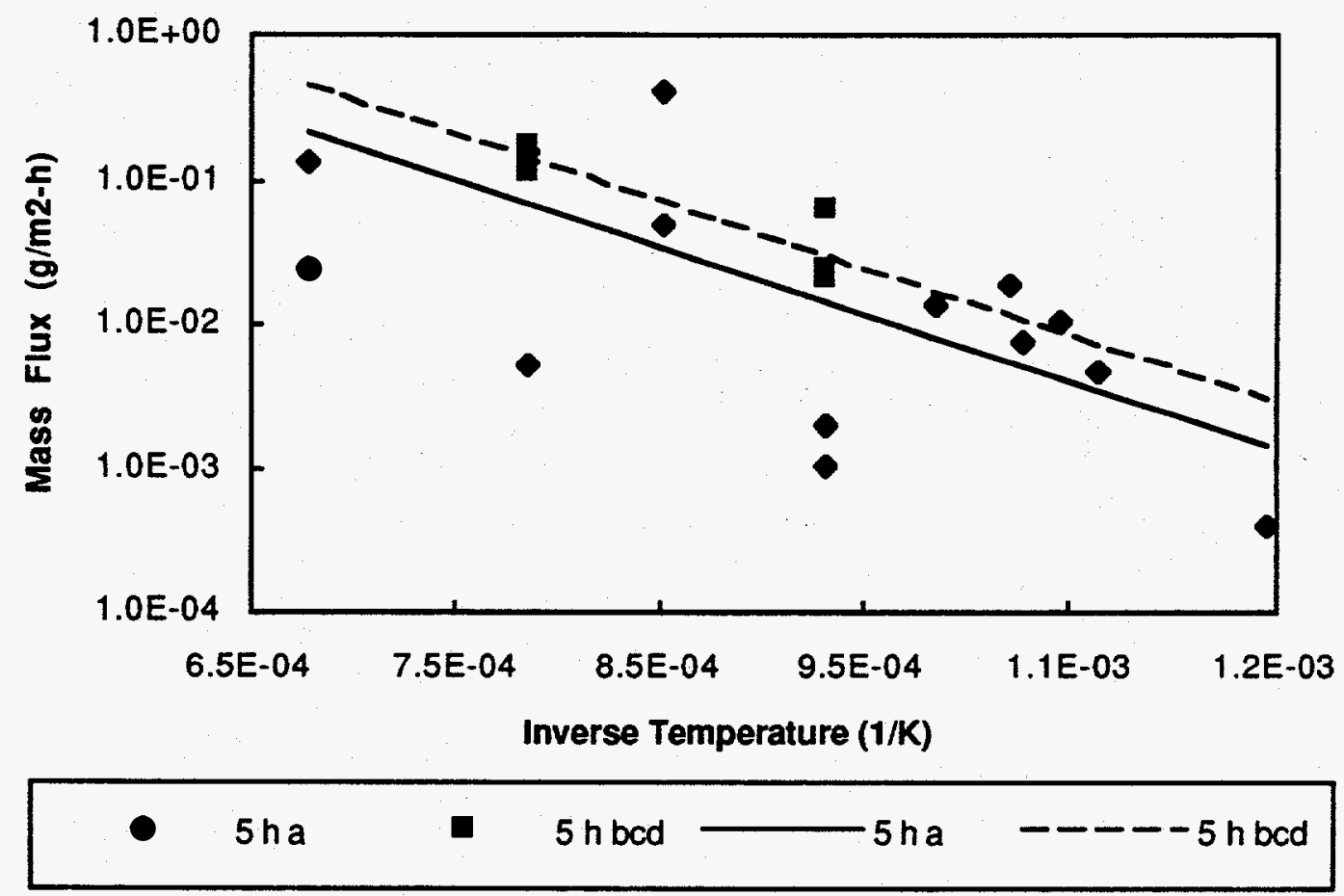

Figure 79. V mobility from V alloy exposed to air; 5 hour tests 

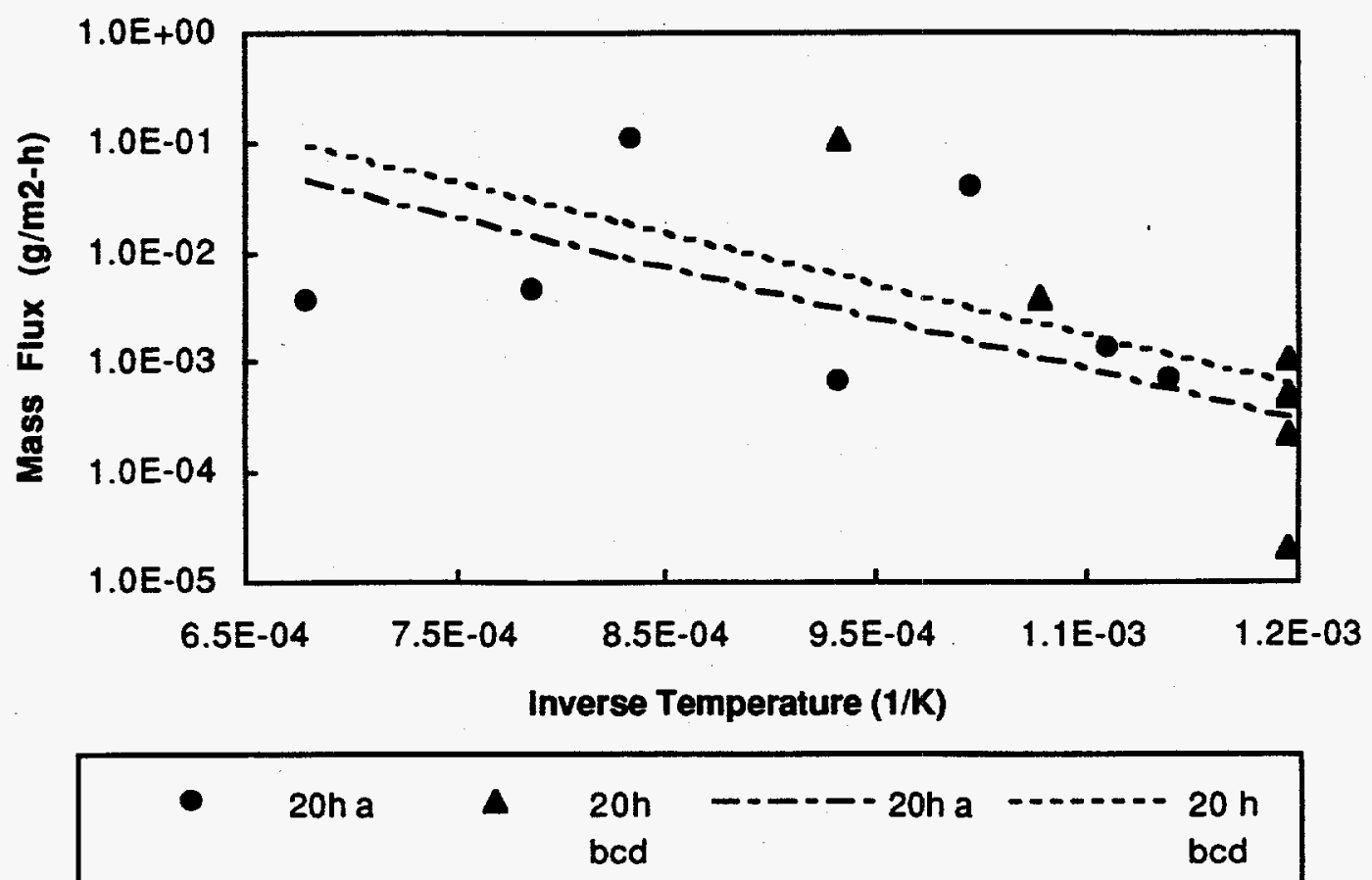

Figure 80. $\mathrm{V}$ mobility from $\mathrm{V}$ alloy exposed to air; 20 hour tests

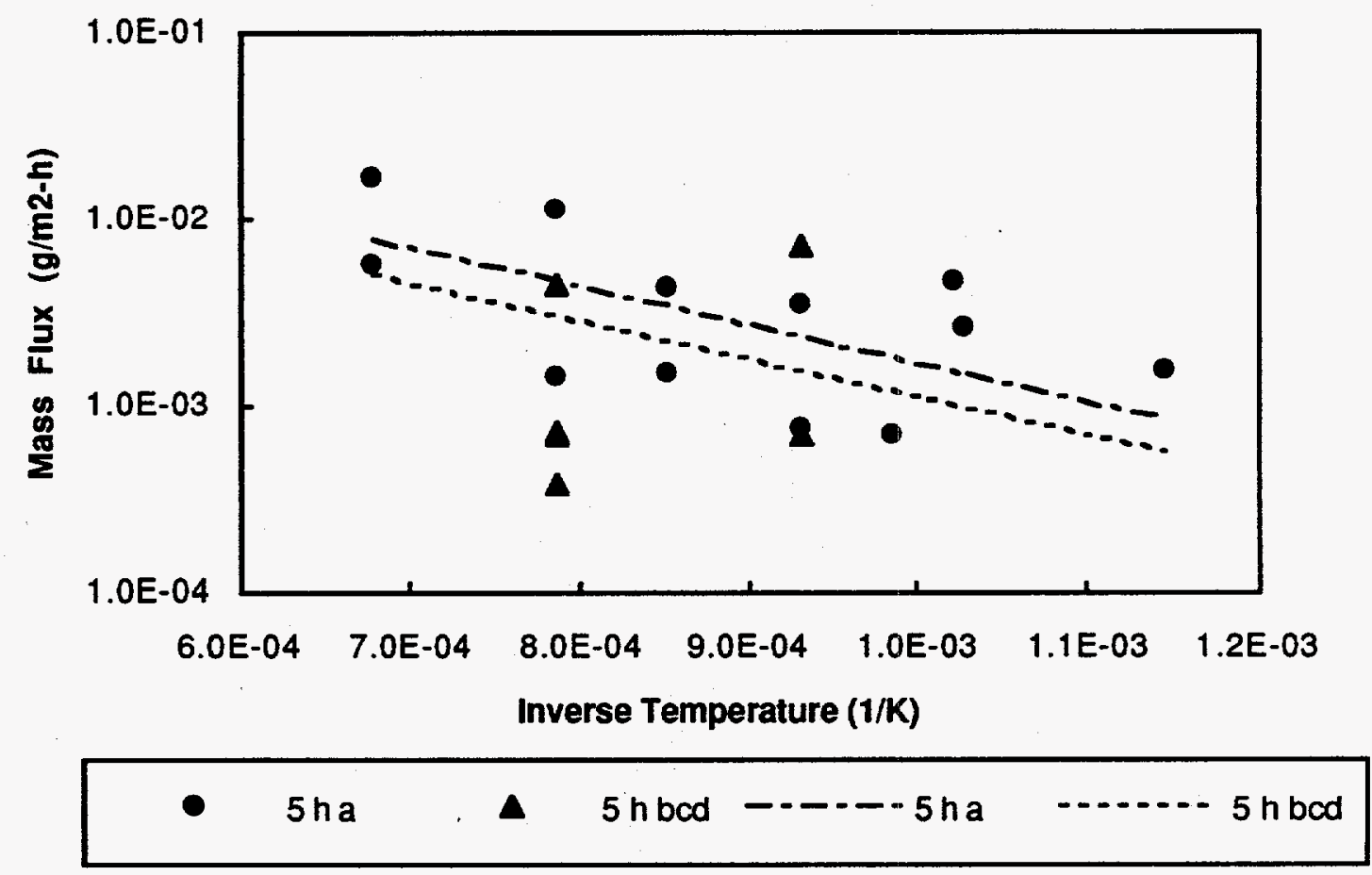

Figure 81. Cr mobility from $\mathrm{V}$ alloy exposed to air, 5 hour tests 


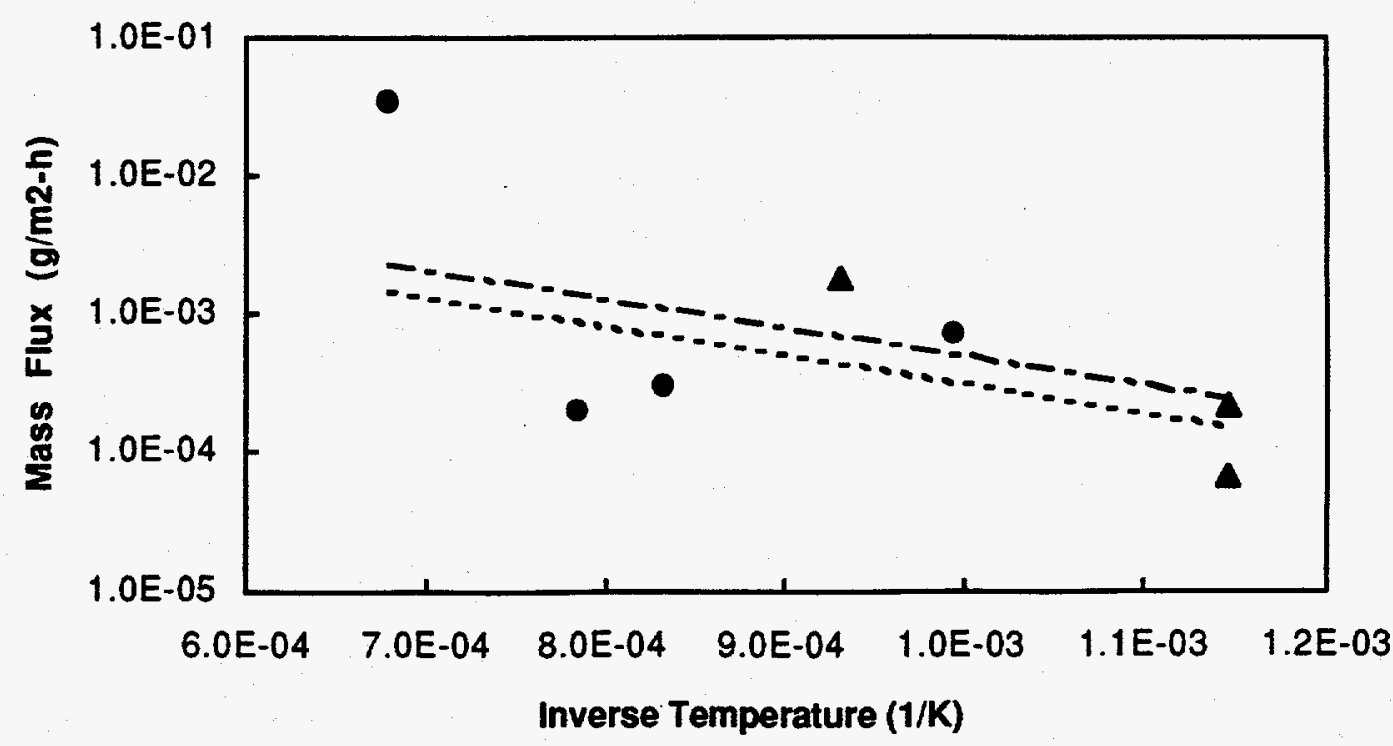

Figure 82. Cr mobility from $V$ alloy exposed to air, 20 hour tests

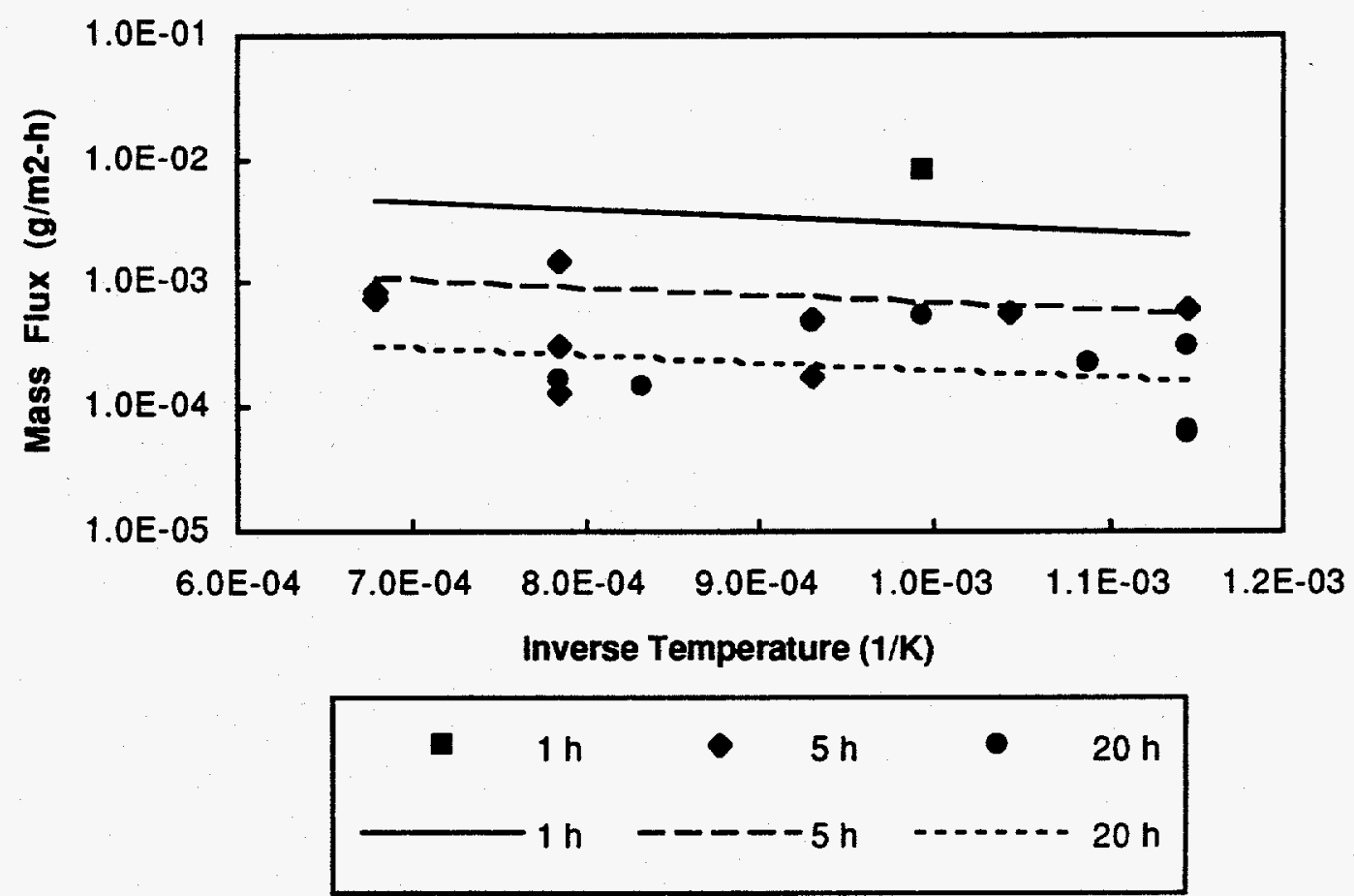

Figure 83. Ti mobility from $V$ alloy exposed to air 

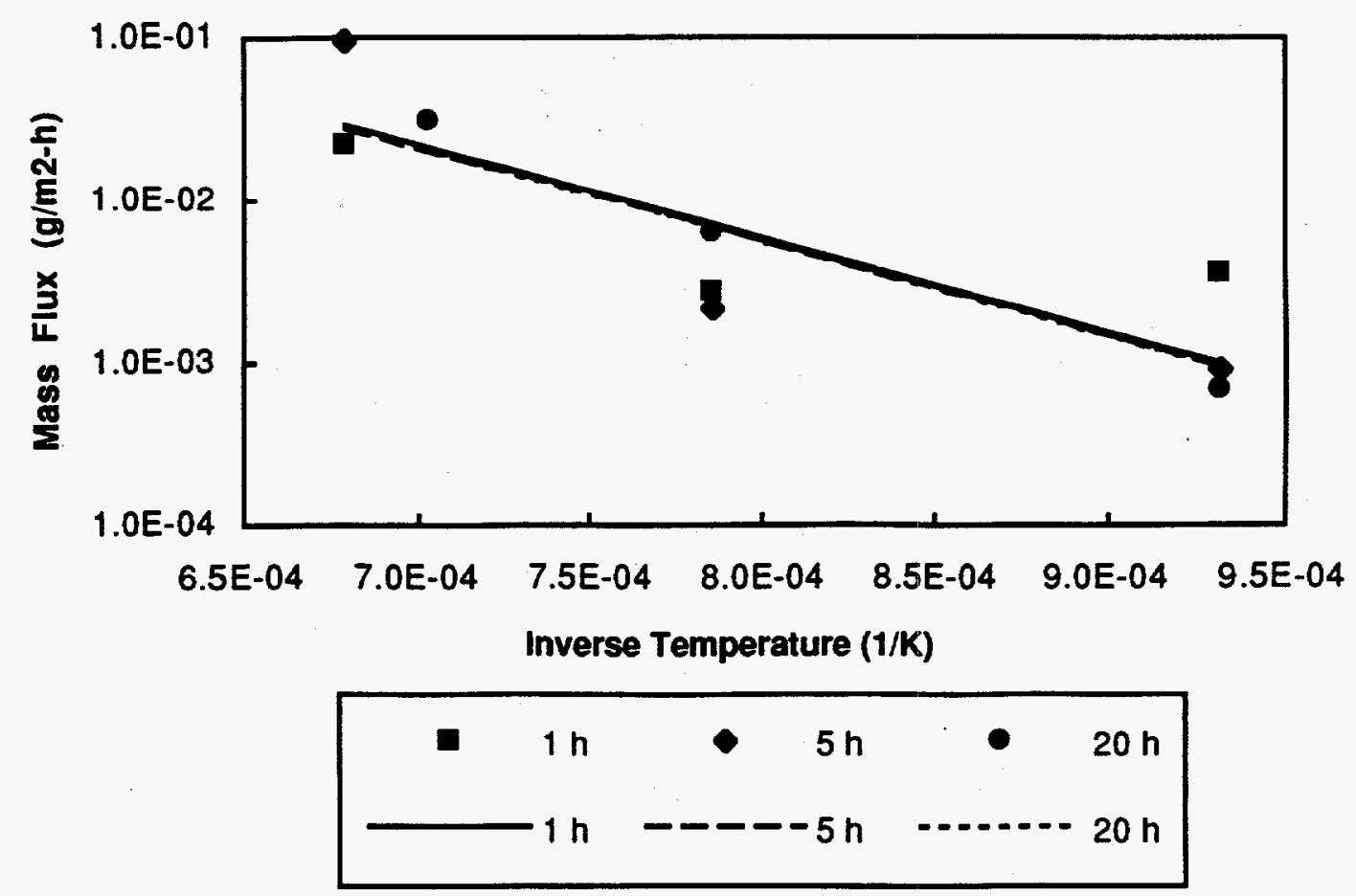

Figure 84. V mobility from $\mathrm{V}$ alloy exposed to steam

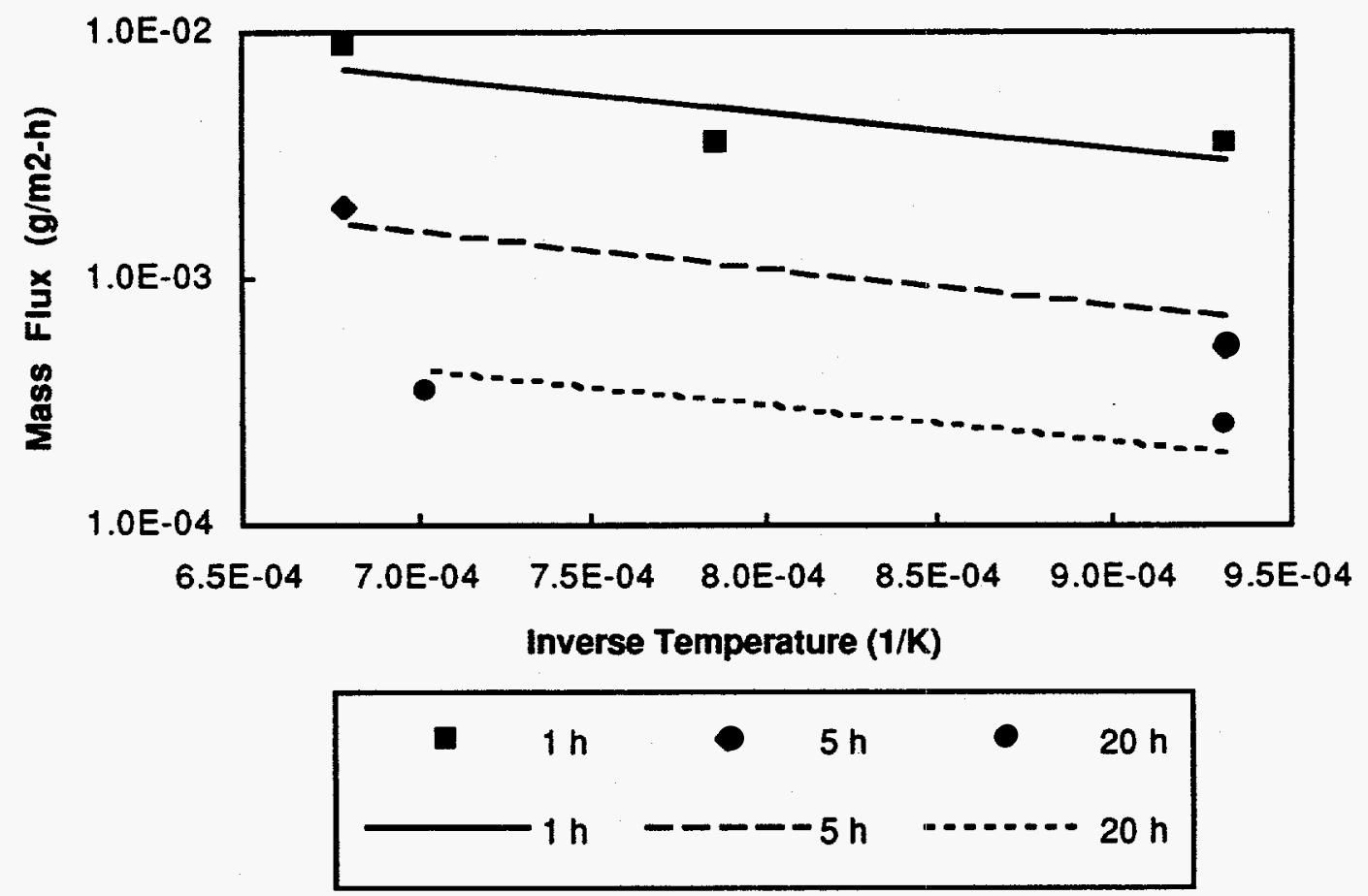

Figure 85. Ti mobility from $\mathrm{V}$ alloy exposed to steam 


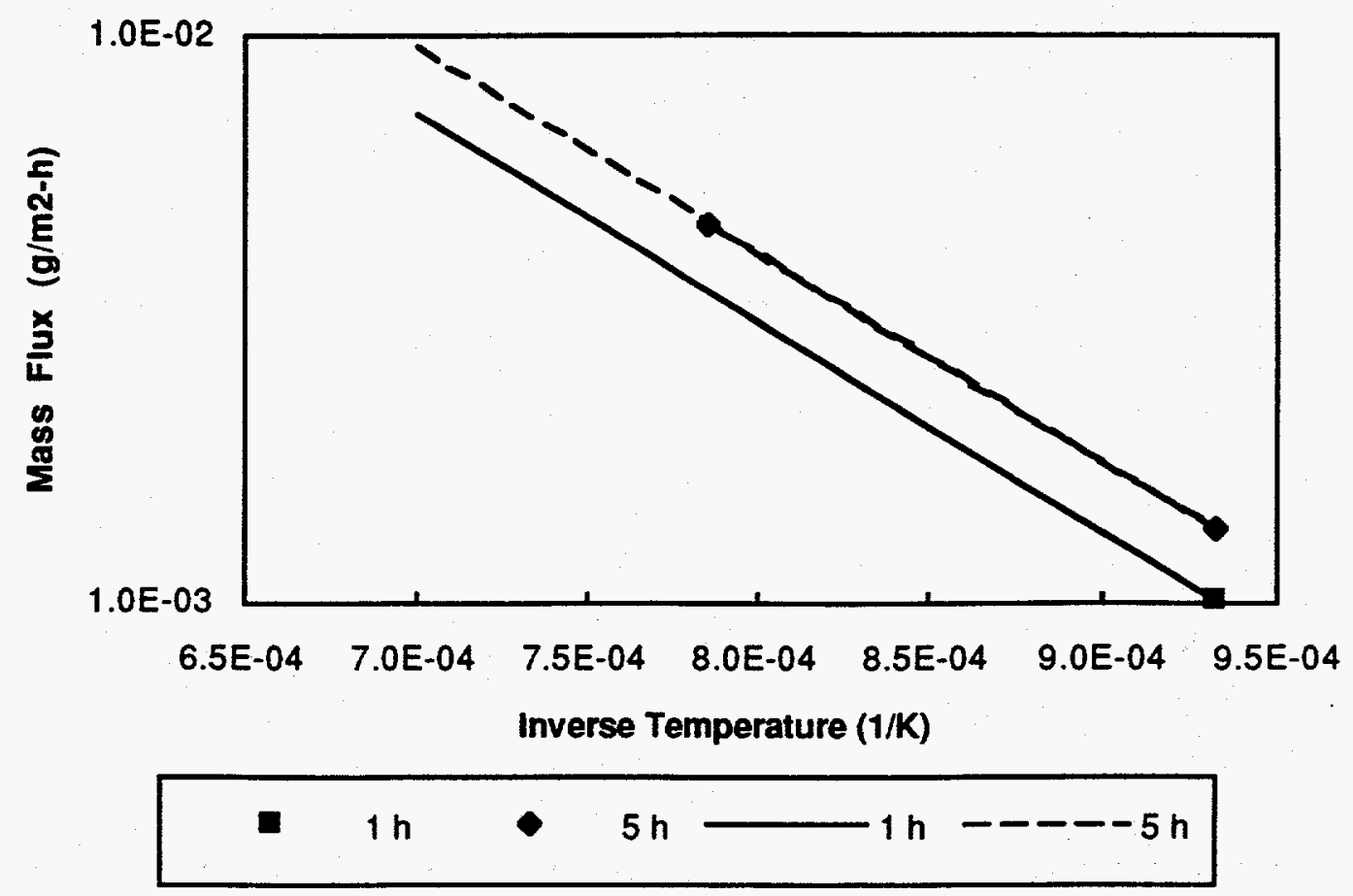

Figure 86. Cr mobility from $V$ alloy exposed to steam

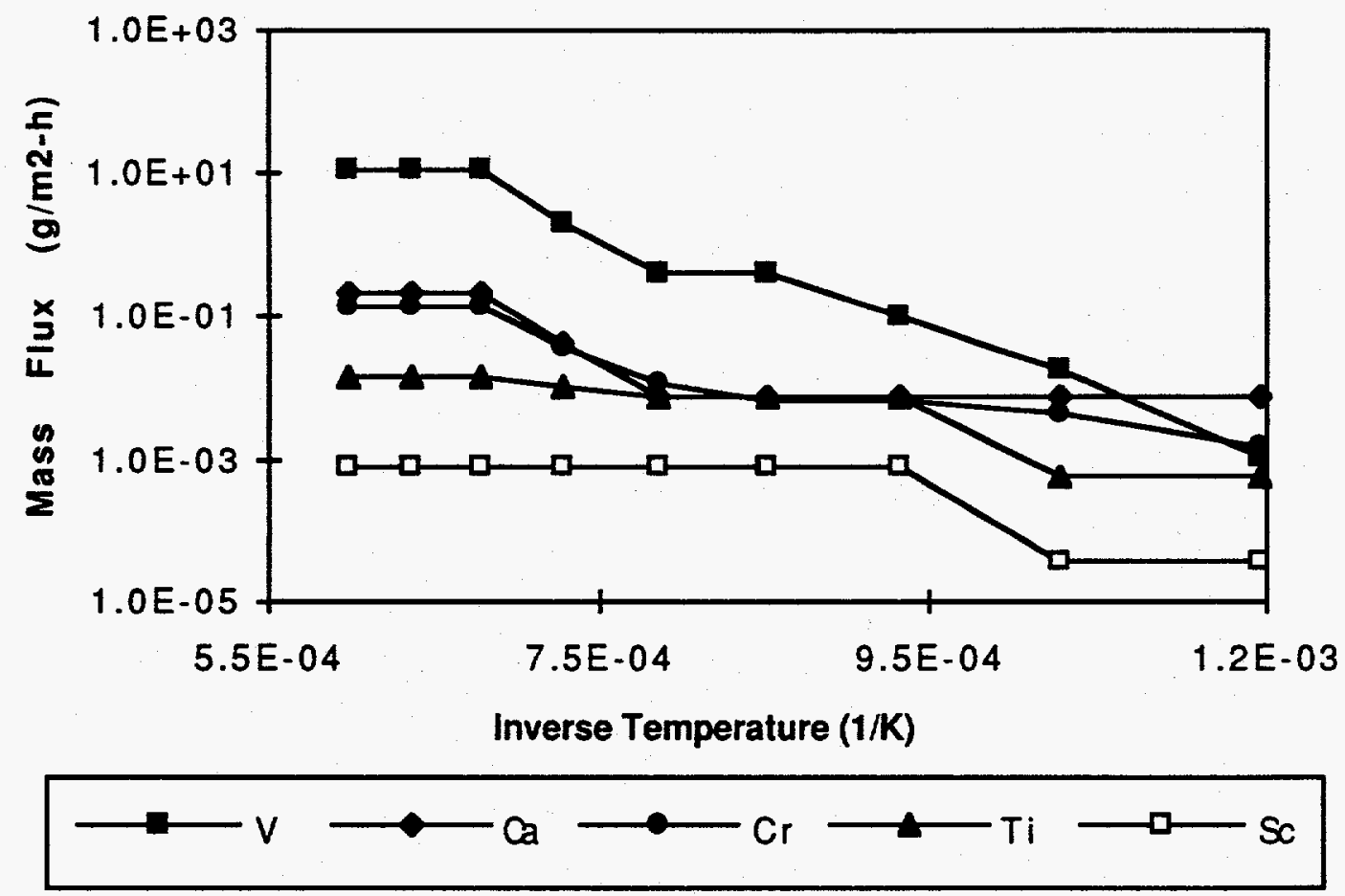

Figure 87. Cumulative maximum mobility of elements from $\mathrm{V}$ alloy exposed to air 


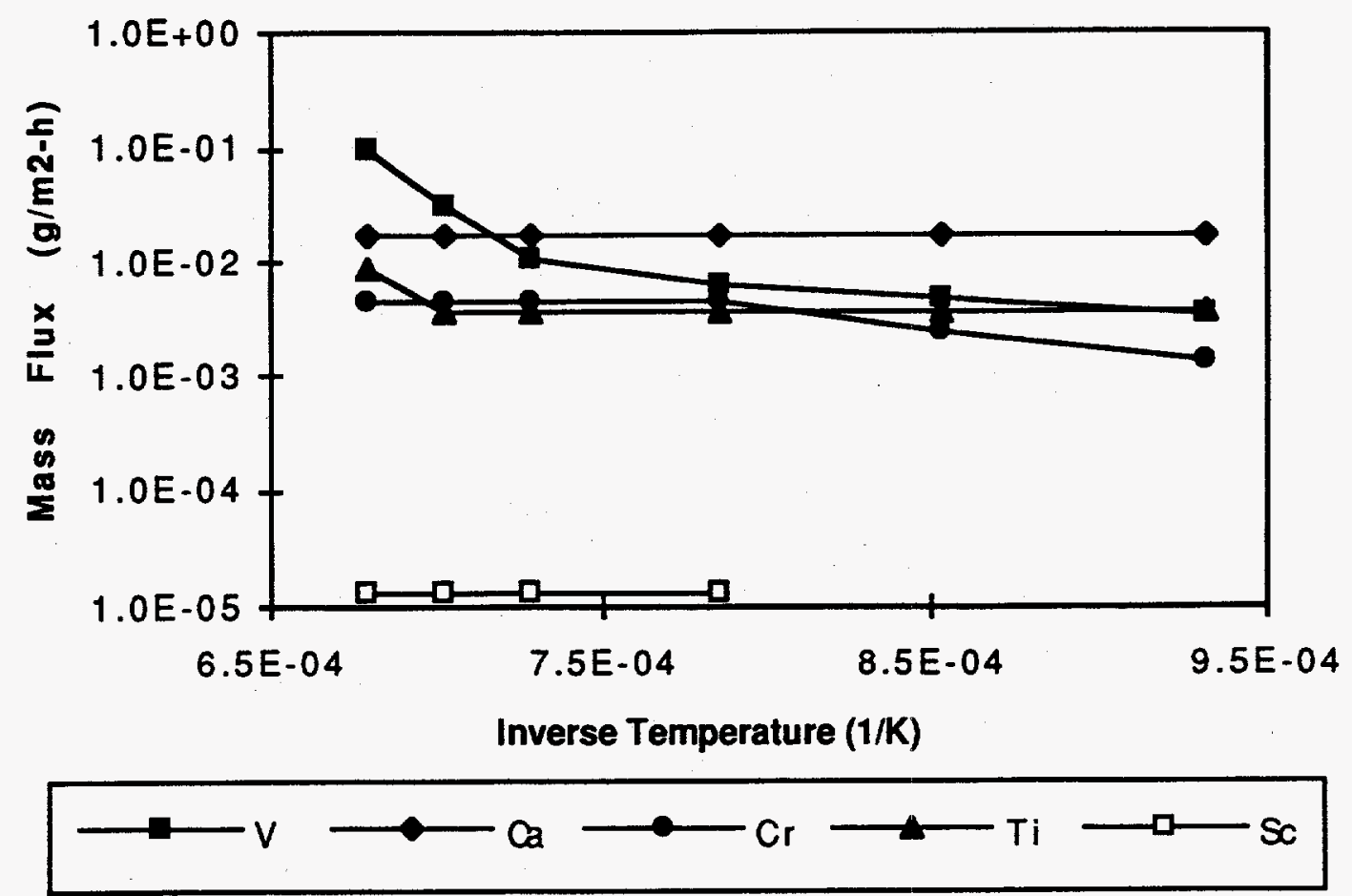

Figure 88. Cumulative maximum mobility of elements from $\mathrm{V}$ alloy exposed to steam 


\subsection{USING MOBILITY DATA IN SAFETY ASSESSMENTS}

There are two basic ways to use the mobility data in safety assessments. One is to use the cumulative maximum mobility as described in Section 2. The other is to use the curve fits to the data. Until data validation and new curve fits are done, at which point we will reassess the database, we will use the cumulative maximum mobility.

The fractional rate of mobilization of a particular element in an alloy at a given temperature is calculated using the following equation:

$$
\dot{M} F=\frac{\Gamma}{W P \times \rho \times \delta}
$$

where $\dot{M} F$ is the mobilization fraction per unit time, $\Gamma$ is the mass flux of the element, $W P$ is the weight fraction of the element in the material (composition after irradiation should be used if available), $\rho$ is the density of the material, and $\delta$ is the thickness of the component that is being analyzed (for example, the thickness of the first wall). $\Gamma$ is either the cumulative maximum mass flux or the mass flux from the curve fit (see Section 2 for explanations of these options).

If the moler percent of an element in the irradiated material is significantly different from the moler percent in the test sample, adjusting for composition may be applicable. From equation (2), the mass flux from the irradiated material can be calculated using

$$
\Gamma=\Gamma_{0}\left(\frac{w}{w_{0}}\right)^{D}
$$

where $\Gamma_{0}$ is the mass flux of the element from the sample, $w$ is the moler percent of the element in the irradiated material, and $w_{0}$ is the moler percent of the element in the test sample. $D$ is the composition exponent from curve fits. If the irradiated composition of an element is lower than the composition in the test sample, it is conservative not to adjust the volatility rates. But, if the composition is higher than in the sample, the conservative approach would be to scale upward linearly $(D=1)$.

The fractional mobilization rate for each element is multiplied by the time at temperature, its corresponding radioactive inventory $(\mathrm{Bq}$, calculated using an activation code such as FISPACT or REAC) and dose per Bq of element released (calculated using a dose code such as MACCs, (Abbott, et. al, 1993)). This gives the offsite dose assuming all material mobilized is released. (In actuality, some of the material mobilized will settle out during transport to the site boundary; the activation products task also includes investigations of behavior and processes during the transport of materials, however that is 
not covered in this report. Documentation of our tungsten transport investigation can be found in Hagrman, et. al, 1994.12)

The importance of mobilization fractions can be seen by comparing the IBEED with the MBEED (see Section 3.0). For this analysis, we look only at the first wall (surface area of $2000 \mathrm{~m}^{2}, .005 \mathrm{~m}$ thick), and assume a fluence of $1 \mathrm{MWyr} / \mathrm{m}^{2}$. The fractional mobilization rate scales linearly with surface area thus can easily be scaled for the desired area. For most cases, the flux is $1 \mathrm{MW} / \mathrm{m}^{2}$, however we do not have activation calculations at this flux for all materials, thus some cases are scaled. This can have an influence on the results (see for example, Sublet and Butterworth (1992) and Piet (1992)), however it is adequate for our purposes here. Actual dose values will change under different assumptions; we include this section so the reader can get an idea of which isotopes are radiologically important. The doses given correspond to 1 hour at temperature. The value of 1 hour is used so that the results can be scaled easily to typical accident durations by multiplying the dose by the desired time. The dose calculations used here assume worst case conditions: stability class $F, 1 \mathrm{~m} / \mathrm{s}$ wind speed, ground level release, $1 \mathrm{~km}$ site boundary. The doses are Early Effective Dose as calculated using MACCS (Abbot, et. al (1993)). We use the cumulative maximum flux in all calculations.

In the following tables, we present the IBEED, the MBEED for $600^{\circ} \mathrm{C}$ (and in some cases where we do not have data at $600^{\circ} \mathrm{C}, 800^{\circ} \mathrm{C}$ ), and the MBEED for $1000^{\circ} \mathrm{C}$. The IBEED can be easily scaled to determine the dose due to tokamak dust if the dust has the same composition as the first wall. In the MBEED, we assume all material mobilized is released (in actuality, some of the material mobilized will settle out during transport to the site boundary). Isotopes contributing to more than $1 \%$ of the total early dose are listed. We do not list isotopes that contribute below $1 \%$ because they do not significantly contribute to the dose. Unless mobilization fractions for elements contributing $10 \%$ or more to dose are shown to be lower than we currently assume, there is no reason to be concerned with those contributing less than $1 \%$.

Tables 25 and 26 give dose information for dispersion-strengthened copper. Co is the largest contributor to dose. Using mobilization fractions indicates the importance of elements other than $\mathrm{Cu}$ and $\mathrm{Co}$ (which dominate the IBEED). In particular, $\mathrm{Fe}$ and $\mathrm{Zn}$ are significant.

Table 27 gives dose information for PCA steel. Co and Mn dominate the IBEED, while Co and Ta dominate the MBEED.

12 Additional documentation of our transport-related work can be found in the following engineering design files: D.A. Petti, "Estimate of Activation Product Transport Through ITER Confinements," ITER/US/94/EN/SA-7, May 6, 1994, and G.R. Smolik, A.W. Erickson, and D.L. Hagrman, "Characteriztion of Aerosols Released by a Tungsten Alloy," ITER/93/US/TE/SA-6, June 25, 1993. 
Tables 28 and 29 give dose information for HT-9. The IBEED is dominated by Mn. It is interesting to note that the dose for an accident in air, the MBEED is dominated by $\mathrm{Co}$, while in steam, $\mathrm{Mn}$ is the most significant.

The activation calculations used in calculating the early doses from $\mathrm{Nb}$ and $\mathrm{W}$ were not as detailed as those used for other materials. It is possible that more detailed activation output would indicate that isotopes other than those listed in Tables 30 through 33 would contribute more than $1 \%$ to the dose. Based on the current activation calculations, $\mathrm{Nb}$ and $\mathrm{Ta}$ dominate in air and water ingress accidents with $\mathrm{Nb}$. Tungsten doses are dominated by W, Ta, and Re.

Tables 34 and 35 show that for V5Cr5Ti, the IBEED is dominated by Sc. Ca and Na contribute significantly to the MBEED.

When evaluating the importance of certain elements, it is important to consider the numerical value of the dose in addition to the percentage that each element contributes to the dose.

Including mobility fractions lowers the doses relative to the inventory-based dose by factors of about $200-11,000$ at $600^{\circ} \mathrm{C}$, and about $4-1600$ at $1000^{\circ} \mathrm{C}$. Thus the experiments to determine mobility of elements are extremely important.

\begin{tabular}{|c|c|c|c|c|c|}
\hline \multicolumn{2}{|c|}{$100 \%$ Released } & \multicolumn{2}{|c|}{ Release at $600^{\circ} \mathrm{C}$} & \multicolumn{2}{|c|}{ Release at $1000^{\circ} \mathrm{C}$} \\
\hline Isotope & \% Total Dose & Isotope & \% Total Dose & Isotope & \% Total Dose \\
\hline Co 60 & 57.6 & $\mathrm{Fe} 59$ & 39.8 & Co 60 & 82.9 \\
\hline \multirow[t]{6}{*}{$\mathrm{Cu} 64$} & 41.9 & Co 60 & 27.3 & $\mathrm{Zn} 65$ & 8.6 \\
\hline & & $\mathrm{Na} 24$ & 9.6 & $\mathrm{Cu} 64$ & 5.2 \\
\hline & & $\mathrm{Cu} 64$ & 7.3 & Fe 59 & 2.4 \\
\hline & & $\operatorname{Zn} 65$ & 6.6 & & \\
\hline & & H 3 & 5.3 & & \\
\hline & & $\mathrm{Ni} 65$ & 3.4 & & \\
\hline \multicolumn{2}{|c|}{ Total dose: $21,716 \mathrm{mSv}$} & \multicolumn{2}{|c|}{ Total dose: $24.6 \mathrm{mSv}$} & \multicolumn{2}{|c|}{ Total dose: $514.6 \mathrm{mSv}$} \\
\hline
\end{tabular}

Table 25. Isotopes contributing more than $1 \%$ of the early dose during 1-hour air ingress accident with dispersion-strengthened copper 


\begin{tabular}{|c|c|c|c|c|c|}
\hline \multicolumn{2}{|c|}{$100 \%$ Release } & \multicolumn{2}{c|}{ Release at $600^{\circ} \mathrm{C}$} & \multicolumn{2}{c|}{ Release at $1000^{\circ} \mathrm{C}$} \\
Isotope & \% Total Dose & Isotope & \% Total Dose & Isotope & \% Total Dose \\
\hline $\mathrm{Co} 60$ & 57.6 & $\mathrm{Co} 60$ & 81.5 & Co 60 & 59.1 \\
\hline $\mathrm{Cu} 64$ & 41.9 & $\mathrm{Fe} 59$ & 11.2 & $\mathrm{Zn} 65$ & 29.0 \\
\hline & & $\mathrm{Zn} 65$ & 2.1 & $\mathrm{Fe} 59$ & 8.1 \\
\hline & & $\mathrm{Na} 24$ & 2.1 & $\mathrm{Na} 24$ & 1.5 \\
\hline & & $\mathrm{H}-3$ & 1.2 & & \\
\hline & & & & & \\
\hline & & & & & \\
\hline \multicolumn{2}{|r|}{ Total dose: $21,716 \mathrm{mSv}$} & \multicolumn{2}{|c|}{ Total dose: $111.0 \mathrm{mSv}$} & \multicolumn{3}{c|}{ Total dose: $153.0 \mathrm{mSv}$} \\
\hline
\end{tabular}

Table 26. Isotopes contributing more than $1 \%$ of the early dose during 1-hour water ingress accident with dispersion-strengthened copper

\begin{tabular}{|c|c|c|c|c|c|}
\hline \multicolumn{2}{|c|}{$100 \%$ Release } & \multicolumn{2}{|c|}{ Release at $600^{\circ} \mathrm{C}$} & \multicolumn{2}{|c|}{ Release at $1000^{\circ} \mathrm{C}$} \\
\hline Isotope & \% Total Dose & Isotope & \% Total Dose & Isotope & \% Total Dose \\
\hline Co 58 & 57.7 & Ta 182 & 74.9 & Ta 182 & 63.5 \\
\hline Mn 54 & 10.9 & W 187 & 5.2 & Mo 99 & 8.2 \\
\hline Co 57 & 10.4 & P 32 & 3.8 & W 187 & $\overline{4.4}$ \\
\hline $\mathrm{Ta} 182$ & 5.4 & $\mathrm{Nb} 95$ & 3.5 & P 32 & 3.3 \\
\hline Co 60 & $\overline{4.6}$ & $\mathrm{Zr} 89$ & 3.1 & $\mathrm{Nb} 95$ & 3.0 \\
\hline Mn 56 & 2.8 & Y 88 & 1.4 & Co 58 & 2.8 \\
\hline Cr 51 & 2.8 & Zr 95 & 1.2 & Mn 54 & 2.7 \\
\hline Ni 57 & 1.2 & Co 58 & 1.0 & $\mathrm{Zr} 89$ & 2.6 \\
\hline $\mathrm{Fe} 55$ & 1.1 & & & Y 88 & 1.2 \\
\hline Fe 59 & 1.1 & & & Zr 95 & 1.0 \\
\hline \multicolumn{2}{|c|}{ Total dose: $30,696 \mathrm{mSv}$} & \multicolumn{2}{|c|}{ Total dose: $22.2 \mathrm{mSv}$} & \multicolumn{2}{|c|}{ Total dose: $26.2 \mathrm{mSv}$} \\
\hline
\end{tabular}

Table 27. Isotopes contributing more than $1 \%$ of the early dose during 1-hour air ingress accident with PCA 


\begin{tabular}{|c|c|c|c|c|c|}
\hline \multicolumn{2}{|c|}{$100 \%$ Release } & \multicolumn{2}{|c|}{ Release at $600^{\circ} \mathrm{C}$} & \multicolumn{2}{|c|}{ Release at $1000^{\circ} \mathrm{C}$} \\
\hline Isotope & \% Total Dose & Isotope & \% Total Dose & Isotope & \% Total Dose \\
\hline Mn 54 & 67.7 & Co 58 & 45.1 & Mn 54 & 54.3 \\
\hline Mn 56 & 15.4 & $\operatorname{Co} 57$ & 10.3 & Mn 56 & 12.3 \\
\hline $\mathrm{Fe} 55$ & 5.1 & Cr 51 & 9.6 & Co 58 & 11.4 \\
\hline Cr 51 & 4.8 & Mn 54 & 8.7 & Mo 99 & 10.2 \\
\hline Co 58 & 2.8 & P 32 & 7.6 & Co 57 & 2.6 \\
\hline & & Co 60 & 4.8 & Cr 51 & 2.4 \\
\hline & & Ta 182 & 3.1 & P 32 & 1.9 \\
\hline & & Mn 56 & 2.0 & Co 60 & 1.2 \\
\hline & & $\mathrm{Nb} 95$ & 2.0 & & \\
\hline & & Zr 89 & 1.9 & & \\
\hline & & Sc 48 & 1.1 & & \\
\hline \multicolumn{2}{|c|}{ Total dose: $8,232 \mathrm{mSv}$} & \multicolumn{2}{|c|}{ Total dose: $16.8 \mathrm{mSv}$} & \multicolumn{2}{|c|}{ Total dose: $66.3 \mathrm{mSv}$} \\
\hline
\end{tabular}

Table 28. Isotopes contributing more than $1 \%$ of the early dose during 1-hour air ingress accident with HT-9 


\begin{tabular}{|c|c|c|c|c|c|}
\hline \multicolumn{2}{|c|}{$100 \%$ Release } & \multicolumn{2}{|c|}{ Release at $600^{\circ} \mathrm{C}$} & \multicolumn{2}{|c|}{ Release at $1000^{\circ} \mathrm{C}$} \\
\hline Isotope & \% Total Dose & Isotope & \% Total Dose & Isotope & \% Total Dose \\
\hline Mn 54 & 67.7 & Mn 54 & 32.9 & Mn 54 & 41.8 \\
\hline Mn 56 & 15.4 & Co 58 & 16.0 & Co 58 & 10.4 \\
\hline $\mathrm{Fe} 55$ & 5.1 & Ta 182 & 8.6 & Mn 56 & 9.5 \\
\hline Cr 51 & 4.8 & Mn 56 & 7.5 & Ta 182 & 5.5 \\
\hline \multirow[t]{13}{*}{ Co 58} & 2.8 & $\mathrm{Nb} 95$ & 5.4 & $\mathrm{Fe} 55$ & 4.3 \\
\hline & & $\mathrm{Zr} 89$ & 5.1 & $\mathrm{Nb} 95$ & 3.5 \\
\hline & & Co 57 & 3.7 & Zr 89 & 3.3 \\
\hline & & Sc 48 & 2.9 & Cr 51 & 2.9 \\
\hline & & Cr 51 & 2.7 & Co 57 & 2.4 \\
\hline & & Y 88 & 2.3 & Sc 48 & 1.9 \\
\hline & & Mo 99 & 2.0 & W 181 & 1.7 \\
\hline & & Zr 95 & 2.0 & W 187 & 1.7 \\
\hline & & Co 60 & 1.7 & Y 88 & 1.5 \\
\hline & & V 48 & 1.2 & Mo 99 & 1.3 \\
\hline & & $\mathrm{Nb} 96$ & 1.1 & Zr 95 & 1.3 \\
\hline & & H 3 & 1.1 & Co 60 & 1.1 \\
\hline & & & & W 185 & 1.1 \\
\hline \multicolumn{2}{|c|}{ Total dose: $8,232 \mathrm{mSv}$} & \multicolumn{2}{|c|}{ Total dose: $6.2 \mathrm{mSv}$} & \multicolumn{2}{|c|}{ Total dose: $9.5 \mathrm{mSv}$} \\
\hline
\end{tabular}

Table 29. Isotopes contributing more than $1 \%$ of the early dose during 1 -hour water ingress accident with HT-9

\begin{tabular}{|c|c|c|c|c|c|}
\hline \multicolumn{2}{|c|}{$100 \%$ Release } & \multicolumn{2}{c|}{ Release at $800^{\circ} \mathrm{C}$} & \multicolumn{2}{c|}{ Release at $1000^{\circ} \mathrm{C}$} \\
Isotope & $\%$ Total Dose & Isotope & $\%$ Total Dose & Isotope & \% Total Dose \\
\hline $\mathrm{Nb} 92 \mathrm{~m}$ & 92.9 & Ta182 & 96.7 & Ta182 & 83.5 \\
\hline $\mathrm{Ta} 182$ & 5.2 & $\mathrm{~W} 187$ & 2.3 & Nb $92 \mathrm{~m}$ & 14.1 \\
\hline & & & & W 187 & 2.0 \\
\hline \multicolumn{2}{|l|}{ Total dose: $81,099 \mathrm{mSv}$} & \multicolumn{2}{|c|}{ Total dose: $43.4 \mathrm{mSv}$} & \multicolumn{2}{c|}{ Total dose: $50.3 \mathrm{mSv}$} \\
\hline
\end{tabular}

Table 30. Isotopes contributing more than $1 \%$ of the early dose during 1 -hour air ingress accident with $\mathrm{Nb}$ 


\begin{tabular}{|c|c|c|c|c|c|}
\hline \multicolumn{2}{|c|}{$100 \%$ Release } & \multicolumn{2}{c|}{ Release at $800^{\circ} \mathrm{C}$} & \multicolumn{2}{c|}{ Release at $1000^{\circ} \mathrm{C}$} \\
Isotope & $\%$ Total Dose & Isotope & $\%$ Total Dose & Isotope & \% Total Dose \\
\hline $\mathrm{Nb} 92 \mathrm{~m}$ & 92.9 & $\mathrm{Ta} 182$ & 94.6 & $\mathrm{Nb} 92 \mathrm{~m}$ & 59.6 \\
\hline $\mathrm{Ta} 182$ & 5.2 & $\mathrm{Nb} 92 \mathrm{~m}$ & 2.8 & $\mathrm{Ta} 182$ & 38.6 \\
\hline & & $\mathrm{W} 187$ & 2.3 & & \\
\hline
\end{tabular}

Table 31. Isotopes contributing more than $1 \%$ of the early dose during 1 -hour wateringress accident with $\mathrm{Nb}$

\begin{tabular}{|c|c|c|c|c|c|}
\hline \multicolumn{2}{|c|}{$100 \%$ Release } & \multicolumn{2}{|c|}{ Release at $600^{\circ} \mathrm{C}$} & \multicolumn{2}{|c|}{ Release at $1000^{\circ} \mathrm{C}$} \\
\hline Isotope & \% Total Dose & Isotope & \% Total Dose & Isotope & \% Total Dose \\
\hline W 187 & 78.0 & $\operatorname{Re} 186$ & 26.8 & $\operatorname{Re} 186$ & 84.8 \\
\hline W 181 & 12.8 & W 187 & 26.1 & W 187 & 10.4 \\
\hline W 185 & 4.5 & Ta 182 & 23.8 & Ta 182 & 2.4 \\
\hline Ta 182 & 3.0 & Hf 181 & 17.1 & W 181 & 1.7 \\
\hline \multirow[t]{2}{*}{$\operatorname{Re} 186$} & 1.4 & W 181 & 4.3 & & \\
\hline & & W 185 & 1.5 & & \\
\hline \multicolumn{2}{|c|}{ Total dose: $54,789 \mathrm{mSv}$} & \multicolumn{2}{|c|}{ Total dose: $4.8 \mathrm{mSv}$} & \multicolumn{2}{|c|}{ Total dose: $869.1 \mathrm{mSv}$} \\
\hline
\end{tabular}

Table 32. Isotopes contributing more than $1 \%$ of the early dose during 1 -hour air ingress accident with $\mathrm{W}$ alloy

\begin{tabular}{|c|c|c|c|c|c|}
\hline \multicolumn{2}{|c|}{$100 \%$ Release } & \multicolumn{2}{c|}{ Release at $600^{\circ} \mathrm{C}$} & \multicolumn{2}{c|}{ Release at $1000^{\circ} \mathrm{C}$} \\
Isotope & \% Total Dose & Isotope & \% Total Dose & Isotope & \% Total Dose \\
\hline W 187 & 78.0 & W 187 & 75.1 & W 187 & 81.2 \\
\hline W 181 & 12.8 & W 181 & 12.4 & W 181 & 13.4 \\
\hline W 185 & 4.5 & W 185 & 4.4 & W 185 & 4.7 \\
\hline Ta 182 & 3.0 & Hf 181 & 4.0 & & \\
\hline Re 186 & 1.4 & Ta 182 & 3.6 & & \\
\hline \multicolumn{2}{|r|}{ Total dose: $54,789 \mathrm{mSv}$} & \multicolumn{2}{|c|}{ Total dose: $20.2 \mathrm{mSv}$} & Total dose: $14982.5 \mathrm{mSv}$ \\
\hline
\end{tabular}

Table 33. Isotopes contributing more than $1 \%$ of the early dose during 1 -hour water ingress accident with $\mathrm{W}$ alloy 


\begin{tabular}{|c|c|c|c|c|c|}
\hline \multicolumn{2}{|c|}{ 100\% Release } & \multicolumn{2}{|c|}{ Release at $600^{\circ} \mathrm{C}$} & \multicolumn{2}{|c|}{ Release at $1000^{\circ} \mathrm{C}$} \\
\hline Isotope & $\%$ Total Dose & Isotope & \% Total Dose & Isotope & \% Total Dose \\
\hline Sc 48 & 82.9 & Sc 48 & 52.3 & Sc 48 & 83.1 \\
\hline Sc 46 & 12.1 & $\mathrm{Ca} 45$ & 13.1 & Sc 46 & 12.2 \\
\hline Cr 51 & 1.9 & $\mathrm{Na} 24$ & 11.8 & Sc 47 & 1.8 \\
\hline \multirow[t]{5}{*}{ Sc 47} & 1.8 & Ca 47 & 9.0 & & \\
\hline & & Sc 46 & 7.7 & & \\
\hline & & Ho 166 & 2.5 & & \\
\hline & & Sc 47 & 1.1 & & \\
\hline & & $\mathrm{Nb} 95$ & 1.1 & & \\
\hline \multicolumn{2}{|c|}{ Total dose: $8380 \mathrm{mSv}$} & \multicolumn{2}{|c|}{ Total dose: $10.5 \mathrm{mSv}$} & \multicolumn{2}{|c|}{ Total dose: $144.3 \mathrm{mSv}$} \\
\hline
\end{tabular}

Table 34. Isotopes contributing more than $1 \%$ of the early dose during 1-hour air ingress accident with $\mathrm{V}-5 \mathrm{Cr}-5 \mathrm{Ti}$

\begin{tabular}{|c|c|c|c|c|c|}
\hline \multicolumn{2}{|c|}{$100 \%$ Release } & \multicolumn{2}{|c|}{ Release at $800^{\circ} \mathrm{C}$} & \multicolumn{2}{|c|}{ Release at $1000^{\circ} \mathrm{C}$} \\
\hline Isotope & \% Total Dose & Isotope & $\%$ Total Dose & Isotope & \% Total Dose \\
\hline Sc 48 & 82.9 & Sc 48 & 29.9 & Sc 48 & 29.8 \\
\hline Sc 46 & 12.1 & $\mathrm{Ca} 45$ & 21.9 & $\mathrm{Ca} 45$ & 21.9 \\
\hline Cr 51 & 1.9 & $\mathrm{Na} 24$ & 19.8 & $\mathrm{Na} 24$ & 19.7 \\
\hline \multirow[t]{4}{*}{ Sc 47} & 1.8 & $\mathrm{Ca} 47$ & 15.1 & Ca 47 & 15.0 \\
\hline & & Sc 46 & 4.4 & Sc 46 & 4.4 \\
\hline & & Ho 166 & 4.2 & Ho 166 & 4.2 \\
\hline & & $\mathrm{Nb} 95$ & 1.9 & $\mathrm{Nb} 95$ & 1.9 \\
\hline \multicolumn{2}{|c|}{ Total dose: $8380 \mathrm{mSv}$} & \multicolumn{2}{|c|}{ Total dose: $6.3 \mathrm{mSv}$} & \multicolumn{2}{|c|}{ Total dose: $6.3 \mathrm{mSv}$} \\
\hline
\end{tabular}

Table 35. Isotopes contributing more than $1 \%$ of the early dose during 1-hour water ingress accident with $\mathrm{V}-5 \mathrm{Cr}-5 \mathrm{Ti}$ 


\subsection{RECOMMENDATIONS AND FUTURE PLANS}

The majority of our future work will involve supporting ITER. We must assemble mobility information in 1994 for the ESECS, and later provide input for a PSAR. A part of our work will continue to support commercial reactor designs, when those materials are different from those planned for ITER. Vanadium alloys, which are ITER-relevant, are also commercial-reactor relevant.

The current ITER EDA baseline design is a water-cooled 316 stainless steel reactor with a copper divertor (and possibly first wall). The shield material is Inconel. The backup design is a liquid metal cooled $\mathrm{V}-5 \mathrm{Cr}-5 \mathrm{Ti}$ reactor. Both designs incorporate $\mathrm{Be}$ as a coating on plasma-facing materials. Our work plans focus on these materials.

In general, we must focus on gathering data at lower temperatures $\left(600-800^{\circ} \mathrm{C}\right.$ range, and where possible, down to $400^{\circ} \mathrm{C}$ ). We plan on accomplishing this by increasing sample size, increasing test times, and having analytic work done on instruments with detection limits as low as possible. We must continue to look for ways of lowering detection limits. We must argue for mobilization fractions at least below $0.1 \%$ for ITER. Our plans for our 1995 work include designing and building a moderate scale facility; this will use a considerably larger sample than our current facility.

There are four areas where we do not yet have data. These are Be in air, 316SS in steam (with the exception of $\mathrm{Co}$ and $\mathrm{Mn}$ ), and Inconel in air and steam. Our current schedule is to test 316SS or PCA in steam in 1994 and 1995, Inconel in late 1994, and Be in air in 1995.

In many cases, we have a significant amount of data, however it has not been validated. We will begin statistical validation of the data in 1994 in preparation for regulatory scrutiny. This will include new curve fits, and in some cases, fitting the data with two separate lines. To reduce scatter in the data from selected future tests, we will try to identify which material is volatilized, and which material is actually spalling off the sample.

Additionally, we will be filling in gaps in our data, measuring mobility of elements where we believe our data are not adequate. Our future plans include updating this report to include recent $\mathrm{Cu}$-air and $\mathrm{Cu}$-steam tests, including the effect of composition on mobility ( $\mathrm{Cu}$ alloy composition can change significantly due to transmutation under irradiation), Be-steam tests, and updating this report to include $\mathrm{V}$-5Cr-5Ti-air tests (focusing in particular on Sc and Ca mobility). Should the ITER design again focus on a water-cooled shield in a V-5Cr-5Ti design, additional V alloy-steam tests would be necessary; we currently have no plans to do these tests. 
In some cases, we recommend modeling as opposed to experiments. It is difficult, if not impossible (without using radioactive samples) to measure the mobility of elements that are also present in glassware and reagents as contamination. An example of this is $\mathrm{Na}$ mobility from the $\mathrm{V}$ alloy. It may also be necessary to model $\mathrm{Ca}$ volatility from the $\mathrm{V}$ alloy; results from tests in 1994 will determine which option we will pursue.

We do not currently recommend further W-air/steam or Nb-air/steam tests. These materials are not currently part of the ITER EDA design, and are not favored for use in commercial reactors because they are not low activation. Should ITER include these materials, we would need to do further testing; our database currently contains only exploratory data. The data we have show very little scatter, however additional testing would be necessary, particularly at the lower temperatures.

We will continue to be flexible to ITER needs. This report will be updated as new data and curve fits are available. Thus, it will serve as the basis for the ESECS, and later the PSAR for ITER. 


\subsection{REFERENCES}

Abbott, M.L., S.L. Harms, and A.S. Rood, "Dose Calculations for Accidental Airborne Releases of ITER Activation Products," EGG-EEL-10994, DRAFT, September, 1993.

Hagrman, D.L., G.R. Smolik, D.A. Petti, and K.A. McCarthy, "Aerosol Behavior of a Tungsten Alloy for Fusion Reactors," presented at the 11th Topical Meeting on the Technology of Fusion Energy, New Orleans, Louisiana, June 19-23 1994, to be published in Fusion Technology.

Henslee, S.P., "The Volatility of Vanadium From a Candidate Fusion Reactor Alloy," Transactions of the American Nuclear Society, 46, June 1984, pp. 284-286.

Henslee, S.P., and R.M. Neilson, Jr., "Elemental Volatility of HT-9 Fusion Reactor Alloy," Fusion Technology, 8, 1985, p. 1392.

Neilson, Jr., R.M., "Volatility of Vanadium From a Candidate Fusion Reactor Alloy," Journal of Nuclear Materials, 141-143 (Part B), November-December 1986, pp. 607-610.

Piet, S.J., H.G. Kraus, R.M. Neilson, Jr., and J.L. Jones, "Oxidation/Volatilization Rates in Air for Candidate Fusion Reactor Blanket Materials, PCA and HT-9," Journal of Nuclear Materials, 141-143 (1986), pp. 24-28.

Piet, S.J., R.M. Neilson, Jr., G.R. Smolik, and G.A. Reimann, "Initial Experimental Investigation of the Elemental Volatility From Steel Alloys For Fusion Safety Application," EGG-FSP-8459, April 1989a.

Piet, S.J., E.T. Cheng, and L.J. Porter, "Accident Safety Comparison of Elements to Define Low Activation Materials," EGG-FSP-8552, July 1989 b.

Piet, S.J. "Exploratory Study of Burn Time, Duty Factor, and Fluence on ITER Activation Hazards," EGG-FSP-10396, August 1992.

Porter, Lisa J., "Upgrade of a Fusion Accident Analysis Code and its Application to a Comparative Study of Seven Fusion Reactor Designs," MIT report, PFC/RR-89-10, June 1989.

Smolik, G.R., R.M. Neilson, Jr., and S.J. Piet, "Volatility From Copper and Tungsten Alloys for Fusion Reactor Applications," 13th IEEE Symposium on Fusion Engineering, Knoxville, TN, October 2-6, 1989, pp. 670-673. 
Smolik, G.R., B.J. Merrill, S.J. Piet, and D.F. Holland, "Evaluation of Graphite/Steam Interactions for ITER," EGG-FSP-9154, September 1990.

Smolik, G.R., B.J. Merrill, S.J. Piet, and D.F. Holland, "Evaluation of Graphite/Steam Interactions for ITER Accident Scenarios," Eusion Technology, 19(3, part 2A), May 1991a, pp. 1342-1348.

Smolik, G.R., S.J. Piet, and R.M. Neilson, "Predictions of Radioactive Tungsten Release for Hypothetical ITER Accidents," Fusion Technology, 19(3), May 1991b, pp. 13981402.

Smolik, G.R., B.J. Merrill, and R.S. Wallace, "Implications of Beryllium:Steam Interactions in Fusion Reactors," Journal of Nuclear Materials, 191-194 (1992a), pp. 153157.

Smolik, G.R., "Tungsten Alloy Oxidation Behavior in Air and Steam," EGG-FSP-10166, March $1992 b$.

Smolik, G.R., and K.A. McCarthy, "Oxidation and Volatilization of a Niobium Alloy," EGG-FSP-10341, July 1992c.

Smolik, G.R., B.J. Merrill and R.S. Wallace, "Reaction of Porous Beryllium in Steam," EGG-FSP-10346, July 1992d.

Smolik, G.R., and K.A. McCarthy, "Volatility Measurements From Vanadium Alloys in Air," ITER/US/93/TE/SA-13, September 30, 1993.

Sublet, J-Ch. and G.J. Butterworth, "The Influence of the Neutron Spectrum, Flux and Irradiation Time on the Activation Behavior of First Wall Materials," 17th Symposium of Fusion Technology, Rome, September 14-18, 1992. 


\section{APPENDIX A LISTING OF LAB NOTEBOOKS}

This appendix contains a listing of the lab notebooks documenting mobility tests during the period December 1980 to September 1993. (Some lab notebooks contain both mobility testing and transport testing information. Although transport tests are not covered in this report, the notebooks will be documented here.) Tests are mobility tests unless otherwise noted.

Book \#1: (only marked "Fusion Safety")

Start: December 19, 1980

Page 19: long-term experimental plan

Page 57: June 1982, first PCA tests (PCA-83-1 through 13)

Page 92: July 1983, first V alloy test descriptions

End: May, 1984

Book \#2: (only marked "Fusion Safety Lab Notes")

Start: July, 1983

Page 1: July, 1983, first V alloy tests (V-83-1 through 14)

Page 10: December 1983, first HT-9 tests (HT9-84-15 through 27)

Page 16: February, 1984, second PCA tests (PCA-84-28 through 31)

End: April, 1984

\section{Book \#3, INEL-NBU-679:}

Start: January, 1985

Page 2: January, 1985, third PCA tests (PCA-1 through 35, intermixed with HT-9 testing, 36/37 on page 37)

Page 13: May, 1985, second HT-9 tests (HT9-1 through 36)

Page 29: September, 1985, second V alloy tests (V-1 through 11)

Page 39: January, 1986, third V alloy tests (V-14 through 19)

Page 43: March 1986, third HT-9 tests (HT9-37 through 53)

Page 49: June, 1986, fourth $\mathrm{V}$ alloy tests (V-20 through 28)

Page 55: July, 1987, first $\mathrm{Cu}$ alloy tests (Cu-1 through 14)

Page 64: August, 1987, Mn steel tests (MN-1 through 6)

Page 67: September, 1987, second $\mathrm{Cu}$ alloy tests ( $\mathrm{Cu}-15$ through 26)

Page 73: September, 1987, fifth V alloy tests (V-29 through 38)

Page 81: January, 1988, fourth HT-9 tests (HT9-54 through 61)

Page 87: June, 1988, first graphite tests (in air) 
Page 103: September, 1988, first W alloy tests (1G through 10G)

End: December, 1988

\section{INEL-NBU-735}

Start: January, 1985

Page 23: March, 1985, PCA volatility results (PCA-3 through 13)

Page 37: December, 1985, V alloy volatility results (V-1 through 2)

Page 73: December, 1989, discussion about quartz wool analyses

Page 83: Procedures for processing Be volatiles for fusion safety tests

Page 85: February, 1991, first Be tests, (Be-1 through 27)

Page 96: December, 1991, first $\mathrm{Nb}$ alloy tests (Nb1 through 23)

End: May, 1992

INEL-NBU-1412: "Fusion safety - weights, measurements, and analysis":

Start: September, 1983

Page 4: November, $1985, \mathrm{~V}$ alloy sample preparation

Page 22: June, 1987, $\mathrm{Cu}$ alloy sample preparation

Page 37: early, 1988, W alloy sample preparation

Page 44: August, 1988, W alloy sample chemical analysis

Page 47: September, 1988, W alloy pre-test, post-test masses

Page 74: January, 1989, 1989 HT-9 pre-test, post-test masses

Page 98: April, 1990, 1990 HT-9 pre-test, post-test masses

Page 101: July, 1991, Nb alloy sample preparation

Page 101: October, 1991, Nb alloy chemical analysis

Page 103: October, 1991, Nb alloy pre-test, post-test masses

Page 104: November, 1991, W alloy sample preparation

Page 106: November, 1992, Nb alloy pre-test, post-test masses

Page 109: May, 1992, plasma-sprayed W pre-test, post-test masses

Page 115: July, 1992, W alloy sample preparation

Page 116: Proposed method to produce experimental alloys

Page 118: September, 1992, V alloy sample preparation

Page 123: October, 1992, PCA pre-test masses

Page 124: March, 1993, V alloy sample preparation, continued

Page 134: May, 1993, $\mathrm{V}$ alloy pre-test masses

Page 137: June, 1993, Cu alloy sample preparation

End: August, 1993 
Book \#4, INEL-NBU-1452: "Fusion Safety-Activation Products-Lab Experiments 3"

Start: December, 1988

Page 1: December, 1988, first $W$ alloy tests continued (11G through 13)

Page 4: January, 1989, fifth HT-9 tests (HT9-89-1 through 23)

Page 41: April, 1989, sixth HT-9 tests (HT9-89-24 through 34)

Page 55: November, 1989, second W alloy tests (14G through 24G)

Page 69: May, 1990, seventh HT-9 tests (HT9-90-1 through 17)

Page 100: February 1991, eighth HT-9 tests (HT9-91-21 through 31)

Page 115: September, 1991, first $\mathrm{Nb}$ alloy tests (Nb-92-1 through 23)

Page 145: June, 1992, plasma-sprayed W tests (PSW-1 through 5 and PSW-9)

Page 151: July, 1992, W alloy test 26G

Page 152: July, 1992, plasma-sprayed W tests, continued (PSW-8)

Page 153: September, 1992, pure W test (PW92-1)

Page 155: December, 1992, W oxide preparation for mechanical spalling tests

Page 156: January, 1993, HT-9 oxide preparation for mechanical spalling tests

Page 157: January, 1993, $\mathrm{Nb}$ alloy oxide preparation for mechanical spalling tests

Page 159: February, 1993, HT-9 oxide preparation for mechanical spalling tests

End: February, 1993

INEL-NBU-1581: "Fusion Safety: Graphite/Steam Study"

Start: June, 1989

End: May, 1990

INEL-NBU-2253: "Fusion Safety - Activation Product Task - Beryllium Investigation"

Start: December, 1990

Page 12: January, 1991, first Be tests begin (Bel through 23)

Page 90: December, 1991, first plasma-sprayed Be tests begin (Be24 through 27)

Page 105: April, 1992, second Be tests begin (Be28 through 33)

End: May, 1992

INEL-NBU-2876: "Fusion Safety/Activation Products Lab Experiments: Book 4"

Start: July, 1992

Page 3: Begin description of cascade impactor for transport tests

Page 7: August, 1992, W alloy tests with cascade impactor (WA-92-1 through 6)

Page 26: October, 1992, PCA tests with cascade impactor (PCA93-1 through 4)

Page 39: November, 1992, W alloy tests with cascade impactor, continued (WA-92-7) 
Page 42: December, 1992, W alloy attrition tests ( $\mathrm{WO}_{3}-93-1$ through 2$)$

Page 46: January, 1993, PCA tests with cascade impactor, continued (PCA93-5)

Page 49: January, 1993, W alloy attrition tests, continued ( $\mathrm{WO}_{3}-93-3$ through 9$), \mathrm{Nb}$ alloy attrition tests $\left(\mathrm{NB}_{2} \mathrm{O}_{5}-93-1\right.$ through 7$)$, HT-9 attrition tests (HT9-93-1 through 3)

Page 81: March, 1993, second set of W alloy tests with cascade impactor (WA-93-1 through 2)

Page 86: March, 1993, $\mathrm{Nb}$ alloy attrition tests, continued $\left(\mathrm{NB}_{2} \mathrm{O}_{5}-93-8\right.$ through 10$)$, W alloy attrition tests, continued ( $\mathrm{WO}_{3}-93-10$ through 13$)$, HT-9 attrition tests, continued (HT9-93-4 through 5)

Page 98: May, 1993, sixth V alloy tests (V293-1 through 12, V193-1 through 7, V393-1 through 3), second PCA tests (PCA93-7 through 14)

End: October, 1993

INEL-NBU-2877: "Fusion Safety/Activation Products-Analytical Results"

Start: September, 1982

Page 5: Chemical analyses reports for PCA

Page 12: Chemical analyses reports for Co in PCA

Page 20: Chemical analyses reports for $\mathrm{Be}$

Page 50: Chemical analyses reports for $\mathrm{Cu}$ alloy

Page 52: Chemical analyses reports for $\mathrm{Cu}$ alloy

Page 60: Chemical analyses reports for HT-9

Page 90: Chemical analyses reports for $\mathrm{Mn}$ steel

Page 95: Chemical analyses reports for $\mathrm{Nb}$ alloy

Page 115: Chemical analyses reports for $\mathrm{W}$ alloy

Page 123: Chemical analyses reports for plasma-sprayed $W$

Page 140: Chemical analyses reports for $V$ alloy

12598: "Fusion Safety/Activation Products Task Lab Exp: Book 5"

Start: September, 1993

Page 7: September, 1993, Cu alloy pre-test masses

Page 8: September, 1993, second Cu alloy tests (CU3B-1 through 12, 01CU1B93 through 10CU1B93, 21CU3B93)

End: October, 1993 


\section{APPENDIX B SPREADSHEETS}

In this appendix, we list the spreadsheets containing the data from mobility tests and the spreadsheets that reduce the data to a form usable in accident safety assessments. Once the data are qualified, we will release copies of these spreadsheets to those who request them.

\section{B.1 Data Spreadsheets}

The spreadsheets containing raw data and the analysis to reduce the raw data into a mass flux are called

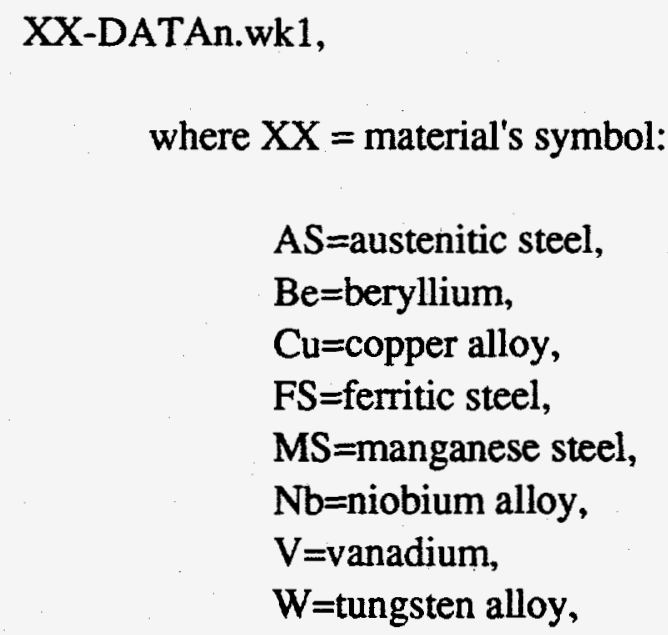

and $\mathrm{n}$ is blank unless there are more data than will fit into one single data spreadsheet, in which case $n$ is $1,2,3 \ldots$.

We have included the file name, the current date, and the date of last change of any data in the data spreadsheets in addition to relevant laboratory notebooks and associated publications, and a comparison of published data to current data. The data spreadsheets are organized in the following manner:

Spreadsheets are divided into ranges (pages), the ranges are separated by lines Titles, footnotes, and explanatory text are at the top of each page

Data is located at the bottom of each page

Page order:

Introduction (documentation, etc.)

Test parameters

Raw mobility data (aliquots, ug/ml) 
Adjustments to raw data, e.g., detection limits, solution blanks, quartz wool analyses

(in some cases) ppm of elements mobilized

Mobility fluxes

Macro for printing spreadsheet, list of range names

Existing DATA spreadsheets:
AS-DATA
Be-DATA
Cu-DATA
FS-DATA1
FS-DATA2
FS-DATA3
FS-DATA4
Nb-DATA
V-DATA
W-DATA

\section{B.2 Mobility Data Analysis Spreadsheet}

The spreadsheets that reduce the mobility flux data points from the data spreadsheets into a form that is usable in safety assessments are called XX-FLUXn.wk1 where XX and n are the same as described in Section B.1 for the data spreadsheets. (One exception to this is that there are two spreadsheets supplementing the FS-FLUX spreadsheet, FS-AIR and FS-STEAM.) The FLUX spreadsheets are organized in the following manner:

Spreadsheets are divided into ranges (pages), the ranges are separated by lines Analysis of oxidation via weight change

Analysis of mobility data

Table of cumulative maximum mobility data points to use in safety assessments

Existing FLUX spreadsheets:
AS-FLUX
Be-FLUX
Cu-FLUX
FS-AIR
FS-FLUX
FS-STEAM
Nb-FLUX
V-FLUX 
W-FLUX

\section{B.3 Master Spreadsheet}

The MASTER.wk1 spreadsheet contains tables of mobility as a function of temperature (cumulative maximum mobility data points from FLUX spreadsheets) for each material. The MASTER spreadsheet is organized in the following manner:

Spreadsheets are divided into ranges (pages), the ranges are separated by lines Introductory material, including the date of last change of information for each alloy type

Oxidation rates from the literature for $\mathrm{Be}$ and $\mathrm{C}$

Summary information, including mobility, for each alloy type

\section{B.4 Records Management}

The original lab notebooks are stored in Galen Smolik's office (IRC 603/D8), a record copy of all notebooks is in Kathy McCarthy's cubicle, EROB 3rd floor, M1, second drawer of the 4-drawer file. Two copies of the spreadsheets are maintained on disk, one copy with Galen Smolik, and one with Kathy McCarthy. 


\section{APPENDIX C ELEMENTAL RELEASE CATEGORIES}

This appendix contains a release fractions that appear in Appendix A of Piet, et. al (1989). These release fractions include both mobilization and transport from the reactor confinement building. Five release categories are defined:

1. Elements with gaseous species at room temperature, very likely to be mobilized and transported (reference release fraction is $100 \%$ )

2. Elements with gaseous species at reactor operating temperatures $\left(<500^{\circ} \mathrm{C}\right)$, very likely to be mobilized and fairly likely to be transported (reference release fraction is $30 \%$ )

3. Elements with gaseous species in likely accident conditions $\left(<1000^{\circ} \mathrm{C}\right)$ (reference release fraction is $10 \%$ )

4. Elements with gaseous species in severe accident conditions $\left(<1500^{\circ} \mathrm{C}\right)$ (reference release fraction is $3 \%$ )

5. Elements without gaseous species even in severe accident conditions (reference release fraction is $1 \%$ )

Based on these criteria, the release fractions on the following page are estimated. 
Element Release Fraction Element Release Fraction Element Release Fraction

\begin{tabular}{llllll}
\hline $\mathrm{Ag}$ & 0.01 & $\mathrm{He}$ & 1.00 & $\mathrm{Pr}$ & 0.01 \\
$\mathrm{Al}$ & 0.01 & $\mathrm{Hf}$ & 0.01 & $\mathrm{Pt}$ & 0.01 \\
$\mathrm{Ar}$ & 1.00 & $\mathrm{Hg}$ & 0.30 & $\mathrm{Rb}$ & 0.30 \\
$\mathrm{As}$ & 0.30 & $\mathrm{Ho}$ & 0.01 & $\mathrm{Re}$ & 0.30 \\
$\mathrm{Au}$ & 0.01 & $\mathrm{I}$ & 0.30 & $\mathrm{Rh}$ & 0.01 \\
$\mathrm{~B}$ & 0.01 & $\mathrm{In}$ & 0.10 & $\mathrm{Ru}$ & 0.01 \\
$\mathrm{Ba}$ & 0.10 & $\mathrm{Ir}$ & 0.01 & $\mathrm{~S}$ & 1.00 \\
$\mathrm{Be}$ & 0.10 & $\mathrm{~K}$ & 0.30 & $\mathrm{Sb}$ & 0.03 \\
$\mathrm{Bi}$ & 0.01 & $\mathrm{Kr}$ & 1.00 & $\mathrm{Sc}$ & 0.01 \\
$\mathrm{Br}$ & 0.30 & $\mathrm{La}$ & 0.01 & $\mathrm{Se}$ & 0.30 \\
$\mathrm{C}$ & 1.00 & $\mathrm{Li}$ & 0.30 & $\mathrm{Si}$ & 0.01 \\
$\mathrm{Ca}$ & 0.10 & $\mathrm{Lu}$ & 0.01 & $\mathrm{Sm}$ & 0.01 \\
$\mathrm{Cd}$ & 0.10 & $\mathrm{Mg}$ & 0.30 & $\mathrm{Sn}$ & 0.01 \\
$\mathrm{Ce}$ & 0.01 & $\mathrm{Mn}$ & 0.03 & $\mathrm{Sr}$ & 0.03 \\
$\mathrm{Cl}$ & 1.00 & $\mathrm{Mo}$ & 0.30 & $\mathrm{Ta}$ & 0.01 \\
$\mathrm{Co}$ & 0.01 & $\mathrm{~N}$ & 1.00 & $\mathrm{~Tb}$ & 0.01 \\
$\mathrm{Cr}$ & 0.10 & $\mathrm{Na}$ & 0.30 & $\mathrm{Tc}$ & 0.30 \\
$\mathrm{Cs}$ & 0.30 & $\mathrm{Nb}$ & 0.01 & $\mathrm{Te}$ & 0.10 \\
$\mathrm{Cu}$ & 0.30 & $\mathrm{Nd}$ & 0.01 & $\mathrm{Ti}$ & 0.10 \\
$\mathrm{Dy}$ & 0.01 & $\mathrm{Ne}$ & 1.00 & $\mathrm{Tl}$ & 0.03 \\
$\mathrm{Er}$ & 0.01 & $\mathrm{Ni}$ & 0.03 & $\mathrm{Tm}$ & 0.01 \\
$\mathrm{Eu}$ & 0.01 & $\mathrm{O}$ & 1.00 & $\mathrm{~V}$ & 0.01 \\
$\mathrm{~F}$ & 1.00 & $\mathrm{Os}$ & 0.30 & $\mathrm{~W}$ & 0.03 \\
$\mathrm{Fe}$ & 0.01 & $\mathrm{P}$ & 0.30 & $\mathrm{Xe}$ & 1.00 \\
$\mathrm{Ga}$ & 0.10 & $\mathrm{~Pb}$ & 0.03 & $\mathrm{Y}$ & 0.01 \\
$\mathrm{Gd}$ & 0.01 & $\mathrm{Pd}$ & 0.01 & $\mathrm{Yb}$ & 0.03 \\
$\mathrm{Ge}$ & 0.10 & $\mathrm{Pm}$ & 0.01 & $\mathrm{Zn}$ & 0.10 \\
$\mathrm{H}$ & 1.00 & $\mathrm{Po}$ & 0.10 & $\mathrm{Zr}$ & 0.03 \\
& & & & &
\end{tabular}

